
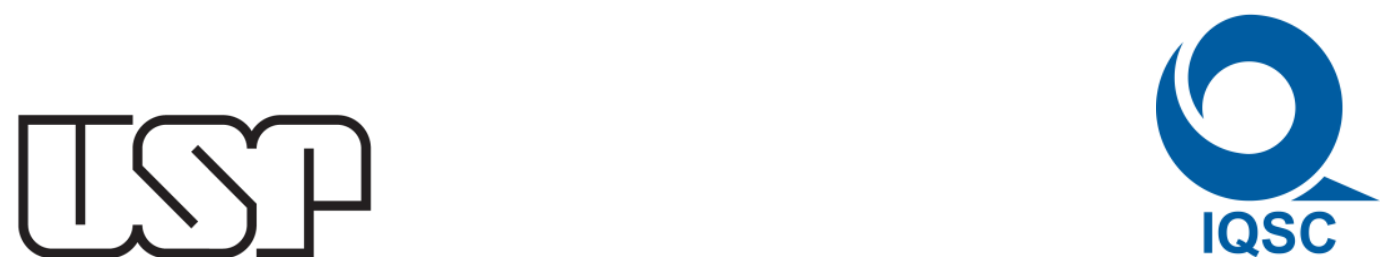

Universidade de São Paulo

Instituto de Química de São Carlos

FRANCISCA GLEYCIARA CAVALCANTE PINHEIRO

\title{
SÍNTESE DE TERMORRÍGIDOS FENÓLICOS SIMULTANEAMENTE À FORMAÇÃO DE COMPÓSITOS: FIBRAS E MANTAS COMO REFORÇO VEGETAL
}





\section{SÍNTESE DE TERMORRÍGIDOS FENÓLICOS SIMULTANEAMENTE À FORMAÇÃO DE COMPÓSITOS: FIBRAS E MANTAS COMO REFORÇO VEGETAL}

Tese apresentada ao Instituto de Química de São Carlos da Universidade São Paulo como parte dos requisitos para obtenção do Título de Doutora em Ciências.

Área de concentração: Química Analítica e Inorgânica

Orientadora: Profa. Dra. Elisabete Frollini

São Carlos 
Autorizo a reprodução e divulgação total ou parcial deste trabalho, por qualquer meio convencional ou eletrônico para fins de estudo e pesquisa, desde que citada a fonte.

Assinatura:

Data:

Pinheiro, Francisca Gleyciara Cavalcante

Síntese de termorrígidos fenólicos simultaneamente à formação de compósitos: fibras e mantas como reforço vegetal / Francisca Gleyciara Cavalcante Pinheiro. — São Carlos, 2020. $200 \mathrm{f}$.

Tese (Doutorado em Química Analítica e Inorgânica) - Instituto de Química de São Carlos / Universidade de São Paulo, 2020.

Orientadora: Profa. Dra. Elisabete Frollini

1. Compósitos. 2. Mantas naturais. 3. Fibra do mesocarpo do dendê. 4.

Lignina Kraft. 5. Termorrígido. I. Título. 
Aos meus pais que eu amo imensamente e que tanto me ensinaram que cada batalha na vida, vencida ou perdida, serve de lição e aprendizado, e que sempre me deram força para que eu nunca desistisse.

Aos meus irmãos, meus companheiros de aventuras e palhaçadas, que sempre me deram força e muito carinho.

Ao meu noivo e futuro marido, que sempre acreditou em mim, me deu apoio, compreensão, força e muito amor.

Amo muito todos vocês. Essa conquísta é nossa! 



\section{Agradecímentos}

Primeiramente eu quero agradecer à Deus por ter me dado força, abençoado e iluminado meu caminho em todos os momentos da minha vida.

Ao meu pai José Pinheiro por todo seu exemplo de luta, superação e generosidade, sempre me ensinando a ser forte e persistente, e por ser "o melhor papai do mundo" sempre. Pai, tenha certeza: "Eu aprendi" e vou continuar aprendendo com você o resto da minha vida.

À minha mãe Fátima, minha melhor amiga e escudeira fiel, meu exemplo de mulher forte, de calmaria, de apoio e de luta. Obrigada por todas as palavras de consolo e por toda a força que você sempre me deu.

À minha Frenfren (Gleycielle), que eu amo de paixão, obrigada pela força, apoio, e pelo exemplo de pessoa mais decidida que eu já conheci. Minha companheira de aventuras desde pequena!

Ao meu irmão Bambão (Abraão), meu eterno bebezão destrambelhado que eu também amo de paixão, pelo apoio, suporte, confiança em mim e por todos os momentos divertidos. Te amo mil milhões, Bão.

Ao meu amor Silvio Gurgel (meu eterno crush), por toda compreensão durante todos esses anos juntos e mais ainda ao longo desse período à distância. Obrigada pela paciência, apoio e força. Obrigada por acreditar em mim mais do que eu mesma, por todo o amor, parceria e companheirismo.

À minha avó, meus tios e primos que torceram por mim sempre. Em especial aos tios Val e Toinha, e ao Jesso (primo) por toda força, torcida e apoio.

Ao Pitchu, meu anjinho de quatro patas, pelo amor incondicional e que só trouxe momentos de alegrias na minha vida.

À minha orientadora Prof. (a) Elisabete Frollini, por toda paciência, compreensão e dedicação durante o período de construção deste trabalho. Obrigada pela oportunidade, apoio e contribuição na minha formação pessoal e profissional.

À minha amiga Rachel (Feiosa) por toda força, acolhimento e companheirismo durante todos esses anos em São Carlos. Obrigada por me abrir os olhos nos meus momentos de angústia e preocupação, por fazer eu acreditar que eu sou capaz. Obrigada pela paciência, apoio e pelos momentos de alegrias. Muita gratidão!

Às minha amigas Aline e Camila (Mucas) e minha cunhada Raquel (Reitiel), por toda torcida e apoio. Obrigada por acreditarem em mim.

Às minhas companheiras de aventuras Pati (Fia da Xuxa), Ana e Lidi. Obrigada por todo 
apoio, suporte, amizade e momentos divertidos que passamos juntas. Lidi, obrigada por ter me dado meu anjinho (Pitchu), ele foi essencial para mim esse ano. Vocês são "Topzeras"!

Às pessoas que fizeram parte do meu convívio diário no laboratório, Joice, Roberta Polez (Bem), Deyvid, Roberta Lopes, Danilo, Andrea, Thamiris, Lucas (Lukete) e William. Obrigada pelas boas risadas que demos.

À Cláudia e à Bianca pelo apoio e pelos momentos divertidos no laboratório com as melhores playlists.

Aos meus eternos companheiros de Embrapa, Gabi, Niédja, Menta, Nágila e ao Aurélio. Obrigada por toda torcida à distância.

Ao pesquisador Dr. Renato Carrhá da Embrapa Agroindústria Tropical pela fornecimento da fibra do mesocarpo dendê, colaboração, apoio e parceria neste projeto.

Ao técnico Luiz Ramos pela dedicação na realização das análises térmicas e mecânicas.

Aos funcionários da oficina mecânica por todo suporte dado que foi de extrema importância para realização de experimentos.

Ao Prof. Dr. Leonardo Bresciani Canto (DEMa-UFSCar) por permitir a realização dos ensaios de impacto e flexão; e ao técnico Fernando pelo auxílio na realização destes ensaios.

À pesquisadora Dra. Ana Rita da Embrapa Pecuária Sudeste (São Carlos) pela realização das análises de MIP-OES.

A todos os funcionários da Central de Análises Químicas (CAQI) e da Biblioteca do Instituto de Química de São Carlos (IQSC).

A todos os funcionários da coordenação da pós-graduação do IQSC, em especial à Andreia Cristina por toda paciência e compreensão nesta reta final, e da Universidade de São Paulo (USP/SC) que contribuíram de alguma forma para que esse trabalho fosse executado.

À Universidade de São Paulo e ao Instituto de Química de São Carlos pelo apoio institucional e infraestrutura.

A Capes pela bolsa concedida e ao CNPq e a FAPESP, pelo suporte financeiro. 
"Success is not final, failure is not fatal: it is the courage to continue that counts."

Winston Churchill 



\section{RESUMO}

Pinheiro, F. G. C. Síntese de termorrígidos fenólicos simultaneamente à formação de compósitos: fibras e mantas como reforço vegetal. 2019. 200f Tese (Doutorado em Ciências) - Instituto de Química de São Carlos, Universidade de São Paulo, São Carlos, 2020.

O presente estudo visou a valorização da fibra do mesocarpo de dendê (FMD) e mantas de fibra de sisal (MFS, cristalinidade $=57 \%$ ) e rayon $($ MFR, cristalinidade $=47 \%$ ) como agente de reforço na preparação de compósitos termorrígidos obtidos a partir de resinas fenol-formaldeído (RFF), e compósitos híbridos constituídos por MFS/FMD moída como reforço de matrizes fenólicas. Foram também sintetizadas resinas substituindo $70 \%$ do fenol por lignina Kraft industrial (resina lignina Kraft-fenol-formaldeído- RLKFF), assim como substituindo o formaldeído por glutaraldeído (resina fenol-glutaraldeído- RFG). FMD, dentre outras técnicas também usadas para caracterizar MFS e MFR, foi caracterizada por Microscopia eletrônica por varredura (MEV)-acoplado com Espectroscopia por energia dispersiva (EDS) e espectrometria de emissão óptica por plasma induzida por microondas (MIP-OES). As análises de MEV-EDS e MIP-OES indicaram que a FMD possui superfície rugosa com poros preenchidos por corpos circulares de silício, aproximadamente $1,1 \pm 0,2 \%$, respectivamente. Os termorrígidos e compósitos obtidos a partir das resinas foram caracterizados quanto às resistências ao impacto (Izod) e à flexão, MEV, análise dinâmico-mecânica (DMA) e Termogravimetria. Dentre as propriedades avaliadas para os compósitos, a resistência ao impacto foi selecionada para fins comparativos. Os resultados obtidos a partir dos compósitos de matriz RFF reforçados com FMD foram aquém das expectativas, como consequência de as características das fibras limitarem a porcentagem em massa de fibras a $17 \%$ (resistência ao impacto $46 \mathrm{~J} \mathrm{~m}^{-1}$ ). Assim, FMD foi substituída por MFS e MFR. Dentre os compósitos de matriz RFF reforçados com MFS (42\% em volume) o que apresentou maior resistência ao impacto, foi o que a manta foi previamente imersa em água (visando separação de feixes de fibras, com posterior secagem), e a viscosidade da resina foi reduzida com a adição de etanol (visando aumentar a impregnação das fibras pela resina, com posterior eliminação de etanol), $453 \pm 32 \mathrm{~J} \mathrm{~m}^{-1}$. O compósito de matriz RFF reforçado com MFR (19\% em volume) apresentou melhor resultado de resistência ao impacto normalizado (por unidade de porcentagem em volume de manta), $17 \pm 1,2 \mathrm{~J} \mathrm{~m}^{-1}$, comparado ao compósito reforçado com MFS, $10 \pm 0,7 \mathrm{~J} \mathrm{~m}^{-1}$. O compósito de matriz RFG reforçado com MFR apresentou resistência ao impacto $\left(455 \pm 62 \mathrm{~J} \mathrm{~m}^{-1}\right)$ superior, aos compósitos similares em matrizes RFF $\left(323 \pm 30 \mathrm{~J} \mathrm{~m}^{-1}\right)$ e RLKFF $\left(98 \pm 9 \mathrm{~J} \mathrm{~m}^{-1}\right)$, possivelmente devido a maior molhabilidade das mantas de rayon pela matriz RFG, devido a menor viscosidade desta resina comparativamente à RFF e RLKFF. Em todos os compósitos híbridos reforçados por MFS/FMD moída (matrizes RFF, RFG e RLKFF), a FMD moída atuou como reforço adicional melhorando a propriedade de resistência ao impacto dos compósitos, quando comparados aos respectivos compósitos reforçados apenas por MFS. O amplo conjunto de resultados obtidos, referentes aos reforços, às resinas sintetizadas e aos respectivos compósitos, agrega novos conhecimentos à área de compósitos termorrígidos do tipo fenólico reforçados por fibras oriundas de plantas. Os materiais obtidos apresentam potencial para aplicações como isolante elétrico, partes não estruturais de automóveis, aeronaves, assim como na área naval.

\section{Palavras-chave: Compósito, Mantas naturais, Lignina Kraft, fibra do} mesocarpo do dendê 


\section{$\mathcal{A B S T R A C T}$}

Pinheiro, F. G. C. Synthesis of phenolic thermosetting with simultaneous composites formation: fibers and woven mats as vegetal reinforcement. 2020. 200f Tese (Doutorado em Ciências) - Instituto de Química de São Carlos, Universidade de São Paulo, São Carlos, 2020.

The present study aimed at the valorization of palm oil mesocarp fibers (OPMF), and woven mats (sisal fibers, SFWM, crystallinity $=57 \%$, and rayon, RFWM, crystallinity $=47 \%$ ) using them as reinforcing agents in the preparation of thermoset composites from phenolformaldehyde resins, and hybrids consisting of SFWM/OPMFmilled as reinforcement of phenolic-type matrices (PhFR). Resins were also synthesized by replacing $70 \%$ of phenol by industrial Kraft lignin (Kraft lignin-phenol-formaldehyde resin - KLPhFR) as well as replacing formaldehyde by glutaraldehyde (phenol-glutaraldehyde resin- PhGR). OPMF, among other techniques also used to characterize SFWM and RFWM, was characterized by Scanning electron microscopy - coupled with Energy dispersive x-ray spectroscopy (EDS), and Microwave-induced plasma optical emission spectrometry (MIP-OES). SEM-EDS and MIPOES analyze indicated that OPMF has a rough surface with pores filled with circular silicon bodies, approximately $1.1 \pm 0.2 \%$ of silicon, respectively. Thermosets and composites obtained from resins were characterized for impact strength (Izod) and flexural strength, SEM, dynamic mechanical analysis (DMA) and thermogravimetry. Among the properties evaluated for composites, impact resistance was selected for comparative purposes. Among the properties evaluated for composites, impact strength was selected for comparative purposes. The results obtained from OPMF-reinforced PhFR matrix composites were below expectations as a consequence of the fiber characteristics limited the fiber percentage by mass to $17 \%$ (impact strength $46 \mathrm{~J} \mathrm{~m}^{-1}$ ). Thus, OPMF was replaced by SFWM and RFWM. Among the SFWM (42\% by volume) reinforced PhFR matrix composites the one that presented the highest impact strength was obtained by immersion of SFWM in water (aiming fiber bundle separation, with subsequent drying) and the resin viscosity was reduced with the addition of ethanol (aiming at increasing impregnation of the fibers by the resin, with subsequent elimination of ethanol). The SFWM-reinforced PhFR matrix composite (19\% by volume) showed better impact strength normalized results (per unit volume percentage of the woven mat) compared to the similar SFWM-reinforced composite. The SFWM-reinforced PhGR matrix composite showed higher impact strength $\left(455 \pm 62 \mathrm{~J} \mathrm{~m}^{-1}\right)$ than similar composites in PhFR $\left(323 \pm 30 \mathrm{~J} \mathrm{~m}^{-1}\right)$ and $(98 \pm 9$ $\mathrm{J} \mathrm{m}^{-1}$ ) matrices, possibly due to the higher wettability of rayon woven mat by the RFG matrix, as a consequence of the lower viscosity of this resin compared to PhFR and KLPhFR. In all

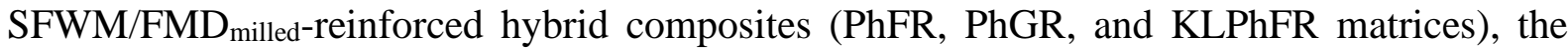
FMD $D_{\text {milled }}$ acted as additional reinforcement, increasing the impact strength of the composites when compared to those reinforced only with SFWM. The broad set of results regarding the reinforcements, synthesized resins, and their composites adds new knowledge to the area of phenolic-type thermoset composites reinforced by plant fibers. The materials prepared have potential for applications such as electrical insulators, non-structural parts of automobiles, aircraft, as well as in the naval area.

Keywords: composite, natural woven mat, Kraft lignin, oil palm mesocarp fiber 



\section{Lista de Fíguras}

Figura 1 - Esquema de classificação de compósitos.

Figura 2 - Exemplos de áreas de aplicação em que os compósitos podem ser inseridos: automotiva (a), construção civil (peça de concreto reforçado com fibra de carbono) (b), naval-náutica (c), aeronave (d) e peça de cerâmica reforçado com CMC para câmara de combustão de foguetes (e) .

Figura 3 - Representação esquemática das estruturas das resinas fenólicas (fenol-formaldeído) resol e

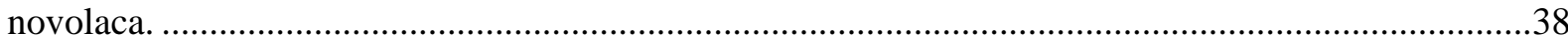

Figura 4 - Formação de metileno glicol (a) e formação do íon fenolato e entre o íon fenolato e o

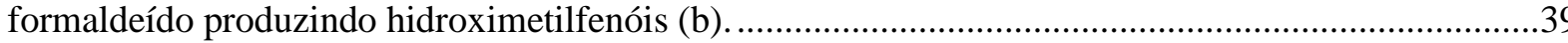

Figura 5 - Reação de formação de derivados dimetilol e trimetilol.........................................................39

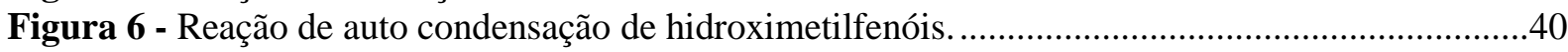

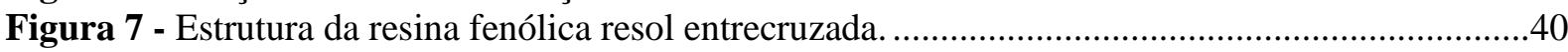

Figura 8 - Reação entre glutaraldeído e a água (a), reação de hidroxialquilação do fenol em meio básico (b) e possível produto formado na reação de síntese da resina fenol-glutaraldeído (c)..............42 Figura 9 - Tipos de árvores de coníferas e folhosas (a) e estrutura química de guaiciala, siringila e p-

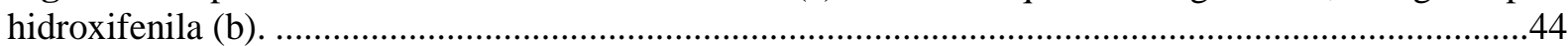

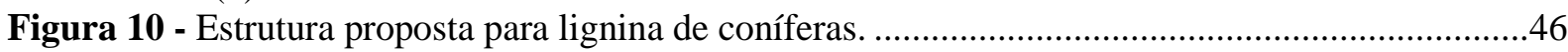

Figura 11 - Ligações presentes entre as unidades monoméricas da lignina........................................47

Figura 12 - Esquema da clivagem das ligações $\alpha$-aril éter da lignina com formação de intermediário

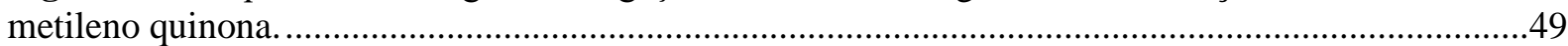

Figura 13 - Esquema da clivagem das ligações $\beta$-aril éter da lignina.................................................49

Figura 14 - Esquema da reação de hidroximetilação da lignina contendo estrutura guaiacila..............51

Figura 15 - Representação esquemática da estrutura da biomassa lignocelulósica- microfibrilas de celulose cercados por hemiceluloses e lignina.

Figura 16 - Dendezeiro Dendezeiro-Elaeais guineensis Jaquim (a), frutos frescos do dendezeiro (b) e fibra do mesocarpo do dendê após extração do óleo (FMD) (c).......................................................54

Figura 17 - Planta de sisal Agave sisalana ${ }^{1}$ (a), fibra de sisal $^{2}$ (b) e manta de sisal $^{3}$ (c) ...................56 Figura 18 - Reação de obtenção da fibra rayon (a), esquema de obtenção da fibra rayon ${ }^{1}$ (b), imagem da manta de fibra rayon (c) ${ }^{2}$ e estrutura molecular da celulose com indicação de ligações hidrogênio inter- (linhas tracejadas vermelhas) e intra-moleculares (linhas tracejadas pretas) (d) ${ }^{3}$.......................58 Figura 19: Representação esquemática da preparação dos compósitos de matriz RFF reforçados com FMD.

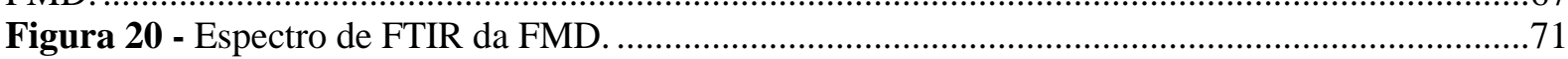

Figura 21 - Micrografias da ponta da FMD não lavada (a) e após a extração com solventes (b)........73

Figura 22 - Micrografias da superfície das FMD (a) e espectro de EDS da análise micro elementar dos

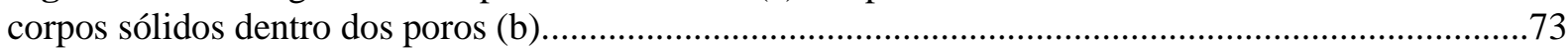

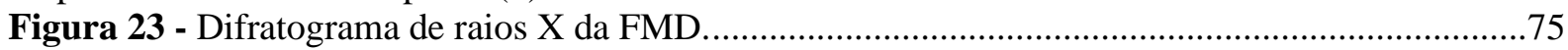

Figura 24 - Curvas termogravimétrica e dTG da FMD, em atmosfera de ar sintético, com taxa de aquecimento de $5{ }^{\circ} \mathrm{C} \mathrm{min}^{-1}$, e fluxo de $50 \mathrm{~mL} \mathrm{~min}{ }^{-1}$.................................................................. 75

Figura 25 - Ilustração do ângulo microfibrilar e das camadas S1 (externa), S2 (intermediária) e S3 (interna) da parede celular das fibras lignocelulósicas.......................................................................78

Figura 26 - Espectros na região de infravermelho da resina fenólica (RFF), do termorrígido fenólico (TRFF) e do compósito reforçado com FMD ( $\mathrm{C}_{\mathrm{RFF}}$ 17\%FMD) ........................................................79

Figura 27 - Fenóis dinucleares formados durante a reação de síntese da resina RFF para a posterior

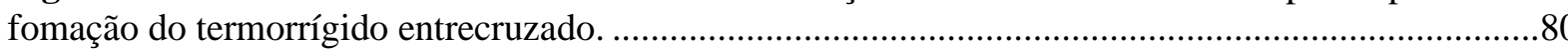

Figura 28 - Espectro de $\mathrm{RMN}-{ }^{13} \mathrm{C}$ da resina fenol-formaldeído (solvente: DMSO-d6, 20000

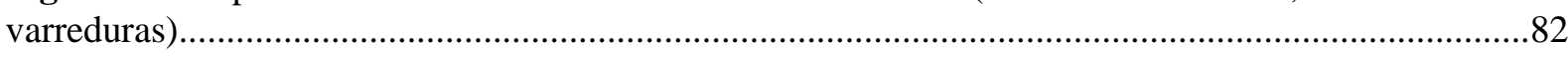

Figura 29 - Curvas TG e dTG da resina fenol-formaldeído (RFF) em atmosfera de ar sintético com razão de aquecimento de $10{ }^{\circ} \mathrm{C} \mathrm{min}^{-1}$ e fluxo de $50 \mathrm{~mL} \mathrm{~min}^{-1}$.

Figura 30 - Curvas TG e dTG do TRFF e do compósito $\mathrm{C}_{\mathrm{RFF}} 17 \% \mathrm{FMD}$ em atmosfera de ar sintético

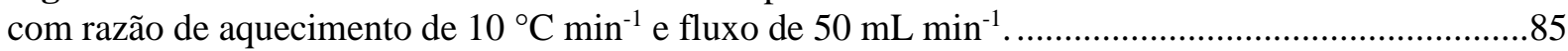
Figura 31 - Resultados de resistência ao impacto Izod dos do termorrígido e dos compósitos fenólicos (RFF) reforçados com FMD (a) e fotografia do corpo-de-prova do $\mathrm{C}_{\mathrm{RFF}} 17 \% \mathrm{FMD}$ após ensaio de impacto (b). 
Figura 32 - Micrografias das superfícies fraturadas, pós-impacto, do termorrígido TRFF (a), e dos compósitos reforçados com FMD, $\mathrm{C}_{\mathrm{RFF}} 19 \% \mathrm{FMD}$ (b), $\mathrm{C}_{\mathrm{RFF}} 17 \% \mathrm{FMD}$ (c), $\mathrm{C}_{\mathrm{RFF}} 16 \% \mathrm{FMD}$ (d) e $\mathrm{C}_{\mathrm{RFF}} 13 \% \mathrm{FMD}(\mathrm{e})$.

Figura 33 - Propriedades de flexão dos compósitos de RFF reforçados com FMD.

Figura 34 - Curvas DMA- Módulo de armazenamento (E') (a) e Tan $\delta$ versus temperatura (b) do termorrígido fenólico (TRFF) e dos compósitos reforçados com FMD (13 a 19\% em massa de fibra).

Figura 35 - Representação da interação entre componentes da fibra lignocelulósica e a matriz fenólica RFF.

Figura 36 - Manta de fibra de sisal (MFS) (a) e manta de fibra rayon (MFR) (b)................................95

Figura 37 - Espectros na região do infravermelho das fibras de sisal (FS) e de rayon (FR)...............100

Figura 38 - Micrografias da superfície (a) e ponta (b) da fibra de sisal e da superfície (c) e da ponta (d)

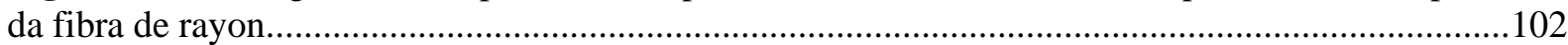

Figura 39 - Difratogramas de raios $X$ das fibras de sisal (a) e rayon (b). .........................................104

Figura 40 - Curva TG e dTG das fibras da manta de sisal (a) e fibra rayon (b) em atmosfera de $\mathrm{N}_{2}, 50$

$\mathrm{mL} \min ^{-1}$ e taxa de aquecimento de $10{ }^{\circ} \mathrm{C} \min ^{-1}$.

Figura 41 - Espectros na região do infravermelho dos compósitos de matriz RFF reforçados com MFS, $\mathrm{C}_{\mathrm{RFF}} 42 \% \mathrm{MFS}$, e MFR, $\mathrm{C}_{\mathrm{RFF}} 10 \% \mathrm{MFR}$.

Figura 42 - Curvas TG e dTG do TRFF (a) e dos compósitos reforçados com MFS, $\mathrm{C}_{\mathrm{RFF}} 42 \% \mathrm{MFS}$ (b) e MFR, $C_{\text {RFF }} 10 \%$ MFR (c), em atmosfera de nitrogênio com razão de aquecimento de $10{ }^{\circ} \mathrm{C} / \mathrm{min} \mathrm{e}$ fluxo de $50 \mathrm{~mL} \mathrm{~min}^{-1}$.....

Figura 43 - Curvas TG e dTG (primeira derivada) dos compósitos híbridos $\mathrm{C}_{\mathrm{RFF}} 38 \% \mathrm{MFS}_{\text {im-ag- }}$ et $9 \% \mathrm{FMD}_{\text {moída }}$ em atmosfera de nitrogênio com razão de aquecimento de $10{ }^{\circ} \mathrm{C} / \mathrm{min}$ e fluxo de 50 $\mathrm{mL} / \mathrm{min}$.

Figura 44 - Resistência ao impacto do termorrígido (TRFF) e dos compósitos de matriz termorrígida fenólica resol reforçados com MFS, $\mathrm{C}_{\mathrm{RFF}} 42 \% \mathrm{MFS}$ e $\mathrm{C}_{\mathrm{RFF}} 42 \% \mathrm{MFS}_{\text {im-ag-et, }}$ e MFR, $\mathrm{C}_{\mathrm{RFF}} 10 \% \mathrm{MFS}$ e $\mathrm{C}_{\mathrm{RFF}} 19 \% \mathrm{MFS}$, (a) e comparativo entre os resultados de resistência ao impacto normalizados dos compósitos reforçados com MFS e MFR (b).

Figura 45 - Imagens corpos-de-prova dos compóstitos $C_{R F F} 42 \% M F S_{\text {im-ag-et }}$ (a) e $C_{R F F} 19 \% M F R$ (b). 113 Figura 46 - Possível interação entre os grupos hidroxilas presentes na matriz RFF e na celulose (fibra rayon).

Figura 47 - Resultados de resistência ao impacto do termorrígido (TRFF) e dos compósitos híbridos de matriz termorrígida fenólica reforçados com MFS/FMD moída, $\mathrm{C}_{\mathrm{RFF}} 38 \% \mathrm{MFS}_{\text {im-ag-et }} 9 \% \mathrm{FMD}_{\text {moída }} \mathrm{e}$ $\mathrm{C}_{\mathrm{RFF}} 35 \% \mathrm{MFS}_{\text {im-ag-et }} 16 \% \mathrm{FMD}_{\text {moída }}$ (a) e comparativo entre os resultados de resistência ao impacto normalizados dos compósitos híbridos reforçados com MFS/FMD moída $_{\text {(b). }}$

Figura 48 - Micrografias das superfícies fraturadas, pós-impacto, dos compósitos de matriz RFF reforçados com $42 \%$ (em volume) de MFS, $\mathrm{C}_{\mathrm{RFF}} 42 \% \mathrm{MFS}$ (a) e $\mathrm{C}_{\mathrm{RFF}} 42 \% \mathrm{MFS}_{\text {im-ag-et }}$ (b).

Figura 49 - Micrografias das superfícies fraturadas, pós-impacto, dos compósitos de matriz RFF reforçados com 10\% (em volume) de MFR (a) e 19\% (em volume) de MFR (b).

Figura 50 - Micrografias das superfícies fraturadas, pós-impacto, dos compósitos de matriz RFF reforçados com MFS/FMD moída, $_{\text {RFF }} 38 \% \mathrm{MFS}_{\text {im-ag-et }} 9 \% \mathrm{FMD}_{\text {moída }}$ (a) e $\mathrm{C}_{\mathrm{RFF}} 35 \% \mathrm{MFS}_{\text {im-ag- }}$ et $16 \% \mathrm{FMD}_{\text {moída }}(\mathrm{b})$.

Figura 51 - Resultados de resistência à flexão dos termorrígido TRFF, compósitos reforçados com MFS, $\mathrm{C}_{\mathrm{RFF}} 42 \% \mathrm{MFS}, \mathrm{C}_{\mathrm{RFF}} 42 \% \mathrm{MFS}_{\text {im-ag-et, }}$ e MFR, $\mathrm{C}_{\mathrm{RFF}} 10 \% \mathrm{MFR}$ e $\mathrm{C}_{\mathrm{RFF}} 19 \% \mathrm{MFR}$ (a), e comparativo entre os resultados de resistência à flexão normalizados dos compósitos reforçados com MFS e MFR (b).

Figura 52 - Resultados de módulo de flexão do termorrígido TRFF, compósitos reforçados com MFS, $\mathrm{C}_{\mathrm{RFF}} 42 \% \mathrm{MFS}, \mathrm{C}_{\mathrm{RFF}} 42 \% \mathrm{MFS}_{\text {im-ag-et }}$, e MFR, $\mathrm{C}_{\mathrm{RFF}} 10 \% \mathrm{MFR}$ e $\mathrm{C}_{\mathrm{RFF}} 19 \% \mathrm{MFR}$ (a), e comparativo entre os resultados de módulo de flexão normalizados dos compósitos reforçados com MFS e MFR (b). ......122 Figura 53 - Resultados de resistência à flexão do TRFF e dos compósitos híbridos $\mathrm{C}_{\mathrm{RFF}} 38 \% \mathrm{MFS}$ im-aget $9 \% \mathrm{FMD}_{\text {moída }}$ e $\mathrm{C}_{\mathrm{RFF}} 35 \% \mathrm{MFS}_{\text {im-ag-et }} 16 \% \mathrm{FMD}_{\text {moída }}$ (a) e comparativo entre os resultados de resistência à flexão normalizados dos compósitos híbridos com o $\mathrm{C}_{\mathrm{RFF}} 42 \% \mathrm{MFS}_{\text {im-ag-et }}(\mathrm{b})$.

Figura 54 - Resultados de módulo de flexão do TRFF e dos compósitos híbridos $\mathrm{C}_{\mathrm{RFF}} 38 \% \mathrm{MFS}_{\text {im-ag- }}$ et $9 \% \mathrm{FMD}_{\text {moída }}$ e $\mathrm{C}_{\mathrm{RFF}} 35 \% \mathrm{MFS}_{\text {im-ag-et }} 16 \% \mathrm{FMD}_{\text {moída }}$ (a) e comparativo entre os resultados de módulo de flexão normalizados dos compósitos híbridos com o $\mathrm{C}_{\mathrm{RFF}} 42 \% \mathrm{MFS}_{\text {im-ag-et }}(\mathrm{b})$. 
Figura 55 - Curvas DMA- Módulo de armazenamento (E') (a) e tan $\delta$ versus temperatura (b) do termorrígido fenólico (TRFF) e dos compósitos reforçados com MFS, $\mathrm{C}_{\mathrm{RFF}} 42 \% \mathrm{MFS}$ e

$\mathrm{C}_{\mathrm{RFF}} 42 \% \mathrm{MFS}_{\text {im-ag-et }}$, e MFR, $\mathrm{C}_{\mathrm{RFF}} 10 \% \mathrm{MFR}$ e $\mathrm{C}_{\mathrm{RFF}} 19 \% \mathrm{MFR}$.

Figura 56 - Curvas DMA- Módulo de armazenamento (E') (a) e Tan $\delta$ versus temperatura (b) do termorrígido fenólico (TRFF) e dos compósitos reforçados com MFS, $\mathrm{C}_{\mathrm{RFF}} 42 \% \mathrm{MFS}_{\text {im-ag-et }}$ e híbridos reforçados com MFS/FMD moída, $_{\text {RFF }} 38 \% \mathrm{MFS}_{\text {im-ag-et }} 9 \% \mathrm{FMD}_{\text {moída }}$ e $\mathrm{C}_{\mathrm{RFF}} 35 \% \mathrm{MFS}_{\text {im-ag-et }} 16 \% \mathrm{FMD}_{\text {móda. }}$

Figura 57 - Espectros na região do infravermelho da resina RFG, do termorrígido (TRFG), e dos compósitos reforçados com MFS, $\mathrm{C}_{\mathrm{RFG}} 42 \% \mathrm{MFS}, \mathrm{MFR}, \mathrm{C}_{\mathrm{RFG}} 19 \% \mathrm{MFR}$, e híbrido MFS/FMD ${ }_{\text {módda, }}$ $\mathrm{C}_{\mathrm{RFG}} 35 \% \mathrm{MFS} 16 \% \mathrm{FMD}_{\text {moída. }}$.

Figura 58 - Espectro de $\mathrm{RMN}-{ }^{13} \mathrm{C}$ da resina fenol-glutaraldeído (solvente DMSO-d6, 20000 varreduras).

Figura 59 - Curvas TG e dTG (primeira derivada) da resina fenol-glutaraldeído (RFG) em atmosfera de nitrogênio com razão de aquecimento de $10{ }^{\circ} \mathrm{C} / \mathrm{min}$ e fluxo de $50 \mathrm{~mL} / \mathrm{min}$.

Figura 60 - Curvas TG e dTG (primeira derivada) do termorrígido TRFG (a), e dos compósitos $\mathrm{C}_{\mathrm{RFG}} 42 \% \mathrm{MFS}$ (b), $\mathrm{C}_{\mathrm{RFG}} 19 \% \mathrm{MFR}$ (c) e híbrido $\mathrm{C}_{\mathrm{RFG}} 35 \%$ MFS16\%FMD mó́da $(\mathrm{d})$, em atmosfera de nitrogênio com razão de aquecimento de $10{ }^{\circ} \mathrm{C} / \mathrm{min}$ e fluxo de $50 \mathrm{~mL} \mathrm{~min}{ }^{-1}$.

Figura 61 - Resultados de resistência ao impacto do termorrígido TRFG, e dos compósitos

$\mathrm{C}_{\mathrm{RFG}} 42 \% \mathrm{MFS}, \mathrm{C}_{\mathrm{RFG}} 19 \% \mathrm{MFR}$ e $\mathrm{C}_{\mathrm{RFG}} 35 \% \mathrm{MFS} 16 \% \mathrm{FMD}_{\text {moída }}$ (a), e comparativos entre os resultados de resistência ao impacto normalizados dos compósitos $\mathrm{C}_{\mathrm{RFG}} 42 \% \mathrm{MFS}, \mathrm{C}_{\mathrm{RFG}} 19 \% \mathrm{MFR}$ e

$\mathrm{C}_{\mathrm{RFG}} 35 \% \mathrm{MFS} 16 \% \mathrm{FMD}_{\text {moída. }}$

Figura 62 - Micrografias das superfícies fraturadas, pós-impacto, do termorrígido TRFG (a), dos compósitos reforçados com MFS, $\mathrm{C}_{\mathrm{RFG}} 42 \% \mathrm{MFS}$ (b), MFR, $\mathrm{C}_{\mathrm{RFG}} 19 \% \mathrm{MFR}$ (c), e compósito híbrido MFS/FMD ${ }_{\text {moída }}, \mathrm{C}_{\mathrm{RFG}} 35 \% \mathrm{MFS} 16 \% \mathrm{FMD}_{\text {moída }}(\mathrm{d})$.....

Figura 63 - Resultados de resistência à flexão (a), comparativo entre os resultados resistência à flexão normalizados(b), resultados de módulo de flexão (c) e comparativo entre os resultados de módulo de flexão normalizados dos compósitos $\mathrm{C}_{\mathrm{RFG}} 42 \% \mathrm{MFS}, \mathrm{C}_{\mathrm{RFG}} 19 \% \mathrm{MFR}$ e $\mathrm{C}_{\mathrm{RFG}} 35 \% \mathrm{MFS} 16 \% \mathrm{FMD}_{\text {mó́da }}$ (d).

Figura 64 - Curvas DMA- Módulo de armazenamento (E') (a) e Tan $\delta$ (b) do termorrígido fenólico versus temperatura (TRFG) e dos compósitos matriz RFG reforçados com MFS, $\mathrm{C}_{\mathrm{RFG}} 42 \% \mathrm{MFS}$, MFR,

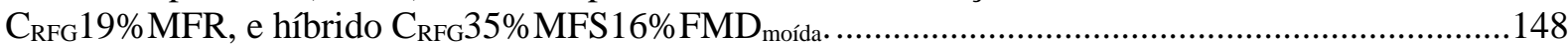
Figura 65 - Esquema da clivagem das ligações $\alpha-\mathrm{O}-\mathrm{H}$ da lignina com formação de intermediário metileno quinona.

Figura 66 - Espectros na região de infravermelho da lignina Kraft, da resina RLKFF, termorrígido TRLKFF, e dos compósitos de matriz RLKFF reforçados com MFR, $\mathrm{C}_{\mathrm{RLKFF}} 19 \% \mathrm{MFR}$, e híbrido MFS/FMD moída $_{\text {, }} \mathrm{C}_{\mathrm{RLKFF}} 38 \%$ MFS9\%FMD

Figura 67 - Esquema da reação de hidroximetilação da lignina contendo estrutura guaiacila..............160

Figura 68 - Espectro bidimensional heteronuclear de gHSQC ${ }^{1} \mathrm{H}-{ }^{13} \mathrm{C}$ da região aromática (a), alifática (b) e constuintes principais e possíveis subunidades identificados na lignina Kraft (c)....................163

Figura 69 - Espectro de $\mathrm{RMN}-{ }^{13} \mathrm{C}$ da resina lignina-fenol-formaldeído............................................166

Figura 70 - Curvas TG e dTG (primeira derivada) da lignina kraft (a) e da resina RLKFF (b) em

atmosfera de $\mathrm{N}_{2}$ a $50 \mathrm{~mL} \mathrm{~min}-1$ e taxa de aquecimento de $10{ }^{\circ} \mathrm{C} \min ^{-1}$ 168

Figura 71 - Curvas TG e dTG (primeira derivada) do termorrígido TRLKFF (a), compósito

$\mathrm{C}_{\mathrm{RLKF}} 19 \% \mathrm{MFR}$ (b) e compósito híbrido $\mathrm{C}_{\mathrm{RLKFF}} \mathrm{MFS} 9 \% \mathrm{FMD}_{\text {moída }}$ (c) em atmosfera de $\mathrm{N}_{2}$ a $50 \mathrm{~mL}$ $\min ^{-1}$ e uma taxa de aquecimento de $10{ }^{\circ} \mathrm{C} \mathrm{min}-1$

Figura 72 - Resultados de resistência ao impacto do termorrígido TRLKFF, e dos compósitos $\mathrm{C}_{\mathrm{RLKFF}} 19 \% \mathrm{MFR}$ e $\mathrm{C}_{\mathrm{RLKFF}} 38 \% \mathrm{MFS} 9 \% \mathrm{FMD}_{\text {móda }}$ (a), e comparativo entre os resultados de resistência ao impacto normalizados os compósitos de matriz RLKFF (b).

Figura 73 - Micrografias das superfícies fraturadas, pós-impacto, dos compósitos reforçados com MFR, $C_{\text {RLKFF }} 19 \%$ MFR (a) e híbrido MFS/FMD ${ }_{\text {moída }}, C_{\text {RLKFF }} 38 \%$ MFS9\%FMD moída $(b)$.

Figura 74 - Resultados de resistência à flexão e módulo de flexão normalizados dos compósitos $\mathrm{C}_{\mathrm{RLKFF}} 19 \%$ MFR e $\mathrm{C}_{\mathrm{RLKFF}} \mathrm{MFS} 9 \% \mathrm{FMD}_{\mathrm{mo}}$

Figura 75 - Curvas DMA- Módulo de armazenamento (E') e tan $\delta$ versus temperatura (b) dos compósitos matriz RLKFF reforçados com MFR, $\mathrm{C}_{\mathrm{RLKFF}} 19 \% \mathrm{MFR}$, e híbrido 


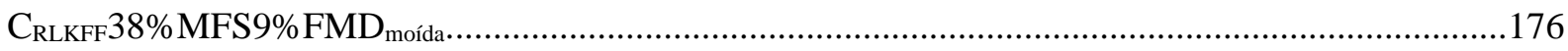




\section{Lista de Tabelas}

Tabela 1- Ciclo de cura para a obtenção do termorrígido e compósitos de matriz fenólica do tipo resol.

Tabela 2 - Códigos e descrição dos compósitos de matriz RFF reforçados com diferentes porcentagens em massa de FMD.

Tabela 3 - Possíveis atribuições para as principais bandas de absorção observadas na FMD .............71

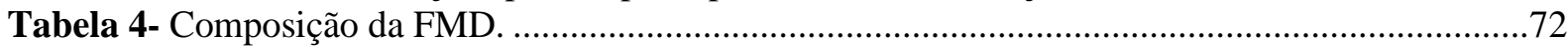

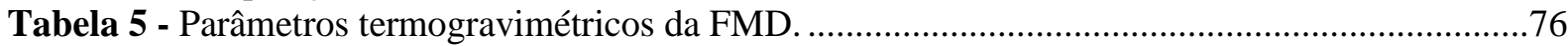

Tabela 6 - Valores médios da resistência à tração, alongamento na ruptura e módulo elástico das fibras

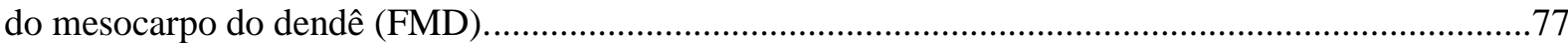

Tabela 7- Principais bandas de absorção observadas nos compósitos de matriz termorrígida reforçados

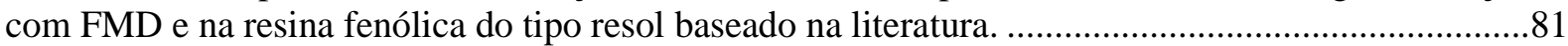

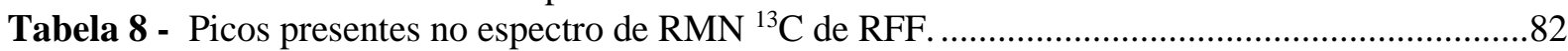

Tabela 9 - Massa molar ponderal média $(M \mathrm{w})$, massa molar numérica média $(M \mathrm{n}) \mathrm{e}$

polidispersividade $(\mathrm{Mw} / \mathrm{Mn})$ da resina fenólica.Resina Fenólica .......................................................83

Tabela 10 - Modo de preparo dos compósitos reforçados com MFS e MFR, e híbridos de MFS/rayon

e MFS/FMD

Tabela 11: Ciclo de cura para a obtenção dos termorrígidos e compósitos de matriz fenólica do tipo resol......

Tabela 12: Possíveis atribuições para as principais bandas de absorção observadas nas fibras de sisal e rayon.

Tabela 13: Composição química das fibras da manta de sisal e comparação com dados da literatura

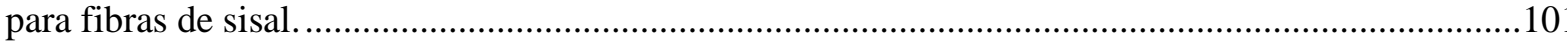

Tabela 14: Parâmetros termogravimétricos da FS e FR em atmosfera de nitrogênio. .........................105

Tabela 15: Possível atribuição para as principais bandas de absorção observadas nos compósitos de matriz termorrígida RFF reforçados com MFS e MFR.

Tabela 16 - Modo de preparo dos compósitos de matriz RFG reforçados com MFS e MFR, e híbrido

MFS/FMD

Tabela 17: Ciclo de cura para a obtenção do termorrígido e compósitos de matriz fenol-glutaraldeído.

Tabela 18 - Possíveis atribuições das principais bandas de absorção observadas nos compósitos de matriz termorrígida RFG reforçados com MFS, MFR e híbrido MFS/FMD moída. ................................135

Tabela 19: Massa molar ponderal média $(M \mathrm{w})$, massa molar numérica média $(M \mathrm{n}) \mathrm{e}$ polidispersividade $(M \mathrm{w} / M \mathrm{n})$ da resina fenol-glutaraldeído.....

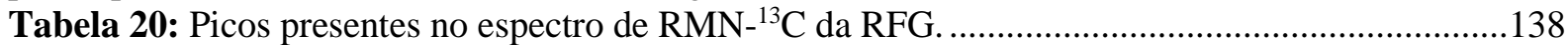

Tabela 21: Modo de preparo dos compósitos de matriz RLKFF reforçados com MFR, e híbrido

MFS/FMD

Tabela 22: Ciclo de cura para a obtenção do termorrígido e compósitos de matriz lignofenólica. ....153

Tabela 23: Resultados de teor de lignina klason, umidade, açúcares e análise elementar da lignina

Kraft antes e após etapa de purificação.

Tabela 24 - Principais bandas de absorção observadas na lignina kraft, na resina RLKFF, no termorrígo TRLKFF e nos compósitos de matriz termorrígida RLKFF reforçados com MFR, $\mathrm{C}_{\mathrm{RLKFF}} 19 \% \mathrm{MFR}$, e híbrido MFS/FMD ${ }_{\text {moída }}, \mathrm{C}_{\mathrm{RLKFF}} 38 \%$ MFS9\%FMD moída.

Tabela 25 - Massa molar ponderal média $(M w)$, massa molar numérica média $(M n)$ e polidispersividade $(M w / M n)$ por picos e total da lignina kraft após purificação e acetilação e da resina lignina Kraft-fenol-formaldeído.

Tabela 26 - Atribuição dos sinais dos espectros de $g \mathrm{HSQC}\left({ }^{13} \mathrm{C}-{ }^{1} \mathrm{H}\right)$ das unidades constituintes da lignina kraft.

Tabela 27 - Picos presentes no espectro de RMN $-{ }^{13} \mathrm{C}$ da RLKFF. 


\section{Lista de Siglas}

DMA - Análise dinâmico-mecânica

TGA - Análise Termogravimétrica

BCA - Bagaço de cana-de-açúcar

CRFF13\%FMD - Compósito de matriz resina fenol-formaldeído reforçado com $13 \%$ em massa de fibra do mesocarpo do dendê

CRFF16\%FMD - Compósito de matriz resina fenol-formaldeído reforçado com $16 \%$ em massa de fibra do mesocarpo do dendê

CRFF17\%FMD - Compósito de matriz resina fenol-formaldeído reforçado com $17 \%$ em massa de fibra do mesocarpo do dendê

CrFF19\%FMD - Compósito de matriz resina fenol-formaldeído reforçado com $19 \%$ em massa de fibra do mesocarpo do dendê

CRFF $42 \%$ MFS - Compósito de matriz resina fenol-formaldeído reforçado com $42 \%$ em volume de manta de fibra de sisal

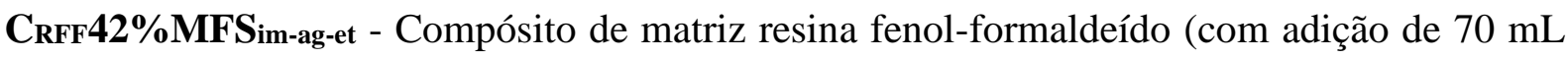
de etanol para redução da viscosidade da resina) reforçado com $42 \%$ em volume de manta de fibra de sisal (após imersão da manta em água)

CRFF10\%MFR - Compósito de matriz resina fenol-formaldeído reforçado com $10 \%$ em volume de manta de fibra rayon

CRFF19\%MFR - Compósito de matriz resina fenol-formaldeído reforçado com 19\% em volume de manta de fibra rayon

CRFF38\%MFSim-ag-et9\%FMDmoída - Compósito de matriz resina fenol-formaldeído (com adição de $70 \mathrm{~mL}$ de etanol para redução da viscosidade da resina) reforçado com $38 \%$ em volume de manta de fibra de sisal (após imersão da manta em água) e 9\% em massa de fibra do mesocarpo do dendê moída

CRFF35\%MFS $_{\text {im-ag-et16\%FMD }}$ mó́da - Compósito de matriz resina fenol-formaldeído (com adição de $70 \mathrm{~mL}$ de etanol para redução da viscosidade da resina) reforçado com 35\% em volume de manta de fibra de sisal (após imersão da manta em água) e 16\% em massa de fibra do mesocarpo do dendê moída

CRFG42\%MFS - Compósito de matriz resina fenol-glutaraldeído reforçado com $42 \%$ em volume de manta de fibra de sisal

CRFG19\%MFR - Compósito de matriz resina fenol-glutaraldeído reforçado com 19\% em volume de manta de fibra rayon 


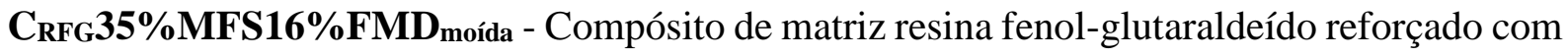
$35 \%$ em volume de manta de fibra de sisal e $16 \%$ em massa de fibra do mesocarpo do dendê moída

CRLKFF 19\% MFR - Compósito de matriz resina lignina Kraft-fenol-formaldeído reforçado com $19 \%$ em volume de manta de fibra rayon

CRLKFF38\% MFS9\%FMDmoída - Compósito de matriz resina lignina Kraft-fenol-formaldeído reforçado com $38 \%$ em volume de manta de fibra de sisal e $9 \%$ de fibra do mesocarpo do dendê moída

SEC - Cromatografia por exclusão de tamanho

$\boldsymbol{\delta} \mathbf{C} / \boldsymbol{\delta} \mathbf{H}$ - Cross-peaks

dTG - Derivada primeira

DMSO - Dimetilsulfóxido

DMSO-d6 - Dimetilsulfóxido deuterado

MIP-OES - Espectrometria de emissão óptica por plasma induzida por microondas

FTIR - Espectroscopia na região do infravermelho por transformada de Fourier

EDS - Espectroscopia por energia dispersiva

B - Fibras de banana

FCD - Fibras do cacho do dendê

C - Fibras de carbono

J - Fibras de juta

L - Fibras de linho

FR - Fibra de rayon

FS - Fibra de sisal

FMD - Fibra do mesocarpo do dendê

FMDmoída - Fibra do mesocarpo do dendê moída

Grupo MacromoLignocell - Grupo de Materiais Macromoleculares e Fibras Lignocelulósicas gHSQC- Heteronuclear Single Quantum Coherence

ICr - Índice de cristalinidade

ILI - International Lignin Institute

HGS - Lignina com estrutura típica

MFS - Manta de fibra de sisal

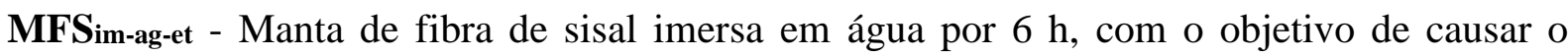
afastamento dos feixes de fibras e facilitar a impregnação da resina e posteriormente submetida a secagem $\left(24 \mathrm{~h}\right.$ a temperatura ambiente seguido de estufa, $\left.105^{\circ} \mathrm{C}\right)$ 
MFR - Manta de fibra rayon

$\overline{\mathbf{M}} \boldsymbol{n}$ - Massa molar numérica média

$\overline{\boldsymbol{M}} \boldsymbol{w}$ - Massa molar ponderal média

MDF - Medium density fiberboard

MEV - Microscopia Eletrônica de Varredura

E' - Módulo de armazenamento

$\overline{\boldsymbol{M}} \boldsymbol{w} / \overline{\boldsymbol{M}}$ n- Polidispersividade

RFF - Resina fenol-formaldeído

RFG - Resina fenol-glutaraldeído

RLKFF - Resina lignina Kraft-fenol-formaldeído

RMN-13 C - Ressonância magnética nuclear de ${ }^{13} \mathrm{C}$

Tan $\boldsymbol{\delta}$ - Tan delta

$\mathbf{T}_{\mathbf{g}}$ - Temperatura de transição vítrea

TdMáx - Temperatura do pico (curva dTG) em que a velocidade de perda de massa é máxima

Tonset - Temperatura inicial de decomposição

TRFF - Termorrígido de resina fenol-formaldeído

THF - Tetrahidrofurano 


\section{SUMMÁRIO}

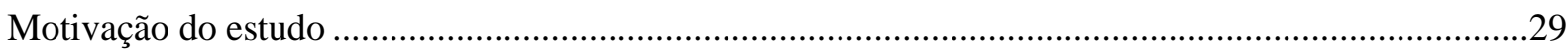

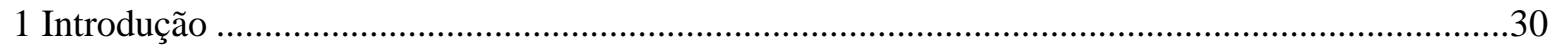

1.1 Compósitos: definição, tipos, propriedades e aplicações ............................................................30

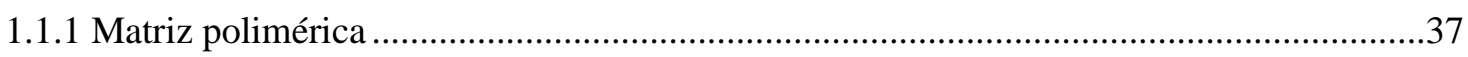

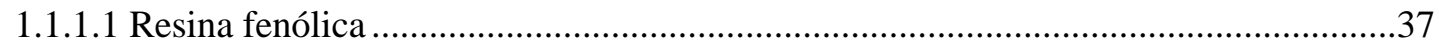

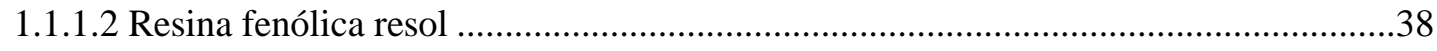

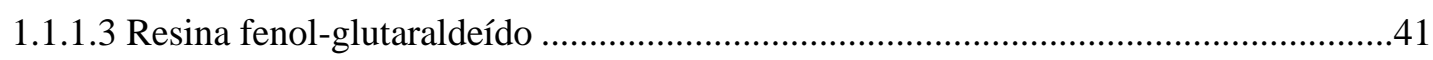

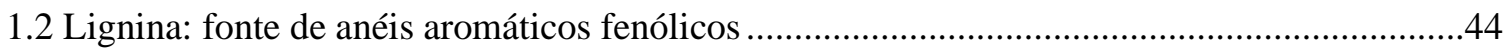

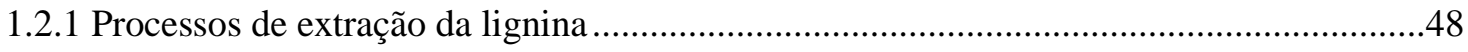

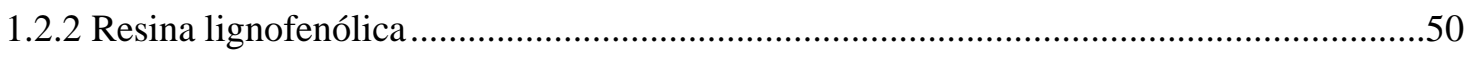

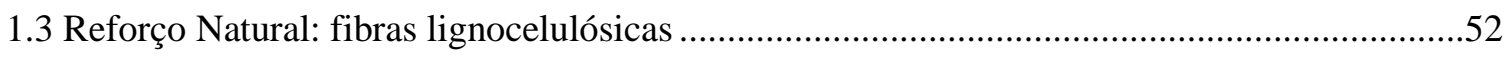

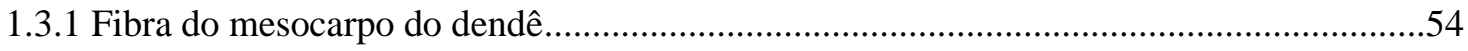

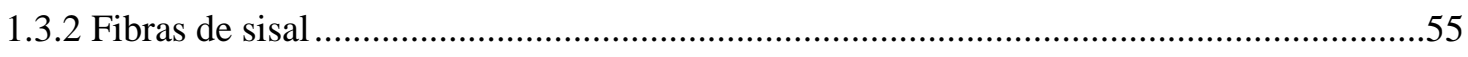

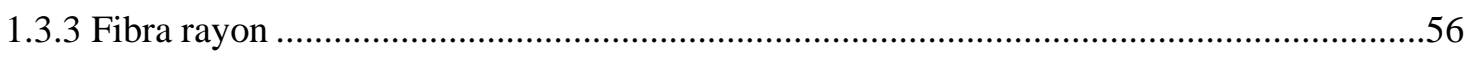

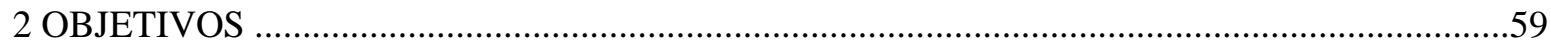

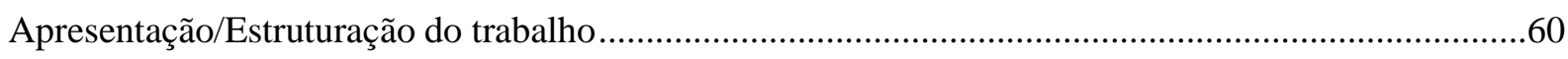

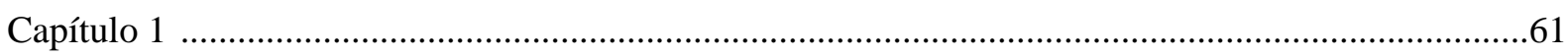

Síntese de resina fenol-formaldeído: obtenção de compósitos de matriz termorrígida reforçadas com

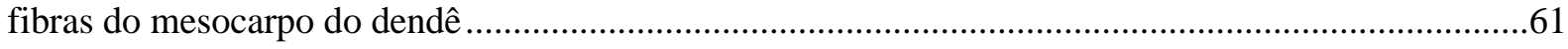

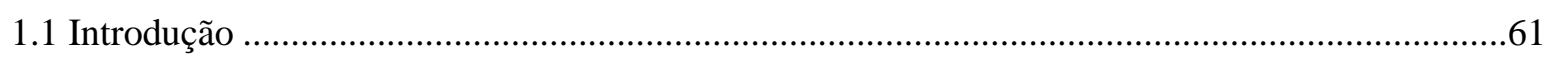

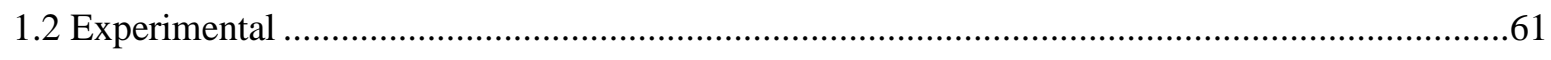

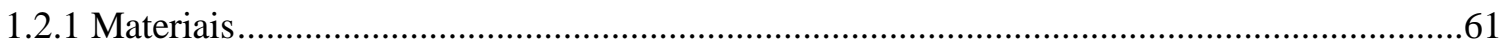

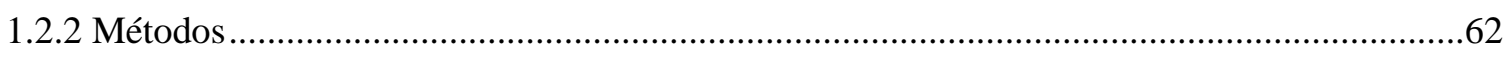

1.2.2.1 Caracterização da fibra do mesocarpo do dendê (FMD) .............................................62

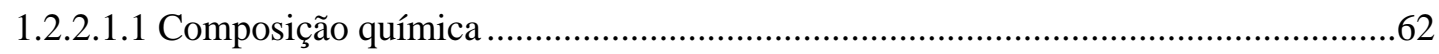

1.2.2.1.1.1 Teor de umidade ............................................................................62

1.2.2.1.1.2 Teor de cinzas.........................................................................62

1.2.2.1.1.3 Determinação de lignina Klason insolúvel e solúvel em meio ácido ...63

1.2.2.1.1.4 Teor de Holocelulose.........................................................................64

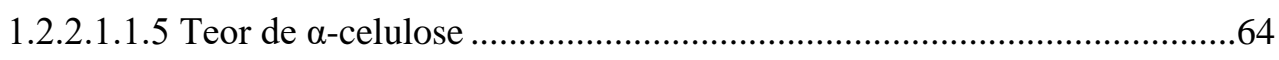

1.2.2.1.2 Espectroscopia na região do infravermelho por transformada de Fourier (FTIR) ..65

1.2.2.1.3 Microscopia eletrônica de varredura ……….........................................................65

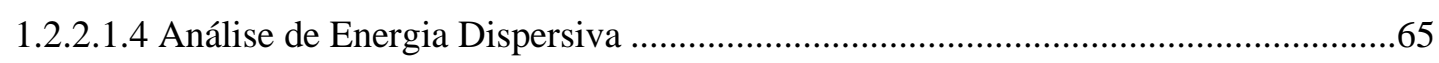

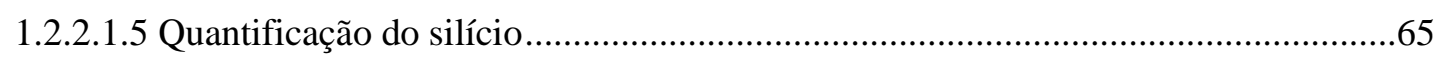

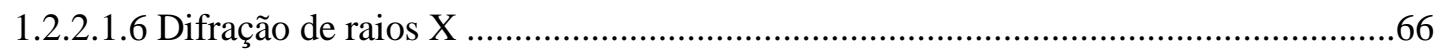

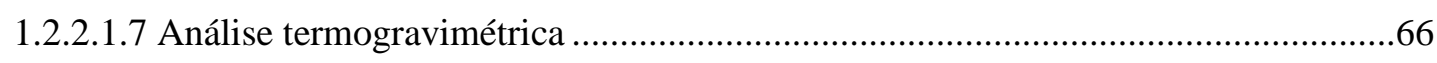

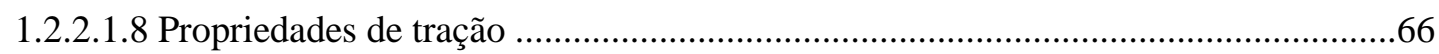

1.2.2.2 Síntese de resina fenólica do tipo resol para preparação de compósitos reforçados por 
fibras vegetal .66

1.2.2.2.1 Síntese da resina (pré-polímero) fenol-formaldeído resol (RFF) ............................66

1.2.2.3 Preparação de compósitos de matriz RFF reforçado com fibra vegetal ..........................67

1.2.2.3.1 Adição do agente acelerador de cura....................................................................67

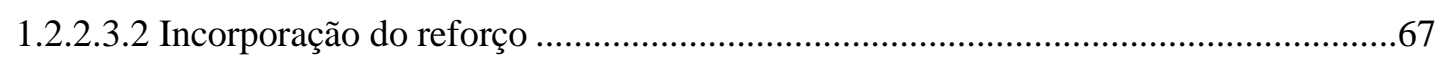

1.2.2.3.3 Moldagem do termorrígido e dos compósitos .......................................................68

1.2.2.4 Caracterização da resina fenol-formaldeído resol (RFF) e dos compósitos ....................69

1.2.2.4.1 Espectroscopia na região do infravermelho por transformada de Fourier (FTIR) ..69

1.2.2.4.2 Cromatografia por exclusão de tamanho (SEC) ..................................................69

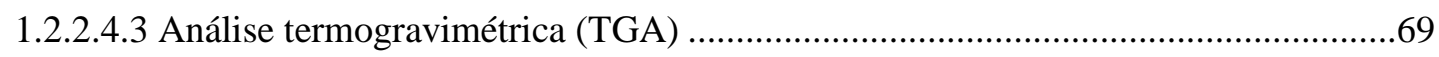

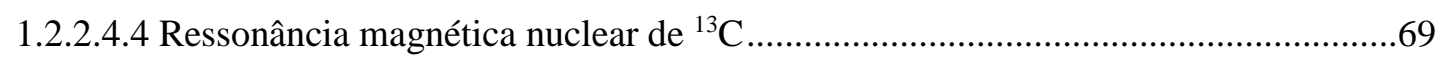

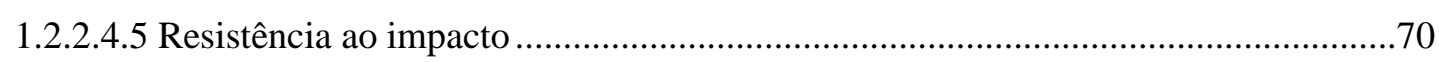

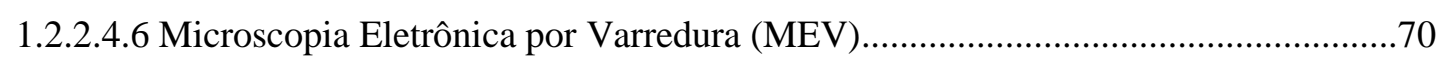

1.2.2.4.7 Propriedades de flexão ....................................................................................70

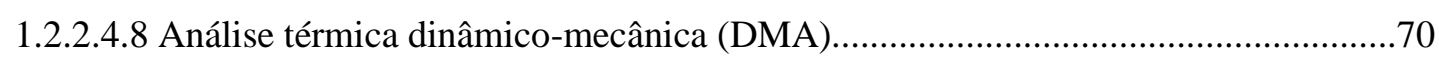

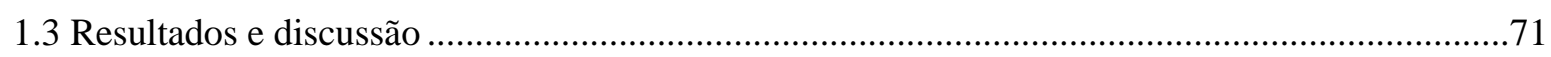

1.3.1 Caracterização da fibra do mesocarpo do dendê.................................................................

1.3.1.1 Espectroscopia na região do infravermelho por transformada de Fourier (FTIR) ..........71

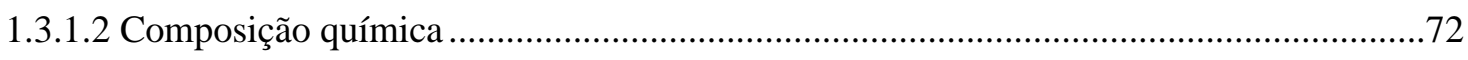

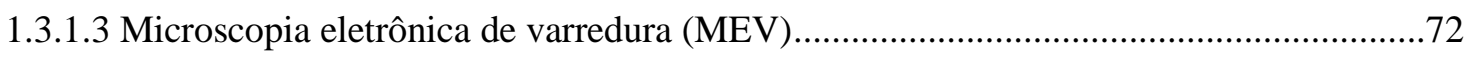

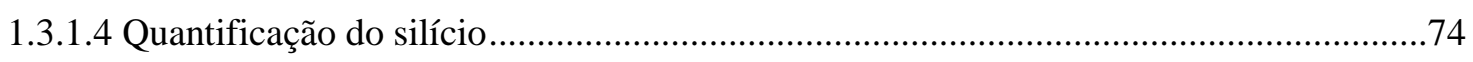

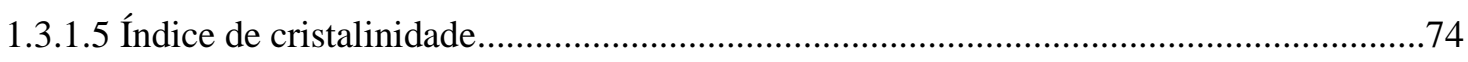

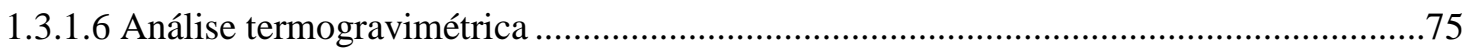

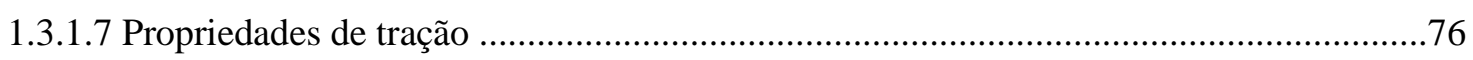

1.3.2 Caracterização da resina (RFF), termorrígido (TRFF) e compósitos fenol-formaldeído....79

1.3.2.1 Espectroscopia na região do infravermelho por transformada de Fourier (FTIR) ..........79

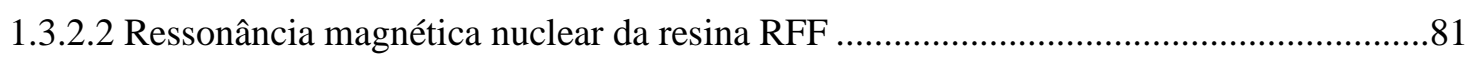

1.3.2.3 Determinação da massa molar média por cromatografia de exclusão por tamanho da

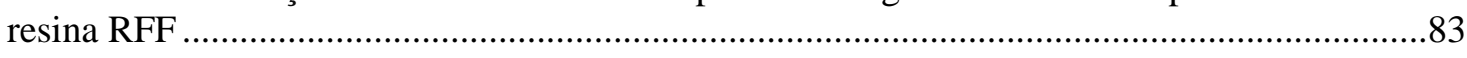

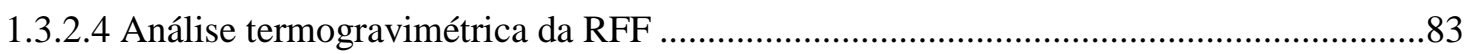

1.3.2.5 Análise termogravimétrica de TRFF e dos compósitos ...............................................84

1.3.2.6 Resistência ao Impacto Izod do termorrígido fenol-formaldeído (TRFF) e dos

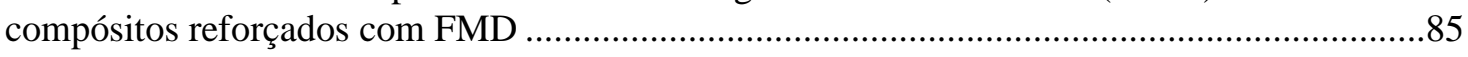

1.3.2.7 Microscopia Eletrônica de Varredura (MEV) do termorrígido fenol-formaldeído

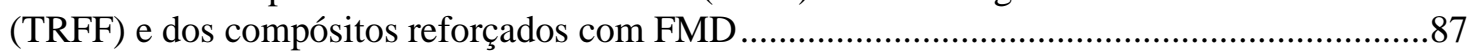

1.3.2.8 Resistência à flexão do termorrígido fenol-formaldeído (TRFF) e dos compósitos

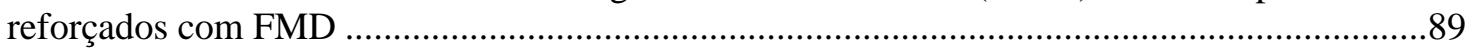

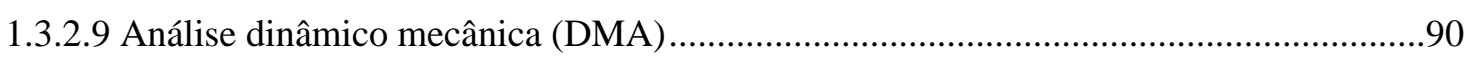

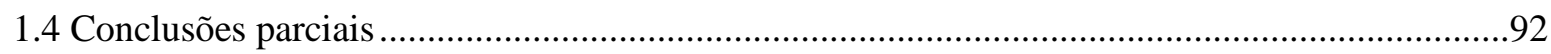

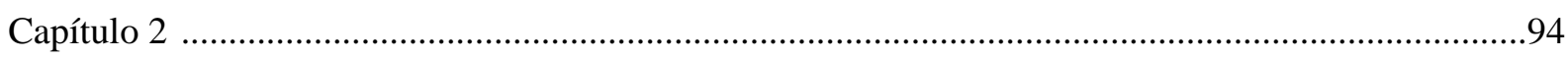

Síntese de resina fenol-formaldeído: obtenção de compósitos de matriz termorrígida reforçadas com 
mantas de fibras de sisal e de rayon, manta de fibra de sisal e fibra do mesocarpo do dendê moída ....94

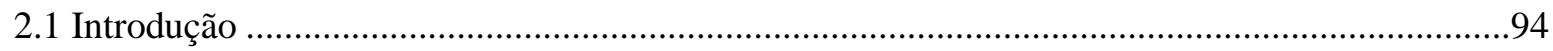

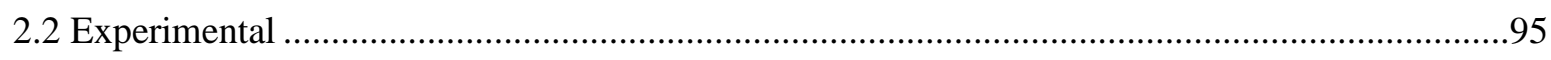

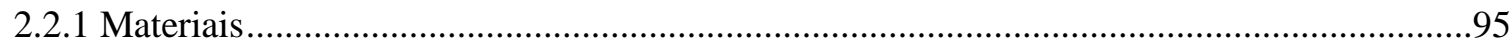

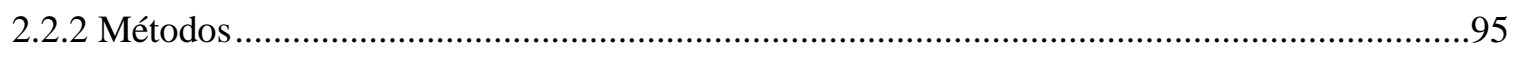

2.2.2.1 Caracterização das fibras da manta de sisal (MFS) e rayon (MFR) ..............................95

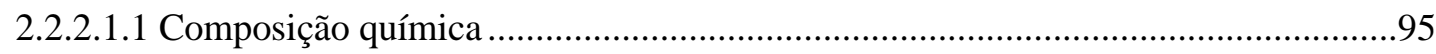

2.2.2.1.2 Espectroscopia na região do infravermelho por transformada de Fourier (FTIR) ..95

2.2.2.1.3 Microscopia eletrônica de varredura (MEV) .........................................................96

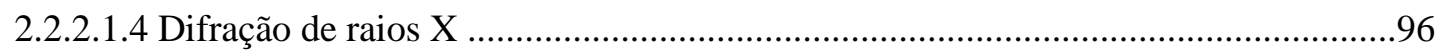

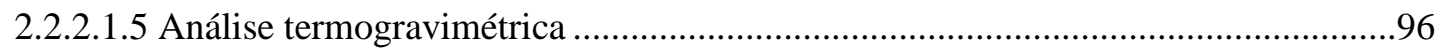

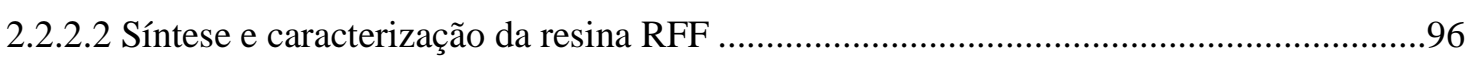

2.2.2.3 Preparação de compósitos de matriz RFF reforçado com fibra e mantas de fibra vegetal

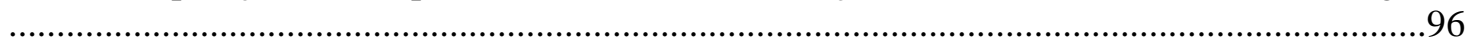

2.2.2.3.1 Adição do agente acelerador de cura................................................................96

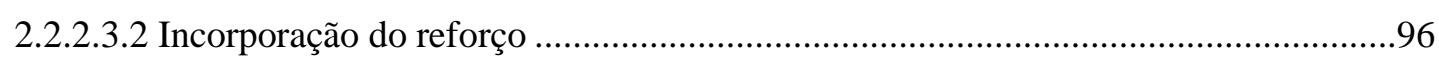

2.2.2.4 Moldagem do termorrígido e dos compósitos ...............................................................98

2.2.2.5 Caracterização da resina RFF e dos compósitos ...........................................................98

2.2.2.5.1 Espectroscopia na região do infravermelho (FTIR) ............................................98

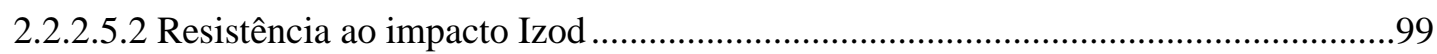

2.2.2.5.3 Microscopia Eletrônica por Varredura (MEV).......................................................99

2.2.2.5.4 Ensaio de resistência à flexão............................................................................99

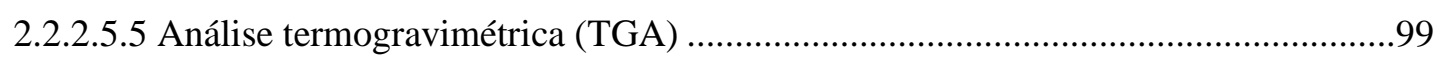

2.2.2.5.6 Análise dinâmico mecânica (DMA) .......................................................................99

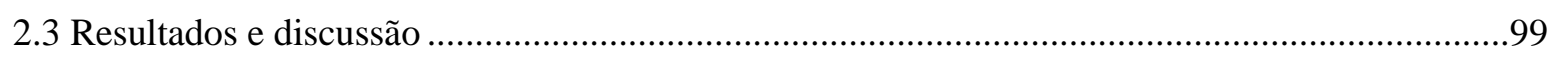

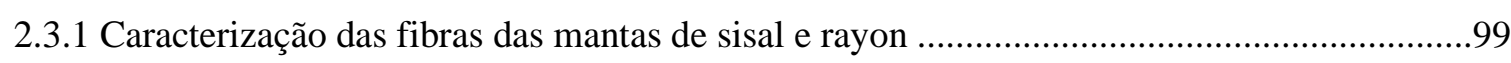

2.3.1.1 Espectroscopia na região do infravermelho por transformada de Fourier (FTIR) .........99

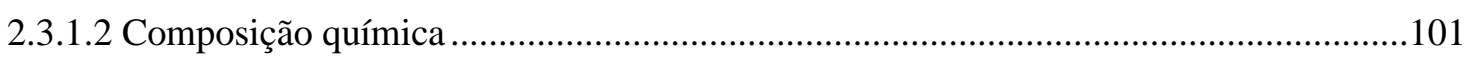

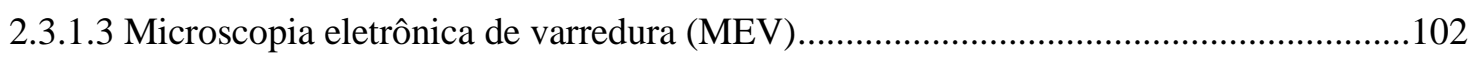

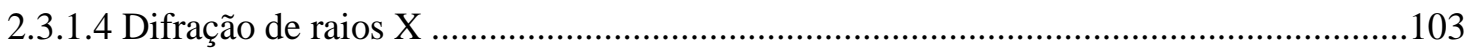

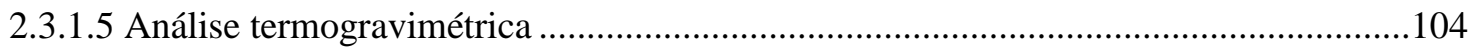

2.3.2 Caracterização dos compósitos de matriz termorrígida RFF reforçados com MFS e MFR, e

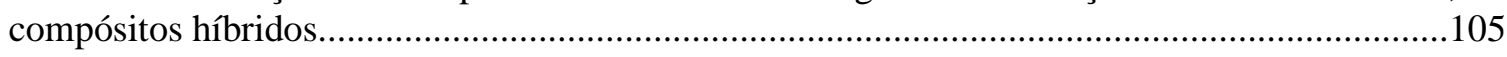

2.3.2.1 Espectroscopia na região do infravermelho por transformada de Fourier (FTIR) ........105

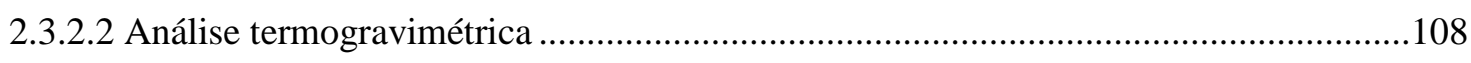

2.3.2.2.1 Compósitos matriz termorrígida RFF reforçados com MFS e MFR .......................108

2.3.2.2.2 Compósitos híbridos de matriz termorrígida RFF reforçados com MFS/FMD moída

2.3.2.3 Resistência ao Impacto Izod.................................................................................110

2.3.2.3.1 Compósitos matriz termorrígida RFF reforçados com MFS e MFR ......................110 
2.3.2.3.2 Compósitos híbridos de matriz termorrígida RFF reforçados com $\mathrm{MFS} / \mathrm{FMD}_{\text {moída }}$

2.3.2.4 Microscopia Eletrônica de Varredura (MEV) ..................................................116

2.3.2.4.1 Compósitos de matriz termorrígida RFF reforçados com MFS e MFR ...............116

2.3.2.4.2 Compósitos híbridos de matriz termorrígida RFF reforçados com MFS/FMD moída

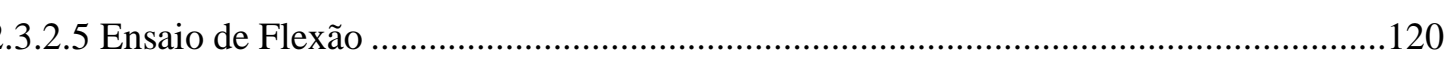

2.3.2.5.1 Compósitos reforçados com MFS, $\mathrm{C}_{\mathrm{RFF}} 42 \% \mathrm{MFS}$ e $\mathrm{C}_{\mathrm{RFF}} 42 \% \mathrm{MFS}_{\text {im-ag-et, }}$, e reforçados com MFR, $\mathrm{C}_{\mathrm{RFF}} 10 \% \mathrm{MFR}$ e $\mathrm{C}_{\mathrm{RFF}} 19 \% \mathrm{MFR}$................................................120

2.3.2.5.2 Compósitos híbridos de matriz termorrígida RFF reforçados com MFS/FMD moída

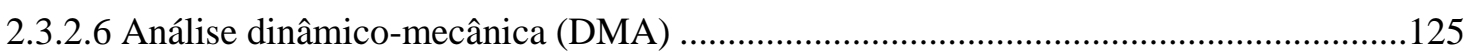

2.3.2.6.1 Compósitos matriz termorrígida RFF reforçados com MFS e MFR....................125

2.3.2.6.2 Compósitos híbridos de matriz termorrígida RFF reforçados com $\mathrm{MFS} / \mathrm{FMD}_{\text {moída }}$

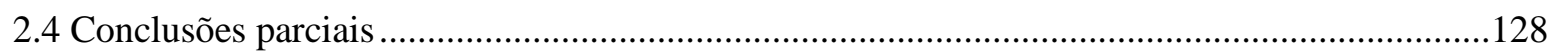

Capítulo 3

.130

Síntese de resina fenol-glutaraldeído: obtenção de compósitos de matriz termorrígida reforçados com manta de sisal, manta de rayon, e híbrido constituído por manta de sisal e fibra do mesocarpo do dendê moída.

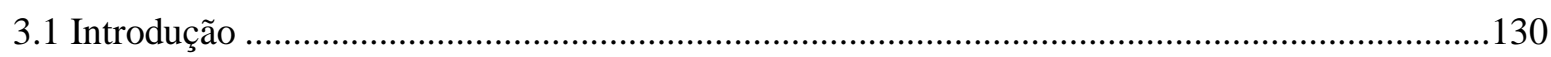

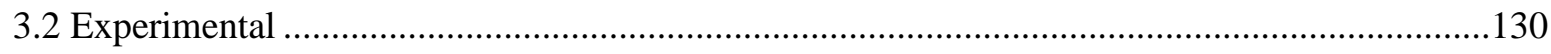

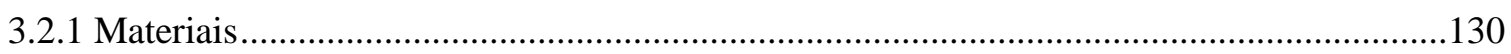

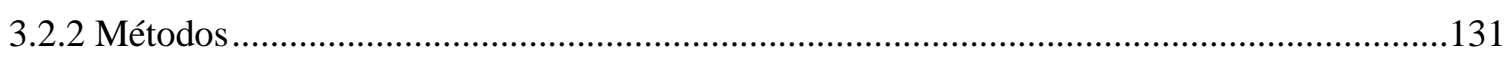

3.2.2.1 Caracterização das fibras que compõem as mantas utilizadas como reforço, MFS e

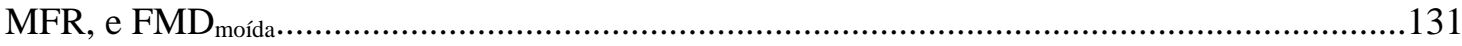

3.2.2.2 Síntese de resina fenol-glutaraldeído para preparação de compósitos reforçados por

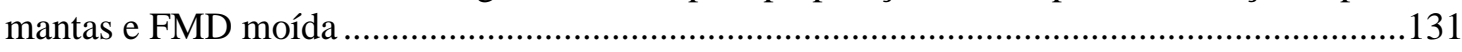

3.2.2.2.1 Síntese da resina (pré-polímero) fenol-glutaraldeído resol (RFG) .........................131

3.2.2.3 Preparação dos compósitos reforçados com fibra vegetal.............................................131

3.2.2.3.1 Adição do agente acelerador de cura...............................................................131

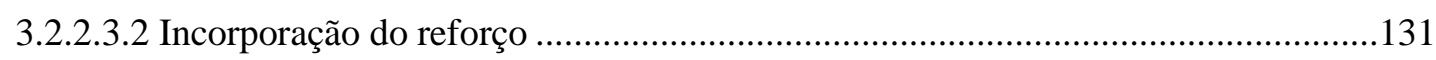

3.2.2.3.3 Moldagem do termorrígido e dos compósitos .......................................................132

3.2.2.4 Caracterização do pré-polímero, do termorrígido e dos compósitos.............................133

3.2.2.4.1 Espectroscopia na região do infravermelho por transformada de Fourier (FTIR) 133

3.2.2.4.2 Cromatografia por exclusão de tamanho (SEC) ...................................................133

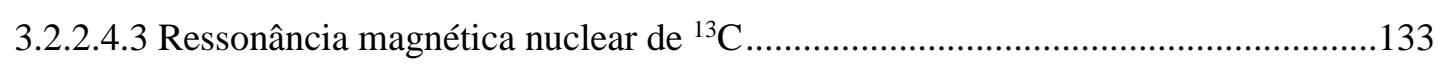

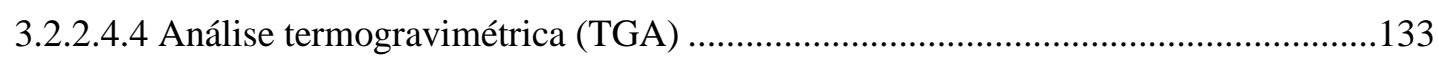

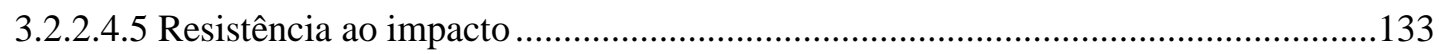

3.2.2.4.6 Microscopia Eletrônica por Varredura (MEV)......................................................133

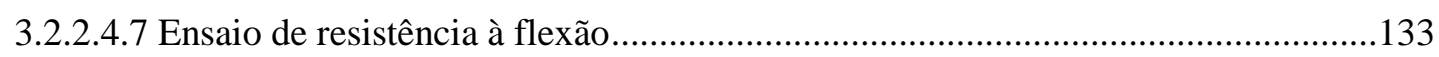

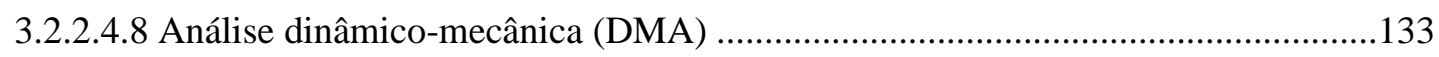


3.3 Resultados e discussão

3.3.1 Caracterização do pré-polímero, termorrígido e compósitos ……………………….........134

3.3.1.1 Espectroscopia na região do infravermelho por transformada de Fourier (FTIR) ........134

3.3.1.2 Determinação da massa molar média por cromatografia de exclusão por tamanho do

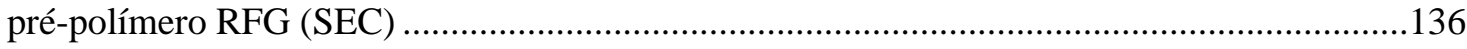

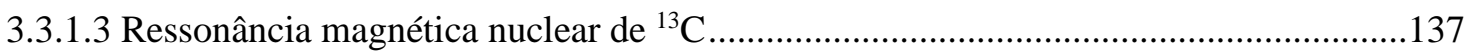

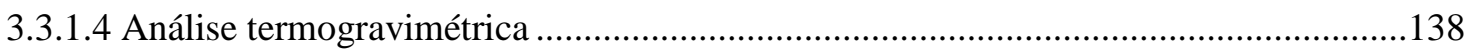

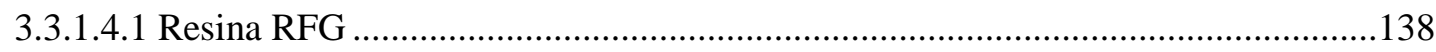

3.3.1.4.2 Termorrígido TRFG e compósitos de matriz RFG reforçados com MFS, MFR e híbrido MFS/ FMDm

3.3.1.5 Impacto Izod do termorrígido TRFG e dos compósitos de matriz RFG reforçados com

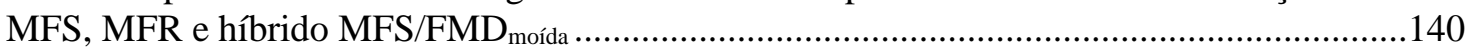

3.3.1.6 Microscopia eletrônica de varredura do termorrígido TRFG e dos compósitos de matriz RFG reforçados com MFS, MFR e híbrido MFS/FMD moída...................................................142

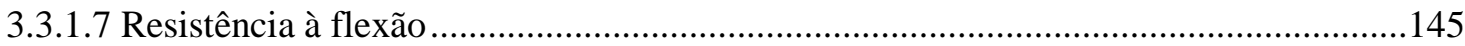

3.3.1.8 Análise dinâmico mecânica do termorrígido TRFG e dos compósitos de matriz RFG reforçados com MFS, MFR e híbrido MFS/FMD moída …........................................................147

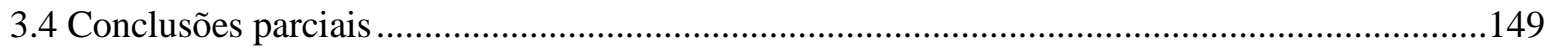

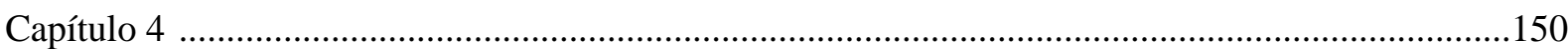

Síntese de resina lignofenólica: obtenção de compósitos de matriz termorrígida reforçados com manta de sisal, manta de rayon, e híbrido constituído por manta de sisal e fibra do mesocarpo do dendê moída

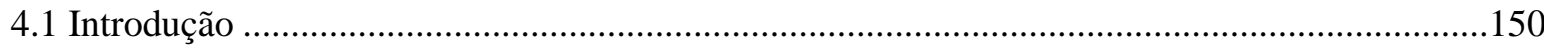

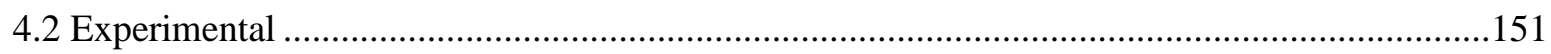

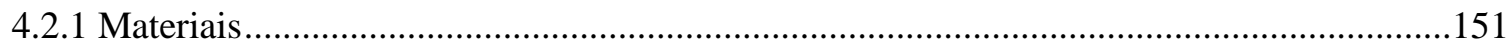

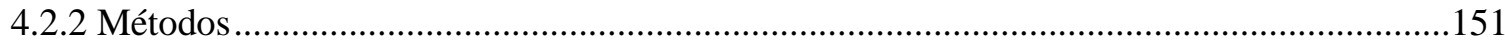

4.2.2.1 Caracterização das fibras que compõem as mantas utilizadas como reforço, MFS e

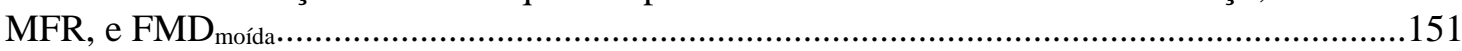

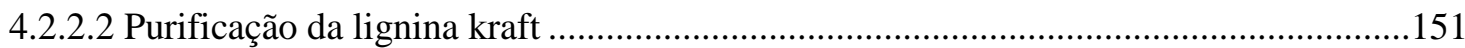

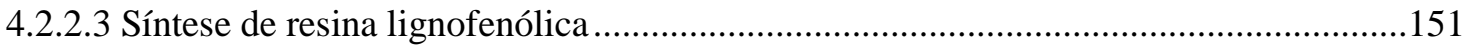

4.2.2.3.1 Síntese da resina (pré-polímero) lignina Kraft : fenol : formaldeído (RLKFF) ....151

4.2.2.4 Preparação dos compósitos de matriz lignofenólica reforçado com MFR e

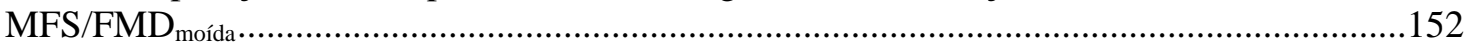

4.2.2.4.1 Adição do agente acelerador de cura ..................................................................152

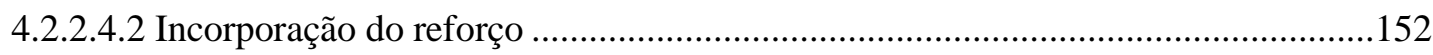

4.2.2.4.3 Moldagem do termorrígido e dos compósitos ......................................................153

4.2.2.5 Caracterização da LK, pré-polímero, do termorrígido e dos compósitos......................154

4.2.2.5.1 Determinação do teor de lignina Klason total .......................................................154

4.2.2.5.2 Análise elementar, determinação de açucares residual e cinzas............................154

4.2.2.5.3 Espectroscopia na região do infravermelho por transformada de Fourier (FTIR) 154

4.2.2.5.4 Cromatografia por exclusão de tamanho (SEC) ……….......................................154

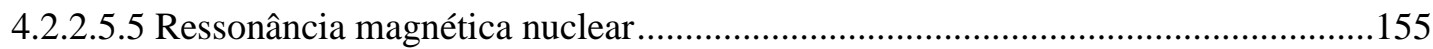




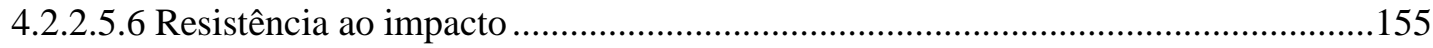

4.2.2.5.7 Microscopia Eletrônica por Varredura (MEV).....................................................155

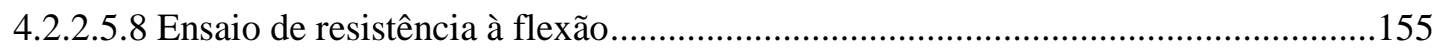

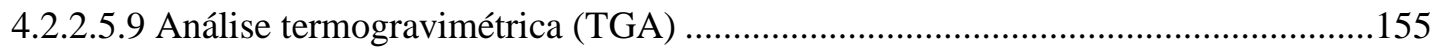

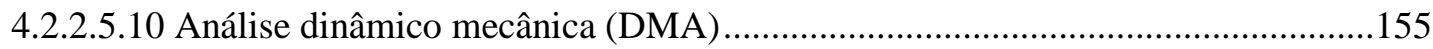

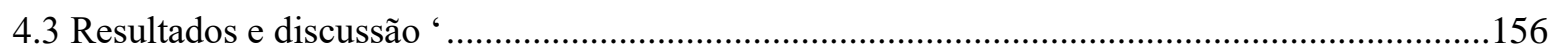

4.3.1 Caracterização da lignina Kraft, resina lignina-fenol-formaldeído e dos compósitos de matriz RLKFF reforçados com MFS, MFR e híbrido MFS/FMD moída ..........................................156

4.3.1.1 Purificação, teor de impurezas, teor de lignina Klason total e análise elementar da

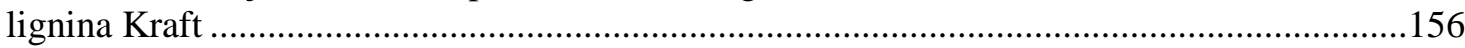

4.3.1.2 Espectroscopia na região do infravermelho da lignina Kraft, da resina RLKFF, termorrígido TRLKFF e compósitos

4.3.1.3 Determinação da massa molar média por cromatografia de exclusão por tamanho da lignina Kraft e da resina RLKFF......................................................................................161

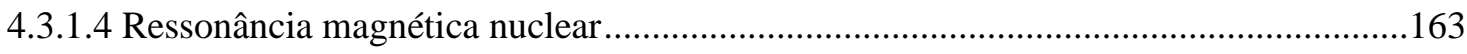

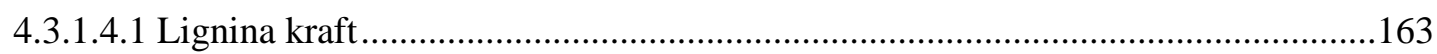

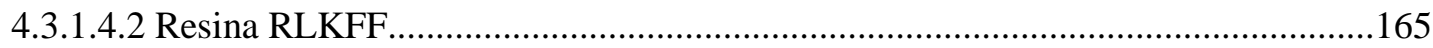

4.3.1.5 Análise termogravimétrica da Lignina kraft e resina RLKFF.....................................167

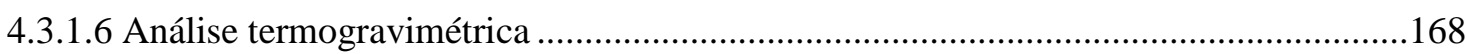

4.3.1.7 Resistência ao impacto dos compósitos de matriz RLKFF ...........................................170

4.3.1.8 Microscopia eletrônica de varredura ..........................................................................172

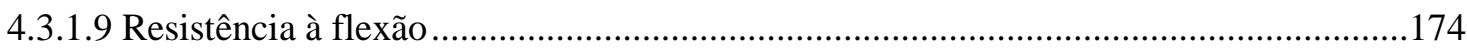

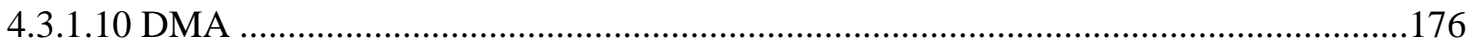

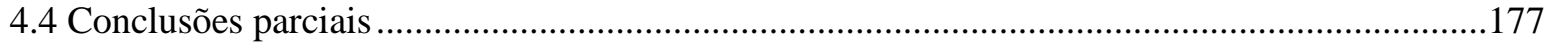

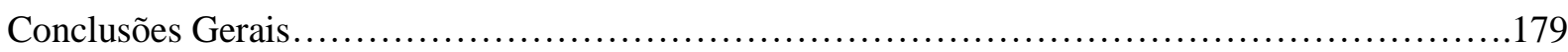

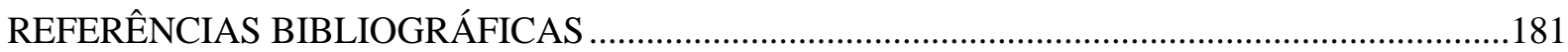





\section{Motívação do estudo}

A busca por materiais alternativos, visando atender as restrições ambientais, vem incentivando gradativamente as indústrias a desenvolverem pesquisas nesta área. Estes materiais devem idealmente apresentar boas propriedades físicas e mecânicas, baixo custo e, ao mesmo tempo, causem menor impacto ambiental do que aqueles convencionalmente utilizados. As fibras lignocelulósicas se inserem neste contexto, pois em algumas aplicações podem substituir as fibras sintéticas (aramidas, vidro, carbono), que são amplamente usadas como reforço de compósitos poliméricos. Características como biodegradabilidade (dependendo da matriz polimérica), resistência, leveza, não abrasividade, as tornam atrativas aplicações como agente de reforço em matrizes poliméricas termorrígidas ou termoplásticas (ORUE et al., 2016; RANA; GUPTA; SRIVASTAVA, 2017; IBRAHIM et al., 2018; VIEIRA et al., 2018; DE OLIVEIRA et al., 2018; KUMAR; KUMAR; BHOWMIK, 2018; DA SILVA; OLIVEIRA; FROLLINI, 2018).

As fibras naturais têm sido amplamente utilizadas nas indústrias em uma gama crescente de produtos, incluindo materiais para a indústria aeroespacial (ASIM et al., 2018), automotiva em empresas da Audi Group (Ford e Volksvagen) na obtenção de compósitos para peças de automóveis, e de construção, como reforço em concreto e cimento (ALEMDAR; SAIN, 2008; AL-OQLA; SAPUAN, 2014; ZUKOWSKI et al., 2018; LUMINGKEWAS et al., 2018). Muitas fibras lignocelulósicas, como sisal, curauá, bagaço de cana-de-açúcar, juta, têm sido usadas como reforço em compósitos em estudos desenvolvidos no Grupo de Materiais Macromoleculares e Fibras Lignocelulósicas (MacromoLignocell), onde o presente estudo foi desenvolvido (FROLLINI et al., 2004; TRINDADE et al, 2005, 2008; RAMIRES; OLIVEIRA; FROLLINI, 2013, DE OLIVEIRA et al., 2017; SILVA et al., 2018). Fibras como linho (DAVIS et al., 2019), kenaf (SEMAN et al., 2019), coco (SURECHA et al., 2019) e cânhamo (SEPE et al., 2019) também são reportadas na literatura como reforço em compósitos.

As fibras utilizadas no presente estudo corresponderam às fibras do mesocarpo do dendê (FMD), manta de fibras de sisal (MFS) e de rayon (MFR). FMD e MFS se destacam no Brasil devido à sua grande disponibilidade. A FMD consiste em um resíduo produzido a partir da extração do óleo das sementes do fruto do dendê. Parte desta fibra é utilizada para produção de energia nas próprias indústrias de processamento deste fruto, e o restante gera acúmulo no meio ambiente. Já a fibra de sisal se destaca pela sua grande aplicabilidade em materiais e áreas em que há necessidade de utilização de fibras que possuam boas propriedades mecânicas, como elevada resistência. Neste mesmo sentido, se encaixa a fibra rayon, uma fibra celulósica de 
elevada resistência, tenacidade e estabilidade térmica, obtida a partir de fontes renováveis.

Diante da importância e grande aplicabilidade que as matrizes termorrígidas possuem, poucos trabalhos na área de compósitos reforçados por fibras vegetais são encontrados na literatura, principalmente compósitos fenólicos, comparativamente às matrizes termoplásticas. Neste contexto, o presente estudo abordou a síntese de resinas fenólicas, fenol-formaldeído, fenol-glutaraldeído e lignofenólica, sendo que nesta última a lignina Kraft foi utilizada como substituinte parcial do fenol na síntese de resina.

\section{Introdução}

\subsection{Compósítos: definição, tîpos, propriedades e aplicações}

Compósitos são materiais que consistem de dois ou mais componentes/fases combinados em nível macroscópico. Um deles é chamado de reforço e o outro, matriz, na qual o reforço será aplicado. A fase de reforço pode ser tanto na forma de fibras, quanto partículas ou flocos. A matriz pode ser cerâmica, metálica ou polimérica. Esta última receberá ênfase ao longo do texto, pois foi a utilizada no presente estudo. De acordo com o tipo de reforço, os compósitos podem ser classificados conforme esquema apresentado na Figura 1.

Figura 1 - Esquema de classificação de compósitos.

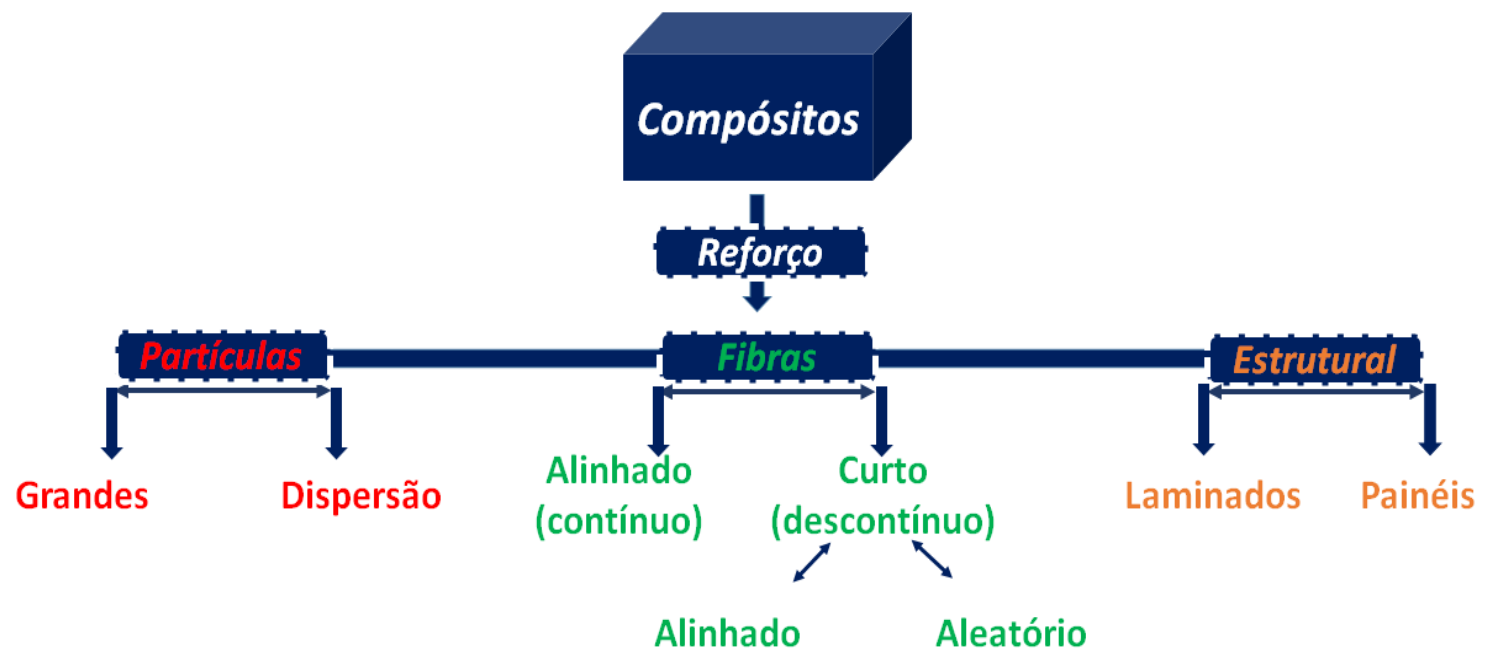

Fonte: Adaptado de Kaw (2006).

Quando se utiliza uma matriz polimérica, termorrígida ou termoplástica, para a preparação destes materiais, têm-se os compósitos poliméricos. Os polímeros termoplásticos são aqueles que não sofrem entrecruzamento, são moldáveis a altas temperaturas e pressão, e 
podem ser reprocessados (KAW, 2006). Os polímeros termorrígidos possuem elevada resistência térmica, não podem ser reprocessados, e podem sofrer entrecruzamento apenas com aquecimento e/ou pressão aliada a aquecimento, dentre outras possibilidades. Durante o entrecruzamento as cadeias se unem fortemente por ligações covalentes, o que os tornam infusíveis e insolúveis (SAUNDERS, 1931; PASCAULT et al., 2002; KAW, 2006). Dentre as matrizes poliméricas bastante utilizadas pode-se citar: polietileno (DE CASTRO et al., 2015), resina fenólica (DA SILVA et al., 2018), epóxi (BUNEA et al., 2019), polisuccinato de butileno (ZHANG et al., 2019), polipropileno (CORREIA et al., 2019) e poliéster (ISLAM et al., 2019).

A fabricação de compósitos não é uma prática recente. Desde a antiguidade se tem conhecimento que o primeiro compósito, mesmo não tendo essa denominação naquela época, feito pelo homem foi com tiras da planta de papiro dispostas em duas camadas perpendicularmente uma à outra e que os egípcios utilizavam palha para fortalecer tijolos feitos de barro (HERAKOVICH, 2012). A área de compósitos evoluiu ao longo dos anos, incluindo o surgimento de fibras sintéticas. A utilização destas como reforço iniciou-se após a Segunda Guerra Mundial (AL-OQLA; SALIT, 2017).

Em termos de aplicação, os compósitos (Figura 2), exercem importância particular em cada uma delas, por exemplo, nos setores de engenharia quando preparados tanto com fibras longas quanto contínuas e que possuem a capacidade de reduzir tanto o peso como os custos de manutenção, pois possuem elevada resistência à corrosão e à fadiga. O Boeing 787 Dreamliner, por exemplo, foi o primeiro avião comercial a ser construído com 50\% de compósitos (PILATO, 2010).

Para serem aplicados, as propriedades destes materiais precisam ser avaliadas com precisão. As propriedades mecânicas, por exemplo, são fortemente afetadas pela adesão interfacial entre a fibra utilizada como reforço e a matriz polimérica. Uma fraca adesão pode levar à uma maior formação e propagação de falhas, trincas e fissuras quando o compósito é submetido a uma força ou estresse (THAKUR; SINGHA, 2015).

Outros fatores que também são primordiais quanto às propriedades mecânicas desses materiais são a geometria e a distribuição do reforço, as propriedades individuais de cada componente, e a proporção entre o volume/massa de reforço em relação à matriz. O estresse deve ser transferido da matriz para as fibras, então uma má distribuição de fibra no compósito, por exemplo, pode gerar a formação de pontos de concentração que podem prejudicar as propriedades do material, e a geometria e a orientação podem levar a obtenção de compósitos anisotrópicos, ou seja, que possuem propriedades diferentes em direções diferentes (ALOQLA; SALIT, 2017). 
Figura 2 - Exemplos de áreas de aplicação em que os compósitos podem ser inseridos: automotiva (a), construção civil (peça de concreto reforçado com fibra de carbono) (b), naval-náutica (c), aeronave (d) e peça de cerâmica reforçado com CMC para câmara de combustão de foguetes (e) .

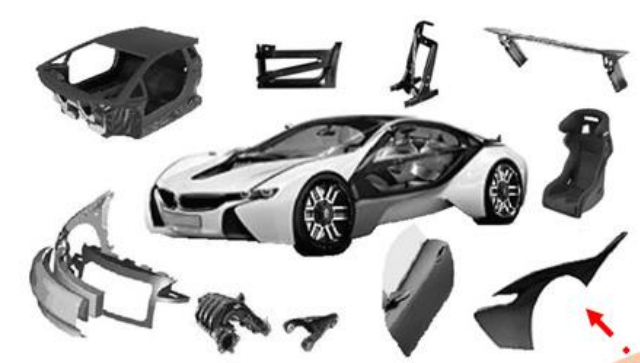

(a)

\section{Compósitos}

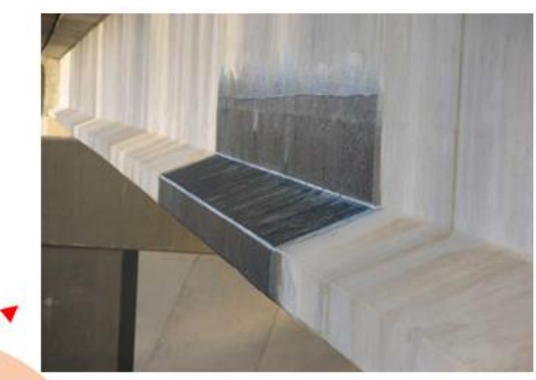

(b)

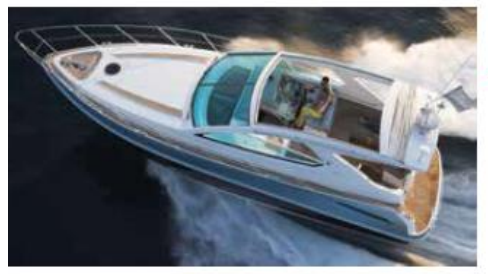

(c)

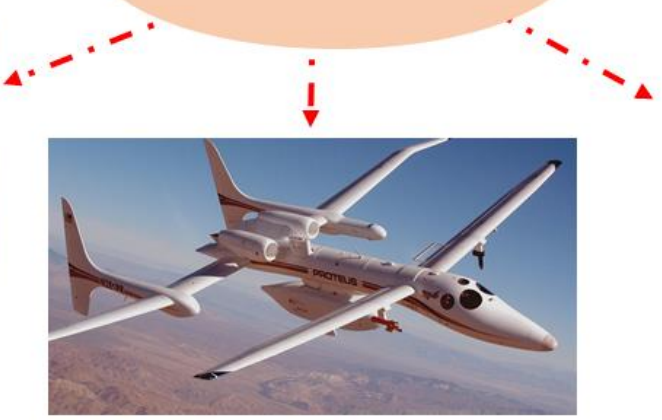

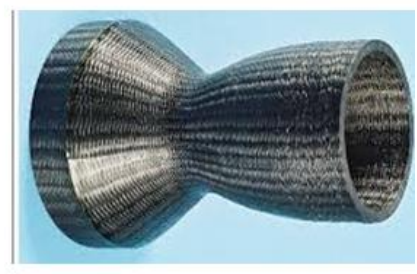

(e)

(d)

Fonte: (a) GUTIÉRREZ et al. (2014)

(b) https://www.engenhariacivil.com/estruturas-betao-compositos-reforcados-fibras-carbono

(c) http://www.aviacao.org/article/materiais-compositos/12/

(d) http://www.aviacao.org/article/materiais-compositos/

(e) https://www.engenhariacivil.com/estruturas-betao-compositos-reforcados-fibras-carbono

Quanto ao tipo de fibra a ser utilizada como reforço em compósitos, estas podem ser de natureza sintética como: fibra de vidro (CALABRESE et al., 2019), carbono (KERN et al., 2019), basalto (SERGI et al., 2019), e/ou naturais como: sisal (DE OLIVEIRA et al., 2017, bagaço de cana-de-açúcar (GUNA et al., 2019),), curauá (TEIXEIRA et al., 2019), dentre outras, tanto na forma de fibras curtas como longas. Como as fibras naturais são o objeto do estudo, estas serão destacadas ao longo do texto.

Nordin et al. (2017) observaram em compósito de polipropileno reforçado com $50 \%$ de FMD, uma resistência ao impacto de $44,2 \mathrm{~J} \mathrm{~m}^{-1}$, o qual pode ser resultante da elevada quantidade de fibra em relação à matriz e/ou da formação de aglomerados, que cria vazios nos compósitos. Isso pode levar a uma fraca tranferência de estresse da matriz para as fibras.

De maneira geral, quanto maior a porcentagem de fibras, melhores serão algumas propriedades mecânicas do material. No entanto, existe uma quantidade limite de fibras que 
deve ser adicionada na matriz polimérica, e acima deste pode ocasionar uma fraca adesão fibra/matriz e porosidade no material, devido a quantidade insuficiente de resina para impregnar adequadamente todas as fibras (SHAHZAD, 2017).

De Oliveira et al. (2017) obtiveram resultados satisfatórios ao utilizarem $30 \%$ em massa de fibra de sisal $(3 \mathrm{~cm})$ como reforço em matriz fenol-formaldeído, $435 \mathrm{~J} \mathrm{~m}^{-1}$ contra $19 \mathrm{~J} \mathrm{~m}^{-1}$ de resistência ao impacto do termorrígido fenólico resol. Ainda, os autores realizaram tratamento na fibra de sisal com ultra-som por 1h visando aumentar a adesão fibra-matriz e, consequentemente, melhorar as propriedades mecânicas dos compósitos. Com isso, foi possivel a obtenção de compósitos com resistência ao impacto de aproximadamente $500 \mathrm{~J} \mathrm{~m}^{-1}$. Esta melhora foi resultante do aumento da interação fibra-matriz ocasionado pelo colapso de microbolhas que foram formadas e que podem ter separado melhor os feixes de fibra e, assim, levar a um aumento da impregnação das mesmas.

Silva e colaboradores (2018) prepararam compósitos de matriz termorrígida fenolformaldeído tipo resol reforçada com bagaço de cana-de-açúcar (30 a 70\% em massa). Os autores obtiveram uma melhor resistência ao impacto com $70 \%$ em massa de bagaço de canade-açúcar, $70 \mathrm{~J} \mathrm{~m}^{-1}$. A mesma tendência foi observada nos resultados de resistência à flexão e módulo de flexão, indicando que a inserção de fibras levou a um aumento na rigidez do material.

Yusup e colaboradores (2019) prepararam compósitos de matriz epóxi reforçados com 5 \% em massa de fibra do cacho do dendê $(3-5 \mathrm{~mm})$. Os autores obtiveram resultados de resistência ao impacto (Charpy) e à flexão de $81 \mathrm{~J} \mathrm{~m}^{2}$ e $68 \mathrm{MPa}$ (ambos utilizando a fibra não tratada), respectivamente. Ainda, os autores notaram, com base na análise de microscopia eletrônica de varredura (MEV), que houve descolamento fibra-matriz relacionadas à fraca adesão entre ambas. $\mathrm{O}$ resultado de flexão obtido pelos autores foi considerado baixo pelos mesmos e pode ter sido ocasionado pela heterogeneidade da fibra e distribuição da mesma no compósito (HARISH et al., 2009).

Além de compósitos com fibras curtas, é possível encontrar na literatura artigos que descrevem o usode mantas de fibras como reforço em compósitos e quando as mantas são intercaladas com a matriz formando camadas têm-se os compósitos laminados. Rajesh e colaboradores (2017) avaliaram as propriedades mecânicas de compósitos reforçados com manta de fibra de juta e fibras curtas de juta dispostas de maneira aleatória em matriz de poliéster. Com base no ensaio de tração, os autores observaram que o compósito com fibra curta sofreu falha antes do compósito com manta. Isto está relacionado à maior capacidade de carga devido à presença de manta no compósito, resultando em uma falha com menor taxa de deformação. Com base no ensaio de resitência à flexão, os compósitos com fibras curtas 
apresentaram uma redução desta propriedade comparado ao mesmo compósito com manta, que pode estar associado à uma distribuição não uniforme do estresse durante o ensaio.

Hamdan et al. (2017) avaliaram as propriedades de compósitos laminados de matriz epóxi-poliéster reforçados com mantas de fibra de rami (quatro mantas com feixes em $0^{\circ}$ ). Os autores observaram que não houve diferença significativa em propriedades como resistência à flexão e tração no laminado comparado à matriz (sem reforço). Uma das principais desvantagens da utilização de mantas com feixes unidirecionais é a baixa resistência à tração e compressão, e ao cisalhamento no plano (KIM; SHAM, 2000).

Fares e colaboradores (2019), ao avaliarem a influência do aumento do número de mantas de algodão em compósitos de matriz de polipropileno, observaram a partir das micrografias da região de fratura a presença de trincas na matriz ao redor da fibra sem causar o descolamento entre ambas, indicando boa adesão. Os autores também observaram que houve um aumento o módulo de flexão e da resistência à tração com o aumento do número de mantas.

Dentre as caracterizações bastante utilizadas para se avaliar o comportamento e as propriedades mecânicas dos compósitos tem-se a análise dinâmico-mecânica (DMA). A partir desta é possível avaliar a densidade de reticulação, armazenamento/perda de energia, relaxações primárias, entre outros. Tanto a morfologia quanto a interação fibra-matriz são determinantes das propriedades dinâmico-mecânica dos materiais (RAMIRES et al., 2010; COSTA et al., 2016).

Alguns autores observaram a partir do módulo de armazenamento (obtido na análise dinâmico mecânica), que este aumenta com o volume de fibras dos compósitos. Isto pode ser atribuído ao fato de o módulo de Young das fibras ser maior que o da matriz polimérica, levando a um efeito positivo de transferência de estresse da matriz para as fibras, via interface, quando o material é submetido a uma solicitação mecânica (YANG et al., 2019).

Porém, isso também depende muito do tipo e do comprimento da fibra que está sendo utilizada, assim como a interação e a forma com que a mesma está distribuída na matriz polimérica. Por exemplo, Luz et al. (2018) observaram que o aumento do volume de fibras de bagaço de cana-de-açúcar, $10 \mathrm{~cm}$ de comprimento, levou à uma redução do módulo de armazenamento quando comparado a matriz, resina epóxi. O uso de fibras longas e aleatórias pode ter favorecido uma orientação menos eficiente das fibras na matriz que pode ter gerado defeitos e pontos de concentração que prejudicaram as propriedades do material (MEGIATTO JÚNIOR, 2006).

Regiões em que a matriz se encontra ao redor da fibra, imediatamente posterior à interface, podem ter propriedades diferentes quando comparadas com o restante do material 
(PAIVA; FROLLINI, 2001; TRINDADE et al., 2005). Ainda, a inserção de fibras pode interferir no entrecruzamento de matriz termorrígida, pois podem dificultar a difusão das cadeias dos pré-polímeros (ou resinas) para o estabelecimento das ligações, o que pode resultar em um material heterogêneo em relação à densidade de ligações cruzadas (TRINDADE et al., 2005).

Já com base na curva Tan $\delta$ (delta) versus temperatura, também obtida a partir de DMA, é possível avaliar o amortecimento do material, ou seja, a capacidade do mesmo dissipar energia (COSTA et al., 2016). Quando há uma redução do valor máximo do pico da curva Tan $\delta$, significa que o material tem menos habilidade de dissipar energia. Ainda com base nesta curva, é possível obter informações sobre a heterogeneidade ou não do material baseando-se no alargamento do pico da curva e da temperatura de transição vítrea, que está relacionada ao pico Tan $\delta$ (RAMIRES, 2010; DE OLIVEIRA SANTOS et al., 2014; COSTA et al., 2016).

Quando um mesmo compósito possui fibras de natureza diferentes, estes são denominados de compósitos híbridos. Estes são materiais constituídos por dois ou mais tipos de fibras que combinados em uma única matriz polimérica podem fornecer propriedades mecânicas melhores ou intermediárias, quando comparadas com o mesmo compósito apenas com uma fibra individual (SAFRI et al., 2018). Na hibridação as propriedades mecânicas do compósito final geralmente podem ser relacionadas à combinação de propriedades mecânicas e de superficie de ambas as fibras com a matriz polimérica e, portanto, as desvantagens de um componente podem ser compensadas pela adição do outro (VALENTE et al., 2011; SARASINI; FIORE, 2018; NAVEEN et al., 2019).

$\mathrm{Na}$ literatura artigos científicos reportam tanto a hibridação utilizando dois ou mais fibras de mesma natureza, sintéticas ou naturais (VIVEK; KANTHAVEL, 2019; CHEE et al., 2019), quanto distintas, sintéticas e naturais (SARASINI et al., 2016; HAMOUDA et al., 2017; RICCIARDI et al., 2019) na preparação de compósitos.

A versatilidade de combinações entre diferentes tipos de fibras aliado com a obtenção de melhores propriedades pode facilitar a difusão deste tipo de material para as indústrias automotiva, naval, construção, dentre outras. Outro ponto interessante dos compósitos híbridos é que estes podem ser preparados utilizando a combinação entre fibras curtas, fibras curtas e mantas, e entre mantas, que também podem ser contituídas por um ou mais tipos de fibras.

Ramlee et al. (2019) prepararam compósitos híbridos de matriz fenólica (novolaca) utilizando fibras curtas (13 mm) de bagaço de cana-de-açúcar (BCA) e fibras do cacho do dendê como reforço (FCD) em diferentes proporções, como também compósitos com as fibras isoladas. Os autores observaram que o compósito híbrido com proporção de 35\% FCD:15\% 
BCA foi o que apresentou melhores resultados de resistência à tração e módulo de Young, comparado com os demais. A adição de FCD proporcionou melhor resistência mecânica devido à maior porcentagem de celulose presente nesta fibra quando comparado com BCA, e a adição de BCA ajudou a reduzir o teor de água e a presença de vazios na matriz. Uma grande presença de vazios pode levar à redução de propriedades como resistência à flexão e módulo de flexão (LIU et al., 2006).

Vieira et al. (2018) avaliaram as propriedades de compósitos de matriz epóxi reforçados com 10 a 30\% (em volume) de manta híbrida composta por $70 \%$ (em massa) de fibra de malva e 30\% (em massa) de fibra de juta. Os compósitos contendo 30\% em volume de manta híbrida apresentaram maior valor de resistência ao impacto Izod, $198 \pm 11,5 \mathrm{~J} \mathrm{~m}^{-1}$, comparado aos demais. Os autores observaram que os compósitos reforçados com a manta não sofreram ruptura transversal completa, como ocorre na matriz (sem reforço). A trinca se propagou da matriz para a fibra, mas devido a conformidade da manta (feixes de fibras alinhadas a $0^{\circ}$ e $90^{\circ}$ ), não houve ruptura e a mesma apenas deformou. $\mathrm{O}$ uso da manta fez com que o material absorvesse mais energia (FU et al., 1999). Uma das vantagens de se utilizar mantas a 0 e $90^{\circ}$, por exemplo, é que em alguns casos a mesma pode atuar como uma barreira impedindo a propagação transversal da trinca, aumentando a energia de absorção do material quando submetido ao ensaio de impacto Izod (NASCIMENTO et al., 2012; PEREIRA et al., 2017).

Chee et al. (2019) avaliaram os efeitos da hibridação em compósitos de matriz epóxi utilizando manta de bambu e manta de kenaf. Os autores observaram efeitos positivos em relação à hibridação (50\% bambu:50\% kenaf). O módulo de armazenamento do compósito de bambu/epóxi foi mais alto do que o compósito de kenaf/epóxi, e os valores do módulo de armazenamento dos compósitos híbridos apresentaram valor intermediário entre bambu/epóxi e kenaf /epóxi. Um fato importante observado pelos autores foi que a estabilidade dimensional foi fortemente influenciada pela orientação das fibras, sendo que na direção das fibras transversais houve uma expansão proeminente, e na direção das fibras longitudinais a expansão foi relativamente baixa. Segundo os autores, o compósito híbrido obtido pode ser utilizado em aplicações automotivas ou de construção, pois estas exigem materiais com alta estabilidade dimensional e propriedades mecânicas dinâmicas.

Terwadkar e Walame (2019) prepararam compósitos de matriz epóxi reforçados com fibra de kenaf, manta de fibra de banana, e híbrido constituído por manta de fibra de banana/kenaf (fibra curta). Os autores obtiveram melhor resistência à flexão no compósito reforçado apenas com manta de fibra de banana, tanto comparado aos demais compósitos quanto à matriz sem reforço. O compósito híbrido apresentou uma redução desta propriedade 
devido à maior presença de vazios no mesmo, enquanto em relação à resistência ao impacto e ao módulo de flexão, o mesmo compósito apresentou melhores propriedades comparativamente aos demais.

Como citado anteriormente, é possível obter compósitos utilizando mais de uma manta que podem ser de mesma natureza ou não, sendo denominados de laminados híbridos. Sarasini et al. (2016) utilizaram lâminas intercaladas de fibras de carbono (C) e linho (L) em matriz epóxi. Foram preparados compósitos com duas sequências de empilhamento: LCL e CLC. Ao comparar os resultados de flexão, os autores observaram que os compósitos apresentaram delaminação e o compósito CLC apresentou resultado ligeiramente superior quando comparado com LCL. No compósito LCL a tolerância ao dano por impacto foi maior, impedindo assim uma maior propagação da trinca no laminado.

\subsubsection{Matriz poliméríca}

\subsubsection{Resína fenólica}

As resinas fenólicas são matrizes poliméricas que possuem elevada resistência térmica, baixa flamabilidade, baixa produção de fumaça, isolante elétrico e boa estabilidade dimensional (WANG et al., 2014; FENG et al., 2017). Estas propriedades as tornam atrativas em aplicações como sistemas de proteção térmica e em compósitos para interiores de aeronaves e cargas (PILATO, 2010).

Os primeiros produtos à base de resina fenólica foram obtidos em 1872 por A. Von Baeyer. Porém, esta resina só se tornou atratativa em 1907 quando Leo H. Baekeland conseguiu desenvolver um método econômico que permitia obter peças duras e resistentes a partir de moldagem com calor e pressão (KNOP; PILATO, 1985). A resina fenólica é considerada o primeiro plástico sintético, passando a ser comercializada com o nome de bakelite em 1911 (CRESPY; BOZONNET; MEIER, 2008; HIRANO; ASAMI, 2013).

As resinas fenólicas são obtidas a partir da reação entre fenol e aldeído, sendo o formaldeído o mais comumente utilizado. A reação envolve primeiramente na adição do aldeído ao fenol, seguido de crescimento da cadeia, ocorrendo a formação do pré-polímero (ou resina), finalizando com a etapa de cura ou também chamada de entrecruzamento (GARDZIELLA; PILATO, KNOP, 2013), em que ocorrre a formação das ligações cruzadas. As resinas fenolformaldeído, podem ser de dois tipos: novolaca e resol (Figura 3). As resinas do tipo resol são sintetizadas em meio básico com excesso de formaldeído no meio, e as novolacas são sintetizadas em meio ácido com excesso de fenol. A resina fenólica do tipo resol será enfatizada, 
pois esta foi utilizada como matriz polimérica no presente estudo.

Figura 3 - Representação esquemática das estruturas das resinas fenólicas (fenol-formaldeído) resol e novolaca.

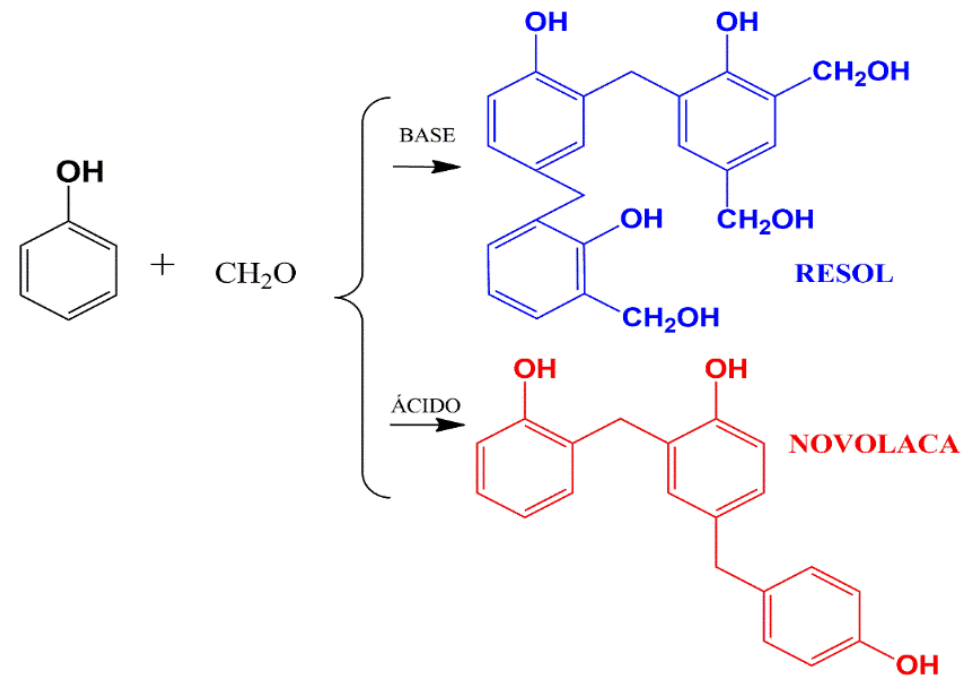

$\mathrm{Na}$ literatura é possível encontrar uma grande variedade de aplicações destas resinas como: adesivos na fabricação painéis de fibras (MDF- Medium density fiberboard) e de partículas baseados em madeira e fibras lignocelulósicas (PODSCHUN et al., 2016; ABDELWAHAB; NASSAR, 2011); matriz polimérica na preparação de compósitos (RAMIRES et al., 2010; DA SILVA et al., 2018; RASHID et al., 2017; PRASHANTH; HANUMANTHARAJU, H. G.; LOKESH, 2019) matriz para material de fricção (MIFUKA; 2019); espumas (TANG et al., 2019; BRACEGIRDLE et al., 2019); compósitos para isolamento térmico (GE et al., 2019), dentre outras.

\subsubsection{Resína fenólica resol}

A síntese de resina fenólica resol ocorre inicialmente através da formação do ânion fenolato em meio básico, por exemplo usando $\mathrm{KOH}$, ocorrendo a estabilização deste ânion através da "deslocalização" da carga negativa. No híbrido de ressonância, as maiores densidades de carga encontram-se nas posições orto e para do anel fenólico (Figura 4). Por utilizar uma solução aquosa de formaldeído, também chamada de formalina na síntese, o mesmo encontra-se na forma de metileno glicol $\left(\mathrm{HO}-\mathrm{CH}_{2}-\mathrm{OH}\right)$ (Figura 4) (WERSTLER, 1985), sendo este que irá reagir com o ânion fenolato para formar orto-hidroximetilfenóis e para-hidroximetilfenóis. A hidroximetilação, inserção dos grupos hidroximetila ou metilol, ocorreu nas posições orto e para, pois estas posições são ativadas para ataque eletrofílico devido 
à “deslocalização" de elétrons (SAUNDERS, 1998; PILATO, 2010).

Figura 4 - Formação de metileno glicol (a) e formação do íon fenolato e entre o íon fenolato e o formaldeído produzindo hidroximetilfenóis (b).

(a)

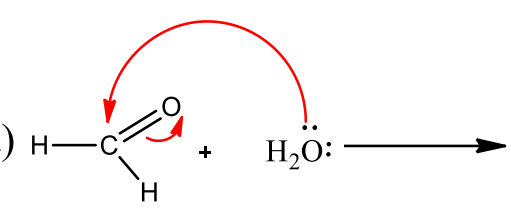<smiles>C1COC2CCOCC2CO1</smiles><smiles>CCC(O)O</smiles>

(b)

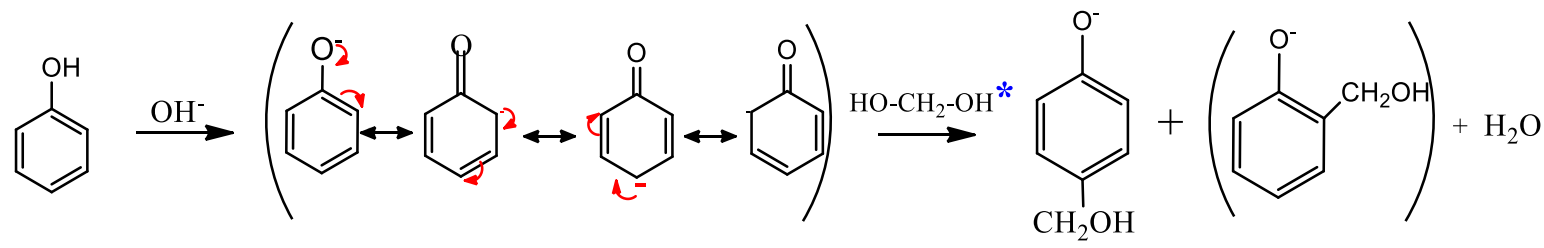

Fonte: Adaptado de SAUNDERS (1998).

Estes hidroximetilfenóis (Figura 4) possuem reatividade maior com o formaldeído do que com o fenol original. Isto se deve à ativação do anel frente a um ataque eletrofílico ocasionado pelo efeito eletrônico doador de elétrons do grupo hidoximetila para o anel aromático. O grupo metileno ligado ao anel doa eletrons por efeito indutivo doador de carbono com hibridização $\mathrm{sp}^{3}$ frente a carbono com hibridização $\mathrm{sp}^{2}$, e por hiperconjugação envolvendo as ligações -C-H. Assim, outras reações de substituição podem ocorrer havendo a formação de derivados dimetilol e trimetilol, como mostrado na Figura 5 (SAUNDERS, 1998; RAMIRES, 2010; EL MANSOURI; YUAN; HUANG, 2011). Estes possuem boa estabilidade em meio alcalino, mesmo assim não há impedimento para que ocorram outras reações de condensação havendo a formação de fenóis dinucleares e polinucleares, que estão ligados entre si por pontes metilênicas, na maioria dos casos, ocorrendo a formação de água e formaldeído como subprodutos da reação (Figura 6).

Figura 5 - Reação de formação de derivados dimetilol e trimetilol.

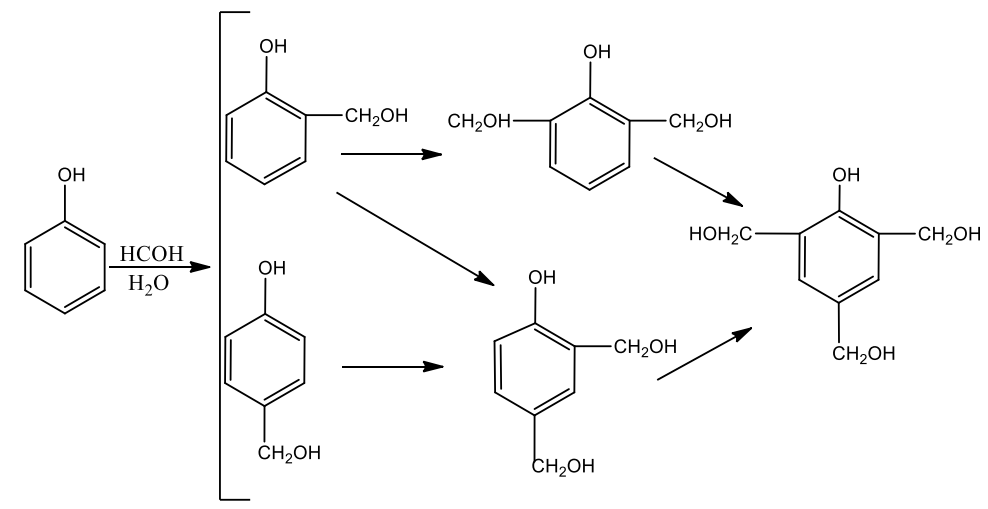


Fonte: SAUNDERS (1998).

Figura 6 - Reação de auto condensação de hidroximetilfenóis.

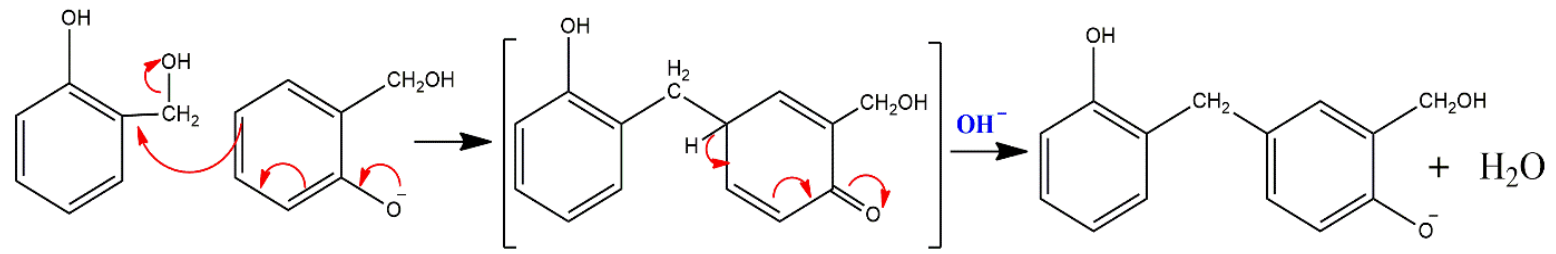

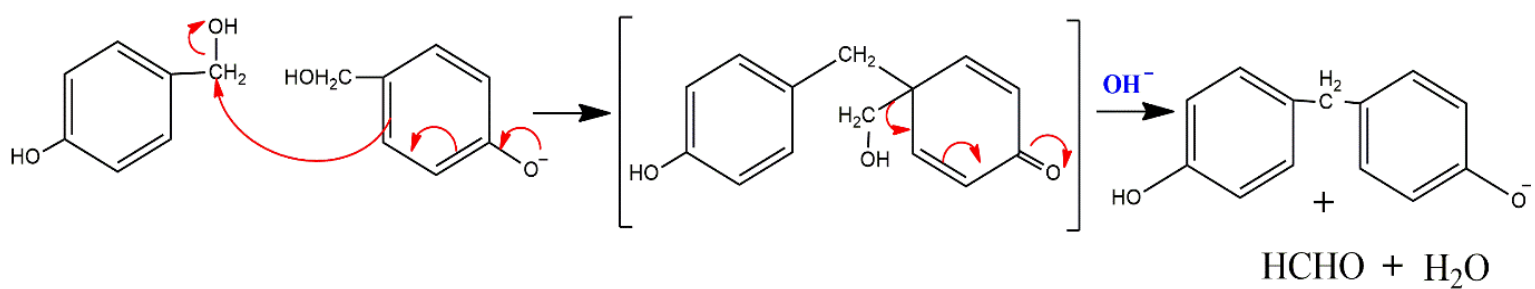

Fonte: Adaptado de SAUNDERS (1998).

Em seguida, os grupos metilol sofrem condensação com outro grupo fenol ou metilolfenol levando à formação de um polímero de cadeia linear que após aquecimento sofre cura, através da formação de ligações cruzadas (FARIS et al., 2017), gerando materiais termorrígidos (Figura 7).

Figura 7 - Estrutura da resina fenólica resol entrecruzada.

Fonte: Autoria própria.

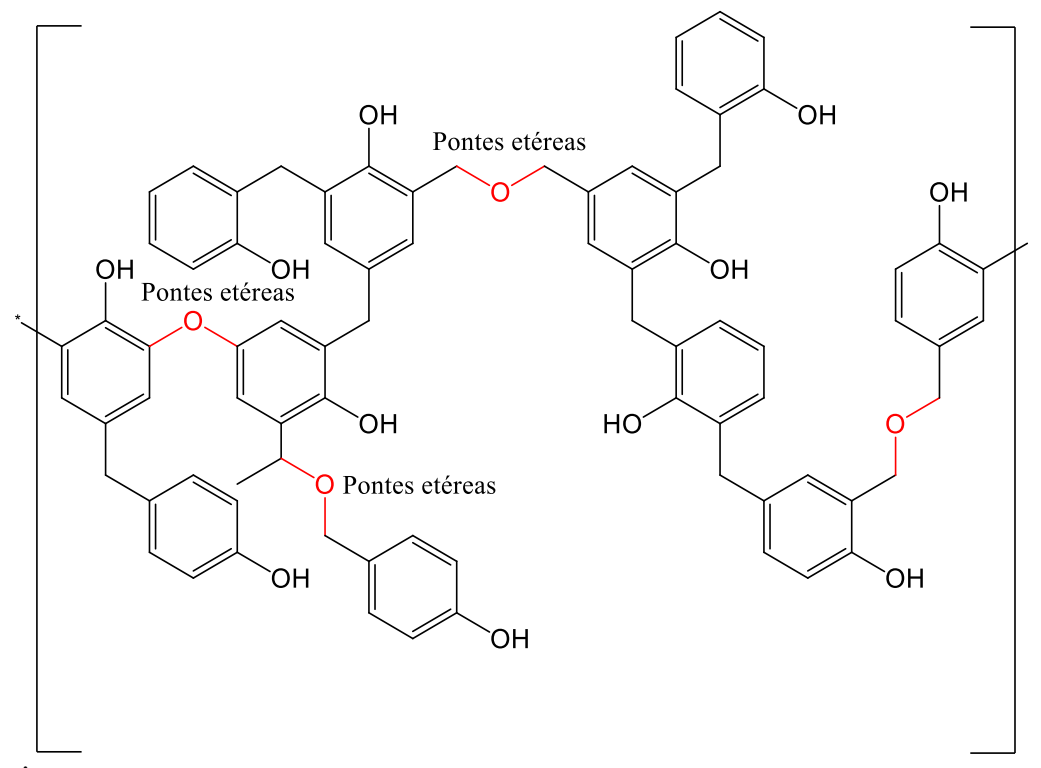

As propriedades dos termorrígidos como elevada resistência a estresse, temperatura, dentre outras, devido sua estrutura altamente entrecruzada após a cura (ATHIJAYAMANI et al., 2017) os tornam atrativos. Porém, o entrecruzamento leva a baixa resistência a fraturas, tornando-os mais frágeis do que os termoplásticos, necessitando assim da utilização de um 
material como reforço estrutural que leva à formação de compósitos.

$\mathrm{Na}$ literatura são reportados estudos sobre a utilização de resinas fenólicas como matrizes poliméricas para preparação de compósitos. Athijayamani e colaboradores (2017) utilizaram fibra de areca (palmeira) na preparação de compósitos híbridos de matriz fenólica. Os autores observaram que a adesão interfacial entre a fibra e a matriz polimérica foi fraca, o que teria sido comprovado pelo arrancamento da fibra, que também pode estar relacionado a pouca impregnação da matriz polimérica.

Ramires et al. (2010) utilizaram fibras de sisal como reforço em matriz polimérica de resina lignina organosolve-formaldeído. Os autores notaram que a adesão entre a fibra e a matriz foi satisfatória sendo possível a obtenção de bons resultados de resistência ao impacto, $500 \mathrm{~J}^{-\mathrm{m}^{-1}}$, no compósito reforçado com $40 \%$ em massa de fibra de sisal, resultante da boa transferência de carga entre ambas. Já Razera e Frollini (2006) avaliaram a influência do tratamento de superfície, alcalino e ar ionizado, em fibras de juta nas propriedades finais do compósito de matriz termorrígida fenólica. Concluíram que o tratamento das fibras com solução de $\mathrm{NaOH} 5 \%$ proporcionou uma maior resistência à flexão e maior porcentagem de alongamento na ruptura à fibra. Como consequiência, o compósito reforçado com esta fibra apresentou melhores propriedades de resistência ao impacto se comparado ao preparado com as fibras não tratadas e tratadas com ar ionizado.

Prashanth et al. (2019) prepararam compósitos de resina fenólica intercalando seis camadas de fibras de juta (J) e banana (B) nas seguintes sequências JJBBJJ e BBJJBB. Ao avaliar as propriedades mecânicas do material, os autores observaram que a inserção das fibras reduziu a característica quebradiça da matriz. Além disso, houve um aumento da resistência ao impacto e da temperatura de deflexão térmica para o compósito com maior porcentagem de fibra de juta, que pode estar associado com a maior adesão interfacial desta com a matriz polimérica comparativamente à fibra de banana.

Diante da importância que as resinas fenólicas possuem em diversas áreas de aplicação, esforços vêm sendo realizados com o intuito de produzir resinas a partir de matérias primas renováveis, como a substituição do fenol proveniente da indústria petrolífera de elevado custo de produção e não-renovável por lignina (PAIVA; FROLLINI (2002), RAZERA; FROLLINI (2004); TRINDADE et al.(2005); PAIVA; FROLLINI (2006), RAMIRES et al. (2010), DA SILVA et al., (2012); RAZERA et al. (2014); DE OLIVEIRA et al. 2017).

\subsubsection{Resina fenol-glutaraldeído}

O glutaraldeído é um dialdeído (cadeia linear de cinco carbonos) que pode ser obtido a 
partir de fontes naturais pela oxidação de componentes da biomassa (DA SILVA et al., 2013; BARBOSA et al., 2014). Além disso, este possui toxicidade inferior comparado ao formaldeído.

A estrutura I (Figura 8- a) é formada a partir da reação do glutaraldeído com a água, já que este reagente é comercializado em meio aquoso. A reação ocorre nas posições orto e/ou para do anel aromático, pois estas posições são ativadas para ataque eletrofílico devido à "deslocalização" de elétrons (Figura 8- b), havendo a inserção de grupos hidroxialquila nas posições ativadas dos anéis aromáticos, prosseguindo com a formação do pré-polímero fenolglutaraldeído através de autocondensação. A Figura 8- a ilustra um possível mecanismo de reação considerando a reação entre o fenol e o glutaraldeído em meio básico.

Figura 8 - Reação entre glutaraldeído e a água (a), reação de hidroxialquilação do fenol em meio básico (b) e possível produto formado na reação de síntese da resina fenol-glutaraldeído (c).

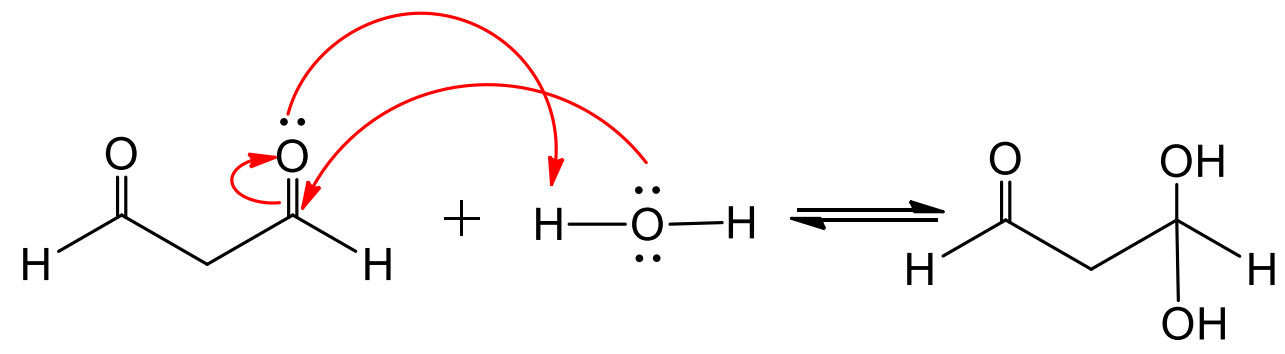

Estrutura I

(a)
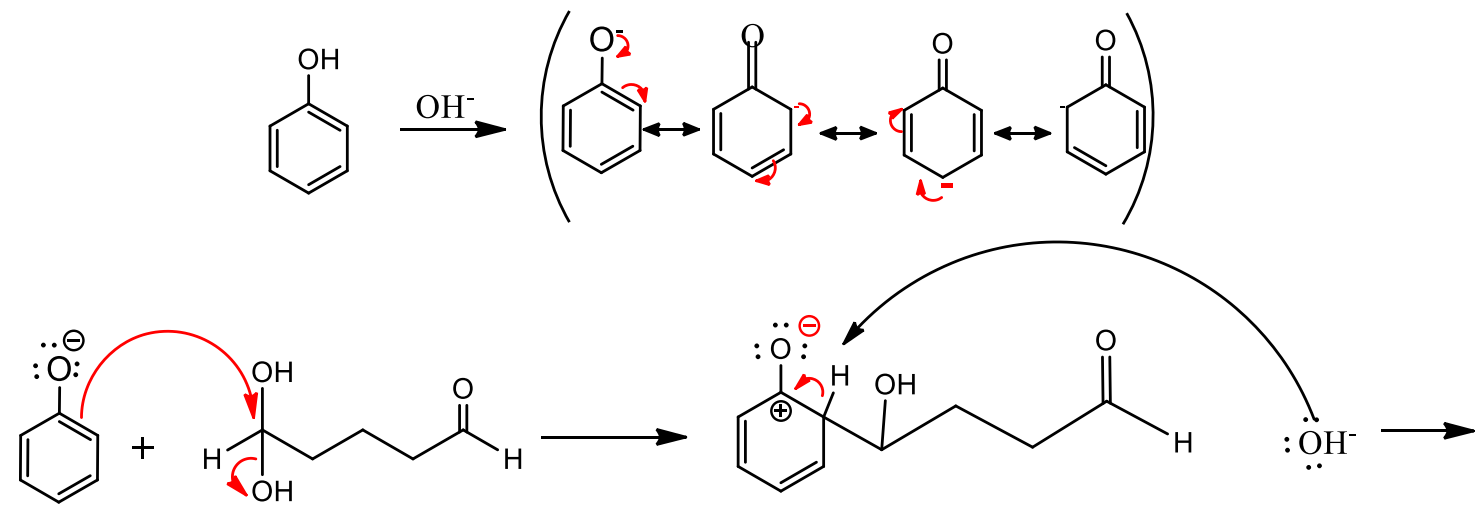<smiles>CC(C)[C@H](C)CC(=O)CCCC(O)c1ccccc1[O-]</smiles>

(b) 


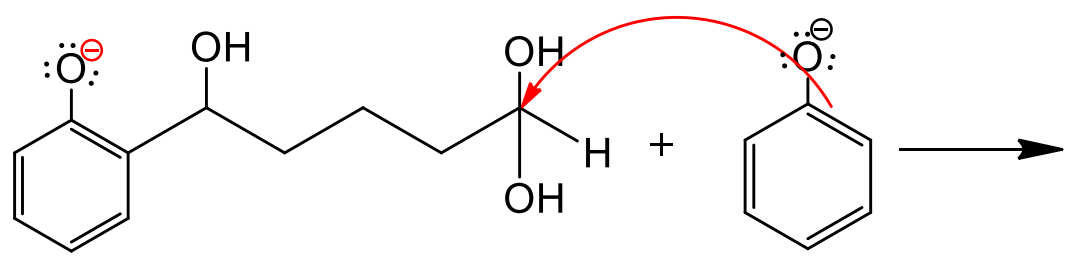

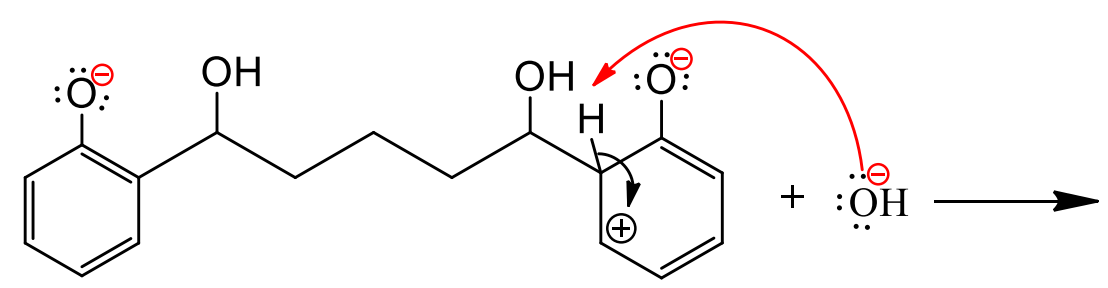

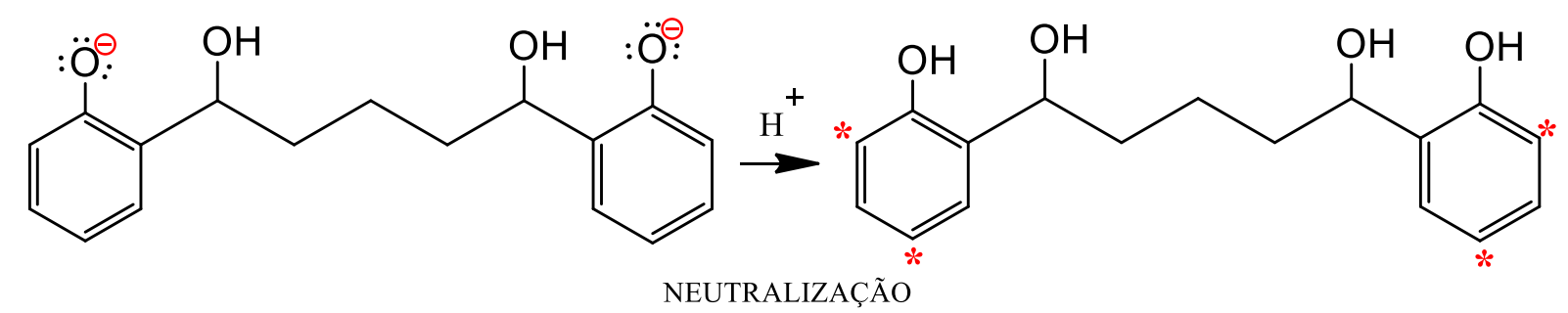

(c)

$\mathrm{Na}$ literatura poucos trabalhos são reportados referentes à síntese desta resina. Wu et al. (2017a) utilizaram glutaraldeído como agente modificador da resina fenol-formaldeído para utilização como agente de crosslinking em adesivo à base de proteína de soja. Os autores também realizaram a síntese da resina fenol-glutaraldeído a fim de comparar produtos envolvidos em ambas as reações. Com base no espctro de $\mathrm{RMN}-{ }^{13} \mathrm{C}$, os autores observaram como parte dos produtos reacionais fenol- $\mathrm{CH}(\mathrm{OH}) \mathrm{CH}_{2} \mathrm{CH}_{2} \mathrm{CH}_{2} \mathrm{CHO}$ e fenol$\mathrm{CH}(\mathrm{OH}) \mathrm{CH}_{2} \mathrm{CH}_{2} \mathrm{CH}_{2} \mathrm{CH}(\mathrm{OH})$-fenol (Figura 8- c), indicando que estruturas fenólicas hidroxialquiladas sofrem condensação entre si, formando posteriormente um pré-polímero. Sendo que a hidroxialquilação dos segmentos da cadeia polimérica ocorre sempre nas posições orto e para (ambas indicadas pelo asterisco vermelho) (Figura 8- c).

Esta resina foi utilizada no presente estudo como uma matriz polimérica para a preparação de compósitos reforçados com mantas de fibra de sisal (MFS), e de fibra rayon (MFR) e compósitos híbridos reforçados por MFS/fibra do mesocarpo do dendê moída. Esta resina foi utilizada pela primeira vez como matriz polimérica para a preparação de compósitos reforçados com mantas de fibra de sisal, e de fibra rayon e híbridos constituído por manta de fibra de sisal e fibra do mesocarpo do dendê moída. 


\subsection{Lígnina: fonte de anéis aromátícos fenólicos}

A substituição de matérias-primas não renováveis por materiais originados a partir de fontes naturais vem sendo um dos assuntos de grande interesse por parte das indústrias nos últimos anos, visando reduzir o impacto ambiental. Devido à sua composição, a madeira, a qual é composta por celulose, hemiceluloses e lignina como constituintes principais, pode ser utilizada como uma excelente de fenol. As madeiras podem ser classificadas em duas categorias: coníferas (softwood) e folhosas (hardwood) (Figura 9-a) que possuem de 25 a $31 \%$ (GALKIN; SAMEC, 2016; LOHRE; KLEINERT; BARTH, 2017), e 16 a 32\% de lignina (DOS SANTOS et al., 2014; ERDOCIA et al., 2017), respectivamente. As folhosas e coníferas possuem predominância de estruturas guaiacila e siringila, e guaiacila (Figura 9-b), em sua composição, respectivamente. Ainda as biomassas não madeiras como, palha de cereais e gramíneas, possuem a predominânia de p-hidroxifenila (GOSSELINK, 2011).

Figura 9 - Tipos de árvores de coníferas e folhosas (a) e estrutura química de guaiciala, siringila e $p$ hidroxifenila (b).
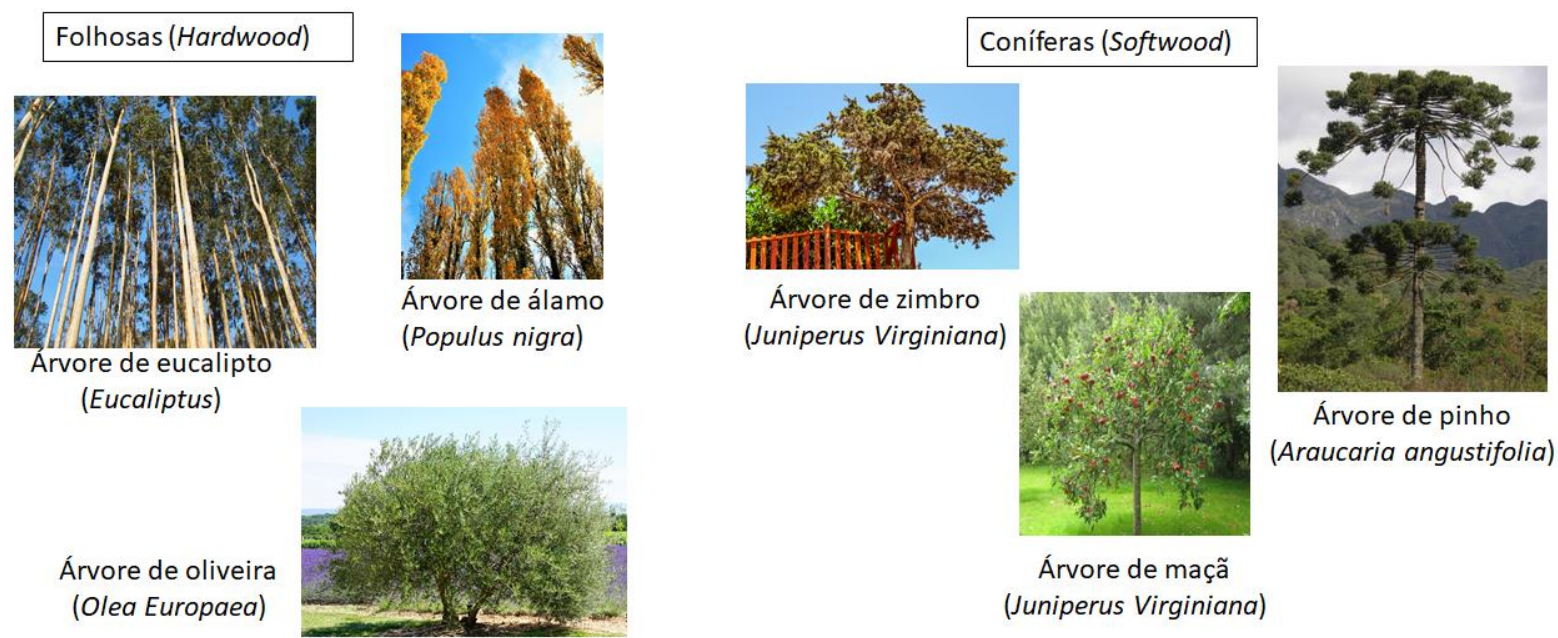

(a) 


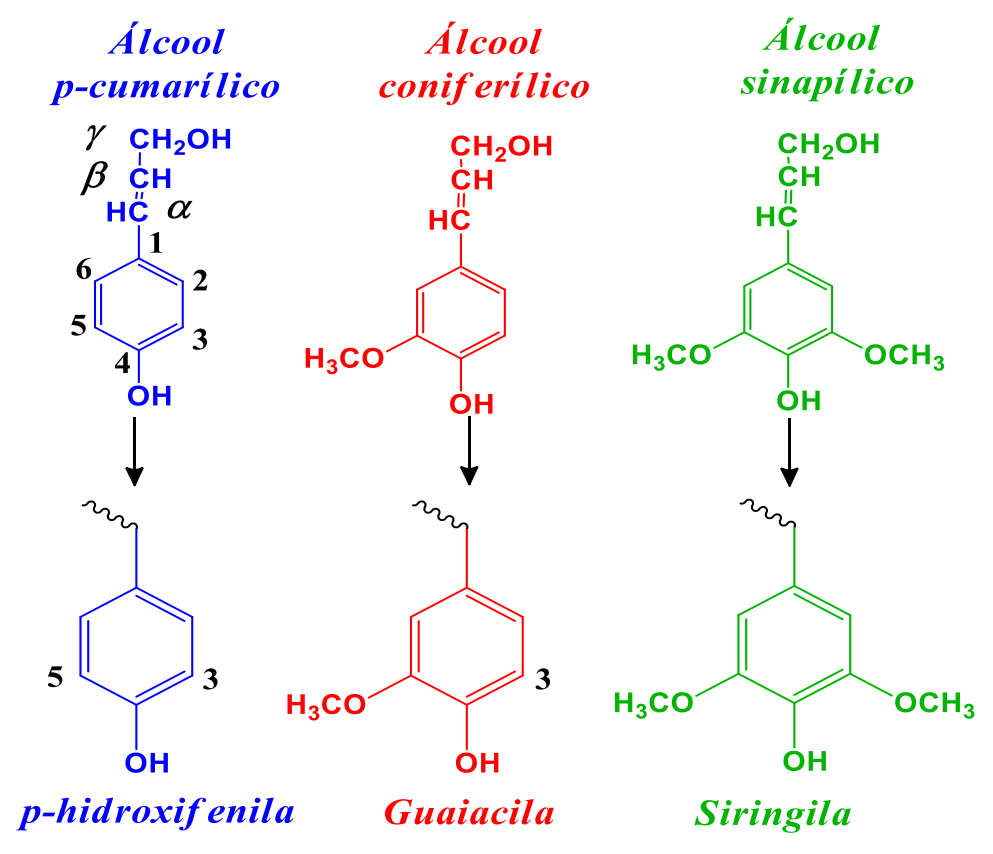

(b)

Fonte: Autoria própria.

A lignina in natura, também chamada de protolignina, possui natureza hidrofóbica, sendo insolúvel em sistemas aquosos (GOSSELINK, 2011). É uma macromolécula fenólica de estrutura tridimensional complexa (Figura 10) e amorfa, presente predominante na parede celular das plantas vasculares, sendo constituída por unidades fenilpropanóides derivadas dos álcoois p-cumarílico, coniferílico e sinapílico: guaiacila, siringila e para-hidroxilfenila (Figura 9- b), respectivamente, as quais se diferenciam entre si pela presença de grupos orto-metil substituintes do anel aromático (HU et al., 2018).

As unidades monoméricas da lignina se ligam de maneira randômica por acoplamento, possibilitando a formação de várias subunidades estruturais (PILÓ-VELOSO et al., 1993). Tipos de ligações variadas são encontradas na estrutura da lignina como: carbono-carbono entre as cadeias alifáticas $\left(\beta-\beta^{\prime}\right)$, entre a cadeia alifática e o anel aromático $(\beta-5$ e $\beta-1)$ e entre os anéis aromáticos (5-5'), ligações tipo éter entre cadeias alifáticas e anéis aromáticos ( $\beta$-O-4 e $\alpha$-O-4) e entre anéis aromáticos, dentre outras (PILÓ-VELOSO et al., 1993; LAURICHESSE; AVÉROUS, 2013) (Figura 11).

As unidades guaiacila e $p$-hidroxifenila (Figuras 9- b) da lignina possuem as posições C3 e C-5 do anel aromático livres e aptas para reagir com grupos hidroximetila, sendo mais reativas em sínteses de resinas do tipo fenol-formaldeído. Em contrapartida, as unidades siringila possuem estas posições impedidas pela presença de grupos metoxilas (RAMIRES et 
al., 2010) e, portanto, são menos reativas. Há vários outros grupos funcionais presentes em sua estrutura, como hidroxila fenólica, hidroxila alcóolica, unidades aromáticas e ligações do tipo éter.

Por muitos anos a lignina foi considerada pelas indústrias de polpação como um subproduto indesejado, sendo utilizada apenas como combustível de caldeiras para gerar vapor e eletricidade, pois algumas biorefinarias centralizavam suas atividades na plataforma em que se usam apenas os carboidratos como precursores químicos, como para a produção de biocombustível (GALKIN; SAMEC, 2016; MABROUK et al., 2017; FERNANDEZRODRIGUEZ et al., 2016). Apenas $2 \%$ da lignina Kraft produzida nas indústrias de polpação é recuperada (HOLLADAY et al., 2007).

Figura 10 - Estrutura proposta para lignina de coníferas.

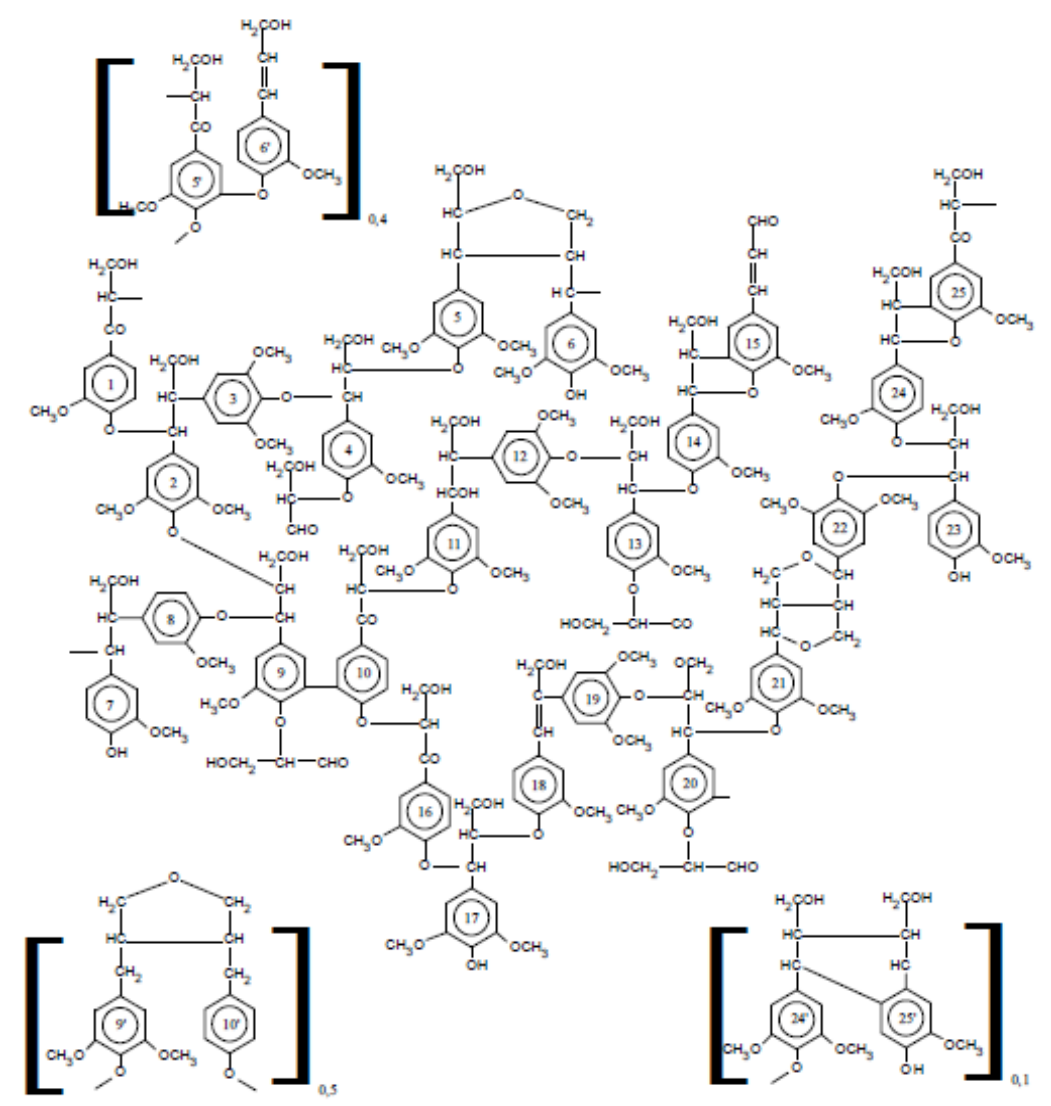

Fonte: ADLER, 1977. 
Figura 11 - Ligações presentes entre as unidades monoméricas da lignina.
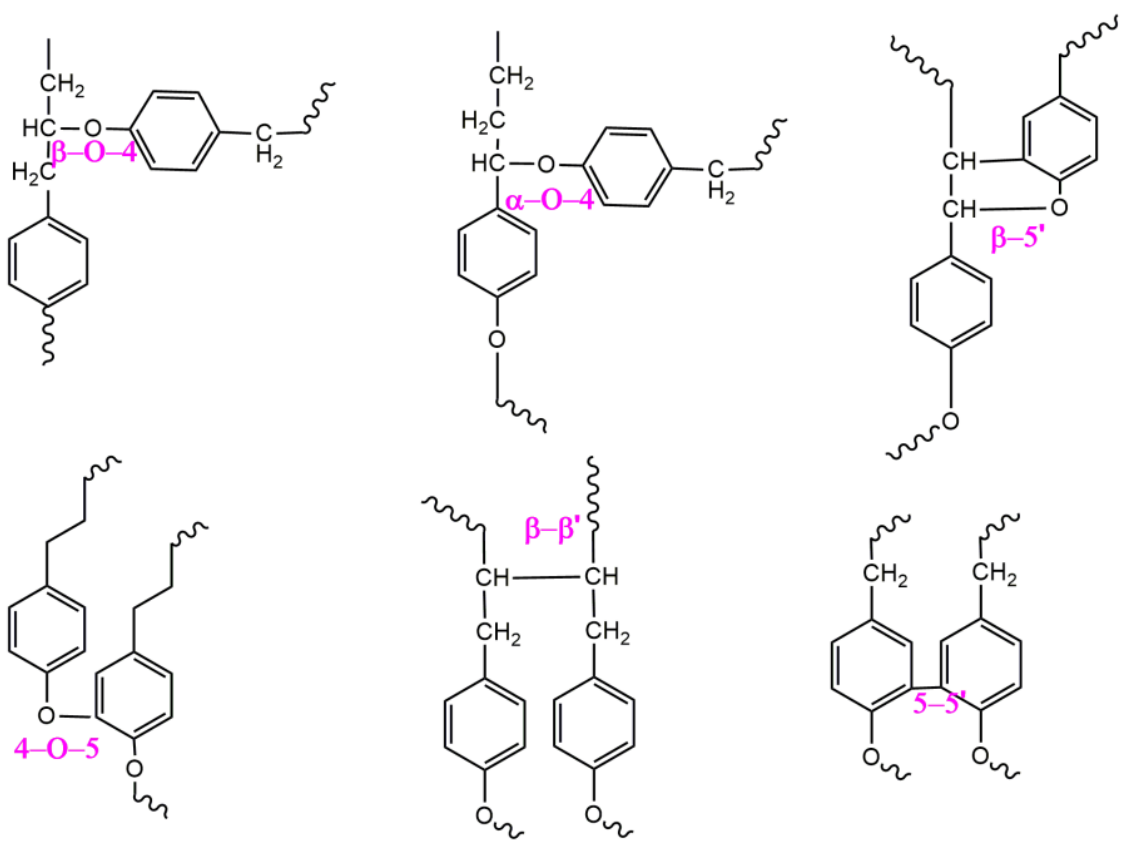

Fonte: Adaptado de Adler (1977).

Diante da importância que as resinas fenólicas possuem em diversas áreas de aplicação, estudos têm sido desenvolvidos visando substituição total ou parcial do fenol, um reagente de elevada toxicidade e à base de petróleo pela lignina (SAARI et al., 2016).

No Brasil, a empresa Suzano Papel e Celulose se destaca na produção de celulose e lignina a partir da madeira de eucalipto. Além disso, em 2019 esta empresa lançou uma plataforma tecnológica denominada Ecolig, totalmente voltada para o desenvolvimento de especialidades químicas com base em lignina. Nos Estados Unidos, empresa como a Domtar, Stora Enso na Finlândia e a West Fraser no Canadá abriram recentemente novas plantas visando aumentar o aproveitamento de lignina. A Domtar e a Stora Enso, por exemplo, posssuem uma capacidade de produção de 75.000 ton de lignina por ano utilizando o processo Lignoboost (HU et al., 2018). A divisão de biomateriais da empresa Stora Enso vem desenvolvendo pesquisas tendo em vista a utilização de lignina como substituinte do fenol na síntese de resina fenólica para aplicação em painéis de madeira (plywood) e outras aplicações similares. A empresa de papel finlandesa, Domtar, já conseguiu êxito na obtenção de uma resina com $50 \%$ de substituição do fenol aplicada em madeira compensada em escala industrial e $75 \%$ em escala de laboratório (MCCOY, 2016).

A utilização de resinas lignina-aldeído ou lignina-fenol-aldeído como substituintes da resina fenólica convencional podem ser utilizadas tanto na preparação de compósitos de matriz termorrígida usando fibras lignocelulósicas como bagaço de cana de açúcar (PAIVA; 
FROLLINI, 2001), fibra de juta (RAZERA; FROLLINI, 2004; RAZERA et al., 2014), fibra de curauá (TRINDADE et al., 2008), fibra de sisal (RAMIRES et al., 2010; DE OLIVEIRA et al., 2017) como reforço estrutural, quanto na preparação de painéis de madeira: MDF, madeira compensada, painéis de partículas orientadas, painéis de palha, dentre outros (YANG et al., 2015; GHORBANI et al., 2017).

\subsubsection{Processos de extração da lignina}

A obtenção de lignina se dá em grande parte em processos industriais de polpação a partir da madeira, sendo a macromolécula produzida como efluente destas indústrias. Dentre os processos de polpação mais utilizados atualmente têm-se: polpação Kraft ("tradicional" e lignoboost), Soda e Sulfito, sendo possível a obtenção de ligninas com diferentes características. Vale destacar que tanto a fonte quanto a severidade do processo de extração utilizado interferem na estrutura da lignina obtida, e consequentemente em suas propriedades e reatividade (ALEKHINA et al., 2015).

Nas indústrias de papel e celulose a polpação Kraft é o processo industrial mais utilizado até hoje, seguido do processo Sulfito, sendo obtida a lignina Kraft e o lignossulfonato, respectivamente. A polpação soda é mais utilizada para biomassas lignocelulósicas diferentes de madeiras, e consiste na submissão da biomassa a uma solução de $\mathrm{NaOH}$ em temperaturas próximas a $160{ }^{\circ} \mathrm{C}$ (GUO et al., 2014; KIM; UM, 2018). O processo sulfito consiste na dissolução da biomassa lignocelulósica em meio básico, neutro ou ácido e um sal de sulfito $\left(\mathrm{Na}_{2} \mathrm{SO}_{3}\right)$ (FATEHI et al., 2016; DESHPANDE et al., 2018). Nestes processos um licor negro rico em lignina é gerado, que possui esta coloração devido aos grupos funcionais cromóforos presentes na estrutura da lignina, como grupos carboxila, carbonilas, quinonas, radicais hidroperóxi, grupos hidroxila fenólico, entre outros, que são gerados durante a degradação da mesma.

O processo Kraft, de maneira geral, consiste na dissolução da lignina e hemiceluloses submetendo a biomassa à um tratamento alcalino com hidróxido de sódio e um sal de sulfeto, geralmente sulfeto de sódio. Os ânions hidróxido e hidrossulfeto reagem com a lignina levando à fragmentação através da clivagem das ligações $\alpha-\mathrm{O}-4, \alpha-\mathrm{O}-\mathrm{H}$ e $\beta-\mathrm{O}-4$ (LIITIA et al., 2003; GALKIN; SAMEC, 2016; CARVAJAL; GÒMEZ; CARDONA, 2016) da lignina e do complexo lignina-carboidrados.

O processo Kraft Lignoboost difere do Kraft "tradicional" em relação ao modo de acidificação do meio para obtenção da lignina. Neste, há a acidificação do licor negro (rico em 
açúcares solúveis e lignina) obtido após a polpação da madeira através da injeção de gás dióxido de carbono $\left(\mathrm{CO}_{2}\right)$. Após a precipitação, a pasta é condicionada para aglomerar antes que a lignina sólida seja separada do licor negra na etapa de filtração. Esta lignina aglomerada é ressuspendida em água acidificada com ácido sulfúrico $(\mathrm{pH} 2,5-4,0)$ No processo Kraft tradicional a lignina é precipitada em apenas uma etapa através da adição de ácido sulfúrico (redução do pH) no licor negro (WALLMO et al., 2018).

Neste processo a clivagem das ligações $\alpha-\mathrm{O}-4, \alpha-\mathrm{O}-\mathrm{H}$ e $\beta-\mathrm{O}-4$ resulta na formação de um intermediário metileno quinona seguido de adição nucleofílica $\left(\mathrm{S}^{2-}\right)$, como apresentado na Figura 12 e 13 (GIERER, 1970, 1982; LIITIA et al., 2003; GALKIN; SAMEC, 2016). Estas reações ocasionam o aumento de grupos hidroxila fenólica, que sofre dissociação em valores de pH elevados, levando a solubilização da lignina (GARCIA et al., 2012; HELANDER, 2014).

Figura 12 - Esquema da clivagem das ligações $\alpha$-aril éter da lignina com formação de intermediário metileno quinona.
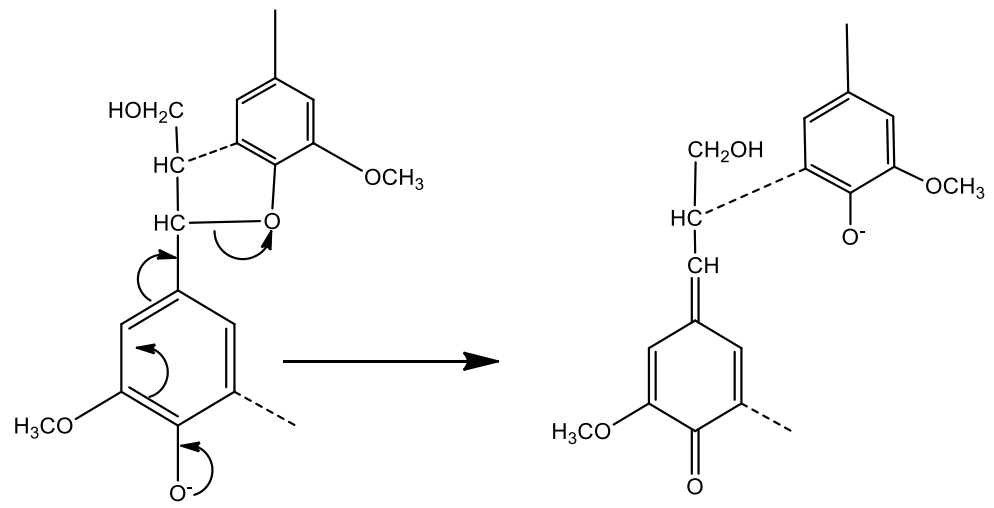

Fonte: Gierer, 1970, 1982.

Figura 13 - Esquema da clivagem das ligações $\beta$-aril éter da lignina.
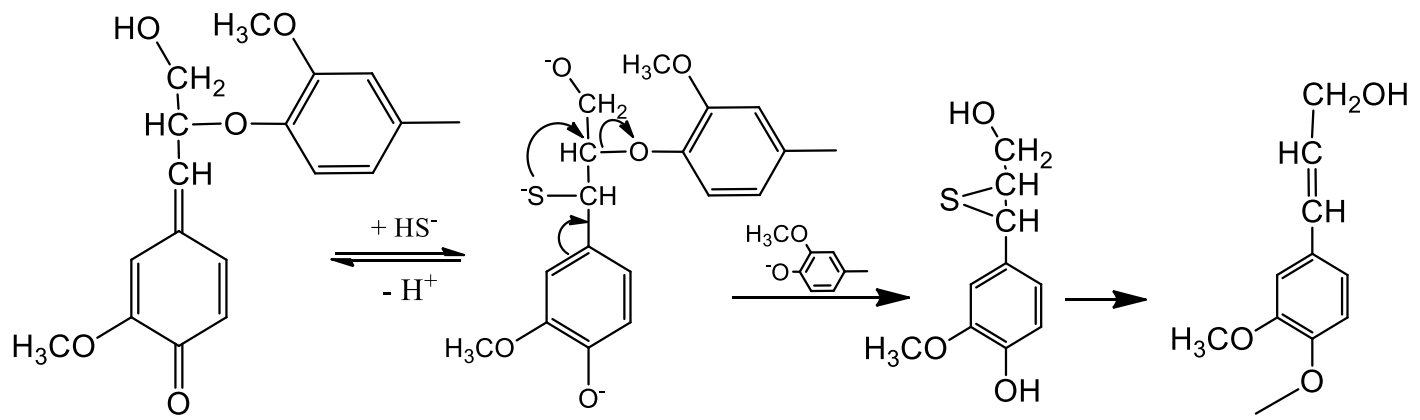

Fonte: Adapatado de Gierer (1980). 
A lignina Kraft possui enxofre em sua composição e açúcares e/ou algum material inorgânico como impurezas que podem afetar diretamente sua reatividade (CONSTANT et al, 2016). Este enxofre encontra-se na forma de tiol ligado na estrutura da lignina por ligação covalente e esta lignina é parcialmente solúvel água e solúvel em solução alcalinas ou orgânicas (LAURICHESSE; AVÉROUS, 2013).

Segundo o ILI (International Lignin Institute) são produzidas entre 40 e 50 milhões de toneladas de lignina Kraft como resíduo das indústrias de papel e grande parte desta não é comercializada, sendo queimada em fornos para produção de energia e recuperação de produtos químicos (HU et al., 2018).

\subsubsection{Resína lígnofenólica}

A utilização da lignina em processos de síntese de resinas se torna desafiador devido sua estrutura complexa e heterogênea, massa molar média elevada e solubilidade restrita em alguns solventes.

A reatividade da lignina como substituinte do fenol em síntese de resina é dependente da proporção em que seus constituintes estão presentes. No caso de aplicação da lignina em síntese de resina lignofenólica, a estrutura menos reativa é a siringila, pois esta possui as posições C3 e C5 do anel aromático impedidas estericamente por grupos metoxilas. A guaiacila possui apenas uma das posições (C3) impedida, e a $p$-hidroxifenila (Figura 11) possui ambas posições livres para reagir com formaldeído, (EL MANSOURI et al., 2006; RAMIRES et al., 2010).

Devido possuír a posição C5 do anel aromático livre, as unidades guaiacila são capazes de formar ligações C-C entre as unidades fenilpropanóicas, mesmo que a maioria das ligações presentes nas ligninas, de maneira geral, seja do tipo $\beta-\mathrm{O}-4$. Ao contrário das unidades siringila que possuem as posições C3 e C5 impedidas. Durante a polpação, estas ligações C-C presentes nas unidades guaiacila não são clivadas devido sua elevada estabilidade e, portanto, ligninas que possuem estas unidades como predominantes apresentam maior massa molar do que as ligninas que possuem predominância de siringila (CHAKAR; RAGAUSKAS, 2004; HUSSIN et al., 2017).

A síntese da resina ligno-fenólica, lignina-fenol-formaldeído, consiste primeiro na reação de hidroximetilação da lignina através da inserção de grupos hidroximetila na posição orto em relação ao grupo hidroxila do anel aromático através da reação entre a lignina e o formaldeído

(Figura 14) (SAUNDERS, 1988; EL MANSOURI; YUAN; HUANG, 2011; ABDELWAHAB; NASSAR, 2011). 
Após a hidroximetilação, a lignina hidroximetilada sofre condensação com fenol e outras moléculas de lignina, no caso de resinas lignina-fenol-formaldeído, e nas resinas ligninaformaldeído a lignina hidroximetilada sofre condensação com outras moléculas de lignina (ABDELWAHAB; NASSAR, 2011).

A lignina industrial possui maior presença de impurezas, tais como açúcares remanescentes do processo de polpação e compostos inorgânicos, que influenciam em sua reatividade (LORA; GLASSER, 2002), sendo necessário em alguns casos a realização de uma etapa de purificação prévia à utilização da lignina.

Figura 14 - Esquema da reação de hidroximetilação da lignina contendo estrutura guaiacila.

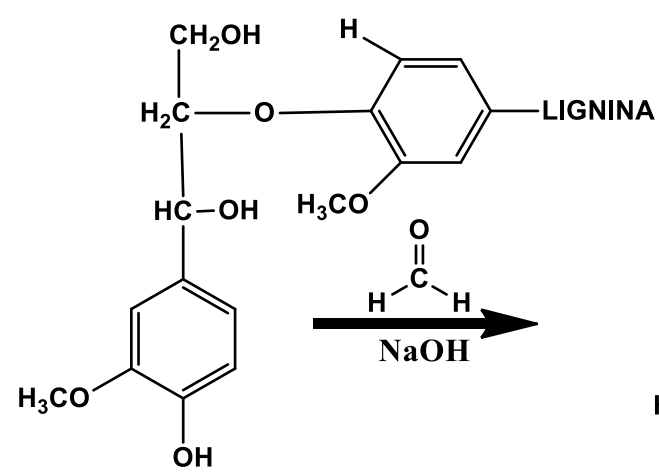

Lignina Guaiacila

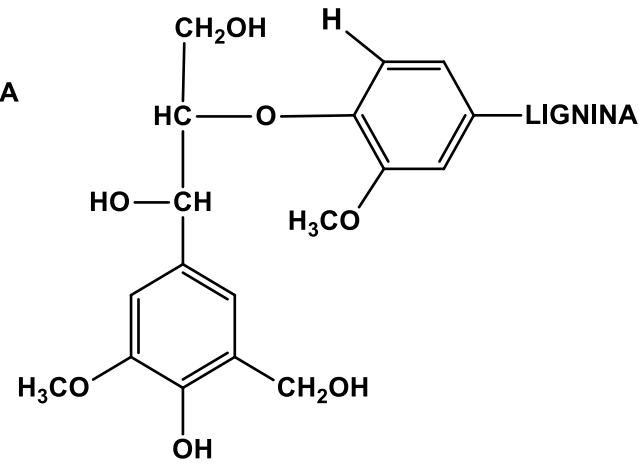

Lignina Guaiacila Hidroximetilada

Fonte: Ramires e Frollini (2010)

Ramires et al. (2010) obtiveram resultados satisfatórios ao prepararem compósitos utilizando a lignina organossolve industrial, obtida a partir do bagaço de cana-de-açúcar, como substituinte (100\%) do fenol na síntese de resina com formaldeído. Em relação às características estruturais desta lignina, a mesma apresenta maior teor de unidades $p$-hidroxifenila comparativamente a ligninas com outra procedência, o que favorece a reação com formaldeído. Os autores reforçaram esta matriz termorrígida com $40 \%$ em massa de fibra de sisal e obtiveram uma resistência ao impacto de aproximadamente $500 \mathrm{~J} \mathrm{~m}^{-1}$.

Hussin et al. (2017) ao analisarem as ligninas Kraft e organossolve, ambas de kenaf, observaram, baseado nos resultados de $\mathrm{RMN}-{ }^{1} \mathrm{H}$ e ${ }^{13} \mathrm{C}$, uma maior presença de estruturas siringila, seguida de guaiacila, em ambas as ligninas. Ainda, os autores obtiveram um maior conteúdo de hidroxilas fenólicas na lignina Kraft se comparada à organossolve. Isso pode estar associado às condições mais severas do processo Kraft utilizado pelos autores, em relação ao organossolve, que pode ter levado a uma maior clivagem da ligações aril-éter, causando maior despolimerização da lignina. Ao utilizarem ambas as ligninas como substituintes de $50 \%$ do 
fenol em síntese de resina lignofenólica, os autores observaram que os painéis de madeira contendo a resina com 50\% de lignina Kraft apresentaram maior resistência à tração e módulo de flexão. Isso pode ter sido consequência de maior entrecruzamento, o que levou à melhores propriedades do adesivo final.

A lignina Kraft proveniente do processo de polpação industrial foi utilizada para preparar o pré-polímero lignofenólico, e posteriormente preparar compósitos reforçados com manta de fibra de sisal (MFS), manta de fibra rayon (MFR) e compósitos híbridos reforçados por MFS/fibra do mesocarpo do dendê moída.

\subsection{Reforço Natural: fíbras lígnocelulósícas}

A substituição de fibras sintéticas por fibras lignocelulósicas como agente de reforço na preparação de compósitos tem recebido crescente atenção ao longo dos anos em diversas áreas de aplicação (DE OLIVEIRA et al., 2015; DE OLIVEIRA et al., 2017; SRINIVAS et al., 2017; TITA et al., 2018; CAMPOS et al., 2019). Aos serem feitos com fibras naturais, os compósitos se tornam mais sustentáveis e leves do que materiais feitos de aço, por exemplo, o qual é bastante utilizado na indústria automotiva na confecção de peças de automóveis. Diante disso, os fabricantes iniciaram a substituição de peças feitas de aço por compósitos para reduzir o peso de veículo (SAFRI et al., 2018). Compósitos reforçados com fibras naturais têm sido utilizados na área automotiva por empresas do Grupo Audi (Ford e Volkswagen), , entre outras, como reforço em painéis automotivos (FARUK et al., 2012), aplicações leves (MANIMARAM et al., 2018) e indústria de construção de linhas aéreas (SHINOJ et al., 2011; BALAKRISHNAN et al., 2016).

As fibras lignocelulósicas são biodegradáveis, resistentes, leves e não abrasivas (DE OLIVEIRA SANTOS et al., 2014; OLIVEIRA et al., 2015; SRINIVAS et al., 2017; TITA et al., 2018), tornando-as atrativas como matérias-primas para atuarem como substituintes de fibras sintéticas como aramidas, vidro, carbono, dentre outras, que são amplamente usadas como reforço em plástico, por exemplo.

As fibras naturais possuem em sua composição principalmente celulose, hemiceluloses e lignina, além de umidade, cinzas (material inorgânico), pectina e ceras em menor quantidade (Figura 15). A celulose é uma macromolécula polimérica formada por unidades de D-anidro glicose, que são interligadas por ligações $\beta-1,4$ (SAHA et al., 2016). Possui quatro polimorfos e um alto grau de polimerização e cristalinidade, que está relacionado com a resistência das fibras lignocelulósicas (PANDEY, 1999). 
Figura 15 - Representação esquemática da estrutura da biomassa lignocelulósica- microfibrilas de celulose cercados por hemiceluloses e lignina.

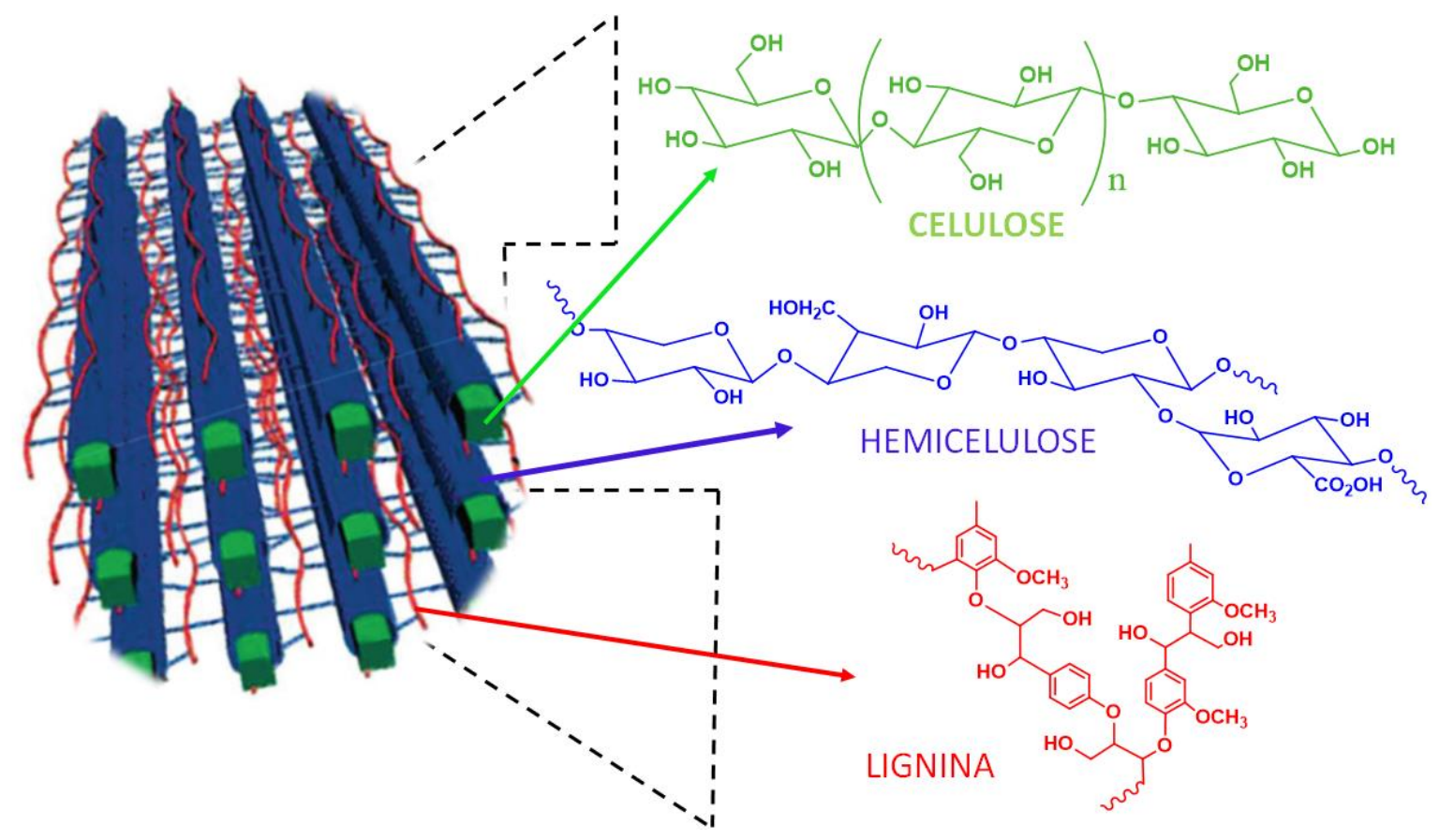

Fonte: Adaptada de FANG et al. (2017).

As hemiceluloses são heteropolímeros que fazem a ligação entre celulose e lignina, sendo compostas por carboidratos hexoses e pentoses, tais como glicose, xilose, galactose, manose e arabinose (MUSSATTO; DRAGONE, 2016), e ácidos urônicos como 4-metilglucurônico, Dglucurônico e D-galactourônico, ligados covalentemente (SUN et al., 2016). A lignina é uma macromolécula aromática, tridimensional, altamente ramificada e formada por estruturas do tipo guaiacil, siringil e p-hidroxifenil como suas principais unidades constituintes (Figura 11b). Essas unidades de fenilpronano são derivadas dos álcoois de coniferil, sinapil e p-coumaryl, respectivamente (CHANGZHI et al., 2015).

Nas últimas décadas o número de pesquisas visando a utilização de fibras naturais como reforços vem apresentando um considerável crescimento. Isto se deve ao fato do grande excedente de fibras gerado no meio ambiente, tanto no Brasil quanto no mundo. O Brasil se destaca pela produção de fibras de cana-de-açucar, dendê, côco, dentre outras. Estas, ao serem processadas nas indústrias, produzem fibras que são consideradas como excedentes e que mesmo sendo aproveitadas para geração de energia nas próprias indústrias, é gerado um excedente que causa acúmulo no meio ambiente. 


\subsubsection{Fíbra do mesocarpo do dendề}

Elaeis guineenses Jacq., fibra do mesocarpo do dendê (Figura 16) é uma planta africana nativa e é a principal cultura de óleo atualmente cultivada no mundo (AWALLIDIN et al., 2015), sendo a Malásia o maior produtor desta planta seguido pela Indonésia e Tailândia (UMAR; URMEE, JENNINGS, 2018). O principal produto produzido e exportado por esses países, obtido a partir do processamento desta planta, é o óleo de dendê ou também conhecido como óleo de palma. O Brasil é o $12^{\circ}$ maior plantador e produtor de óleo de palma com uma área cultivada estimada em cerca de 236 mil hectares (ABRAPLAMA, 2018) e teve uma produção de dendezeiros de aproximadamente 1,6 milhão de toneladas em 2017 (FAO, 2019).

Desde o processamento até a obtenção do óleo de dendê, algumas fibras são obtidas como: as fibras de mesocarpo do dendê (FMD) e as fibras do cacho de dendezeiro (FCD). A FMD é obtida após o processo de extração de óleo das sementes do fruto do dendê, sendo este óleo utilizado para produção de biodiesel e bioetanol (DERMAN et al., 2018). FCD é a parte fibrosa após a separação do fruto (SHINOJ et al., 2011). Esse processo produz uma grande quantidade dessa biomassa, sendo parte utilizada como combustível na usina de óleo de palma para produção de energia, e parte é deixada como resíduo, causando problemas ambientais (ENG et al., 2014; WU et al., 2017b).

Figura 16 - Dendezeiro Dendezeiro-Elaeais guineensis Jaquim (a), frutos frescos do dendezeiro (b) e fibra do mesocarpo do dendê após extração do óleo (FMD) (c).

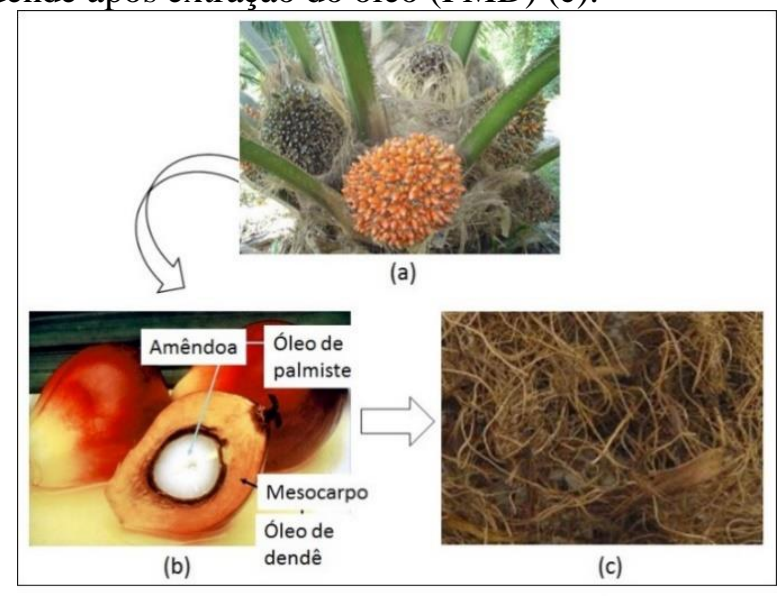

Fonte: www.infobibos.com

Diversas pesquisas têm sido realizadas visando a utilização desse resíduo na produção de painéis compósitos (KHALID et al., 2015), extração de celulose (ABDULLAH et al., 2016), produção de painéis aglomerados (SUBIYANTO et al., 2018), absorvedor de som natural para controle de ruído (KALAIVANI et al., 2018) e como fonte de lignina (NOGUEIRA et al., 2019). Além disso, o óleo obtido a partir deste fruto também pode ser 
usado para a produção de óleo microbiano, que é obtido através de pré-tratamento e hidrólise enzimática, seguido de cultivo microbiano de açúcar fermentescível por microorganismos oleaginosos (AHMAD et al., 2019).

As fibras obtidas do fruto do dendê possuem, geralmente, em sua composição corpos de silício aderidos à superfície que podem causar problemas na recuperação de substâncias químicas no licor negro obtido pelo processo de polpação destas fibras (YUAN et al., 2016; XU et al., 2018).

A FMD foi utilizada no presente estudo como um reforço em compósitos de matriz fenol-formaldeído e como reforço híbrido constituído por manta de fibra de sisal e FMDmoída em compósitos de matriz fenol-formaldeído, fenol-glutaraldeído e lignofenólica.

\subsubsection{Fübras de sisal}

Dentre as fibras lignocelulósica mencionadas anteriormente como promissores agente de reforço em compósitos, a fibra de sisal se destacou com êxito em compósitos de matriz termorrígida fenólica e lignofenólica, poliuretânica e lignopoliuretânica, tanino-fenólica e glioxal-fenólica (MEGIATTO JR et al., 2009; BOTARO et al., 2010; RAMIRES et al., 2010; DA SILVA et al., 2012; RAMIRES; FROLLINI, 2012; DE OLIVEIRA et al., 2017).

As fibras de sisal possuem excelentes propriedades mecânicas (Ramires, 2010), sendo o Brasil o maior produtor mundial desta fibra. Esta é uma fibra lignocelulósica composta por aproximadamente $56 \%$ de celulose, $32 \%$ de hemiceluloses e $15 \%$ de lignina (DE OLIVEIRA et al., 2017), sendo originária da planta Agave sisalana (Figura 17- a), que é encontrada principalmente na região Nordeste e em Goiás (CONAB, 2018).

No Brasil a produção de sisal até início de 2018 foi de aproximadamente 67 mil ton. (CONAB, 2018; DE OLIVEIRA et al., 2017). As fibras de sisal são obtidas após o desfibramento da folha que consiste em uma etapa de mucilagem mediante uma raspagem mecânica, sendo em seguida colocadas em varais feitos de arame para secagem ao sol, como apresentado na Figura 17-b. 
Figura 17 - Planta de sisal Agave sisalana ${ }^{1}$ (a), fibra de $\operatorname{sisal}^{2}$ (b) e manta de sisal ${ }^{3}$ (c).

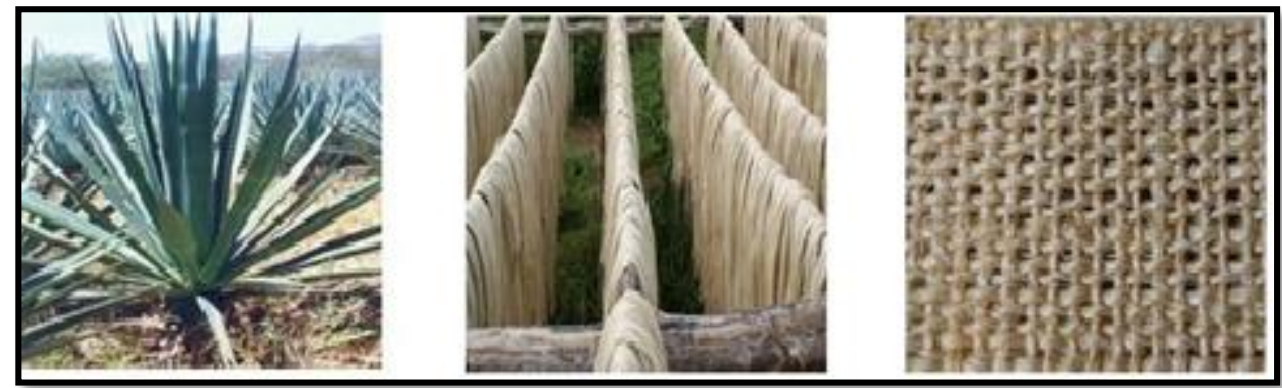

(a)

(b)

(c)

(a)

${ }^{1}$ Fonte:www.agencia.cnptia.embrapa.br/Repositorio/Planta+de+sisal+sadia+e+com+sintomas+de+5onteúdo+do+tron

co_000gxaa8ure02wx7ha0myh2lo2p6dvt9.jpg

${ }^{2}$ Fonte:http://www.ciflorestas.com.br/5onteúdo.php?id=5338 3

Fonte: Autoria própria.

Por possuir elevada resistência à tração, as fibras obtidas desta planta possuem grande aplicabilidade na confecção de bolsas, na fabricação de tapetes, cordas, revestimentos, mantas, dentre outros (MAYA et al., 2017; SISALL, 2017). A manta de sisal pode ser constituída por fibras curtas e aleatórias prensadas, ou por feixes longos de fibra entrelaçados entre si de forma perpendicular (Figura 17- c). Esta última possibilidade também pode ser encontrada comercialmente como "tapete de sisal"1. Apesar da fibra de sisal possuir várias aplicações, ainda é gerado um excedente que fica acumulado nos campos de plantação, e que poderiam ser utilizados como agente de reforço estrutural na elaboração de compósitos (RAMIRES et al., 2010; DE OLIVEIRA et al., 2017). Além disso, a exportação desta fibra é considerável, sendo o dado disponível mais recente de aproximadamente 48 mil toneladas (início de 2018) (FENAGRO, 2018). Assim, é desejável que maior valor seja agregado a esta fibra, tanto para comercialização no mercado interno como externo.

A manta de fibras de sisal foi utilizada no presente estudo como agente de reforço em matriz fenol-formaldeído, fenol-glutaraldeído e lignofenólica. Não se tem conhecimento até o presente momento da utilização de manta de sisal como reforço destas matrizes poliméricas, como foi investigado no presente estudo.

\subsubsection{Fíbra rayon}

Outro material que vem ganhando grande destaque como reforço na área de compósitos é a fibra celulósica regenerada denominada rayon (SHAMSUDDIN; LEE; BISMARCK, 2016;

\footnotetext{
${ }^{1}$ http://www.sisalsul.com.br/produto/40/tapetes-de-sisal
} 
SURESH; THIRUCHITRAMBALAM; SHANMUGAM, 2016). Esta é uma fibra "man-made" produzida a partir de uma fonte natural, a polpa celulósica mercerizada obtida a partir das fibras lignocelulósicas. Sua composição consiste basicamente de celulose e sua obtenção inicia com a dissolução da polpa celulósica em uma solução de hidróxido de sódio 17,5 \% (em massa), sendo obtida a celulose-soda. Esta reage com dissulfeto de carbono para formar xantato de celulose de sódio (Figura 18- a), que em seguida é dissolvido em solução de hidróxido de sódio e a celulose é regenerada (Figura 18- a). Em seguida, a viscose é bombeada para um banho de fiação, onde ocorre a precipitação da celulose e a formação de multifilamentos (Figura 18- b), os quais possuem elevada resistência, tenacidade, estabilidade dimensional e termoestabilidade $^{2}$. Devido ao toque suave e caimento semelhante ao algodão, esta fibra também possui grande aplicabilidade na indústria têxtil.

$\mathrm{Na}$ Europa, fibras e mantas produzidas a partir de celulose regenerada ficaram conhecidas como viscose e nos Estados Unidos como rayon (COMNEA-STANCU et al., 2017). A empresa alemã Cordenka se destaca em termos de produção e aplicação desta fibra, tanto na forma de fios como de manta (Figura 18- c), como reforço em pneus e mangueiras, devido suas excelentes propriedades mecânicas ${ }^{2}$. Estas se devem à celulose, um polímero polidisperso e linear formado por unidades de glicose ligadas covalentemente entre si (Figura 18- d). O alto grau de polimerização e cristalinidade da celulose é responsável pela resistência das fibras (PANDEY, 1999; SENA NETO et al., 2013; FIDELIS et al., 2013). Os grupos OH presentes em sua estrutura formam uma rede de ligações hidrogênio, inter e intramoleculares (Figura 18- d), sendo esta primeira responsável pela rigidez da cadeia celulósica (CREDOU; BERTHELOT, 2014).

A forma alomórfica da celulose presente na fibra rayon difere da celulose nativa, porque durante o processo de obtenção da fibra rayon ocorre a conversão de celulose I para celulose II, devido à solvatação do grupos hidroxilas da celulose por íons sódio causando o swelling da mesma (KASCHUK et al., 2017), mudando assim a conformação da cadeia de celulose de paralela para antiparalela (CREDOU; BERTHELOT, 2014; COMNEA-STANCU et al., 2017).

$\mathrm{Na}$ literatura são encontrados alguns estudos utilizando a fibra rayon como reforço em compósitos, tanto na forma de fibra curta, viscose e também como manta híbrida, como as constituídas por rayon/lyocell e rayon/algodão, como reforço em matriz de poliéster, dentre outras (SAVAGE; EVANS, 2014; SURESH; THIRUCHITRAMBALAM; SHANMUGAM, 2016; FRANCISZCZAK; BLEDZKI, 2016; LI et al., 2017; FRANCISZCZAK et al., 2017). 
Figura 18 - Reação de obtenção da fibra rayon (a), esquema de obtenção da fibra rayon ${ }^{1}$ (b), imagem da manta de fibra rayon (c) $)^{2}$ e estrutura molecular da celulose com indicação de ligações hidrogênio inter- (linhas tracejadas vermelhas) e intra-moleculares (linhas tracejadas pretas) (d) ${ }^{3}$.

(a)

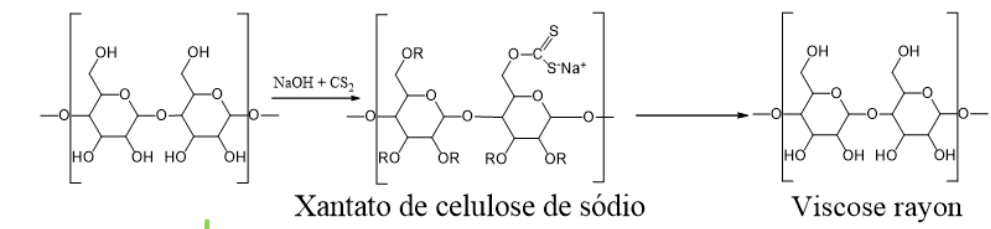

(b)

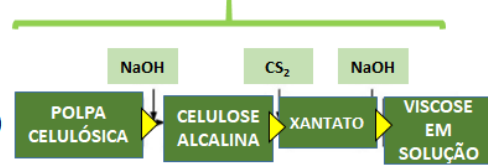

Viscose rayon

(c)
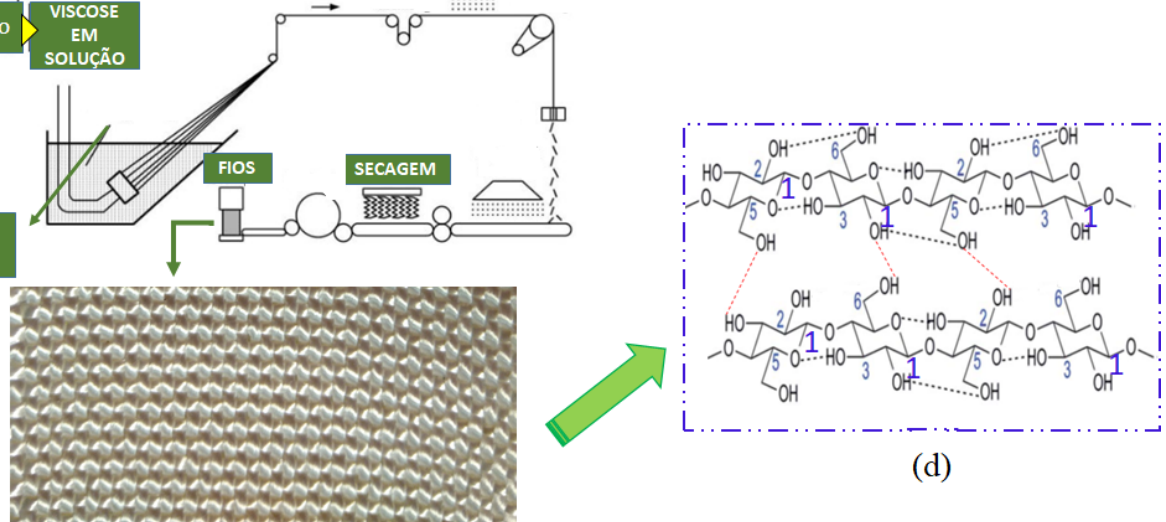

(d)

1Fonte: https://www.deniminnovation.com/2019/02/09/viscose-manufacturing-process/

${ }^{2}$ Fonte: Autoria própria.

${ }^{2}$ Fonte: Credou e Berthelot (2014).

No estudo de Rojo et al. (2014) foi reportado que o uso de fibras rayon (viscose) obtida da madeira de eucalipto com comprimento entre $1,7-38 \mathrm{~mm}$ e densidade linear de 0,17 g/1000 m como reforço em matriz fenólica resol, levou à redução da resistência à flexão quando foi usada porcentagem em massa acima de $7 \%$ de fibra, devido à uma má dispersão da mesma na matriz. Entre 3 e 5\% em massa de fibra, o intertravamento mecânico foi suficiente para transferir a carga da matriz para as fibras, mostrando que a fibra atuou como reforço.

Não se tem conhecimento, até o presente momento, da utilização de mantas de rayon como reforço em compósitos de matriz polimérica fenol-formaldeído, fenolglutaraldeído e lignofenólica, conforme foi investigado no presente estudo. 


\section{OBJETIVOS}

O objetivo central do presente estudo consistiu na valorização de fibras naturais, a fibra do mesocarpo do dendê, a manta de fibra de sisal e a manta de fibra rayon, como reforço de termorrígidos fenólicos. Também se avaliou a utilização da fibra do mesocarpo do dendê moída como carga ou reforço adicional na preparação de compósitos híbridos constituídos por esta fibra e manta de fibra de sisal, de forma pioneira.

Ainda, foram sintetizadas resinas fenólicas utilizando lignina Kraft industrial (obtida da polpação de Eucaliptus) como substuinte do fenol, e glutaraldeído, em substituição ao formaldeído, na síntese de resina fenol-glutaraldeido. 


\section{Apresentação/Estruturação do traba/ho}

Com o intuito de facilitar a leitura do presente estudo, este foi estruturado em capítulos, divididos de acordo com os tipos diferentes de matrizes e reforços utilizados na preparação dos compósitos. No início de cada capítulo será apresentado um breve resumo sobre o que será reportado.

\section{Capítulo 1}

\section{Capítulo 2}

\section{Capítulo 3}

- Síntese de resina fenol-formaldeído: obtenção de compósitos de matriz termorrígida reforçadas com fibras do mesocarpo do dendê

-Síntese de resina fenol-formaldeído: obtenção de compósitos de matriz termorrígida reforçadas com mantas de fibras de sisal e de rayon, manta de fibra de sisal e fibra do mesocarpo do dendê moída

- Síntese de resina fenol-glutaraldeído: obtenção de compósitos reforçados com manta de sisal, manta de rayon, e híbrido constituído por manta de sisal e fibra do mesocarpo do dendê moída

\section{Capítulo 4}

- Síntese de resina lignofenólica: obtenção de compósitos de matriz termorrígida reforçados com manta de sisal, manta de rayon, $e$ híbrido constituído por manta de sisal e fibra do mesocarpo do dendê moída 


\section{Capítulo 1}

\section{Sintese de resina fenol-formaldeído: obtenção de compósitos de matríz termorrígída reforçadas com fíbras do mesocarpo do dendề}

\subsection{Introdução}

Neste capítulo relata-se a síntese de matriz termorrígida fenol-formaldeído do tipo resol, ocorrida simultaneamente à moldagem, a qual foi reforçada com fibra do mesocarpo do dendê, gerando compósitos. O uso de fibras lignocelulósicas como reforço em compósitos de matriz termorrígida e termoplástica já vem sendo investigado no grupo MacromoLignocell com resultados bastante satisfatórios (RAZERA; FROLLINI, 2006; MEGIATTO JUNIOR et al., 2009; CASTRO et al., 2012; DE OLIVEIRA et al., 2015; DE OLIVEIRA et al., 2017), destacando que as fibras vegetais podem ser potenciais substituintes das fibras sintéticas neste tipo de aplicação.

A fibra do mesocarpo do dendê (FMD) foi utilizada no presente estudo devido à sua abundância no país, e necessidade de valorização da mesma. A grande demanda mundial por óleo de dendê em diversas áreas, como a alimentícia, farmaceutica, combustivel, dentre outras, gera uma grande quantidade de fibras oriundas destes processos. Apesar de as indústrias utilizarem estas para geração de energia, ainda é gerado um excedente que fica acumulado no meio ambiente (ENG et al., 2014; CHIENG et al., 2017; WU et al., 2017b).

Os compósitos foram preparados por moldagem sob compressão, em que o ciclo de moldagem foi baseado em estudos anteriores desenvolvidos no grupo MacromoLignocell (RAMIRES, 2010; DE OLIVEIRA, 2010). A heterogeneidade de FMD com relação ao diâmetro impossibilitou o corte da mesma em diferentes comprimentos. Assim, as fibras foram utilizadas como reforço considerando diferentes proporções em massa, relativamente à massa da matriz.

\subsection{Experimental}

\subsubsection{Materiais}


As fibras do mesocarpo do dendê (Elaeis guineensis Jacq.) utilizadas neste trabalho eram originárias do Pará e foram fornecidas pela Embrapa Agroindústria Tropical (Fortaleza, Ceará, Brasil). O tapete de fibra de sisal foi adquirido de Sisal Sul Company (Luz, São Paulo, Brasil). Para a síntese da resina (pré-polímero) e a preparação do compósito foram utilizados fenol (Synth, 99\%), formaldeído (Synth, solução 37\%), hidróxido de potássio (Synth, 97\%) e resorcinol (Vetec, 99\%).

\subsubsection{Métodos}

\subsubsection{Caracterização da fibra do mesocarpo do dendê (FMD)}

Previamente à realização da caracterização e utilização como reforço nos compósitos, FMD foi lavada exaustivamente com água corrente para a retirada de resíduos provenientes do processamento da fibra, e em seguida foi lavada com água destilada a $60{ }^{\circ} \mathrm{C}$ por $1 \mathrm{~h}$, com agitação, sendo este processo repetido três vezes. A fibra lavada foi seca em temperatura ambiente para retirada do excesso de água, e depois seca em estufa de circulação de ar a 105 ${ }^{\circ} \mathrm{C}$, até massa constante. Após esta etapa foi realizada a extração de ceras, terpenos e ácido graxos (extrativos solúveis) em um sistema extrator soxlet com uma mistura de cicloexano/etanol (1:1 v/v) por $10 \mathrm{~min}$. Esta etapa é muito importante, pois a presença de ceras e ácidos graxos nas fibras pode prejudicar a adesão entre fibra e matriz polimérica. $\mathrm{Na}$ sequência, as fibras foram lavadas em água corrente e secas em estufa de circulação de ar a 105 ${ }^{\circ} \mathrm{C}$, até massa constante. Estas condições foram selecionadas a partir de estudos prévios (RAMIRES, 2010; DA SILVA, 2011). Após a secagem, as fibras foram caracterizadas e as análises a seguir foram realizadas em triplicata.

\subsection{Composição química}

\subsection{Teor de umidade}

Pesou-se 1,0 g de cada amostra em um cadinho de porcelana e colocou-se o mesmo numa estufa com circulação de ar a $105^{\circ} \mathrm{C}$, até massa constante. $\mathrm{O}$ teor de umidade foi calculado usando a equação 1:

$$
\text { Teor de umidade }(\%)=\frac{m_{1}-m_{2}}{m_{1}} * 100 \quad \text { Eq. } 1
$$

$\mathrm{m}_{1}$ : massa inicial da amostra $(\mathrm{g})$

$\mathrm{m}_{2}$ : massa da amostra seca $(\mathrm{g})$

\subsection{Teor de cinzas}


O teor de cinzas foi determinado como descrito no padrão TAPPI T214. Pesou-se 1,0 g de cada amostra em um cadinho de porcelana calcinado a $900^{\circ} \mathrm{C}$, o qual foi colocado em uma mufla. $\mathrm{O}$ ciclo de temperatura foi de $105^{\circ} \mathrm{C}(10 \mathrm{~min}) \rightarrow 325^{\circ} \mathrm{C}(1 \mathrm{~h}) \rightarrow 525^{\circ} \mathrm{C}(1 \mathrm{~h})$ $\rightarrow 900^{\circ} \mathrm{C}(4 \mathrm{~h})$. Em seguida, a mufla foi desligada e as amostras foram removidas na temperatura de $120^{\circ} \mathrm{C}$, e colocadas em dessecador para pesagem. O teor de cinzas foi calculado usando a equação 2 :

$$
\operatorname{Cinzas}(\%)=\frac{\left(m_{1}\right)}{\left(m_{2}\right)} * 100 \quad \text { Eq. } 2
$$

$\mathrm{m}_{1}=$ massa de cinzas $(\mathrm{g})$

$\mathrm{m}_{2}=$ massa de amostra inicial $(\mathrm{g})$

\subsection{Determinação de lignina Klason insolúvel e solúvel em meio ácido}

O teor de lignina das fibras foi determinado pela porcentagem de lignina Klason foi determinado como descrito no padrão TAPPI T13m-54. 1,0 g de cada amostra previamente seca foi digerida em $15 \mathrm{~mL}$ de ácido sulfúrico (72\%), com agitação magnética durante $2 \mathrm{~h}$. Em seguida, as amostras pré-digeridas foram colocadas em frasco de reação, sendo adicionados $560 \mathrm{~mL}$ de água destilada. A reação foi feita sob um sistema de refluxo durante 4 h. Em seguida, a lignina foi filtrada em um funil de vidro sinterizado ASTM 4 ou C, e submetida a lavagem sucessiva com água destilada. $O$ funil com lignina foi seco numa estufa de circulação de ar a $105^{\circ} \mathrm{C}$, até massa constante, e em seguida foi realizada a pesagem. $\mathrm{O}$ teor de lignina Klason insolúvel foi calculado a partir da Equação 3:

$$
\text { Lignina Klason insolúvel }(\%)=\frac{m_{1}}{m_{2}} * 100 \quad \text { Eq.3 }
$$

$\mathrm{m}_{1}=$ massa de lignina Klason insolúvel $(\mathrm{g})$

$\mathrm{m}_{2}=$ massa de amostra seca $(\mathrm{g})$

A determinação do teor de lignina Klason solúvel foi realizada por espectroscopia na região do ultravioleta (UV). As amostras foram diluídas em uma solução de ácido sulfúrico 3\% (v/v), 1:10. Em seguida, as amostras foram analisadas em comprimentos de onda de 280 e 215 nm. A concentração de lignina Klason solúvel foi calculada usando a Equação 4: 


$$
C\left(g L^{-1}\right)=\frac{\left(4,53 * A_{215}\right)-A_{280}}{300} \quad \text { Eq. } 4
$$

$\mathrm{C}\left(\mathrm{g} \mathrm{L}^{-1}\right)$ : concentração de lignina Klason solúvel em meio ácido $\left(\mathrm{g} \mathrm{L}^{-1}\right)$

A215: Absorbância a $215 \mathrm{~nm}$ (referente à lignina solúvel)

$A_{280:}$ Absorbância a $280 \mathrm{~nm}$ (referente à furfural e hidroximetilfurfural)

O teor de lignina Klason total foi obtido a partir da soma do teor de lignina Klason insolúvel e solúvel em meio ácido.

\subsection{Teor de Holocelulose}

O teor de holocelulose foi determinado de acordo com o TAPPI T19m-54. 3,0 g de fibras lignocelulósicas previamente secas foram adicionadas a um Erlenmeyer com $120 \mathrm{~mL}$ de água destilada, 2,5 g de clorito de sódio e $1 \mathrm{~mL}$ de ácido acético. Esta reação foi realizada com agitação magnética e aquecimento, usando um banho de banho de óleo a $70^{\circ} \mathrm{C}$. Três adições foram feitas a cada $1 \mathrm{~h}$. A holocelulose foi filtrada em um funil de vidro sinterizado ASTM 2 ou M, sendo submetida a lavagens sucessivas com água destilada. O funil com holocelulose foi seco numa estufa de circulação de ar a $105^{\circ} \mathrm{C}$, até massa constante, e em seguida foi realizada a pesagem. O teor de holocelulose foi calculado a partir da equação 5:

$$
\text { Holocelulose }(\%)=\frac{m_{1}}{m_{2}} * 100 \quad \text { Eq. } 5
$$

$\mathrm{m}_{1}=$ massa de holocelulose $(\mathrm{g})$

$\mathrm{m}_{2}=$ massa de amostra seca $(\mathrm{g})$

\subsection{Teor de $\alpha$-celulose}

O teor de $\alpha$-celulose foi determinado de acordo com o TAPPI T $203 \mathrm{~cm}-99$. O teor de $\alpha$ celulose foi determinado usando solução de $\mathrm{NaOH}$ para remover as hemiceluloses da holocelulose. $1 \mathrm{~g}$ de holocelulose foi utilizado para determinar o teor de $\alpha$-celulose. A amostra foi digerida em solução de $\mathrm{NaOH} \mathrm{4,3} \mathrm{mol} \mathrm{L}^{-1}$ durante 20 min e após isso foi realizada a filtração em um funil de vidro sinterizado ASTM 2 ou M e lavada até que o pH da água de partida fosse atingido. $\mathrm{O}$ funil com celulose foi seco em estufa com circulação de ar a $105^{\circ} \mathrm{C}$, até massa constante e, em seguida, foi realizada a pesagem. A partir da subtração entre os teores de holocelulose e $\alpha$-celulose, foi calculado o conteúdo de hemiceluloses. $O$ teor de $\alpha$-celulose foi calculado a partir da equação 6 : 


$$
\alpha-\operatorname{celulose}(\%)=\frac{m_{1}}{m_{2}} * 100 \quad \text { Eq. } 6
$$

$\mathrm{m}_{1}=$ massa de holocelulose seca $(\mathrm{g})$

$\mathrm{m}_{2}=$ massa de amostra seca $(\mathrm{g})$

\subsection{Espectroscopia na região do infravermelho por transformada de Fourier (FTIR)}

O espectro de FTIR da FMD foi obtido no intervalo de 4000-400 $\mathrm{cm}^{-1}$, usando um aparelho BOMEM MB-102. A fibra foi moída em moinho de facas e seca em estufa a $105^{\circ} \mathrm{C}$ previamente a realização da análise. Pastilha de KBr com uma proporção 1:100 (amostra:KBr, em massa) foi usada nesta análise.

\subsection{Microscopia eletrônica de varredura}

A análise de MEV da fibra do mesocarpo do dendê foi realizada na superfície e na ponta da fibra, previamente fraturadas com nitrogênio líquido. Um microscópio eletrônico de varredura da marca Zeiss-Leica, modelo 440, aceleração de elétrons de $20 \mathrm{kV}$ foi usado. As amostras foram coladas em porta-amostra de alumínio usando fita de carbono, em seguida foram pintadas com tinta-prata e posteriormente revestidas com uma fina camada de ouro (20 $\mu \mathrm{m})$.

\subsection{Análise de Energia Dispersiva}

A análise de Energia Dispersiva (EDS) foi feita usando um equipamento EDX LINK ANALYTICAL, (Isis System Series 300), com detetor de SiLiPentafet, janela ultrafina ATW II (Atmosphere Thin Window), de resolução de $133 \mathrm{eV}$ a 5,9 keV e área de $10 \mathrm{~mm}^{2}$ quadrado, acoplado a um Microscópio Eletrônico ZEISS LEO 440 (Cambridge, England).

\subsection{Quantificação do silício}

O teor de silício na amostra de FMD foi determinado por espectrometria de emissão óptica por plasma induzida por microondas (MIP-OES). A amostra foi preparada usando digestão ácida e alcalina como descrito por Barros et al. (2016). A diluição adicional foi de 10x para corresponder ao digerido com o conteúdo de sólidos dissolvidos $(\leq 3 \%)$. Este é o valor máximo tolerado pelo equipamento MIP OES 4200, da Agilent Technologies, usado 
para determinação de sílica. A determinação foi feita utilizando módulo externo de controle de gás para injetar ar no plasma de $\mathrm{N}_{2}$ e melhorar sua robustez devido à presença de $\mathrm{Na}$ no digerido. Esta análise foi realizada na Embrapa Pecuária Sudeste, São Carlos, SP.

\subsection{Difração de raios $X$}

As principais características que diferem em cada forma polimórfica de celulose são as difrações próximas aos ângulos de Bragg (20). O índice de cristalinidade está relacionado à razão entre as regiões cristalinas e não cristalinas. O índice de cristalinidade (ICr) foi baseado na intensidade relativa de picos específicos e da região não-cristalina (KIM et al., 2016; ALEXANDER, 1969). As equações 7 e 8 foram usadas para calcular o ICr:

$$
\% \text { Amorfa }=\frac{\text { Área }_{\text {Total }}-\text { Área }_{\text {pico }}}{\text { Área }_{\text {Total }}}
$$

$$
\% \text { Cristalinidade }=100-\% \text { Amorfa }
$$

A difração de raios $\mathrm{X}$ foi obtida pelo difratômetro de raios $\mathrm{X}$ da marca Bruker (EUA), modelo D8 Advance equipado com detector LynxEye e software DIFFRAC.EVA V4.

\subsection{Análise termogravimétrica}

A análise termogravimétrica (TGA) foi conduzida utilizando um equipamento Shimadzu TGA-50. Foram pesados de 8 a $10 \mathrm{mg}$, colocadas em cadinhos de platina, e aquecidas de 25 a $800{ }^{\circ} \mathrm{C}$ a uma taxa de aquecimento de $5{ }^{\circ} \mathrm{C} \mathrm{min}^{-1}$, sob um fluxo de atmosfera

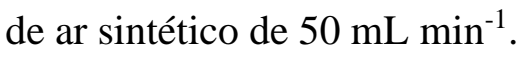

\subsection{Propriedades de tração}

A avaliação de propriedades de tração da FMD, com comprimento médio de $5 \mathrm{~cm}$, previamente secas à $105{ }^{\circ} \mathrm{C}$ por $4 \mathrm{~h}$, foi realizado no equipamento modelo Q800 da TA Instruments (New Castle, DE, EUA) equipado com tensão braçadeira para fibras no modo multifrequência. Durante o teste, as amostras foram submetidas à tensão de $18 \mathrm{~N}$ ou ruptura da fibra a uma taxa constante de $1 \mathrm{~N} \mathrm{~min}^{-1}$.

\subsubsection{Síntese de resina fenólica do tipo resol para preparação de compósitos reforçados por fibras vegetal}

\subsection{Síntese da resina (pré-polímero) fenol-formaldeído resol (RFF)}

A reação de síntese do pré-polímero foi realizada em um sistema composto por um balão 
de reação de três bocas constituído por condensador para refluxo, haste de agitação em "meialua", termômetro, agitador mecânico e manta de aquecimento. O pré-polímero foi preparado segundo condições já estabelecidas em estudos anteriores Silva et al. (2018). Foi utilizada uma proporção de fenol:formaldeído (solução a 37\%): $\mathrm{KOH}$ de 1,0:1,38:0,06, respectivamente. O sistema foi inicialmente aquecido a $70{ }^{\circ} \mathrm{C}$ e em seguida, a manta foi desligada. Como a reação é exotérmica, a temperatura atingiu $97{ }^{\circ} \mathrm{C}$ em $5 \mathrm{~min}$, mantendo-se por $30 \mathrm{~min}$. Em seguida, o sistema retornou a $70{ }^{\circ} \mathrm{C}$, mantendo-se por $1 \mathrm{~h}$. Deixou-se o sistema resfriar até a temperatura ambiente, mediu-se o pH e ajustou-se o mesmo para 7,0 adicionando $\mathrm{HCl}(37 \%)$.

\subsubsection{Preparação de compósitos de matriz RFF reforçado com fibra vegetal}

\subsection{Adição do agente acelerador de cura}

A resina fenólica do tipo resol previamente sintetizada foi aquecida a $40{ }^{\circ} \mathrm{C}$, sendo adicionado gradativamente o agente acelerador de cura, a resorcina, com agitação mecânica, $10 \%$ em massa em relação à massa da resina.

\section{2.2.3.2 Incorporação do reforço}

As fibras foram misturadas com a resina primeiramente em um béquer e em seguida, a mistura foi colocada em um misturador (Empresa JVJ, Pardinho, SP) desenvolvido especificamente para a linha de pesquisa em que o projeto está inserido. A impregnação da fibra pela matriz foi realizada durante 15 min a partir da rotação do compartimento de mistura de 20 rpm. No processo de moldagem, a mistura fibra/matriz foi colocada em um molde metálico contendo cera de carnaúba (agente desmoldante). A Figura 19 ilustra uma representação esquemática do processo de preparação dos compósitos de matriz RFF reforçados com FMD.

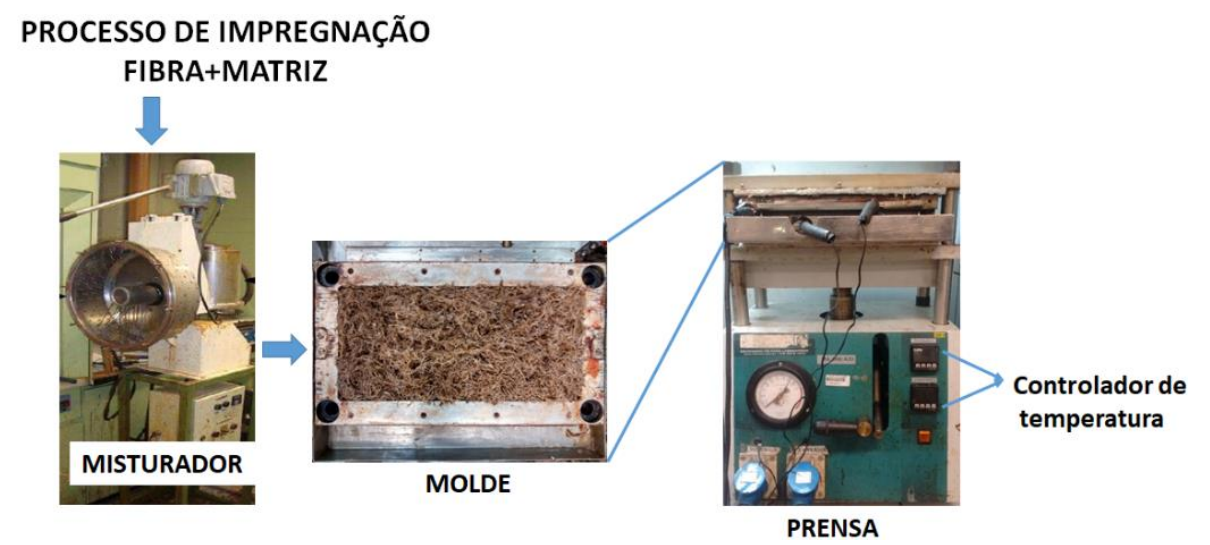

Figura 19: Representação esquemática da preparação dos compósitos de matriz RFF reforçados com FMD. 


\subsection{Moldagem do termorrígido e dos compósitos}

O termorrígido e os compósitos contendo resina fenólica foram moldados por compressão e aquecimento controlados, em molde portátil (30,2 cm de comprimento, 14,1 cm de largura e 0,47 cm de altura) constituído de duas placas, nas quais foram embutidas resistências elétricas. Em seguida, o molde foi fechado e comprimido com o auxílio de uma prensa hidráulica (Figura 19). Os ciclos de cura adotados foram baseados em estudos prévios (DE OLIVEIRA et al., 2017; SILVA et al., 2018).

Os ciclos seguidos para a cura dos termorrígidos e compósitos da matriz fenólica do tipo resol estão apresentados na Tabela 1.

Tabela 1- Ciclo de cura para a obtenção do termorrígido e compósitos de matriz fenólica do tipo resol.

\begin{tabular}{ccc}
\hline Temperatura $\left({ }^{\circ} \mathbf{C}\right)$ & Tempo (min) & Força (ton) \\
\hline 75 & 60 & 0 \\
\hline 85 & 90 & 0 \\
95 & 30 & 10 \\
\hline 105 & 30 & 16 \\
\hline 115 & 60 & 16 \\
\hline 125 & 90 & 16 \\
\hline
\end{tabular}

A partir de $95^{\circ} \mathrm{C}$, a pressão foi gradativamente aumentada, até atingir 10 ton.

Devido à heterogeneidade dos diâmetros da FMD, não foi possível fixar o comprimento das fibras utilizadas para preparação dos compósitos, sendo apenas variada a porcentagem em massa de FMD em cada compósito, 13\%, 16\%, 17\%, e 19\%. Aos compósitos obtidos foram atribuídos os seguintes códigos: CrfF13\%FMD, CrfF16\%FMD, CrfF17\%FMD e CRFF19\%FMD (Tabela 2).

Tabela 2 - Códigos e descrição dos compósitos de matriz RFF reforçados com diferentes porcentagens em massa de FMD.

\begin{tabular}{ll}
\hline Códigos dos compósitos & \multicolumn{1}{c}{ Descrição } \\
\hline $\mathrm{C}_{\mathrm{RFF}} 13 \% \mathrm{FMD}$ & Compósito de matriz RFF reforçado com $13 \%$ em massa de FMD \\
\hline $\mathrm{C}_{\mathrm{RFF}} 16 \% \mathrm{FMD}$ & Compósito de matriz RFF reforçado com $16 \%$ em massa de FMD \\
\hline $\mathrm{C}_{\mathrm{RFF}} 17 \% \mathrm{FMD}$ & Compósito de matriz RFF reforçado com 17 \% em massa de FMD \\
\hline $\mathrm{C}_{\mathrm{RFF}} 19 \% \mathrm{FMD}$ & Compósito de matriz RFF reforçado com 19\% em massa de FMD \\
\hline
\end{tabular}




\subsubsection{Caracterização da resina fenol-formaldeído resol (RFF) e dos compósitos}

O termorrígido não reforçado (TRFF), e os compósitos, foram previamente congelados em nitrogênio líquido, moídos em moinho de bolas para realizar as caracterizações que seguem e que requisitam o material na forma pulverizada.

\subsection{Espectroscopia na região do infravermelho por transformada de Fourier} (FTIR)

Os compósitos foram previamente moídos e analisados usando pastilha de $\operatorname{KBr}(1: 100)$ conforme descrito no item 1.2.2.1.2. A resina foi analisada após deposição sobre pastilha de silício, devido à praticidade de analisar o material desta maneira.

\subsection{Cromatografia por exclusão de tamanho (SEC)}

Esta técnica foi usada para a determinação da massa molar média da resina RFF. Utilizou-se um cromatógrafo líquido HP-SEC, da marca Shimadzu, equipado com bomba LC$10 \mathrm{AD}$, detector espectrofotométrico UV-visível. Foram utilizadas uma pré-coluna PL-gel + 3 colunas em série Plgel 500A $+10^{3} \mathrm{~A}+10^{4} \mathrm{~A}$. O eluente foi THF grau HPLC com fluxo de $1 \mathrm{~mL}$ $\min ^{-1}$, e curva de calibração obtida a partir de padrões de poliestireno, com valores de massa molar média ponderal $(\overline{\mathrm{M}} \boldsymbol{w})$ variando entre 770.000 e $106 \mathrm{~g} \mathrm{moL}^{-1}$.

Foram adicionadas duas gotas de $\mathrm{HCl}$ (solução 37\%) para aumentar a solubilidade do prépolímero em THF. Previamente ao momento da injeção, adicionou-se as duas gotas de ácido na amostra solubilizada (visualmente), agitou-se rapidamente, filtrou-se e então foi realizada a injeção.

\subsection{Análise termogravimétrica (TGA)}

Os compósitos moídos e a resina RFF, com massa de $5 \mathrm{mg}$, foram colocadas em portaamostra de platina, a qual foi aquecida de 25 a $800{ }^{\circ} \mathrm{C}$ com razão de aquecimento de $5^{\circ} \mathrm{C} \mathrm{m^{-1 }}$, sob atmosfera de ar sintético com fluxo de $50 \mathrm{~mL} \mathrm{~min}{ }^{-1}$.

\subsection{Ressonância magnética nuclear de $^{13} \mathrm{C}$}

O pré-polímero RFF foi analisado em equipamento Agilent 500/54 Premium Shielded a $300 \mathrm{~K}$ para obtenção dos espectros de $\mathrm{RMN}$ de ${ }^{13} \mathrm{C}$, em tubos de $5 \mathrm{~mm}$, utilizando DMSO-d6 como solvente e 20000 varreduras. Os deslocamentos químicos foram referenciados ao sinal residual do solvente $\left({ }^{13} \mathrm{C} \delta=39,5 \mathrm{ppm}\right)$. 


\subsection{Resistência ao impacto}

Os ensaios de impacto Izod foram realizados em um equipamento CEAST Resil 25 com martelo instrumentado e energia incidente de $1,75 \mathrm{~J}$, em temperatura de $25 \pm 2{ }^{\circ} \mathrm{C}$. Cada placa de compósito foi cortada e lixada previamente, sem entalhe, com as dimensões especificadas pela norma ASTM D256: 63,5 mm de comprimento x 12,7 mm de largura x 4,5 mm de espessura. Os ensaios foram realizados no Departamento de Engenharia de Materiais da Universidade Federal de São Carlos- UFSCar, SP.

\subsection{Microscopia Eletrônica por Varredura (MEV)}

A análise de MEV dos compósitos foi realizada com os corpos-de-prova após fratura no ensaio de impacto Izod. Estes foram cortados em tamanhos de aproximadamente $1 \mathrm{~cm}$ para serem analisados. Foi utilizado um Microscópio Eletrônico de Varredura Zeiss-Leica 440, aceleração de elétrons de $20 \mathrm{kV}$. As amostras foram coladas em um porta-amostra de alumínio usando fita de carbono em seguida, elas foram pintadas com tinta-prata e, posteriormente, revestidas com uma fina camada de $\mathrm{Au}(20 \mu \mathrm{m})$.

\subsection{Propriedades de flexão}

As propriedades de flexão foram avaliadas seguindo a norma ASTM D790-96a, utilizando-se o método 1 relacionado ao ensaio de flexão em três pontos. Os corpos-de-prova possuíam as seguintes dimensões: $120 \mathrm{~mm}$ de comprimento x $10 \mathrm{~mm}$ de largura x 4,5 $\mathrm{mm}$ de espessura. Foram cortados 6 corpos de prova de cada placa produzida, os quais foram submetidos ao teste de flexão. A razão L/d utilizada foi de 16, o que determina a distância do vão de ensaio, e a velocidade do ensaio foi de $1,5 \mathrm{~mm} \mathrm{~min}^{-1}$. Os ensaios foram realizados no Departamento de Engenharia de Materiais da Universidade Federal de São Carlos- UFSCar, SP.

\subsection{Análise térmica dinâmico-mecânica (DMA)}

A análise dos termorrígidos e dos compósitos via DMA foi realizada em equipamento DMA Q800 da TA Instruments. Os corpos-de-prova dos compósitos possuíam dimensões de $64 \mathrm{~mm}$ de comprimento x $12 \mathrm{~mm}$ de largura x 3,2 mm de espessura. A calibração do equipamento foi realizada com um padrão metálico. O módulo de solicitação mecânica foi de flexão e a garra foi a de flexão de três pontos. As condições experimentais utilizadas foram amplitude de oscilação de $20 \mu \mathrm{m}, 1 \mathrm{~Hz}$ de frequência, taxa de aquecimento de $2{ }^{\circ} \mathrm{C} \min ^{-1}$, e faixa de aquecimento de 30 a $210^{\circ} \mathrm{C}$. 


\subsection{Resultados e discussão}

\subsubsection{Caracterização da fibra do mesocarpo do dendê}

\subsubsection{Espectroscopia na região do infravermelho por transformada de Fourier (FTIR)}

O espectro de FTIR da FMD está apresentado na Figura 20 e a Tabela 3 apresenta as possíveis atribuições para as principais bandas de absorção observadas na FMD. Em $3270 \mathrm{~cm}^{-1}$ observou-se uma banda que pode ser atribuída ao estiramento ou deformação axial de grupos $\mathrm{OH}$ de componentes da fibra, com contribuição de ligações hidrogênio intramoleculares e intermoleculares (RAMIRES, 2010; NORDIN et al., 2013; WANG et al., 2009).

Figura 20 - Espectro de FTIR da FMD.

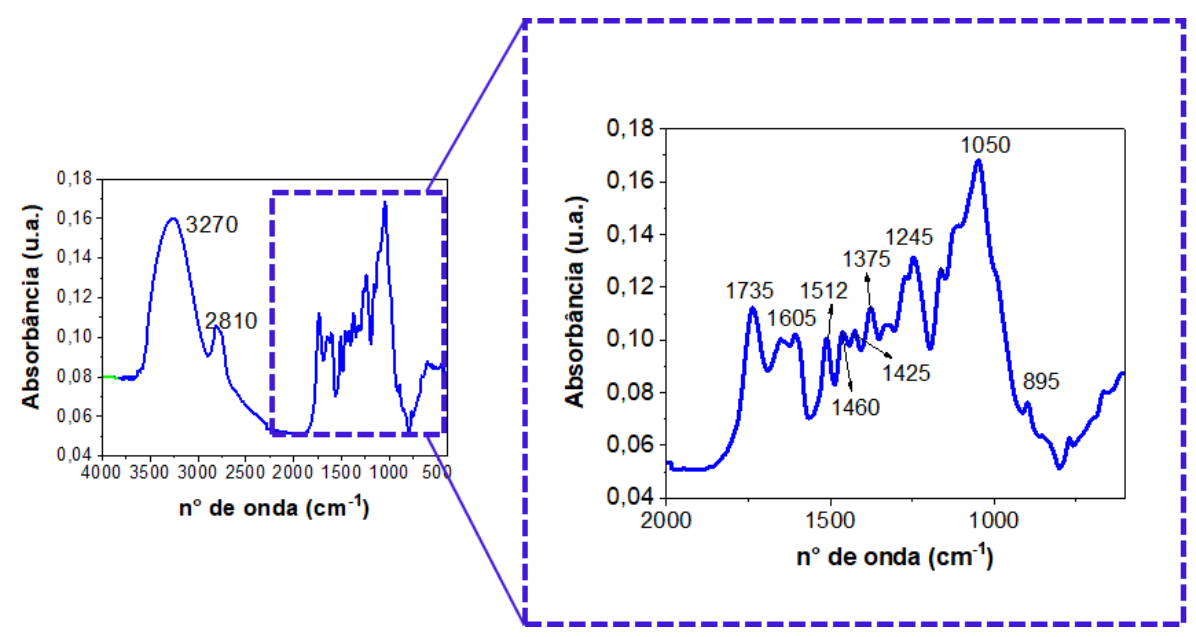

Tabela 3 - Possíveis atribuições para as principais bandas de absorção observadas na FMD.

\section{FMD}

\begin{tabular}{cc}
\hline $\mathbf{n}^{\circ}$ de onda $\left(\mathbf{c m}^{-1}\right)$ & Atribuição \\
\hline $\mathbf{3 2 7 0}$ & Estiramento ou deformação axial de ligações $\mathrm{O}-\mathrm{H}$ \\
\hline $\mathbf{2 8 1 0}$ & Ligação $\mathrm{C}-\mathrm{H}$ de grupos saturados \\
\hline $\mathbf{1 7 3 5}$ & Estiramento de ligações $\mathrm{C}=\mathrm{O}$ \\
\hline $\mathbf{1 6 0 5 - 1 4 2 5}$ & Vibração de anel aromático da lignina \\
\hline $\mathbf{1 3 7 5}$ & Estiramento de ligação C-O presente na lignina e hemiceluloses \\
\hline $\mathbf{1 2 4 5}$ & Vibração assimétrica de ligação C-O-C \\
\hline $\mathbf{1 0 6 0 - 1 0 5 0}$ & Deformação axial de ligaçães C-O-C \\
\hline $\mathbf{8 9 5}$ & Vibração de grupo $\mathrm{C}_{1}$ da celulose \\
\hline
\end{tabular}

(REFERÊNCIAS: SILVERSTEIN et al. 1994; RAMIRES, 2010; WANG et al., 2009; ORUE et al., 2015; PHITSUWAN et al., 2017).

A banda em $2810 \mathrm{~cm}^{-1}$ pode ser atribuída à ligação $\mathrm{C}-\mathrm{H}$ de grupos saturados, e em $1735 \mathrm{~cm}^{-1}$ ao estiramento de ligações de $\mathrm{C}=\mathrm{O}$, de grupos éster, acetil e ácidos fenólicos presentes em extrativos e hemiceluloses, e na lignina, respectivamente (MAHMUD et al., 2013; PHITSUWAN et al., 2017; SAHU; GUPTA, 2018). As bandas de 1600 a $1500 \mathrm{~cm}^{-1}$ 
podem ser associadas à vibração do esqueleto aromático da lignina (BYKOV, 2008). A banda em $1245 \mathrm{~cm}^{-1}$ pode ser associada ao estiramento $\mathrm{C}-\mathrm{O}$ dos grupos acetila das hemiceluloses, e aril-alquil-éter presente na lignina (ORUE et al., 2015; SENTHAMARAIKANNANA; KATHIRESAN, 2018). A banda em $1050 \mathrm{~cm}^{-1}$ pode ser associada aos grupos C-O-C de grupos metoxila da lignina (PALUVAI et al., 2015). A banda em $895 \mathrm{~cm}^{-1}$ refere-se à vibração de carbono 1 da celulose presente na FMD (Figura 18- d) (CARRILLO et al., 2004).

\subsubsection{Composição química}

A composição química da FMD, após lavagem com água e extração com ciclohexanoetanol, está apresentada na Tabela 4. O conhecimento dos componentes principais lignocelulósicos é importante, pois influenciam nas propriedades mecânicas e físicas das fibras vegetais.

Tabela 4- Composição da FMD.

\begin{tabular}{lc}
\hline \multicolumn{1}{c}{ Componente } & $(\%)$ \\
\hline$\alpha$-celulose & $34,5 \pm 1,9$ \\
\hline Hemiceluloses & $27,3 \pm 2,1$ \\
\hline Lignina Klason total & $34,2 \pm 1,4$ \\
\hline Cinzas & $7,1 \pm 0,4$ \\
\hline Umidade & $9,6 \pm 0,3$ \\
\hline
\end{tabular}

Ainda, podem interferir nas propriedades dos compósitos em que as fibras foram utilizadas como agente de reforço (DE OLIVEIRA et al., 2015; SILVA et al., 2018). A composição do FMD utilizada no presente estudo se situou dentro da faixa relatada na literatura: 21-43\% de celulose, $15-33 \%$ de hemiceluloses, $21-31 \%$ de lignina e $2-8 \%$ de cinzas (COSTA et al., 2013; NORDIN et al. , 2013; KABIR; DIN; HAMEED, 2017; OKAHISA et al., 2018). A composição química da biomassa lignocelulósica pode mudar de acordo com o tipo de solo, técnicas de colheita e manejo, condições climáticas, entre outros fatores (MCKENDRY, 2002).

\subsubsection{Microscopia eletrônica de varredura (MEV)}

As micrografias da ponta da FMD mostraram a presença de estruturas cilíndricas internas vazias conhecidas como lúmens (LUZ et al., 2017) (Figura 21-a e -b). 
Figura 21 - Micrografias da ponta da FMD não lavada (a) e após a extração com solventes (b).

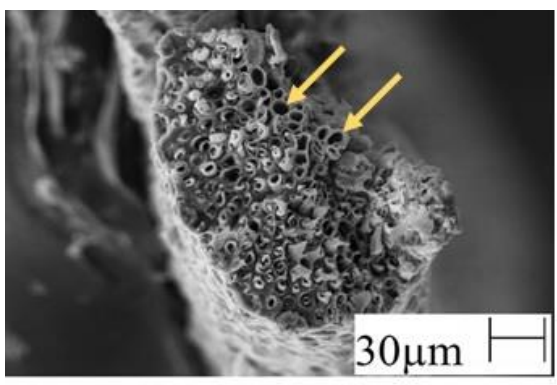

(a)

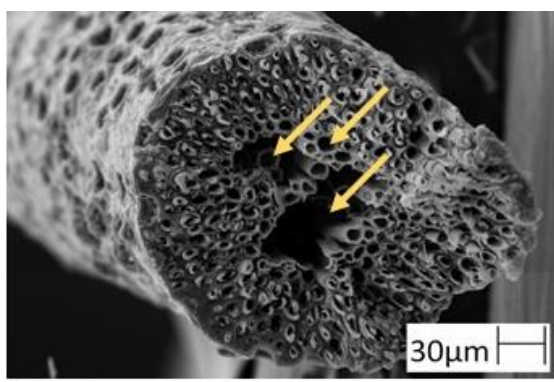

(b)

Quando as fibras lignocelulósicas são usadas como agente de reforço de matrizes poliméricas, a impregnação da resina na fibra pode ser indicada pelo preenchimeto do lúmen (FERREIRA et al., 2015; YAN et al., 2015).

A Figura 22- a mostra que as fibras possuem superfície rugosa, com alguns poros preenchidos por corpos circulares. As fibras obtidas do dendezeiro possuem corpos de silício em sua superfície (SHINOJ et al., 2011; NORDIN et al., 2013; MAHMUD et al., 2013; ABDUL et al., 2016; PALAMAE et al., 2017). No presente estudo, foi possível confirmar a presença deste elemento por meio do mapeamento composicional dos elementos químicos dentro dos poros, o qual foi realizado pela análise de EDs. A Figura 22-b apresenta o espectro de EDS obtido.

Figura 22 - Micrografias da superfície das FMD (a) e espectro de EDS da análise micro elementar dos corpos sólidos dentro dos poros (b).

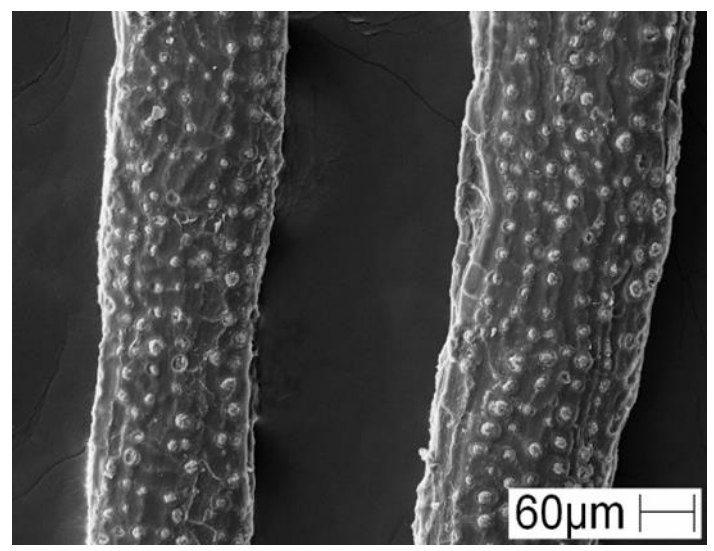

(a)

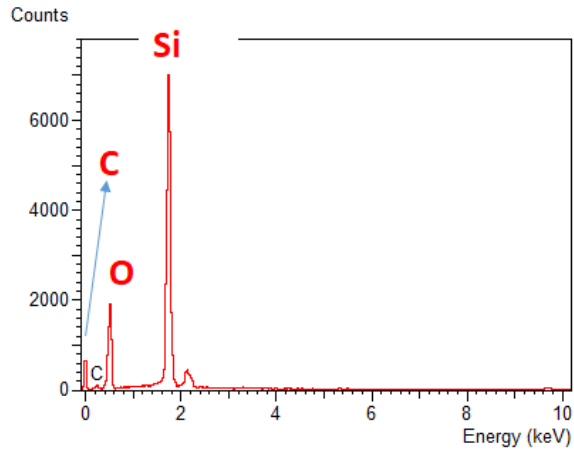

(b)

De acordo com a literatura, a presença destes corpos de sílica pode causar um efeito prejudicial em relação ao uso dessas fibras como agente de reforço na preparação de compósitos, pois pode ser um dos fatores que pode reduzir ou impedir a impregação da fibra 
pela resina.

\subsubsection{Quantificação do silício}

A concentração de silício presente na FMD foi determinada por MIP-OES (Item 1.2.2.1.5). A concentração encontrada nesta no presente estudo, $1,1 \pm 0,2 \%$. A presença de elementos inorgânicos nas fibras lignocelulósicas também depende do tipo de solo, técnicas de colheita e manejo, condições climáticas, entre outros fatores (MCKENDRY, 2002; MANNA et al., 2017). Durante o crescimento de células vegetais, esses corpos de silício provenientes do solo mineral endurecem dentro da parede celular e são fixados na superfície (ABDUL et al., 2016), conforme observado na Figura 22-a.

A remoção de sílica dessas fibras pode melhorar a atuação das mesmas como agente de reforço em compósitos, pois pode intensificar a impregnação da fibra pela matriz. Uma melhor impregnação pode levar a melhores propriedades mecânicas dos compósitos.

\subsubsection{5 Índice de cristalinidade}

$\mathrm{O}$ índice de cristalinidade (ICr) das fibras lignocelulósicas está associado à estrutura supra-molecular da celulose, que possui duas regiões com características distintas: a cristalina e a não-cristalina (KADLA; GILBERT, 2000). A partir da razão entre essas duas regiões é possível calcular o ICr, que pode afetar diretamente as propriedades físicas e mecânicas das fibras naturais. A organização estrutural na parede celular vegetal das fibras lignocelulósicas é decorrente de micro-fibrilas de celulose presas umas às outras, envolvidas por hemiceluloses, que estão ligadas à lignina formando o complexo carboidratos-lignina (CHABBERT et al., 2018). A lignina age como um adesivo entre celulose e hemiceluloses. A integridade linear e a rigidez da estrutura da celulose são em parte decorrentes de ligações hidrogênio intramoleculares e intermoleculares, as quais favorecem a formação de regiões cristalinas (CREDOU; BERTHELOT, 2014). Tanto as hemiceluloses como a lignina não possuem região cristalina.

A Figura 23 mostra o difratograma de raios X da FMD. O ICr da FMD, 25\%, foi semelhante ao observado por Souza et al. (2016), 27\% para FMD e inferior ao reportado por Then et al. (2014), 33\% para fibras de cacho vazio de fruto do dendê. O baixo valor de ICr da FMD é associado ao baixo teor de celulose, 37\% (Tabela 4), presente nessas fibras, comparado a outras fibras como fibras de sisal, que possui $52 \%$ de $\alpha$-celulose e ICr de $55 \%$ (DE OLIVEIRA et al., 2017). 
Figura 23 - Difratograma de raios X da FMD.

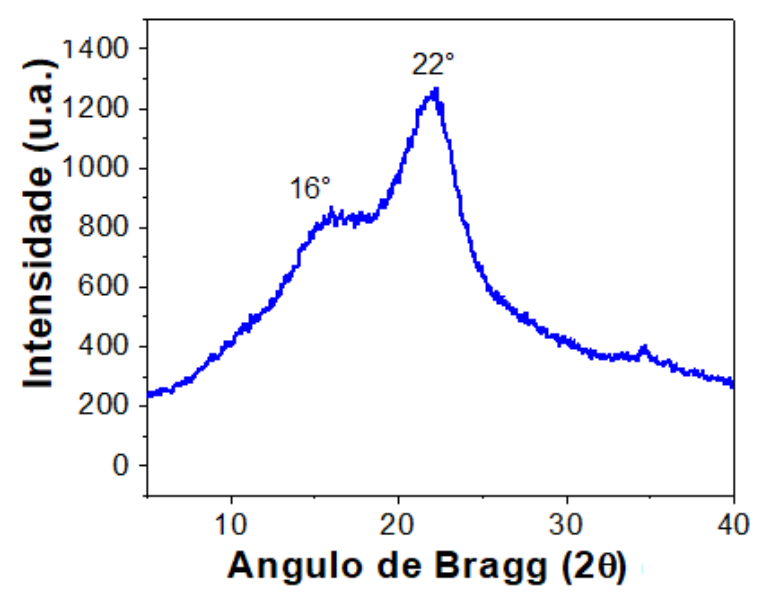

Os picos $2 \theta \approx 16^{\circ}$ e $22^{\circ}$ nos difratogramas da FMD (Figura 23) são característicos da celulose I (FRENCH, 2014; NASCIMENTO et al., 2014; SOUZA et al., 2016). A celulose possui várias formas alomórficas e a celulose I está presente na celulose nativa (CREDOU; BERTHELOT, 2014). As propriedades mecânicas das fibras lignocelulósicas estão relacionadas ao alto grau de polimerização e cristalinidade da celulose, que é responsável pela resistência das fibras (PANDEY, 1999; SENA NETO et al., 2013; FIDELIS et al., 2013).

\subsubsection{Análise termogravimétrica}

A estabilidade térmica da FMD foi avaliada por meio da técnica de análise termogravimétrica (TGA). A Figura 24 mostra uma perda de massa de aproximadamente 4\% até $100{ }^{\circ} \mathrm{C}$, que está relacionada à vaporização de água proveniente de umidade residual.

Figura 24 - Curvas termogravimétrica e dTG da FMD, em atmosfera de ar sintético, com taxa de aquecimento de $5^{\circ} \mathrm{C} \mathrm{min}^{-1}$, e fluxo de $50 \mathrm{~mL} \mathrm{~min}^{-1}$.

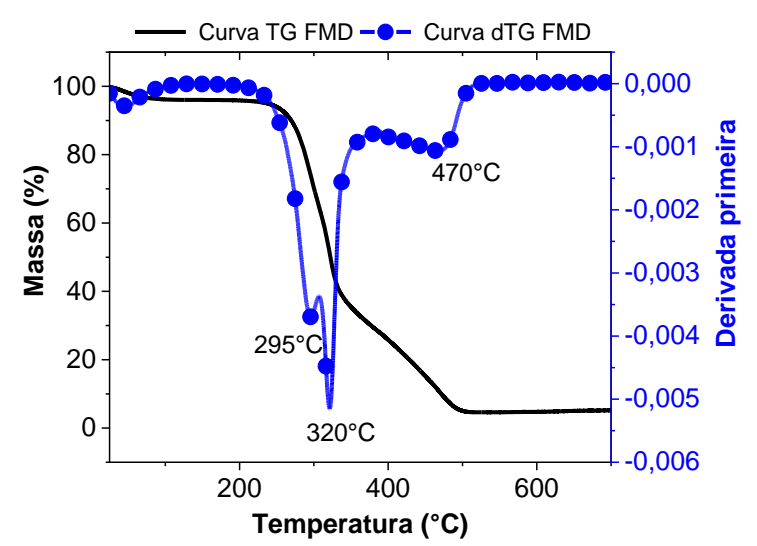


Para serem usadas em aplicações como reforço em compósitos, a temperatura de processamento dessas fibras deve ser limitada até a temperatura inicial de decomposição ( $\mathrm{T}_{\text {onset }}$ ) (NETO et al., 2015). A FMD apresentou $\mathrm{T}_{\text {onset }}$ de aproximadamente $270{ }^{\circ} \mathrm{C}$.

A curva dTG (Figura 24) mostra os eventos térmicos, e os dados correspondentes estão listados na Tabela 5. A temperatura do pico ( $\mathrm{T}_{\mathrm{dMÁx}}$ ) (Tabela 5) observada na curva dTG refere-se à temperatura na qual a velocidade de perda de massa é máxima (DE OLIVEIRA SANTOS et al., 2014; AHUJA; KAUSHIK; SINGH, 2018).

A Figura 24 mostra um evento com $\mathrm{T}_{\mathrm{dMÁx}}$ (curva dTG) em cerca de $295^{\circ} \mathrm{C}$ e que pode ser atribuída à decomposição de hemiceluloses. Estas possuem uma temperatura de decomposição (200-310 $\left.{ }^{\circ} \mathrm{C}\right)$ inferior às de celulose e lignina (ZHOU et al., 2014), relacionada à decomposição de componentes de sua estrutura não cristalina, tais como galactose, glicose, arabinose, manose e xilose, ligados aleatoriamente entre si por ligações covalentes (WANG et al., 2009; THEN et al., 2014).

Tabela 5 - Parâmetros termogravimétricos da FMD.

\begin{tabular}{|c|c|c|c|c|c|c|c|c|c|}
\hline \multicolumn{3}{|c|}{$\begin{array}{c}1^{\circ} \text { Evento } \\
\left(20-100{ }^{\circ} \mathrm{C}\right)\end{array}$} & \multicolumn{2}{|c|}{$\begin{array}{c}2^{\circ} \text { Evento } \\
\left(200-300{ }^{\circ} \mathrm{C}\right)\end{array}$} & \multicolumn{2}{|c|}{$\begin{array}{c}3^{\circ} \text { Evento (300- } \\
\left.355^{\circ} \mathrm{C}\right)\end{array}$} & \multicolumn{2}{|c|}{$\begin{array}{c}4^{\circ} \text { Evento } \\
\left(365-530{ }^{\circ} \mathrm{C}\right)\end{array}$} & \multirow{2}{*}{$\begin{array}{c}\begin{array}{c}\text { Residuo } \\
\left(800{ }^{\circ} \mathrm{C}\right)\end{array} \\
\text { Massa } \\
(\%)\end{array}$} \\
\hline$\Delta \mathrm{m}$ & $\mathbf{T}_{d}$ MÁx & $\Delta \mathrm{m}$ & $\mathbf{T}_{\text {onset }}$ & T $_{d}$ MÁX & $\Delta \mathrm{m}$ & $\mathbf{T}_{d}$ MÁX & $\Delta \mathrm{m}$ & $\mathbf{T}_{d}$ MÁX & \\
\hline 3,9 & 44 & & 270 & 295 & 28 & 320 & 29 & 470 & 5,8 \\
\hline
\end{tabular}

A decomposição térmica da celulose se inicia após a de hemiceluloses em temperaturas superiores a $310{ }^{\circ} \mathrm{C}$. Isso se deve ao fato de sua composição possuir regiões cristalinas, nas quais cadeias estão altamente ordenadas, conferindo maior estabilidade térmica à celulose em comparação com a estrutura não cristalina de hemiceluloses. Assim, é necessária uma energia maior para causar sua decomposição (ISHAK et al., 2013). Na curva dTG o evento em que a $\mathrm{T}_{\mathrm{dMÁx}}$ foi referente à decomposição de celulose foi observado em $320{ }^{\circ} \mathrm{C}$ (Figura 23). Em temperaturas superiores a $400{ }^{\circ} \mathrm{C}$, a lignina inicia sua decomposição devido à sua estrutura complexa composta por anéis aromáticos que são mais difíceis de se decomporem comparados à hemiceluloses e celulose (PAIV A; FROLLINI, 2006; RAMIRES et al., 2010). Na curva dTG (Figura 24), a $\mathrm{T}_{\mathrm{d} M A ́ x}$ da lignina foi de $470{ }^{\circ} \mathrm{C}$, Tabela 5.

\subsubsection{Propriedades de tração}

As propriedades mecânicas das fibras lignocelulósicas estão relacionadas com a 
composição química, estrutura, ângulo das microfibrilas, dimensões e defeitos celulares e cristalinidade da celulose. Ainda, fibras provenientes de uma mesma planta, mas de regiões diferentes, podem posssuir propriedades diferentes (DUFRESNE, 2008).

Os resultados de resistência à tração, alongamento na ruptura, e módulo elástico da FMD estão apresentados na Tabela 6. O resultado obtido de resistência à tração (Tabela 6) foi superior ao observado por Yusoff et al. (2010) para fibras de cacho do fruto do dendê, 71 MPa, e, para FMD, 80 e 64,5 MPa, obtidos por Then et al. (2013) e Simão et al. (2019), respectivamente. Os valores de resistência à tração obtidos a partir de fibras do dendezeiro podem variar entre 25 e $400 \mathrm{MPa}$ (SREEKALA et al., 2002; KALAM et al., 2005; RAO; RAO, 2007; YUSOFF et al., 2010). O amplo intervalo indica que as fibras oriundas do dendezeiro possuem uma composição química e propriedades mecânicas bastante heterogêneas.

Tabela 6 - Valores médios da resistência à tração, alongamento na ruptura e módulo elástico das fibras do mesocarpo do dendê (FMD).

\section{FMD}

\begin{tabular}{lc}
\hline Resistência à tração & $107 \pm 22 \mathrm{MPa}$ \\
\hline Alongamento na ruptura & $6,0 \pm 1,0 \%$ \\
\hline Módulo elástico & $2,5 \pm 0,2 \mathrm{GPa}$ \\
\hline
\end{tabular}

É importante destacar que esta propriedade é fortemente influenciada pela porcentagem e pelo empacotamento das cadeias da celulose presente nas fibras. Quanto maior o empacotamento das cadeias celulósicas, maior é o índice de cristalinidade e melhores serão as propriedades mecânicas das mesmas (SINHA; ROUT, 2009). Como mencionado, a FMD utilizada no presente estudo possui baixo índice de cristalinidade, $25 \%$, comparado à fibra de sisal, 61\%, o que confere à mesma uma menor resistência à tração que a de sisal, $288 \pm 32$ (Ramires, 2010).

O alongamento na ruptura da FMD (Tabela 6) obtido no presente estudo foi inferior ao obtido por Sreekala e colaboradores (1997), 17 \%, e Simão et al. (2019), 12\%, para fibra do mesocarpo do dendê. No entanto, foi elevado comparado, por exemplo, à fibra de sisal que possui um alongamento na ruptura de 1,1\% 0,2 (RAMIRES, 2010). Esta propriedade está relacionada ao arranjo helicoidal das microfibrilas de celulose (YE, 2006).

As fibras oriundas do fruto do dendê possuem geralmente um ângulo microfibrilar entre 42 e $46^{\circ}$ (JACOB; THOMAS; VARUGHESE, 2004; SREEKALA; KUMARAN; THOMAS, 
1997). O ângulo microfibrilar é o ângulo entre o eixo da fibra e as microfibrilas, e varia de uma fibra para outra (CREDOU; BERTHELOT, 2014; JABBAR, 2017). As microfibrilas cristalinas localizadas na camada S2 (intermediária) (Figura 25) possuem estrutura helicoilal ao redor do eixo da fibra (YE, 2006) e, de maneira geral, fibras com maior ângulo microfibrilar possuem um menor teor de celulose e resistência à tração (JABBAR, 2017). A fibra de sisal, por exemplo, é uma fibra com elevado teor de celulose, 61\%, e ângulo microfibrilar entre 20 e $25^{\circ}$, e uma maior resistência à tração (RAMIRES, 2010) comparativamente à FMD utilizada no presente estudo. A Figura 25 ilustra o ângulo microfibrilar, assim como as camadas S1 (externa), S2 (intermediária) e S3 (interna) da parede celular das fibras lignocelulósicas.

O módulo elástico obtido no presente estudo (Tabela 6) foi semelhante ao obtido por Izani et al. (2013), 2,4 GPa para fibras de cacho do fruto do dendê, e superior ao obtido por Simão et al. (2019), 1,03 GPa para fibras do mesocarpo do dendê. Porém, é possível encontrar na literatura valores de módulo elástico para a FMD de 6,7 GPa (JACOB; THOMAS; VARUGHESE, 2004). Estes valores indicam que além de fatores intrínsecos à fibra, fatores externos como tipo de processamento, época de colheita, condições climáticas e do solo, podem influenciar nas propriedades mecânicas das fibras lignocelulósicas.

Figura 25 - Ilustração do ângulo microfibrilar e das camadas S1 (externa), S2 (intermediária) e S3 (interna) da parede celular das fibras lignocelulósicas.

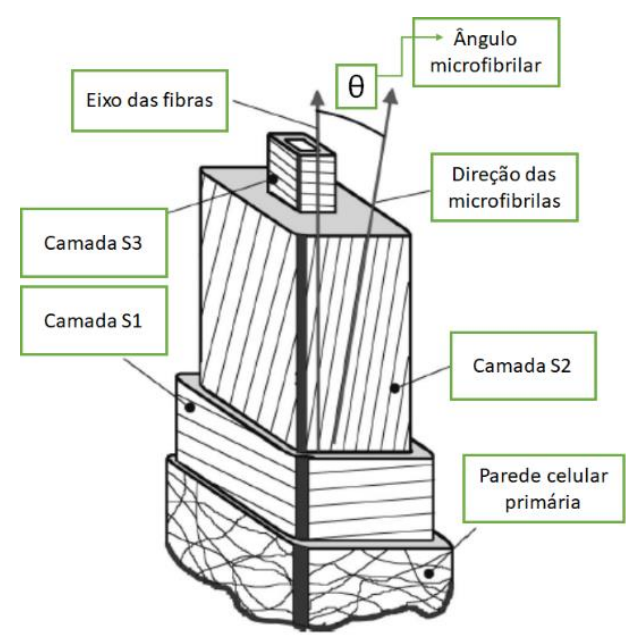

Fonte: Adaptado de Ye (2006).

Vale ressaltar que a capacidade dessas fibras como agente de reforço em compósitos não depende apenas de sua resistência mecânica, mas também da adesão interfacial, que é influenciada pela polaridade da fibra e da matriz, e de propriedades da superfície da fibra (RHAMAN; KHAN, 2007). 


\subsubsection{Caracterização da resina (RFF), termorrígido (TRFF) e compósitos fenol-}

\section{formaldeído}

\subsubsection{Espectroscopia na região do infravermelho por transformada de Fourier (FTIR)}

A Figura 26 apresenta os espectros na região do infravermelho para a resina RFF, TRFF e de apenas um dos compósitos, $\mathrm{C}_{\mathrm{RFF}} 17 \% \mathrm{FMD}$, pois todos apresentaram espectros similares. A Tabela 7 mostra as possíveis atribuições para as bandas de absorção observadas nos mesmos.

Figura 26 - Espectros na região de infravermelho da resina fenólica (RFF), do termorrígido fenólico (TRFF) e do compósito reforçado com FMD ( $\left.\mathrm{C}_{\mathrm{RFF}} 17 \% \mathrm{FMD}\right)$.

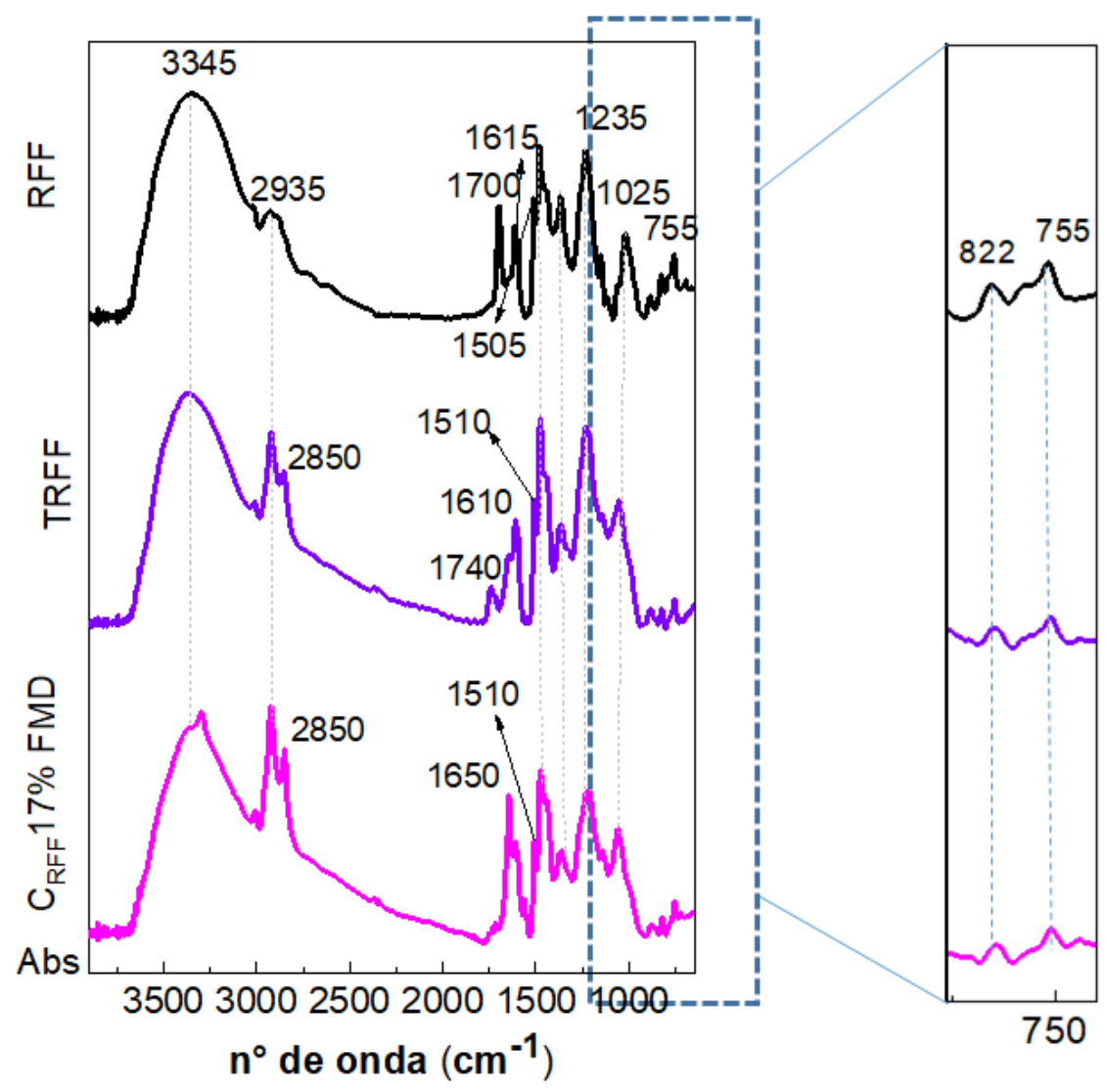

Os espectros da resina fenólica e do termorrígido apresentaram bandas semelhantes. A banda intensa na faixa de 3345 a $3290 \mathrm{~cm}^{-1}$, observada na resina RFF e do TRFF, refere-se à estiramento ou deformação axial de grupos hidroxilas fenólicas e alifáticas . No caso do compósito, esta banda é referente ao estiramento ou deformação axial de grupos hidroxilas alcoólico e fenólico que podem ser referentes a componentes da fibra e à matriz polimérica.

No intervalo de 2960 a $2850 \mathrm{~cm}^{-1}$ foi identificada uma banda característica de ligação C$\mathrm{H}$ de grupos metila e metilenos. A presença de grupos metilenos na resina indica que houve polimerização entre o fenol e o formaldeído e formação de ligações cruzadas resultando em 
uma estrutura termorrígida, Figura 27 (MALUTAN et al., 2008).

Em aproximadamente $1600 \mathrm{~cm}^{-1}$ observa-se uma banda referente ao estiramento (deformação axial) das ligações $\mathrm{C}=\mathrm{C}$ do anel aromático. A banda em $1470 \mathrm{~cm}^{-1}$ é atribuída à deformação angular de ligação $\mathrm{C}-\mathrm{H}$ de grupos metilenos, que podem ser provenientes do processo de entrecruzamento da resina fenólica antes e durante a moldagem do compósito (RAMIRES, 2010).

Os grupos hidroximetilas reagem entre si formando pontes metilenos, as quais são as responsáveis pela formação de ligações cruzadas (BENNAR,1999; RAMIRES et al., 2010). Em aproximadamente 1220 e $1513 \mathrm{~cm}^{-1}$, são observadas as bandas referentes às hidroxilas fenólicas e a vibração do anel aromático, respectivamente (Figura 26) (RAMIRES, 2010; RAZERA, 2006; MEGIATTO JÚNIOR, 2009).

Figura 27 - Fenóis dinucleares formados durante a reação de síntese da resina RFF para a posterior fomação do termorrígido entrecruzado.<smiles>OCc1cc(O)cc(COCc2cccc(CO)c2O)c1</smiles>

Fonte: Saunders (1988).

A banda observada em $1235 \mathrm{~cm}^{-1}$ é referente à deformação axial da ligação C-O-C de éter em pontes éter metilenos $\left(-\mathrm{CH}_{2}-\mathrm{O}-\mathrm{CH}_{2}-\right)$ presentes entre os anéis fenólicos durante a polimerização dos hidroximetilfenóis (Figura 27) e entre os grupos metoxilas presentes na lignina presente na FMD, como apresentado anteriormente no Item 1.3.1.1.

A banda em $1050 \mathrm{~cm}^{-1}$, observada no espectro do termorrígido e no compósito de matriz RFF (Figura 26) pode estar associada à deformação axial da ligação C-O proveniente de grupos hidroximetila.

A banda em $1015 \mathrm{~cm}^{-1}$ refere-se à vibração de ligação C-O de grupos hidroximetila $\left(-\mathrm{CH}_{2}-\mathrm{OH}\right)$ predominantes em resinas do tipo resol (RFF) (Figura 26). Já no termorrígido está 
banda não foi identificada, pois são estes grupos que reagem entre si formando uma rede de ligações cruzadas a partir de pontes metileno, $1475 \mathrm{~cm}^{-1}$. A banda em $755 \mathrm{~cm}^{-1}$ indica crescimento da cadeia polimérica unidas por ligações nas posições orto-orto.

Tabela 7 - Principais bandas de absorção observadas nos compósitos de matriz termorrígida reforçados com FMD e na resina fenólica do tipo resol baseado na literatura.

\begin{tabular}{|c|c|}
\hline \multicolumn{2}{|r|}{ Resina Fenólica tipo resol e Termorrígido* } \\
\hline $\mathrm{n}^{\circ}$ de onda $\left(\mathrm{cm}^{-1}\right)$ & Atribuição \\
\hline 3400 & Deformação axial simétrica de grupos $\mathrm{OH}$ alcoólicos e fenólicos \\
\hline 2950-2850 & Vibração de estiramento de $\mathrm{CH}_{2}$ de grupos metila e metileno \\
\hline $1610-1500$ & Deformação fora do plano de $C=C$ aromáticos \\
\hline 1475 & Deformação angular de ligação $\mathrm{C}$ - $\mathrm{H}$ de grupos metileno \\
\hline 1235 & Deformação axial da ligação $C-O-C$ de éter \\
\hline 1050 & $\begin{array}{c}\text { Vibração de estiramento assimétrico } \mathrm{C}-\mathrm{O}-\mathrm{C} \text { de éter alifático (ponte } \\
\text { éter-metileno) }\end{array}$ \\
\hline 1016-1010 & Estiramento da ligação-C-O do grupo hidroximetila \\
\hline 825 & $\begin{array}{c}\text { Deformação angular da ligação C-H fora do plano em anéis unidos } \\
\text { por ligaçôes orto-para }\end{array}$ \\
\hline 750 & $\begin{array}{c}\text { Deformação angular da ligação C-H fora do plano em anéis unidos } \\
\text { por ligações orto-orto. }\end{array}$ \\
\hline \multicolumn{2}{|r|}{ Compósitos com matriz de resina fenólica $* *$} \\
\hline $\mathrm{n}^{\circ}$ de onda $\left(\mathrm{cm}^{-1}\right)$ & Atribuição \\
\hline 3345-3290 & Deformação axial simétrica de grupos $\mathrm{OH}$ alcoólicos e fenólicos \\
\hline 2960-2850 & Vibração de estiramento de $\mathrm{CH}_{2}$ de grupos metila e metileno \\
\hline $1610-1510$ & Deformação fora do plano de $C=C$ aromáticos \\
\hline 1465 & Deformação angular de ligação $C$ - $H$ de grupos metileno \\
\hline 1365 & Estiramento $\mathrm{C}-\mathrm{H} \mathrm{em} \mathrm{CH}_{3}$ \\
\hline 1250-1227 & Deformação axial da ligação $\mathrm{C}-\mathrm{O}-\mathrm{C}$ de éter \\
\hline 1050 & Estiramento de ligação $-\mathrm{C}-\mathrm{O}$ \\
\hline 822 & $\begin{array}{c}\text { Deformação angular da ligação C-H fora do plano em anéis unidos } \\
\text { por ligaçôes orto-para }\end{array}$ \\
\hline 755 & $\begin{array}{c}\text { Deformação angular da ligação C-H fora do plano em anéis unidos } \\
\text { por ligaçôes orto-orto. }\end{array}$ \\
\hline
\end{tabular}

\subsubsection{Ressonância magnética nuclear da resina RFF}

A Figura 28 e a Tabela 8 são referentes ao espectro de $\mathrm{RMN}^{13} \mathrm{C}$ da resina fenólica resol (fenol-formaldeído), com sinais semelhantes aos encontrados na literatura (WERSTLER, 1985; RAMIRES, 2010; YI et al., 2018; YU et al., 2018). O sinal residual do solvente foi observado em 38,9-40,1 ppm. O espectro de $\mathrm{RMN}-{ }^{13} \mathrm{C}$ mostra sinais característicos de pontes metilênicas em 34,9 e 40,3 ppm. 
Figura 28 - Espectro de $\mathrm{RMN}-{ }^{13} \mathrm{C}$ da resina fenol-formaldeído (solvente: DMSO-d6, 20000 varreduras).

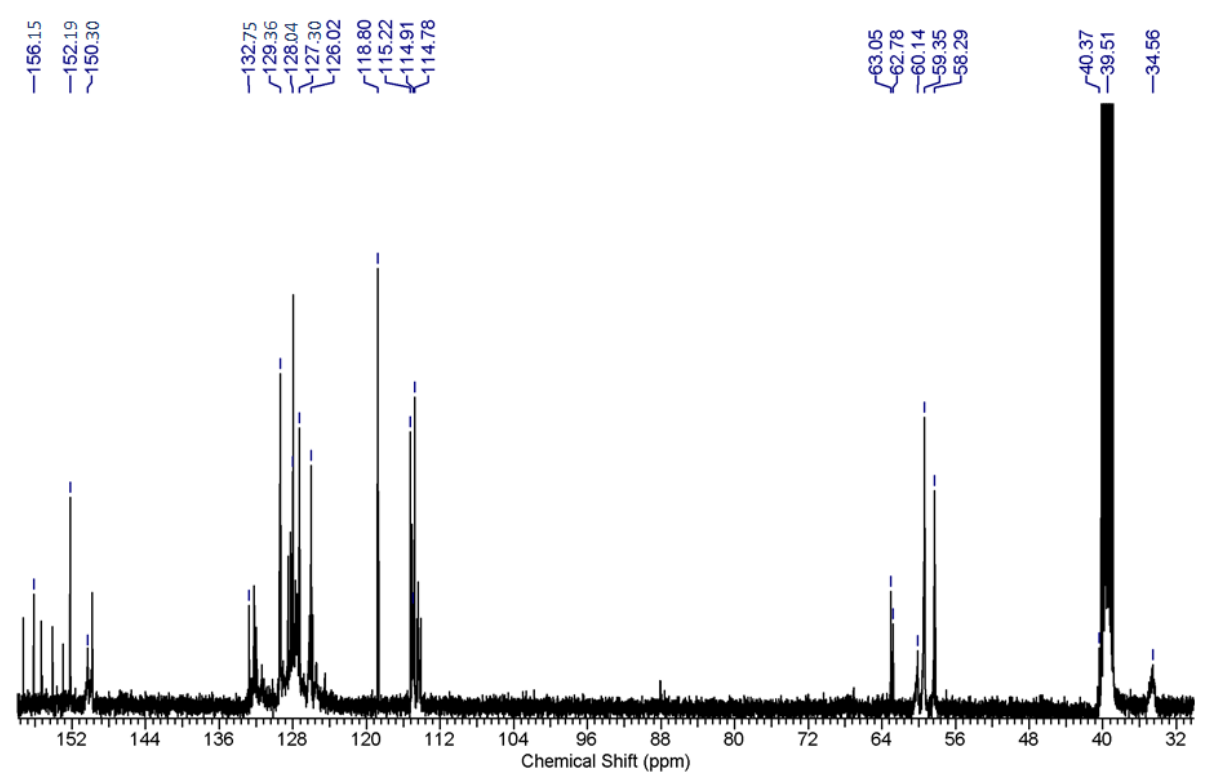

Tabela 8 - Picos presentes no espectro de RMN ${ }^{13} \mathrm{C}$ de RFF.

\begin{tabular}{|c|c|}
\hline \multicolumn{2}{|r|}{ Picos presentes nos espectros de $\mathrm{RMN}{ }^{13} \mathrm{C}$ da $\mathrm{RFF}$} \\
\hline $\begin{array}{l}\text { Deslocamento } \\
\text { químico (ppm) }\end{array}$ & Possíveis atribuições \\
\hline 34,5 & $\mathrm{CH}_{2}$ de grupo metileno entre dois anéis aromáticos na posição orto-para \\
\hline 40,3 & $\mathrm{CH}_{2}$ de grupo metileno entre dois anéis aromáticos na posição para-para \\
\hline $58,2-62,7$ & Grupo $-\mathrm{CH}_{2} \mathrm{OH}$ na posição orto \\
\hline 63,0 & Grupo $-\mathrm{CH}_{2} \mathrm{OH}$ na posição para \\
\hline $114,7-115,2$ & Carbono $\mathrm{C}_{1}$ de anel aromático \\
\hline 118,8 & Carbono orto não substituído \\
\hline $126,5-127,3$ & Carbono orto substituído \\
\hline 128,0 & Carbono na posição meta do anel fenólico \\
\hline 129,3 & Carbono orto substituído \\
\hline 132,7 & Carbono orto do anel fenólico \\
\hline 150,3 & Carbono orto do anel fenólico \\
\hline 152,2 & Carbono na posição orto do anel fenólico substituído \\
\hline 156,1 & Carbono na posição para do anel fenólico substituído \\
\hline
\end{tabular}

(REFERÊNCIAS: WERSTLER, 1985; RAMIRES, 2010; YI et al., 2018; YU et al., 2018).

Entre 58 e 63 ppm podem ser observados os sinais referem-se ao carbono metilol $\left(-\mathrm{CH}_{2} \mathrm{OH}\right)$ em anel substituído na posição orto ou para em relação ao grupo $\mathrm{OH}$ do anel aromático (SAUNDERS, 1998; RAMIRES, 2010; EL MANSOURI; YUAN; HUANG, 2011). O ânion fenolato reage com metileno glicol (solução aquosa de formaldeído) para formar ortohidroximetilfenóis e para-hidroximetilfenóis (Figura 4) (WERSTLER, 1985).

Com isso, nota-se que a hidroximetilação, inserção dos grupos hidroximetila ou metilol, 
ocorreu nas posições orto e para, pois estas posições são ativadas para ataque eletrofílico devido à “deslocalização" de elétrons (Figura 4) (SAUNDERS, 1998; PILATO, 2010). Os picos 114156 ppm são referentes aos carbonos aromáticos.

\subsubsection{Determinação da massa molar média por cromatografia de exclusão por tamanho da resina $\mathrm{RFF}$}

A Tabela 9 apresenta as massas molares médias e a polidispersividade da RFF calculada a partir do cromatograma obtido (dado não mostrado). Após a adição de duas gotas de $\mathrm{HCl}$ na solução resina + THF, a RFF apresentou uma maior solubilidade. Devido a mesma ser preparada em meio alcalino, mesmo após diminuir o $\mathrm{pH}$ até 7 , alguns anéis podem permanecer como fenolatos (sais de fenóis), os quais são insolúveis em solventes orgânicos (THF, no caso).

A resina (pré-polímero, RFF) obtida possui frações com valores de $\bar{M} w$ entre aproximadamente 1000 e $570 \mathrm{~g} \mathrm{~mol}^{-1}$ (Tabela 9). As frações individualmente apresentaram baixos valores de polidispersividade. As frações 1 e 2 são relacionadas às frações macromoleculares e pico 3 pode ser atribuído a dímeros e/ou a fenóis hidroximetilados $\left(\mathrm{C}_{6} \mathrm{H}_{4} \mathrm{OHCH} \mathrm{H}_{2} \mathrm{OH}\right)$.

Tabela 9 - Massa molar ponderal média $(\bar{M} \mathrm{w})$, massa molar numérica média $(\bar{M} \mathrm{n})$ e polidispersividade $(\bar{M} \mathrm{w} / \bar{M} \mathrm{n})$ da resina fenólica.

\begin{tabular}{cccc}
\hline Picos & $\overline{\mathbf{M}} w\left(\mathrm{~g} \mathrm{~mol}^{-\mathbf{1}}\right)$ & $\overline{\mathbf{M}} \boldsymbol{n}\left(\mathrm{g} \mathrm{mol}^{-\mathbf{1}}\right)$ & $\overline{\mathbf{M}} w / \overline{\mathbf{M}} \boldsymbol{n}$ \\
\hline $\mathbf{1}$ & 1008 & 932 & 1,1 \\
\hline $\mathbf{2}$ & 566 & 567 & 1,0 \\
\hline $\mathbf{3}$ & 420 & 416 & 1,0 \\
\hline Média & 634 & 425 & 1,5 \\
\hline
\end{tabular}

$\mathrm{Na}$ etapa de entrecruzamento, que ocorre durante a moldagem, as frações macromoleculares, dímeros, e fenóis hidroximetilados reagem, sendo então incorporados à estrutura química do termorrígido a partir da formação das ligações cruzadas. Após a formação destas, o material se torna infusível (KAW, 2006).

\subsubsection{Análise termogravimétrica da RFF}

A Figura 29 apresenta a curva termogravimétrica e a sua respectiva curva dTG da resina RFF. O primeiro evento, em aproximadamente $160{ }^{\circ} \mathrm{C}$ (curva dTG), pode ser atribuída a evaporação de voláteis liberados durante reações de entrecruzamento, e que podem ocorrer 
durante a varredura de temperatura.

Figura 29 - Curvas TG e dTG da resina fenol-formaldeído (RFF) em atmosfera de ar sintético com razão de aquecimento de $10{ }^{\circ} \mathrm{C} \mathrm{min}^{-1}$ e fluxo de $50 \mathrm{~mL} \mathrm{~min}^{-1}$.

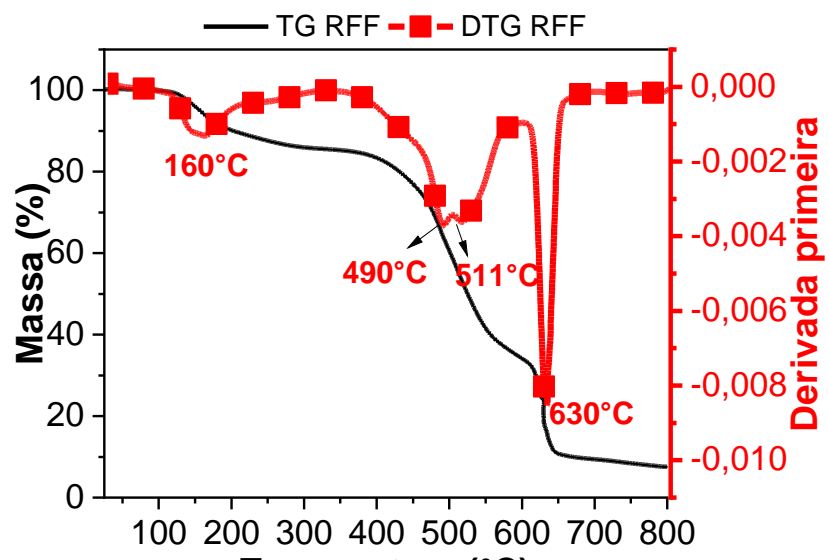

Temperatura $\left({ }^{\circ} \mathrm{C}\right)$

No segundo evento da curva dTG da RFF (Figura 29) observa-se a ocorrência de duas decomposições sucessivas com $\mathrm{T}_{\mathrm{dMÁx}}$ em 490 e $511^{\circ} \mathrm{C}$, que podem estar relacionadas à quebra de ligações de pontes metilenos formadas durante a polimerização da resina e o início da decomposição de anéis aromáticos (KHAN; ASHRAF, 2004). O evento em aproximadamente $630{ }^{\circ} \mathrm{C}\left(\mathrm{T}_{\mathrm{dMÁx}}\right)$ é associado à decomposição de anéis aromáticos do fenol (WANG et al., 2009; LEE; CHANG; TSENG, 2012).

\subsubsection{Análise termogravimétrica de TRFF e dos compósitos}

A Figura 30 apresenta as curvas termogravimétricas e as respectivas curvas dTG do TRFF e apenas do compósito $\mathrm{C}_{\mathrm{RFF}} 17 \% \mathrm{FMD}$, sendo que os demais compósitos apresentaram comportamento similar. O primeiro evento, que apresentou reduzida perda de massa está relacionado à vaporização de umidade residual. $\mathrm{O}$ termorrígido e os compósitos apresentaram uma $\mathrm{T}_{\text {onset }}$ de aproximadamente 365 e $270{ }^{\circ} \mathrm{C}$, respectivamente. A redução na $\mathrm{T}_{\text {onset }}$ do compósito está associada à inserção de FMD que possui $\mathrm{T}_{\text {onset }}$ inferior ao TRFF, $270{ }^{\circ} \mathrm{C}($ Figura 24). 
Figura 30 - Curvas TG e dTG do TRFF e do compósito $\mathrm{C}_{\mathrm{RFF}} 17 \% \mathrm{FMD}$ em atmosfera de ar sintético com razão de aquecimento de $10{ }^{\circ} \mathrm{C} \mathrm{min}^{-1}$ e fluxo de $50 \mathrm{~mL} \mathrm{~min}$.

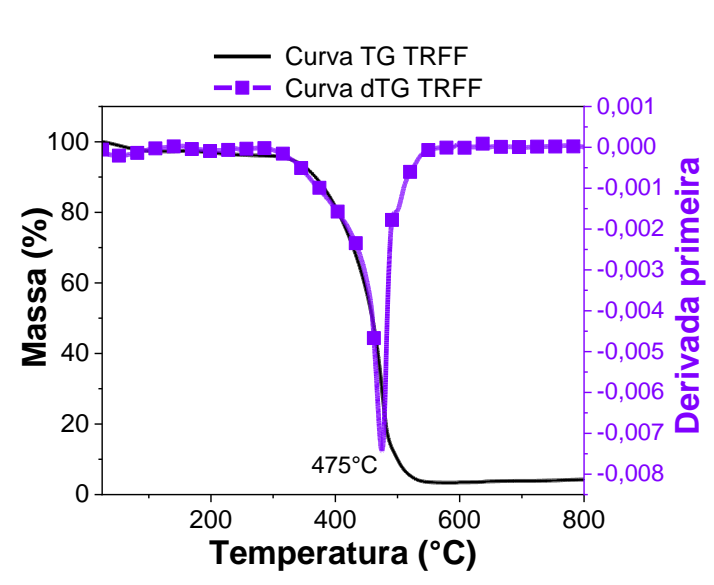

(a)

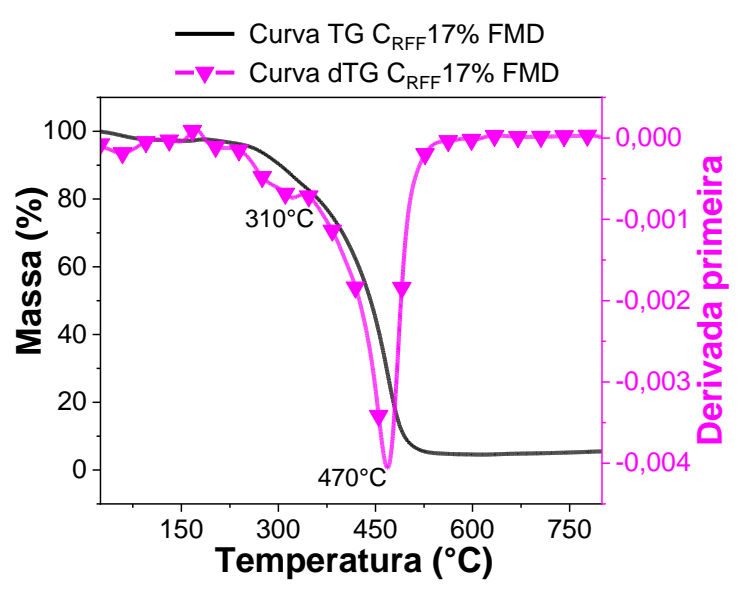

(b)

Para TRFF observa-se apenas um evento acima de $100{ }^{\circ} \mathrm{C}$ na curva de dTG, o qual está relacionado à fragmentação da rede fenólica em $475{ }^{\circ} \mathrm{C}$ (Figura 30- a). O compósito $\mathrm{C}_{\mathrm{RFF}} 17 \% \mathrm{FMD}$ apresentou um pico no segundo evento (curva $\mathrm{dTG}$ ) que apresentou $\mathrm{T}_{\mathrm{dMÁx}} \mathrm{em}$ $310{ }^{\circ} \mathrm{C}$. Este está relacionado a decomposição de celulose, componentes da FMD. Os picos de decomposição das hemiceluloses e da celulose apareceram em 295 e $310{ }^{\circ} \mathrm{C}$ na FMD, respectivamente (Figura 24). A decomposição térmica da celulose inicia após as hemiceluloses, em temperaturas superiores a $310{ }^{\circ} \mathrm{C}$.

O terceiro evento, observado na curva de dTG do compósito $\mathrm{C}_{\mathrm{RFF}} 17 \% \mathrm{FMD}$ pode estar relacionado à decomposição térmica da lignina e da matriz, pois na curva dTG do TRFF a $\mathrm{T}_{\mathrm{dMÁx}}$ foi de $475{ }^{\circ} \mathrm{C}$ e o pico da lignina presente na FMD apareceu em $470{ }^{\circ} \mathrm{C}$ (Figura 24).

\subsubsection{Resistência ao Impacto Izod do termorrígido fenol-formaldeído (TRFF) e dos compósitos reforçados com FMD}

O conhecimento sobre a resistência ao impacto de materiais poliméricos é imprescindível para se avaliar o material para determinada aplicação. Os valores de resistência ao impacto inferem na capacidade total de um material de absorver a energia do impacto aplicado. Esta energia absorvida no momento do impacto pelo material, a qual é a energia necessária para romper o corpo de prova, é medida pelo equipamento.

A Figura 31 apresenta os resultados de resistência ao impacto dos compósitos de matriz RFF reforçados com FMD com variações de massa de 13 a 19\%. Devido à baixa densidade desta fibra, a porcentagem máxima em massa que foi possível utilizar na preparação do compósito foi de $19 \%$. Houve um aumento no valor da energia de impacto no compósito reforçado com $17 \%$ (em massa) de FMD, em comparação ao termorrígido fenólico (TRFF). No 
entanto, quando a porcentagem aumentou para $19 \%$, a resistência ao impacto foi menor que a do TRFF. Este resultado possivelmente reflete o fato de nesta porcentagem ter sido iniciado um processo de emaranhamento das fibras, atuando como um defeito do material, e não como reforço.

Para os compósitos CRFF13\%FMD e CRFF16\%FMD, considerando os respectivos erros, as resistências ao impacto observadas são indistinguíveis daquela do TRFF não reforçado, sendo que a presença de fibras levou a materiais mais heterogêneos que o termorrígido, e com maiores valores de erros (Figura 31- a).

Figura 31 - Resultados de resistência ao impacto Izod dos do termorrígido e dos compósitos fenólicos (RFF) reforçados com FMD (a) e fotografia do corpo-de-prova do $\mathrm{C}_{\mathrm{RFF}} 17 \% \mathrm{FMD}$ após ensaio de impacto (b).

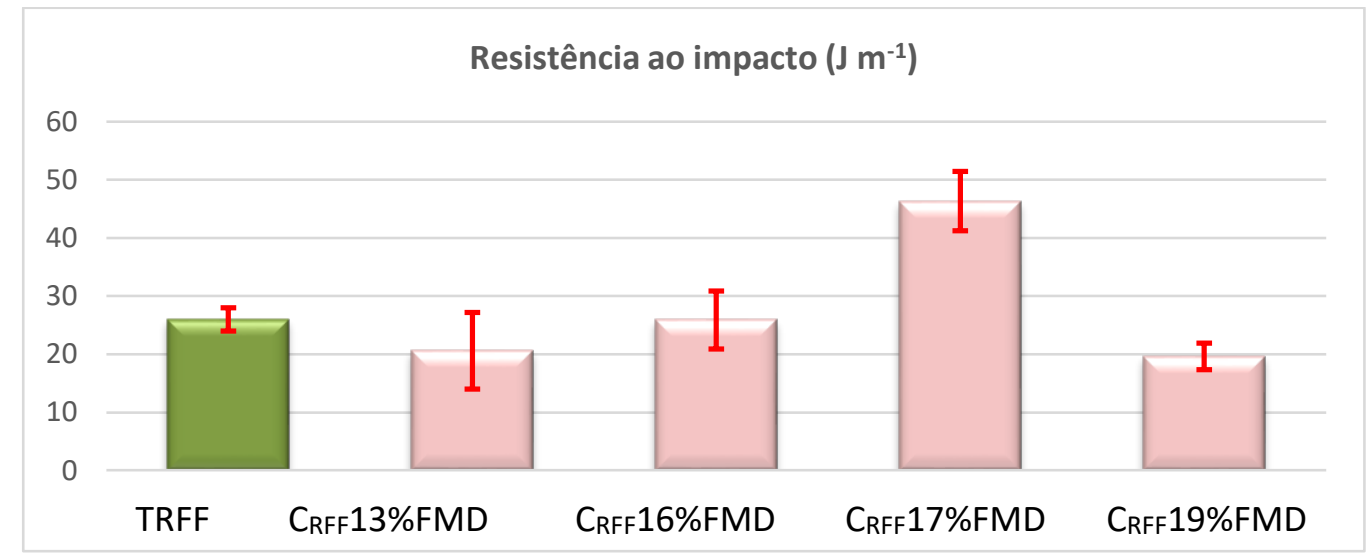

(a)

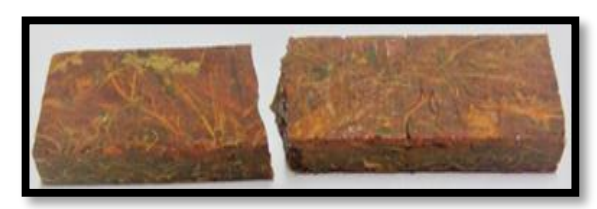

(b)

O melhor resultado de resistência ao impacto foi obtido para o compósito $\mathrm{C}_{\mathrm{RFF}} 17 \% \mathrm{FMD}$, Figura 31- a. A função da fibra lignocelulósica utilizada como reforço no compósito é atuar como portador de carga e estresse, transferido da matriz para as fibras.

A fibra do mesocarpo do dendê é constituída por um emaranhado de fibras bastante heterogêneas que podem ter gerado pontos de concentração de força nos compósitos (THEN et al., 2013), o que interfere na distribuição do impacto (MEGIATTO JÚNIOR, 2006). O aumento no valor de resistência ao impacto do compósito $\mathrm{C}_{\mathrm{RFF}} 17 \% \mathrm{FMD}$, comparativamente ao TRFF, foi muito inferior aos obtidos por Razera et al. (2014) usando como reforço de matriz fenol- 
formaldeído fibras de juta (índice de cristalinidade de $50 \%$ e $69,7 \%$ de teor de celulose) com $40 \mathrm{~mm}$ de comprimento ( $15 \%$ em massa), $72,6 \mathrm{~J} \mathrm{~m}^{-1}$.

Os baixos valores de resistência ao impacto obtidos (Figura 31) devem ser decorrentes do baixo teor de celulose da fibra (Tabela 2), da presença de sílica preenchendo poros (Figura 22), e do fato de se ter usado fibras longas, de diferentes comprimentos, o que dificulta a impregnação da fibra pela resina, assim como a distribuição das fibras na matriz.

Em nenhum dos compósitos reforçados com FMD notou-se a ocorrência de fiber bridging, em que a fibra utilizada como reforço estrutural nos compósitos não sofre quebra durante o ensaio de impacto Izod, formando uma ponte entre a fibra e matriz fraturada (DE OLIVEIRA et al., 2017).

\subsubsection{Microscopia Eletrônica de Varredura (MEV) do termorrígido fenol-formaldeído (TRFF) e dos compósitos reforçados com FMD}

A Figura 32 apresenta as micrografias das superfícis fraturadas (pós-impacto) do termorrígido (TRFF) e dos compósitos de matriz fenólica do tipo resol (RFF) reforçados com FMD. Na Figura 32-a observa-se que o termorrígido (TRFF) e os compósitos apresentaram microvazios (microvoids) (setas azuis). A ocorrência destes está associada à liberação de moléculas de água na reação de entrecruzamento, as quais são vaporizadas, formando os microvazios. Também se notou a presença de regiões de propagação de trincas com regiões espelhadas (setas roxas), o que caracteriza um material do tipo frágil (RAMIRES, 2010), como é o termorrígido.

Na Figura 32, é possível observar algumas regiões em que houve descolamento entre a fibra e a matriz (setas azuis), presença de trincas na matriz (setas verdes), e algumas fibras sofreram ruptura junto com a matriz durante o ensaio de Impacto Izod, indicando adesão entre ambos (DE OLIVEIRA et al., 2017) (setas vermelhas). Porém, não houve preenchimento completo das fibras de dendê pela resina fenólica (setas vermelhas), pois as fibras permaneceram com os lúmens vazios na sua parte interna (Figura 32).

De acordo com Then et al. (2013) e Jawaid et al. (2011) a presença de rupturas e arrancamento das fibras (setas vermelhas) e de descolamento da fibra na matriz (setas azuis), como indicado na Figura 32 também podem estar associados à baixa adesão interfacial entre a fibra hidrofílica e a matriz hidrofóbica, em casos em que as matrizes têm esta característica. 
Figura 32 - Micrografias das superfícies fraturadas, pós-impacto, do termorrígido TRFF (a), e dos compósitos reforçados com FMD, $\mathrm{C}_{\mathrm{RFF}} 19 \% \mathrm{FMD}$ (b), $\mathrm{C}_{\mathrm{RFF}} 17 \% \mathrm{FMD}$ (c), $\mathrm{C}_{\mathrm{RFF}} 16 \% \mathrm{FMD}$ (d) e $\mathrm{C}_{\mathrm{RFF}} 13 \% \mathrm{FMD}(\mathrm{e})$

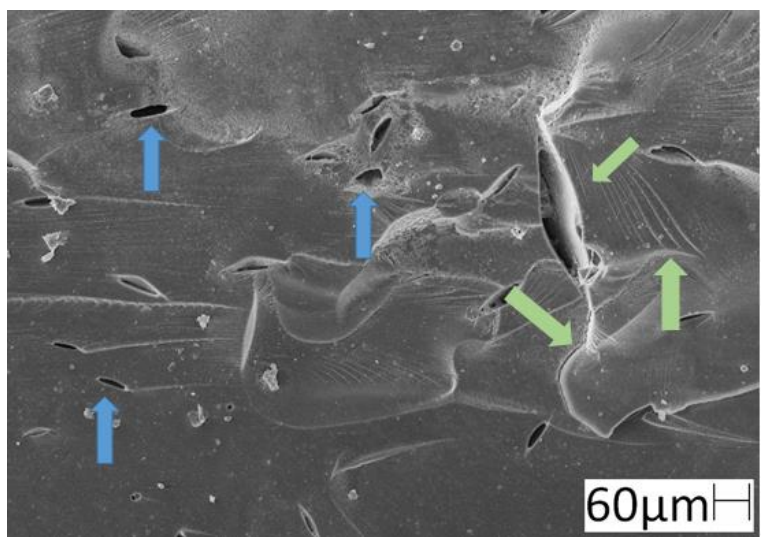

(a)
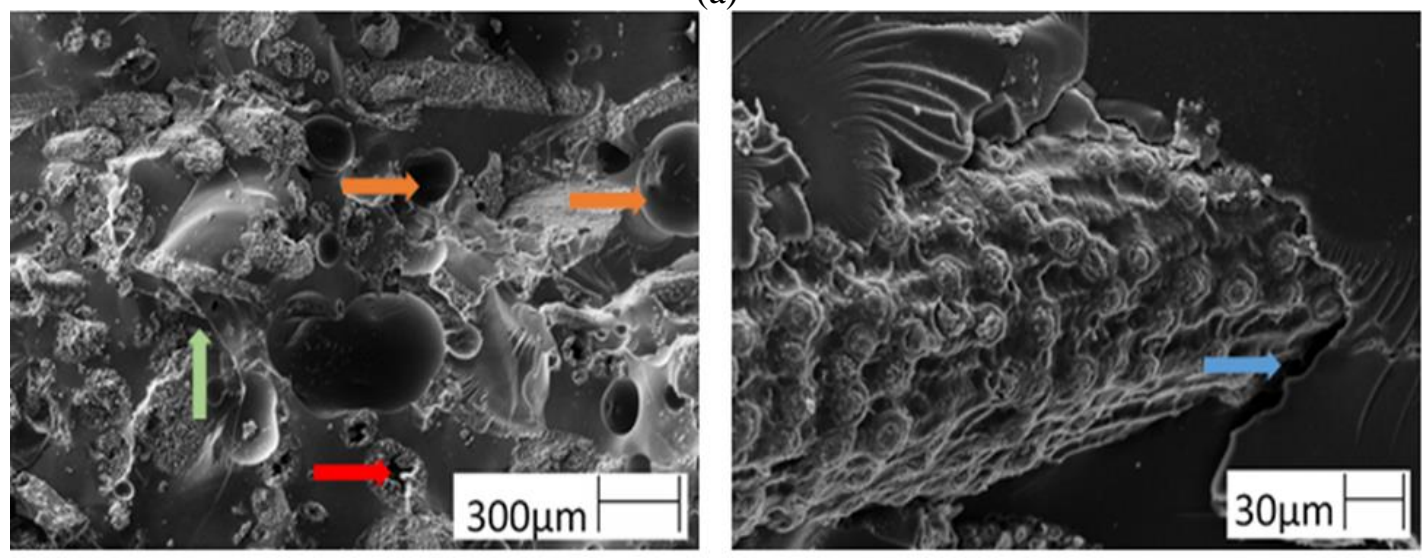

(b)
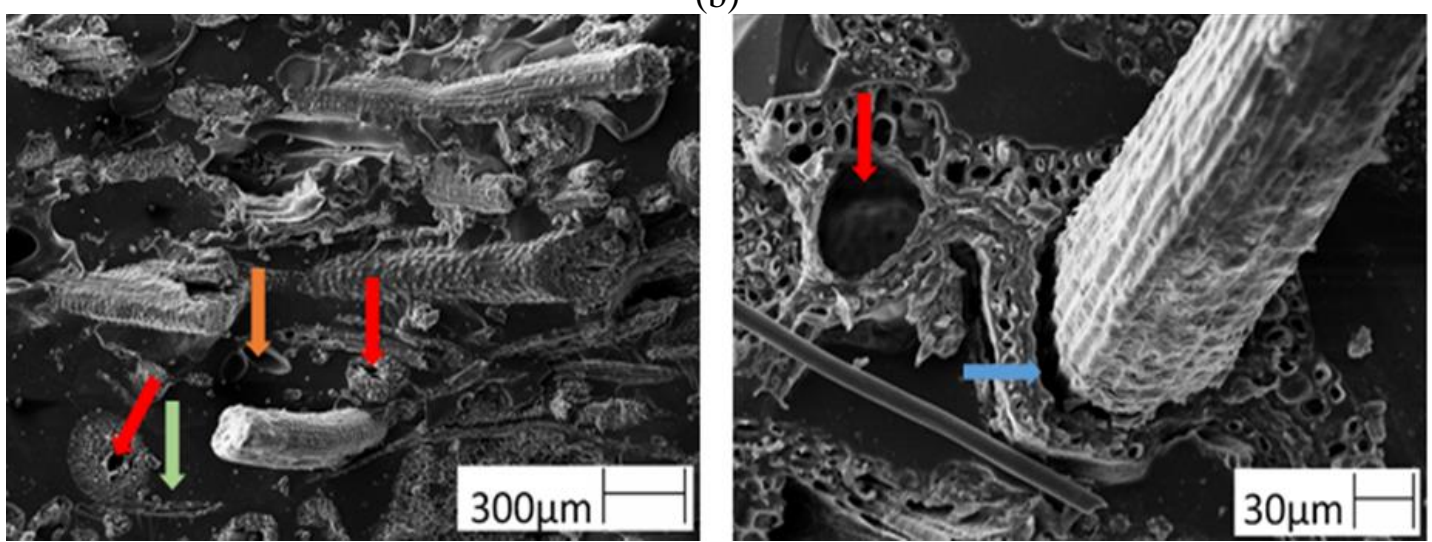

(c)
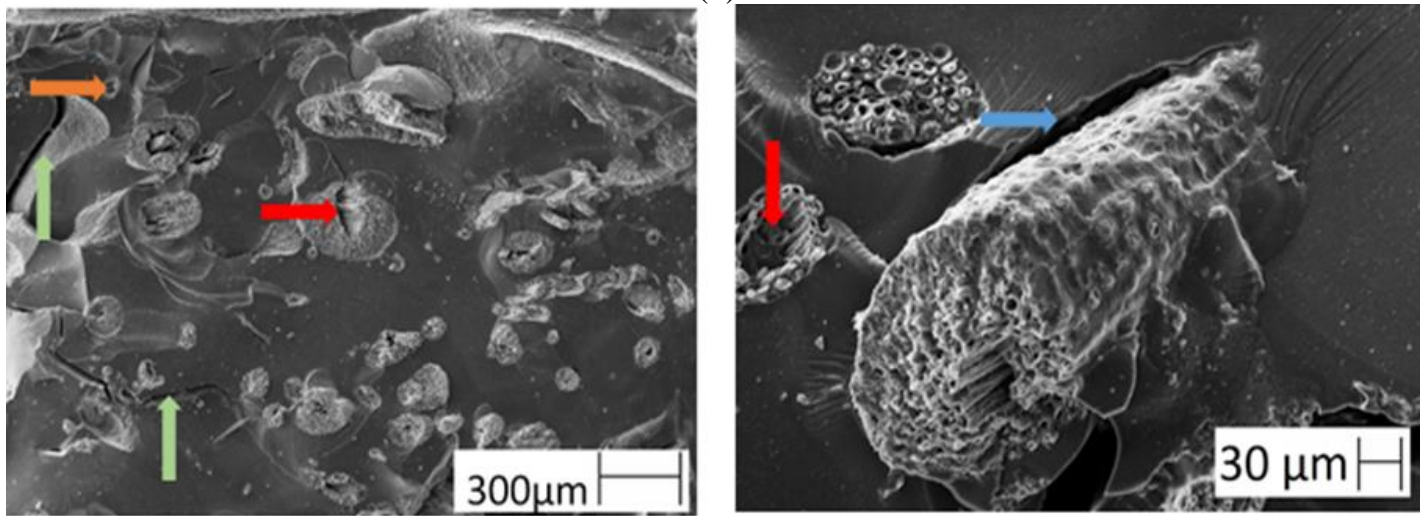

(d) 

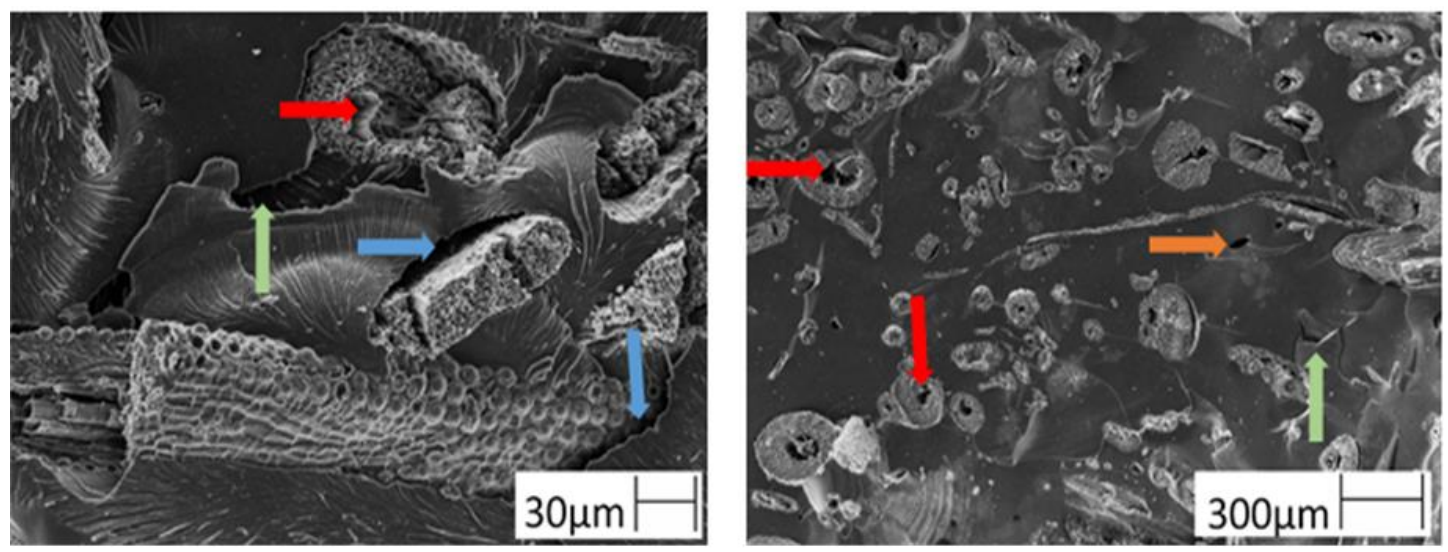

(e)

No presente estudo, as matrizes são constituídas por anéis aromáticos de baixa polaridade, os quais têm afinidade pelos anéis aromáticos da lignina presente na FMD, além de as matrizes serem ricas em grupos polares, como hidroxilas, os quais têm afinidade com os grupos hidroxilas presentes na lignina, hemiceluloses e celulose (RAZERA et al., 2014; DE OLIVEIRA et al., 2017). A presença de sílica nos poros pode ter sido um fator que interferiu na molhabilidade da fibra na resina, conforme mencionado, e contribuído para a baixa adesão fibra-matriz observada.

\subsubsection{Resistência à flexão do termorrígido fenol-formaldeído (TRFF) e dos compósitos reforçados com FMD}

A resistência à flexão corresponde à máxima tensão aplicada na superfície de uma barra exposta a inflexão. Esta tensão submetida pela carga de flexão é resultante da junção de forças de compressão e tração das fibras no compósito. Através do ensaio de flexão é possível obter informações sobre o módulo de flexão, o qual indica o quão rígido é um material, a partir do coeficiente angular da porção linear inicial da curva de tensão-deformação. A Figura 33- a e b apresentam os resultados de resistência à flexão e módulo de flexão obtidos nos compósitos de matriz termorrígida reforçados com FMD em diferentes proporções mássicas. Devido à fragilidade do compósito $\mathrm{C}_{\mathrm{RFF}} 13 \% \mathrm{FMD}$ não foi possível a obtenção de corpos-de-prova adequados para realização do ensaio.

A Figura 33-a mostra que houve uma redução da resistência à flexão nos compósitos quando comparados com TRFF, sendo o melhor resultado de resistência à flexão a do compósito $\mathrm{C}_{\mathrm{RFF}}$ 19\%FMD. Nordin et al. (2017) obteve valor de resistência à flexão inferior a este ao utilizar 50\% (em massa) de fibra do meocarpo do dendê em matriz de polipropileno. 
Figura 33 - Propriedades de flexão dos compósitos de RFF reforçados com FMD.

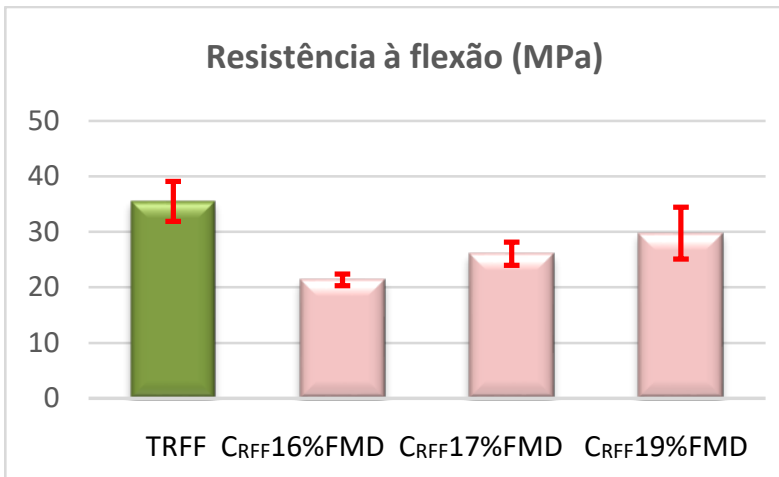

(a)

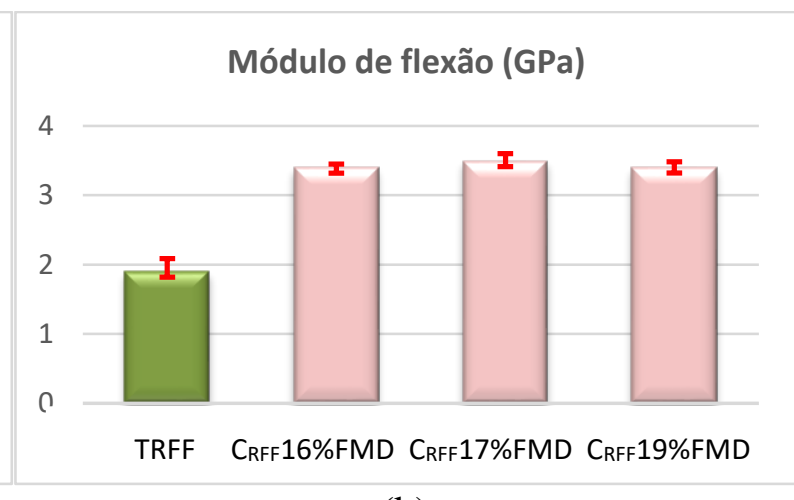

(b)

Yussof et al. (2010) também observou uma redução da resistência à flexão de compósitos de matriz epóxi reforçados entre 5 e $20 \%$ (em volume) de fibra de dendê comparados à amostra sem reforço.

A propriedade de flexão é influenciada pelas propriedades da superfície do compósito, onde predomina a matriz polimérica, pois os compósitos possuem mais polímero do que fibras em sua composição (DE OLIVEIRA et al., 2017). Uma distribuição não uniforme do volume de fibra na matriz, a fraca adesão entre ambas e a presença de vazios (LIU et al., 2006; BLEDZKI et al., 2015; FIORE et al., 2016) podem ter ocasionado a diminuição nos valores de resistência à flexão no presente estudo, Figura 33- a. Yussof et al. (2010) observou a mesma tendência em compósitos de matriz epóxi reforçados com FMD.

Como o módulo de flexão é medido a pequenas deformações, a interferência da adesão interfacial não é tão significativa como na propriedade de flexão (RENNER et al., 2009). Observou-se que houve um aumento no módulo de flexão nos compósitos comparado ao TRFF, indicando que a inserção de fibras aumentou a rigidez do material. No entanto, não houve variação significativa desta propriedade com o aumento da porcentagem em massa de fibra, Figura 33-b.

\subsubsection{Análise dinâmico mecânica (DMA)}

A análise dinâmico-mecânica permite avaliar a densidade de reticulação, armazenamento/perda de energia, relaxações primárias, entre outros. Fatores como propriedades dos componentes, morfologia e interação fibra-matriz são determinantes das propriedades dinâmico-mecânica do material (RAMIRES et al., 2010; COSTA et al., 2016).

A Figura 34 apresenta as curvas de módulo de armazenamento (E') (a) e Tan $\delta$ (Tan delta) (b) versus temperatura do termorrígido fenol-formaldeído (TRFF) e dos compósitos 
reforçados com FMD. A inserção de fibras ocasionou um aumento no E' comparativamente ao termorrígido fenólico, e a proporção em massa de FMD de 17 \% levou ao compósito com maior valor de E', (Figura 34- a), o que corrobora com a mesma tendência observada no ensaio de impacto Izod (Figura 31- a).

Figura 34 - Curvas DMA- Módulo de armazenamento (E') (a) e Tan $\delta$ versus temperatura (b) do termorrígido fenólico (TRFF) e dos compósitos reforçados com FMD (13 a 19\% em massa de fibra).

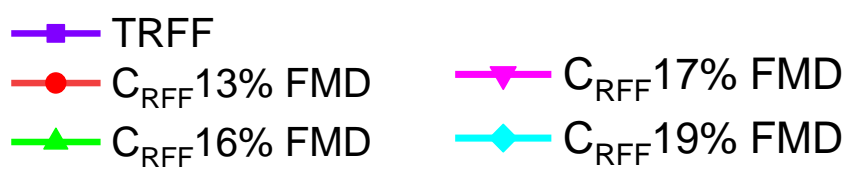

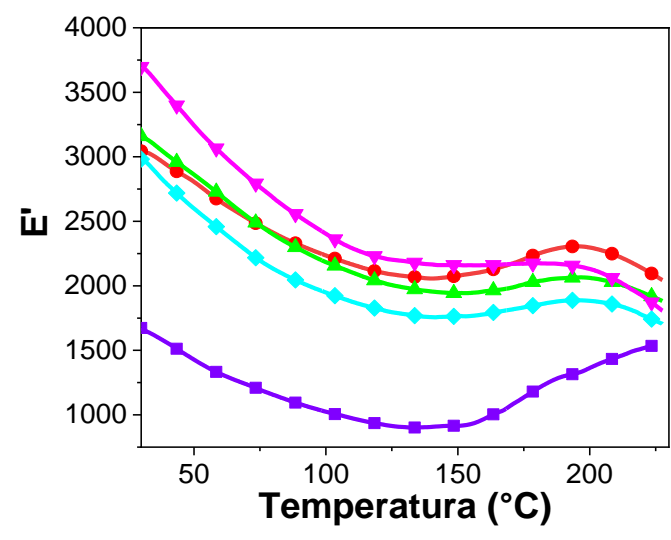

(a)

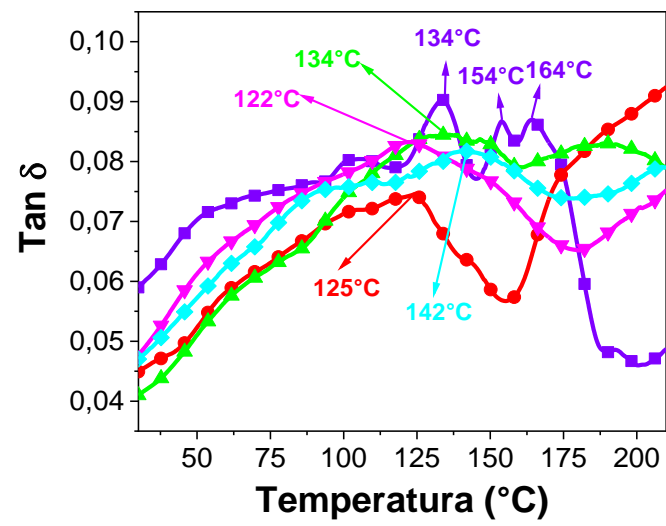

(b)

O módulo de armazenamento está relacionado com a energia armazenada pelo material quando a carga é aplicada e, quanto maior for o módulo de armazenamento mais rígido é o material. Esta rigidez está relacionada com a redução da movimentação dos segmentos das cadeias devido a inserção das fibras. Quanto menor for essa mobilidade, maior é a rigidez do material (RAMIRES et al., 2010; SABA et al., 2017).

A partir de aproximadamente $150{ }^{\circ} \mathrm{C}$ houve um aumento do módulo de armazenamento, o que está relacionado à cura residual da matriz durante a varredura (Figura 34-a). Isto torna o polímero mais rígido devido à ocorrência do aumento do entrecruzamento que reduz a mobilidade dos segmentos das cadeias e, consequentemente, aumenta o módulo de armazenamento.

Em relação às curvas tan $\delta$ versus temperatura (Figura 34-b), seu valor máximo pode ser associado à temperatura de transição vítrea ( $\left.\mathrm{T}_{\mathrm{g}}\right)$ (DE OLIVEIRA SANTOS et al., 2014). Observou-se que as curvas apresentaram características bem distintas entre si, com picos alargados, devido à heterogeneidade dos compósitos. Fatores como tipo e distribuição de fibra 
na matriz, assim como vazios e interação fibra-matriz, interferem diretamente nas curvas $\tan \delta$. Nos compósitos, como a quantidade de termorrígido presente é menor que no material não reforçado, não foram observados picos decorrentes das curas residuais ocorridas durante a varredura.

Em matrizes que possuem uma estrutura entrecruzada, as movimentações de segmentos podem ocorrer entre os pontos de entrecruzamento (PAIVA; FROLLINI, 2006). A Tg do TRFF foi de aproximadamente $135^{\circ} \mathrm{C}$ e os picos observados a $154{ }^{\circ} \mathrm{C}$ e $164{ }^{\circ} \mathrm{C}$ podem ser atribuídos à cura residual que ocorre durante a varredura, a qual leva a segmentos mais curtos entre os pontos de entrecruzamento e, portanto, com maior $\mathrm{T}_{\mathrm{g}}$. Os compósitos apresentaram valores de $\mathrm{T}_{\mathrm{g}}$ variando entre 120 e $142{ }^{\circ} \mathrm{C}$ (Figura 34- b).

A inserção de fibras na matriz pode reduzir/dificultar a movimentação destes segmentos devido às interações intermoleculares, por exemplo, do tipo ligação hidrogênio entre os grupos hidroxila alifáticos e fenólicos (lignina) presentes nas superfícies das fibras, e os grupos hidroxilas fenólicos presentes nas matrizes (Figura 35) (JOSEPH et al., 2002; DE OLIVEIRA et al., 2017), levando à um deslocamento da $\mathrm{T}_{\mathrm{g}}$ para temperaturas superiores à do termorrígido. $\mathrm{O}$ valor de $\mathrm{T}_{\mathrm{g}}$ de compósitos inferior à do termorrígido TRFF podem ter sido ocasionados pela presença de vazios e defeitos na parte interna da matriz ou nas regiões de interface, o que facilitou a movimentação dos segmentos e reduziu a $T_{g}$. A largura do pico $\tan \delta$ pode ser relacionada à homogeneidade do material, sendo observado um alargamento do pico para porcentagens de fibras superiores a $13 \%$, indicando aumento na heterogeneidade do compósito.

Figura 35 - Representação da interação entre componentes da fibra lignocelulósica e a matriz fenólica RFF.

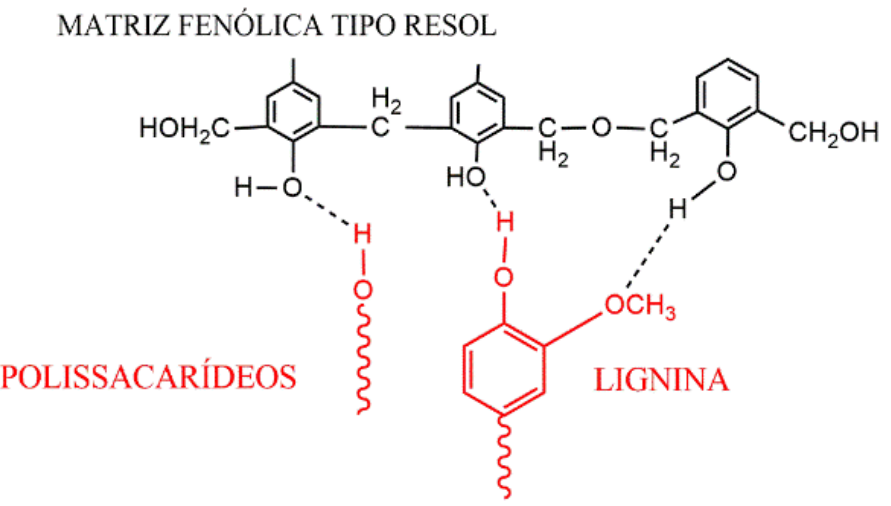

Fonte: Ramires et al. (2010).

\subsection{Conclusões parciais}

O uso das fibras do mesocarpo do dendê como reforço em matriz termorrígida fenol- 
formaldeído do tipo resol levou à obtenção de resultados, principalmente referentes à resistência ao impacto, aquém do esperado. A fibra atuou como reforço somente no compósito reforçado com $17 \%$ em massa de FMD, sendo que se esperava que o elevado teor de lignina, a qual é rica em grupos hidroxilas aromáticos e alifáticos, e anéis aromáticos, levasse a uma maior interação com a matriz polimérica, que apresenta em sua estrutura grupos similares àqueles da lignina. A presença de sílica nos poros das fibras pode ter prejudicado a impregnação e a adesão fibramatriz.

A partir dos resultados de DMA foi possível comprovar a heterogeneidade dos compósitos obtidos, pelo alargamento dos picos das curvas tan $\delta$, ocasionado possivelmente pela própria heterogeneidade da fibra (em termos de comprimento).

A partir dos resultados reportados neste capítulo, foram buscadas alternativas para a valorização das fibras do mesocarpo do dendê na área de compósitos. Neste contexto, as fibras foram usadas na preparação de compósitos híbridos com manta de fibra de sisal (MFS), a fim de avaliar se FMD atuaria como um reforço adicional ou como cargas em compósitos de matriz termorrígida fenol-formaleído, fenol-glutaraldeído e lignina-fenol-glutaraldeído, os quais serão apresentados nos capítulos seguintes. 


\section{Capítulo 2}

\section{Sintese de resina fenol-formaldeído: obtenção de compósitos de matríz termorrígída reforçadas com mantas de fíbras de sisal e de rayon, manta de fíbra de sísal e fíbra do mesocarpo do dendê moída}

\subsection{Introdução}

Como citado no Capítulo 1, as fibras lignocelulósicas são potenciais substituintes de fibras sintéticas como agente de reforço em compósitos. Além da fibra do mesocarpo do dendê, a fibra de sisal se destaca pela sua abundância no Brasil, excelentes propriedades mecânicas e possibilidades de uso como agente de refoço em compósitos de matriz termorrígida fenolformaldeído, lignossulfonato-formaldeído e lignina-formaldeído (RAZERA; FROLLINI, 2004; RAMIRES, 2010; DE OLIVEIRA, 2010).

Outro material que tem destaque como reforço na área de compósitos é a fibra celulósica regenerada denominada rayon (SHAMSUDDIN; LEE; BISMARCK, 2016; SURESH; THIRUCHITRAMBALAM; SHANMUGAM, 2016). Sua composição consiste basicamente de celulose, o que as confere elevada resistência, tenacidade, estabilidade dimensional e termoestabilidade (SHAMSUDDIN; LEE; BISMARCK, 2016; BOY; NARAYANAN; KOTEK, 2018).

Além de poder utilizar a fibra de sisal e a fibra rayon na forma de fios curtos, também é possível encontrá-las na forma de manta, o que pode conferir uma maior resistência ao compósito devido à configuração da mesma ser formada por feixes de fibras perpendiculares entre si a $0^{\circ}$ e $90^{\circ}$.

Neste capítulo relata-se a preparação e propriedades de compósitos de matriz termorrígida fenol-formaldeído do tipo resol reforçados com manta de fibra de sisal (MFS) e manta de rayon (MFR). Adicionalmente, são reportadas a preparação e propriedades de compósitos híbridos contituídos por manta de fibra de sisal e FMD moída (FMD $\left.{ }_{\text {moída}}\right)$.

Os compósitos foram preparados por moldagem com compressão, no qual o ciclo de moldagem foi baseado em trabalhos anteriores desenvolvidos no grupo MacromoLignocell 
(RAZERA; FROLLINI, 2004; RAMIRES, 2010; OLIVEIRA, 2010).

\subsection{Experimental}

\subsubsection{Materiais}

A manta de sisal (MFS) (Figura 36- a) foi adquirida pela empresa Sisal Sul (Luz, São Paulo) e a manta de rayon (MFR) (Figura 36- b) foi cedida pela empresa CORDENKA GmbH \& Co. KG, Industrie Center Obernburg, Alemanha. Os demais materiais e reagentes utilizados já foram apresentados no item 1.2.1 do Capítulo 1.

Figura 36 - Manta de fibra de sisal (MFS) (a) e manta de fibra rayon (MFR) (b).

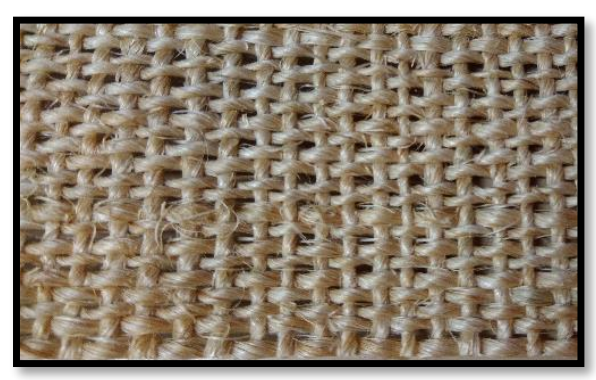

(a)

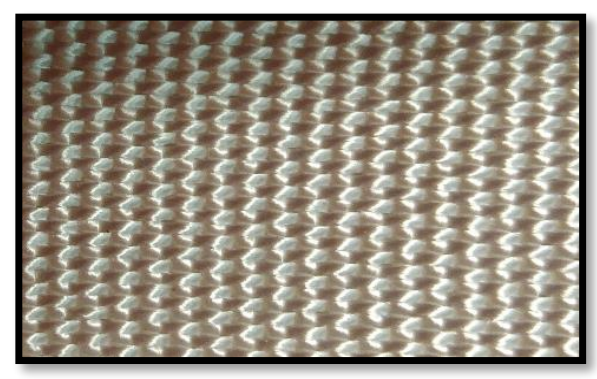

(b)

\subsubsection{Métodos}

\subsubsection{Caracterização das fibras da manta de sisal (MFS) e rayon (MFR)}

Previamente à realização da caracterização, as fibras da MFS foram cortadas e passaram pelo processo de extração com cicloexano/etanol para eliminação de extrativos e ceras, conforme descrito no item 1.2.2.1 do Capítulo 1. Tanto as fibras da MFS (sem extrativos) quando da MFR foram moídas em moinho de bolas criogênico e secas previamente à caracterização.

\subsection{Composição química}

A análise de composição química foi realizada de acordo com o que foi descrito no item

\subsubsection{1 do Capítulo 1.}

\subsection{Espectroscopia na região do infravermelho por transformada de Fourier} (FTIR)

Os espectros de FTIR foram obtidos de acordo com o que foi descrito no item 1.2.2.1.2 do Capítulo 1. 


\subsection{Microscopia eletrônica de varredura (MEV)}

A análise de microscopia eletrônica de varredura foi realizada de acordo com o que foi descrito no item 1.2.2.1.3 do Capítulo 1.

\subsection{Difração de raios $X$}

Os difratogramas e os índices de cristalinidade foram obtidos de acordo com o que foi descrito no item 1.2.2.1.6 do Capítulo 1.

\subsection{Análise termogravimétrica}

A análise termogravimétrica das fibras foi realizada de acordo com o que foi descrito no item 1.2.2.1.7 do Capítulo 1, mas em atmosfera de nitrogênio, visando restringir o uso de ar como atmosfera.

\subsubsection{Síntese e caracterização da resina RFF}

O pré-polímero (resina) RFF, sintetizado e caracterizado como descrito no Capítulo 1, foi utilizado para preparar os compósitos descritos neste capítulo.

\subsubsection{Preparação de compósitos de matriz RFF reforçado com fibra e mantas de fibra vegetal}

\subsection{Adição do agente acelerador de cura}

A adição do agente de cura foi realizada de acordo com o descrito no item 1.2.2.3.1 do

\section{Capítulo 1.}

\subsection{Incorporação do reforço}

Para os compósitos com RFF reforçados com MFS, foi realizado um estudo a fim de se avaliar a influência de diferentes métodos de impregnação nas propriedades do material final. A porcentagem indicada nos códigos dos compósitos contendo apenas MFS e MFR é referente à porcentagem em volume de manta. Nos compósitos híbridos as porcentagens de fibras rayon e $\mathrm{FMD}_{\text {moída }}$ são em massa. Ainda, nestes compósitos a porcentagem em volume de MFS foi de $42 \%$ em ambos compósitos. A \% de mantas indicada nos códigos dos compósitos de matriz RFF se refere à \% em volume da manta, e a \% de FMD moída indicada nas siglas dos compósitos híbridos é referente a massa. 
A Tabela 10 apresenta os diferentes modos de impregnação e preparação dos compósitos reforçados com MFS e MFR, e híbrido MFS/FMD moída.

Tabela 10 - Modo de preparo dos compósitos reforçados com MFS e MFR, e híbridos de MFS/rayon e MFS/FMD moída.

Compósitos de matriz RFF reforçados com MFS

\begin{tabular}{cc}
\hline Compósitos & Modo de preparo \\
\hline $\mathbf{C}_{\mathbf{R F F}} \mathbf{4 2 \%} \% \mathrm{MFS}$ & Imersão da MFS na resina \\
\hline $\mathbf{C}_{\mathbf{R F F}} \mathbf{4 2 \%}$ MFS & \\
&
\end{tabular}

* MFS im-ag $_{\text {: }}$ A MFS ficou imersa em água (ag) por 6h, com o objetivo de afastar os feixes de fibras e facilitar a impregnação da resina; e posteriormente submetida a secagem $(24 \mathrm{~h}$ a temperatura ambiente seguido de estufa, $105^{\circ} \mathrm{C}$ )

**70mL de etanol (et) foram adicionados para reduzir a viscosidade da RFF e facilitar a impregnação da manta

\begin{tabular}{cc}
\hline \multicolumn{2}{c}{ Compósitos de matriz RFF reforçados com MFR } \\
\hline Compósitos & Modo de preparo \\
\hline $\mathbf{C}_{\mathbf{R F F}} \mathbf{1 0 \%}$ MFR & Imersão da MFR na resina \\
\hline $\mathbf{C}_{\mathbf{R F F}} \mathbf{1 9 \%}$ MFR & $\begin{array}{c}\text { Imersão (intercalando as camadas de resina e } \\
\text { manta) }\end{array}$ \\
\hline Compósitos híbridos de matriz RFF reforçados com MFS/FMD
\end{tabular}

\section{Compósitos híbridos de matriz $R F F$ reforçados com $M F S / F M D_{\text {moída }}$ \\ Compósitos \\ Modo de preparo}

$\mathrm{C}_{\mathrm{RFF}} 38 \% \mathrm{MFS}_{\text {im-ag-et }}$ 9\% FMD moída

(Neste compósito a MFS foi realizada a imersão em água)

\section{$\mathrm{C}_{\mathrm{RFF}} 35 \% \mathrm{MFS}_{\text {im-ag-et }} 16 \% \mathrm{FMD}_{\text {moída }}$}

(Neste compósito a MFS foi realizada a imersão em água)
9\% FMD moída $_{\text {em massa }}$

Inicialmente foram adicionados à RFF $70 \mathrm{~mL}$ de etanol para redução da viscosidade. Em seguida, uma parte foi utilizada para pré-impregnação da MFS* e o restante foi adicionado a $\mathrm{FMD}_{\text {moída }}$ (granulometria: 60 tyler).

Após homogeneização (RFF+FMD ${ }_{\text {moída }}$, espalhou-se uma parte da mistura no molde inferior, colocou-se a MFS* pré-impregnada e adicionou-se o restante $16 \%$ FMD $_{\text {móda }}$ em massa

À RFF foram adicionados inicialmente $70 \mathrm{~mL}$ de etanol para redução da viscosidade. Em seguida, uma parte foi utilizada para pré-impregnação da MFS* e à outra foi adicionado a $\mathrm{FMD}_{\text {moída }}$ (granulometria: 60 tyler).

Após homogeneização (RFF+FMDm), espalhouse uma parte da mistura no molde inferior, colocou-se a MFS* pré-impregnada e adicionouse o restante.

*MFSim-ag: MFS ficou imersa em água por $6 \mathrm{~h}$, com o objetivo de causar o afastamento dos feixes de fibras e facilitar a impregnação da resina e posteriormente submetida a secagem ( $24 \mathrm{~h}$ a temperatura ambiente seguido de estufa, $105^{\circ} \mathrm{C}$ ) 
Em todos os processos de prensagem para preparar os compósitos (Tabela 10), o molde foi pré-aquecido em $75{ }^{\circ} \mathrm{C}$ para reduzir a viscosidade da resina RFF, facilitar a penetração da mesma no interior dos feixes de fibras e após $1 \mathrm{~h}$ de imersão, iniciou-se a moldagem. Nos

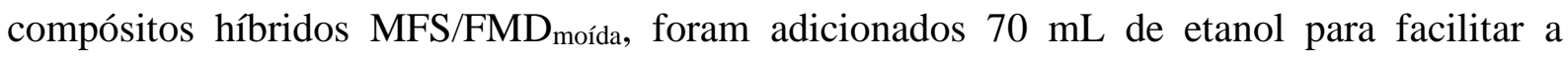

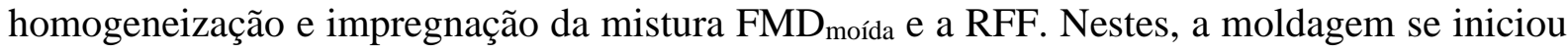
após 90 min com molde aberto e aquecido em $75{ }^{\circ} \mathrm{C}$ para a eliminação do etanol, indicado pela redução da viscosidade da resina.

\subsubsection{Moldagem do termorrígido e dos compósitos}

O termorrígido e os compósitos foram moldados por compressão e aquecimento controlados, em molde portátil, como descrito no item 1.2.2.3.3 do Capítulo 1. O ciclo seguido para a cura dos compósitos de matriz RFF foi o mesmo descrito no item 1.2.2.3.3 do Capítulo 1, havendo apenas algumas modificações quanto à pressão aplicada (Tabela 11). Como no presente capítulo foram usadas mantas como agente de reforço, a absorção de resina na manta não foi a mesma que quando se utilizou fibras curtas (FMD) e, portanto, a pressão foi aumentada aos poucos a partir de $105^{\circ} \mathrm{C}$ para evitar perdas de resina durante a moldagem. Vale destacar que a RFF possui ponto de gelificação na faixa de $95-105{ }^{\circ} \mathrm{C}$ (MEGIATTO JÚNIOR, 2006).

Tabela 11: Ciclo de cura para a obtenção dos termorrígidos e compósitos de matriz fenólica do tipo resol.

\begin{tabular}{ccc}
\hline \multicolumn{3}{c}{ Ciclo de cura } \\
\hline Temperatura $\left({ }^{\circ} \mathbf{C}\right)$ & Tempo $(\mathbf{m i n})$ & Força (ton) \\
\hline $\mathbf{7 5}$ & 60 & 0 \\
\hline $\mathbf{8 5}$ & 90 & 0 \\
\hline $\mathbf{9 5}$ & 30 & 0 \\
\hline $\mathbf{1 0 5}$ & 30 & $0-14$ \\
\hline $\mathbf{1 1 5}$ & 60 & $14-16$ \\
\hline $\mathbf{1 2 5}$ & 90 & 16 \\
\hline
\end{tabular}

\subsubsection{Caracterização da resina RFF e dos compósitos}

\subsection{Espectroscopia na região do infravermelho (FTIR)}

Os espectros de FTIR foram obtidos de acordo com o descrito no item 1.2.2.4.1 do

\section{Capítulo 1.}




\subsection{Resistência ao impacto Izod}

Os ensaios de impacto Izod foram realizados de acordo com o descrito no item 1.2.2.4.5 do Capítulo 1.

\subsection{Microscopia Eletrônica por Varredura (MEV)}

A análise de microscopia eletrônica de varredura foi realizada de acordo com o que foi descrito no item 1.2.2.4.6 do Capítulo 1.

\subsection{Ensaio de resistência à flexão}

O ensaio de resitência à flexão foi realizado de acordo com o descrito no item 1.2.2.4.7 do Capítulo 1.

\subsection{Análise termogravimétrica (TGA)}

A análise termogravimétrica foi realizada de acordo com o que foi descrito no item 1.2.2.4.3 do Capítulo 1, porém em atmosfera de nitrogênio, visando restringir o uso de ar como atmosfera.

\subsection{Análise dinâmico mecânica (DMA)}

A análise de DMA foi realizada de acordo com o descrito no item 1.2.2.4.8 do Capítulo 1. Porém, a presença de mantas como reforço, ao invés de fibras, requisitou o uso de garra dual cantilever e amplitude de oscilação de $15 \mu \mathrm{m}$.

\subsection{Resultados e disscussão}

\subsubsection{Caracterização das fibras das mantas de sisal e rayon}

\subsubsection{Espectroscopia na região do infravermelho por transformada de Fourier (FTIR)}

Os espectros de FTIR das fibras de sisal e rayon estão apresentados na Figura 37, e a Tabela 12 apresenta as possíveis atribuições das bandas identificadas nos espectros. As bandas em 3420 e $3345 \mathrm{~cm}^{-1}$, para as fibras de sisal e rayon, respectivamente, podem ser atribuídas ao estiramento ou deformação axial de ligações $\mathrm{O}-\mathrm{H}$, presentes na celulose, com contribuição de ligação hidrogênio intra e intermolecular (SILVERSTEIN; BASSLER, MORRIL, 1994; NORDIN et al., 2013; WANG et al., 2009). No caso da MFS, esta banda também pode estar associada aos grupos hidroxilas presentes na lignina. A banda em 2900 e $2895 \mathrm{~cm}^{-1}$ para a fibra de sisal e rayon, respectivamente, pode ser atribuída à ligação C-H de grupos saturados. 
Em $1735 \mathrm{~cm}^{-1}$ notou-se uma banda presente apenas no espectro da fibra de sisal que possivelmente está associada ao estiramento de ligações $\mathrm{C}=\mathrm{O}$, as quais referem-se a grupos éster, acetil e ácidos fenólicos que estão presentes em extrativos e hemiceluloses, e lignina, respectivamente (THEN et al., 2014; SAHU; GUPTA, 2018). Esta banda não foi observada no espectro da fibra rayon, pois esta é formada a partir de polpa celulósica mercerizada, que leva a eliminação parcial ou total de hemiceluloses e lignina (ORUE et al., 2015; THEN et al., 2015; BOSSUNIA et al., 2016).

Figura 37 - Espectros na região do infravermelho das fibras de sisal (FS) e de rayon (FR).

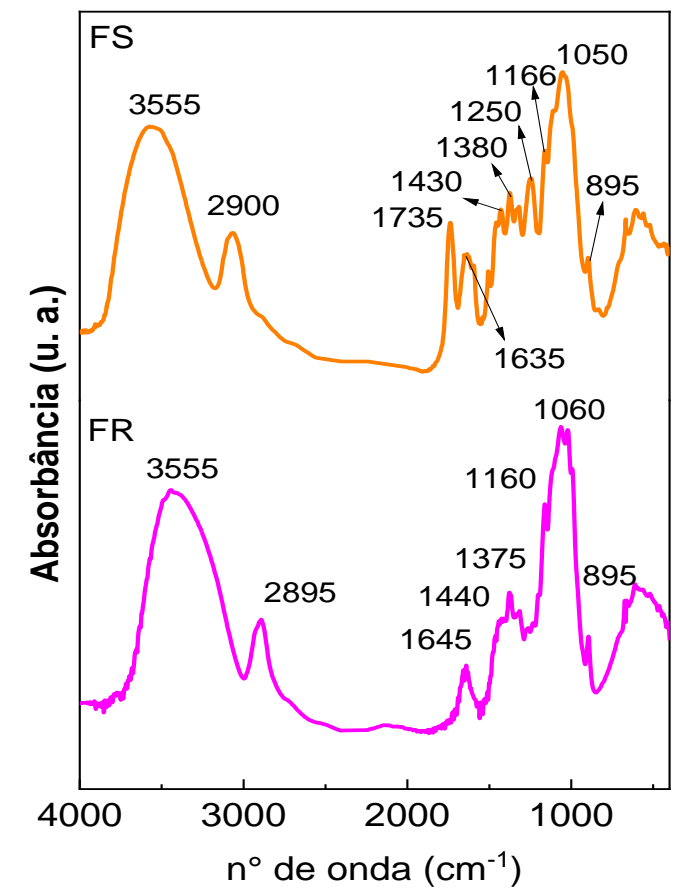

Tabela 12 - Possíveis atribuições para as principais bandas de absorção observadas nas fibras de sisal e rayon.

\begin{tabular}{|c|c|}
\hline \multicolumn{2}{|r|}{ Fibras de sisal e rayon } \\
\hline $\mathrm{n}^{\circ}$ de onda $\left(\mathrm{cm}^{-1}\right)$ & Atribuição \\
\hline 3440-3420 & Estiramento ou deformação axial de ligações O-H \\
\hline $2900-2895$ & Ligação C-H de grupos saturados \\
\hline $1735 *$ & Estiramento de ligações $\mathrm{C}=\mathrm{O}$ \\
\hline 1645 & Absorção de água estrutural \\
\hline $1635 *$ & Associadas à deformação axial de ligações C-C (lignina) \\
\hline $1500 *$ & Vibração de anel aromático da lignina \\
\hline 1440-1435 & Vibração simétrica de grupo $-\mathrm{CH}_{2-}$ \\
\hline 1375-1320 & Deformação angular simétrica e assimétrica de ligação C-H \\
\hline $1250 *$ & Estiramento de ligação C-O presentes na lignina e hemiceluloses \\
\hline 1160 & Vibração assimétrica de ligação C-O-C \\
\hline
\end{tabular}




\begin{tabular}{cc}
\hline $\mathbf{1 0 6 0 - 1 0 5 0}$ & Deformação axial de ligações C-O-C \\
\hline $\mathbf{8 9 5}$ & Vibração de grupo $\mathrm{C}_{1}$ da celulose \\
\hline
\end{tabular}

(REFERÊNCIAS: SILVERSTEIN; BASSLER, MORRIL, 1994; NELSON; O'CONNOR, 1964; CARRILLO et al., 2004; RAMIRES, 2010)

*Apenas para a fibra de sisal.

As bandas em 1050 e $1060 \mathrm{~cm}^{-1}$ presentes na fibra de sisal e rayon podem ser atribuídas à deformação axial de ligações C-O-C dos anéis de glicose e entre os anéis, e à deformação axial de ligação C-O de álcoois (SILVERSTEIN; BASSLER, MORRIL, 1994; RAMIRES et al., 2010). As bandas em 1160 e $896 \mathrm{~cm}^{-1}$ presentes em ambos os espectros podem estar associadas à vibração assimétrica de ligação C-O-C e vibração de grupo $\mathrm{C} 1$ da celulose (Figura 18- d), respectivamente (NELSON; O’CONNOR, 1964).

\subsubsection{Composição química}

A MFS utilizada no presente estudo como agente de reforço de matriz termorrígida fenolformaldeído foi caracterizada em termos de sua composição química após processo de extração ciclohexano: etanol (1:1) (Tabela 13).

Tabela 13 - Composição química das fibras da manta de sisal e comparação com dados da literatura para fibras de sisal.

\begin{tabular}{lccc}
\hline Componente (\%) & Presente estudo & $\begin{array}{c}\text { De Oliveira et al., } \\
\mathbf{2 0 1 7}\end{array}$ & James et al., 2019 \\
\hline Celulose & $57,4 \pm 0,6$ & $51,8 \pm 2,3$ & 63 \\
\hline Hemicelulose & $35,3 \pm 1,1$ & $35,2 \pm 2,4$ & 12 \\
\hline $\begin{array}{l}\text { Lignina klason } \\
\text { total (solúvel + } \\
\text { insolúvel) }\end{array}$ & $11,0 \pm 0,5$ & $12,0 \pm 0,9$ & 5 \\
\hline $\begin{array}{l}\text { Cinzas } \\
\text { Umidade }\end{array}$ & $0,8 \pm 0,1$ & $0,6 \pm 0,1$ & $N I$ \\
\hline NI-não informado pelo autor & $5,0 \pm 0,6$ & $6,8 \pm 0,1$ & $N I$ \\
\hline
\end{tabular}

Como citado, a determinação dos principais componentes lignocelulósicos é importante, pois o mesmo está diretamente atrelado às propriedades das fibras e consequentemente pode influenciar as propriedades do compósito final (PAIVA; FROLLINI, 2006; HASSAN et al., 2010; RAZERA et al., 2014; DE OLIVEIRA et al., 2015).

Ao comparar a porcentagem dos principais constituintes relatados por outros autores com o do presente estudo (Tabela 13), foi possível observar que há diferenças entres os mesmos. 
Isto pode ser atribuído à fatores como a época de colheita, tipo e manejo do solo, condições climáticas, método de extração, dentre outros (FARUK et al., 2012).

\subsubsection{Microscopia eletrônica de varredura (MEV)}

A análise morfológica das fibras de sisal (FS) e da fibra rayon (FR) foi realizada por microscopia eletrônica de varredura para avaliar a morfologia da superfície e ponta das fibras, que compõem a manta de sisal e a manta fibra rayon utilizadas no presente capítulo como agente de reforço em matriz RFF.

As micrografias mostradas em Figura 38 -a e -b são referentes à superfície e a ponta da fibra de sisal. Observou-se que as fibras apresentaram formato longitudinal cilíndrico, superfície não rugosa e lúmens vazios (estruturas internas de formato cilíndrico). A forma da seção transversal ao longo da fibra pode ser circular ou elíptica (NAVEEN et al., 2019). Huang et al. (2016) e Huang et al. (2018) observaram características semelhantes relacionadas à morfologia de fibras de sisal.

Um aspecto muito importante a ser considerado no uso de fibras naturais para a preparação de compósitos é a impregnação das fibras pela matriz polimérica. Isso possivelmente ocorre entre as células da fibra que preenchem os lúmens (FERREIRA et al., 2015; YAN et al., 2015) e, consequentemente, há uma melhora nas propriedades mecânicas do material compósito. Yan et al. (2015) obsevaram que em compósitos de matriz epóxi reforçados com fibra de sisal preparados por injeção, a maior impregnação da resina foi observada pelos lúmens preenchidos de matriz.

Figura 38 - Micrografias da superfície (a) e ponta (b) da fibra de sisal e da superfície (c) e da ponta (d) da fibra de rayon.

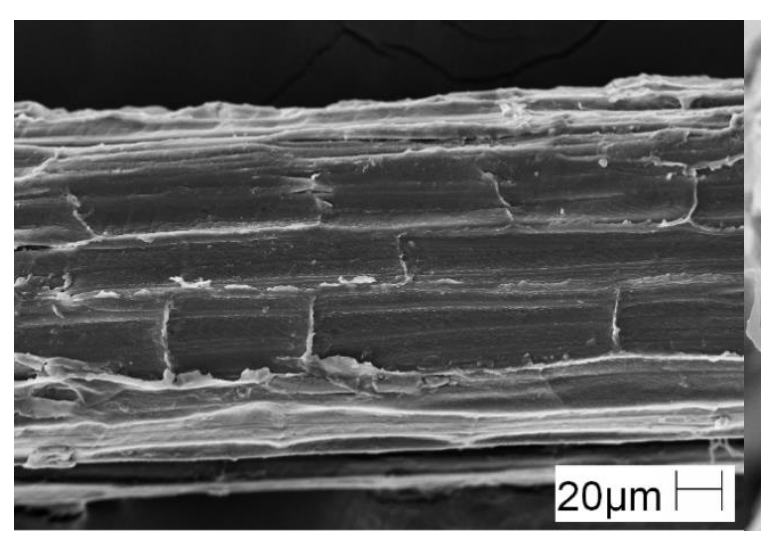

(a)

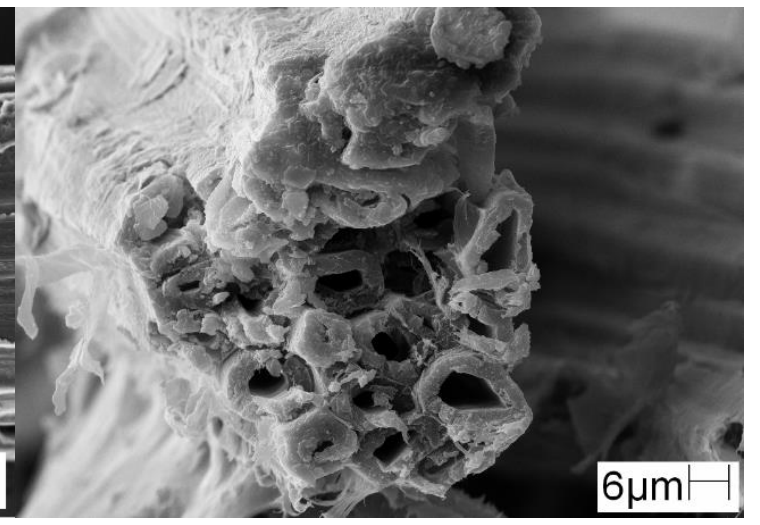

(b) 


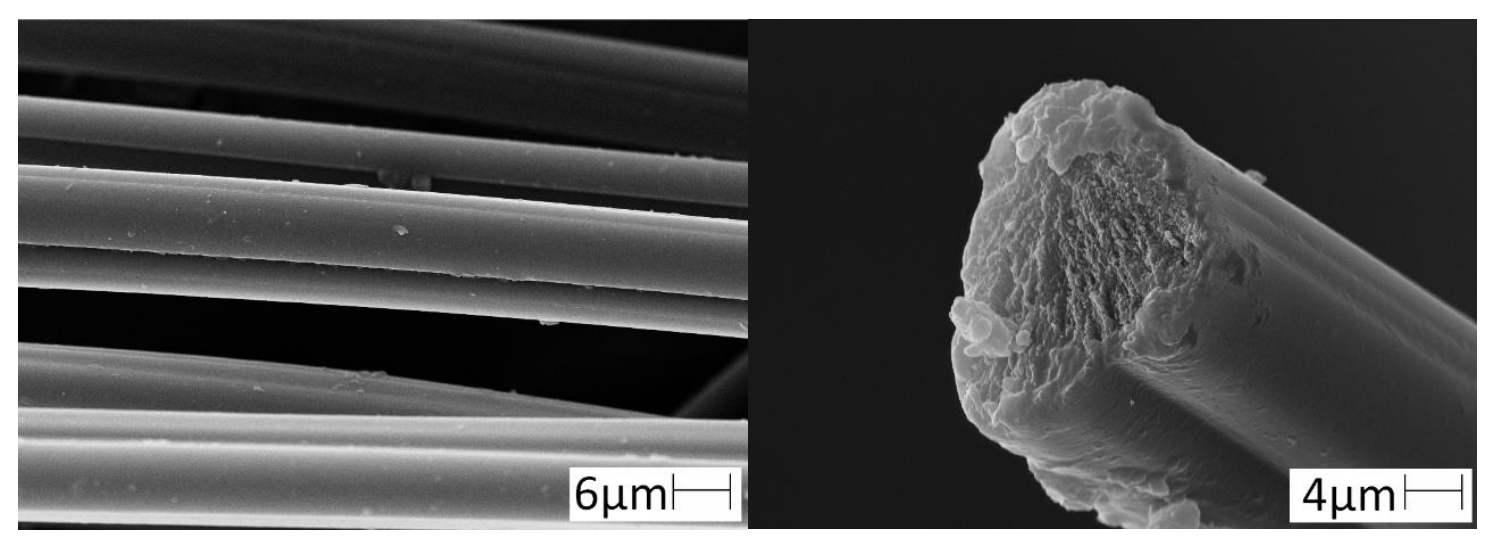

(c)

(d)

As micrografias mostradas em Figura 38-c e -d correspondem à superfície e à ponta de um feixe de fibras rayon, e mostram uma parte interna densa, com uma seção transversal arredondada, e superfície lisa. Destaca-se que esta fibra é produzida via fiação, a partir de celulose, como mencionado, enquanto as fibras de sisal são extraídas diretamente da planta. Zhang et al. (2018) e Teng et al. (2018) observaram aspectos morfológicos semelhantes em fibras de rayon. Segundo especificações fornecidas pela empresa Cordenka, um feixe de fibra rayon é composto por multifilamentos que fazem com que o fio possua uma densidade linear de $1,84 \mathrm{~g} \mathrm{~cm}^{-2}$.

\subsubsection{Difração de raios $X$}

A Figura 39 mostra os difratogramas das fibras que constituem a manta de sisal e da fibra rayon. O índice de cristalinidade ( $\mathrm{ICr}$ ) da fibra de sisal foi de aproximadamente 56\%, próximo ao encontrado por Ramires et al. (2010), 61\%, De Oliveira et al. (2017), 62\%, Krishnaiah et al. (2017), 65\%. O elevado valor de índice de cristalinidade está diretamente relacionado ao elevado teor de celulose presente na fibra, 62\% (Tabela 13), o que pode impactar positivamente as propriedades mecânicas das fibras (PANDEY, 1999; SENA NETO et al., 2013; FIDELIS et al., 2013).

A fibra rayon apresentou um ICr de aproximadamente 47\%. Na Figura 39 (a) se observou picos $2 \theta \approx 15,6^{\circ}$ e $22^{\circ}$ para a fibra de sisal. Já para a fibra rayon, foram observados picos $2 \theta \approx$ $12^{\circ}, 20^{\circ}$ e $21,5^{\circ}$. Os picos apresentados na fibra de sisal são característicos de celulose I (FRENCH et al., 2014; NASCIMENTO et al., 2014; SOUZA et al., 2016; KRISHNAIAH et al., 2017), e os picos em $20^{\circ}$ e $21,5^{\circ}$, observados no difratograma da fibra rayon são relacionados a celulose II (LI et al., 2010; WANG et al., 2014; CHUNG; KIM, 2016). 
Figura 39 - Difratogramas de raios X das fibras de sisal (a) e rayon (b).

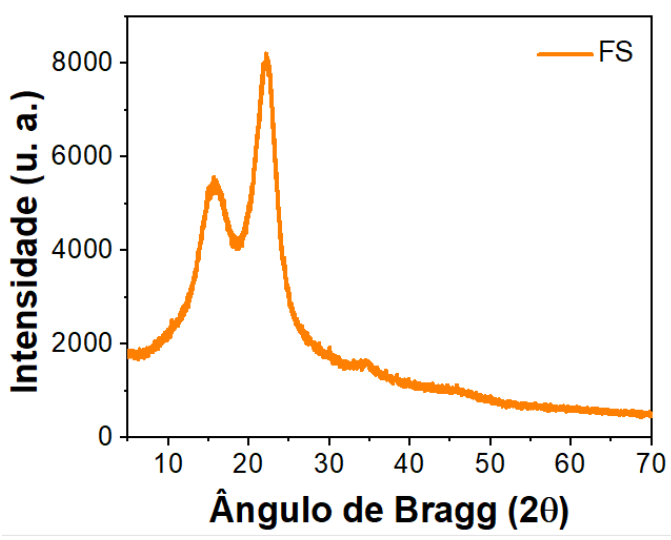

(a)

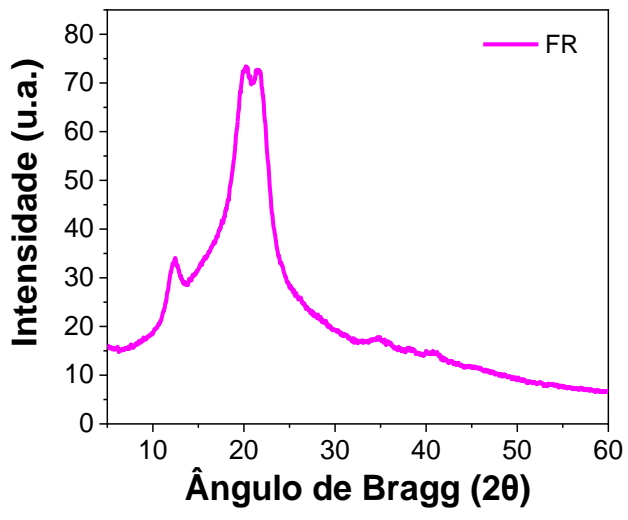

(b)

Durante o tratamento com solução alcalina, como ocorre no processo em que a fibra rayon ou celulose regenerada é obtida, há a conversão de celulose I da polpa celulósica para celulose II, que diferem entre si devido às suas estruturas. A celulose I possui uma estrutura cristalina monoclínica paralela que, durante a mercerização, sofre entumescimento e se converte em celulose II. Esta possui uma estrutura cristalina antiparalela e é termodinamicamente mais estável do que a celulose I (KROON-BATENBURG; KROON, 1997; CREDOU; BETHELOT, 2014; BOSSUNIA et al., 2016). O tratamento alcalino pode causar mudanças nas propriedades mecânicas da fibra devido à reorientação das partes cristalinas e não-cristalinas da celulose (PAIVA; FROLLINI, 2001; RAZERA et al., 2014).

\subsubsection{Análise termogravimétrica}

A decomposição térmica das fibras que compõe a manta de sisal e rayon foram avalidadas por análise termogravimétrica (TGA). A Figura 40 mostra as curvas TG e dTG destas fibras e a Tabela 14 apresenta as temperaturas e perdas de massa observados nos picos das curvas dTG. As fibras de sisal e rayon apresentaram uma perda de massa de aproximadamente $4 \%$ de $0{ }^{\circ} \mathrm{C}$ a $100{ }^{\circ} \mathrm{C}$, que está relacionado à vaporização de umidade residual (KRISHNAIAH et al., 2017). 
Figura 40 - Curva TG e dTG das fibras da manta de sisal (a) e fibra rayon (b) em atmosfera de $\mathrm{N}_{2}, 50$ $\mathrm{mL} \min ^{-1}$ e taxa de aquecimento de $10{ }^{\circ} \mathrm{C} \min ^{-1}$.

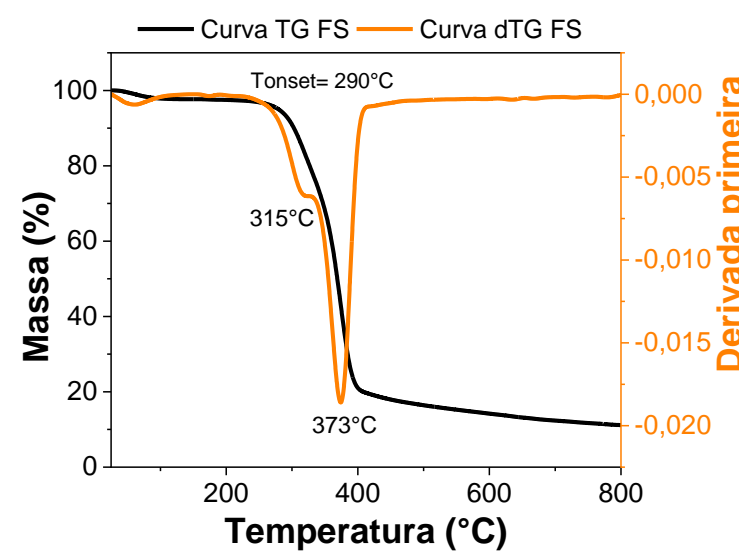

(a)

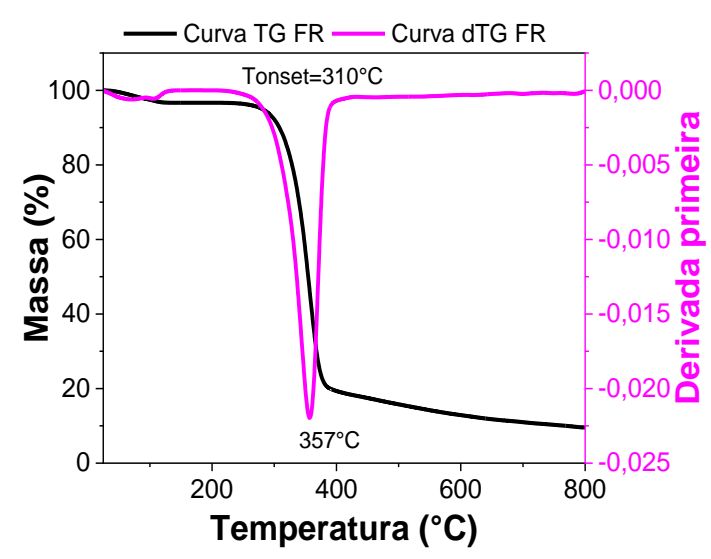

(b)

Tabela 14 - Parâmetros termogravimétricos da FS e FR em atmosfera de nitrogênio.

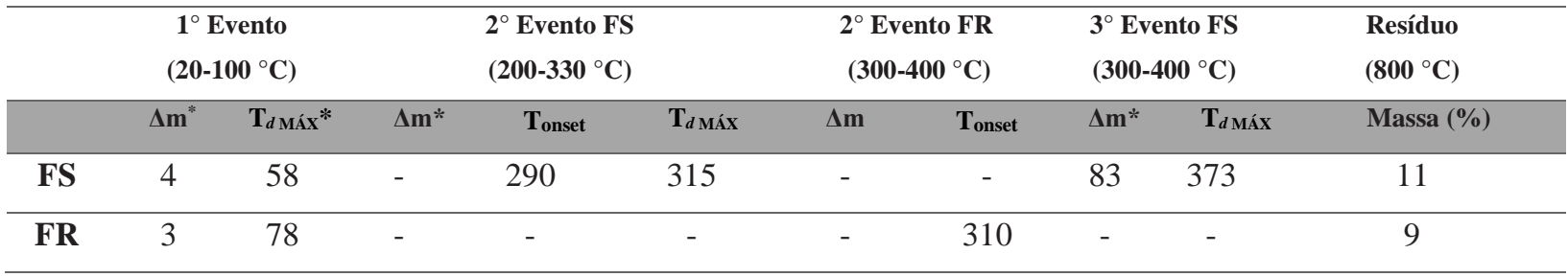

* $\Delta \mathrm{m}$ : variação em massa $(\%) / \mathrm{T}_{\text {onset: }}$ Temperatura inicial de decomposição $\left({ }^{\circ} \mathrm{C}\right) / \mathbf{T}_{\boldsymbol{d}} \mathbf{M}$ áx: Temperatura de decomposição

As temperaturas iniciais de decomposição extrapolada ( $\left.\mathrm{T}_{\text {onset }}\right)$ das fibras de sisal e rayon foram aproximadamente 290 e $320^{\circ} \mathrm{C}$, respectivamente. Quando as fibras são utilizadas como agente de reforço em compósitos, a $\mathrm{T}_{\text {onset }}$ delimita a temperatura de processamento (NETO et al., 2015). $\mathrm{O}$ evento em $315^{\circ} \mathrm{C}$ observado apenas na curva dTG da fibra de sisal é referente à decomposição de hemiceluloses (Figura 40- a). A faixa de temperatura de decomposição das hemiceluloses ocorre entre 220-320 ${ }^{\circ} \mathrm{C}$ (YANG et al., 2007; YUNOS et al., 2012), pois as hemiceluloses são menos estáveis termicamente em relação a lignina e à celulose, por estarem presentes em regiões não cristalinas, e serem constituídas por vários sacarídeos interligados randomicamente (WANG et al., 2009; THEN et al., 2014). Este evento não foi visualizado na fibra rayon, confirmando a eliminação de hemiceluloses no processo de obtenção das fibras (Figura 40- b).

\subsubsection{Caracterização dos compósitos de matriz termorrígida RFF reforçados com MFS} e MFR, e compósitos híbridos

\subsubsection{Espectroscopia na região do infravermelho por transformada de Fourier (FTIR)}


A Figura 41 apresenta os espectros na região do infravermelho obtidos para os compósitos de matriz RFF reforçados com MFS e MFR.

Figura 41 - Espectros na região do infravermelho dos compósitos de matriz RFF reforçados com MFS, $\mathrm{C}_{\mathrm{RFF}} 42 \% \mathrm{MFS}$, e MFR, $\mathrm{C}_{\mathrm{RFF}} 10 \% \mathrm{MFR}$.

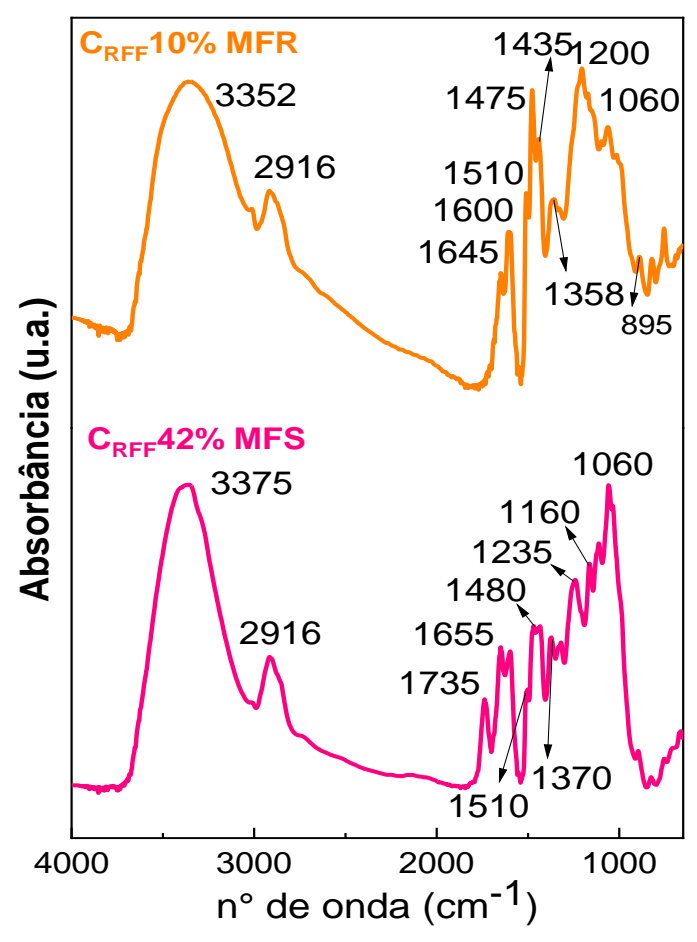

Devido os compósitos $\mathrm{C}_{\mathrm{RFF}} 42 \% \mathrm{MFS}$ e $\mathrm{C}_{\mathrm{RFF}} 42 \% \mathrm{MFS}_{\text {im-ag-et, }}$ possuírem a mesma composição, MFS e RFF, apenas foi apresentado um espectro, pois os demais apresentaram características similares. A mesma tendência foi observada nos espectros dos compósitos $\mathrm{C}_{\mathrm{RFF}} 10 \% \mathrm{MFR}$ e $\mathrm{C}_{\mathrm{RFF}} 19 \% \mathrm{MFR}$, e, portanto, apenas foi apresentado um dos espectros. A Tabela 15 mostra as possíveis atribuições das bandas de absorção observadas nos mesmos. Os espectros da matriz RFF e do termorrígido TRFF foram apresentados no Capítulo 1.

A Figura 41 mostra uma banda intensa na faixa de $3370-3352 \mathrm{~cm}^{-1}$ referente ao estiramento ou deformação axial de grupos hidroxilas alcoólico e fenólico presentes tanto no termorrígido quanto em componentes da fibra, tais como celulose, hemiceluloses e lignina.

A banda em $2916 \mathrm{~cm}^{-1}$, observada em ambos os espectros, pode ser atribuida à vibração de C-H de grupos saturados que podem tanto ser provenientes das fibras quanto da matriz RFF. No caso da matriz, estes grupos podem ser referentes à reação de entrecruzamento do termorrígido devido à formação de ligações cruzadas, Figura 7 (MALUTAN et al., 2008). 
Tabela 15 - Possível atribuição para as principais bandas de absorção observadas nos compósitos de matriz termorrígida RFF reforçados com MFS e MFR.

\begin{tabular}{|c|c|}
\hline \multicolumn{2}{|r|}{$\mathrm{C}_{\mathrm{RFF}} 42 \% \mathrm{MFS} / \mathrm{C}_{\mathrm{RFF}} 10 \% \mathrm{MFR}$} \\
\hline $\mathrm{n}^{\circ}$ de onda $\left(\mathrm{cm}^{-1}\right)$ & Atribuição \\
\hline 3375-3352 & Deformação axial simétrica de grupos $\mathrm{OH}$ alcoólicos e fenólicos \\
\hline 2916 & Vibração de estiramento $\mathrm{C}$ - $\mathrm{H}$ \\
\hline 1735 & Estiramento de ligações $C=O$ \\
\hline $1655-1645$ & Deformação fora do plano de $C=C$ aromáticos \\
\hline $1610-1510$ & Deformação fora do plano de $C=C$ aromáticos \\
\hline $1480-1475$ & Deformação angular de ligação $\mathrm{C}$ - $\mathrm{H}$ de grupos metileno \\
\hline 1235-1200 & Deformação axial da ligação $\mathrm{C}-\mathrm{O}-\mathrm{C}$ de éter em $-\mathrm{CH}_{2-} \mathrm{O}-\mathrm{CH}_{2^{-}}$ \\
\hline \multicolumn{2}{|l|}{1160} \\
\hline 1060 & $\begin{array}{l}\begin{array}{l}\text { Vibração de estiramento assimétrico } \mathrm{C}-\mathrm{O}-\mathrm{C} \text { de éter alifático (ponte éter- } \\
\text { metileno) }\end{array}\end{array}$ \\
\hline 895 & Vibração de C1 da celulose \\
\hline
\end{tabular}

A banda em $1735 \mathrm{~cm}^{-1}$ observada no espectro do compósito $\mathrm{C}_{\mathrm{RFF}} 42 \% \mathrm{MFS}$ está relacionada à estiramento de ligações $\mathrm{C}=\mathrm{O}$, as quais referem-se a grupos éster e ácidos fenólicos que estão presentes em extrativos, hemiceluloses, e lignina, respectivamente, encontrados na fibra de sisal, conforme observado na Figura 37- a (MAHMUD et al., 2013; THEN et al., 2014).

A banda em aproximadamente 1655 e $1600 \mathrm{~cm}^{-1}$ é referente ao estiramento (deformação axial) das ligações $\mathrm{C}=\mathrm{C}$ do anel aromático e/ou de grupos insaturados, os quais podem ser provenientes tanto da matriz quanto da lignina presente na fibra de sisal (SILVERSTEIN; BASSLER, MORRIL, 1994; BYKOV, 2008). No caso do compósito C10\%MFR, esta banda também pode estar atrelada à absorçao de água estrutural que pode se associar às cadeias de celulose (Figura 41) (TIAN et al., 2014; YANG et al., 2017). A banda em $1510 \mathrm{~cm}^{-1}$ está relacionada à vibração de ligações $\mathrm{C}=\mathrm{C}$ de anéis aromáticos provenientes do $\mathrm{TRFF}$ (RAMIRES, 2010; RAZERA, 2006; MEGIATTO JÚNIOR, 2006).

As bandas observadas em ambos espectros dos compósitos $\mathrm{C}_{\mathrm{RFF}} 42 \% \mathrm{MFS}$ e $\mathrm{C}_{\mathrm{RFF}} 10 \% \mathrm{MFR} 1475$ e $1480 \mathrm{~cm}^{-1}$ estão associadas à deformação angular de ligação C-H de grupos metileno, os quais podem ser provenientes do TRFF, formados durante o processo de entrecruzamento da resina fenólica antes e durante a moldagem dos compósitos (RAMIRES, 2010). Os grupos hidroximetila reagem entre si formando pontes metileno, as quais são as responsáveis pela formação de ligações cruzadas (BENNAR,1999; RAMIRES et al., 2010).

As bandas em 1370 e 1360 cm$^{-1}$ estão relacionadas à deformação angular simétrica e assimétrica de ligação C-H presentes na celulose I e II presentes nas fibras de sisal e rayon, respectivamente (SILVERSTEIN; BASSLER, MORRIL, 1994; CARRILLO et al., 2004). 
As bandas em 1200 e $1235 \mathrm{~cm}^{-1}$ são referentes aos grupos hidroxilas fenólicas provenientes do TRFF. A banda em $1060 \mathrm{~cm}^{-1}$ presente em ambos compósitos está associada à deformação axial de ligações C-O-C presentes nos anéis de glicose e entre os anéis, e à deformação axial de ligação $\mathrm{C}-\mathrm{O}$ de álcoois, os quais estão presentes nas FS e FR (SILVERSTEIN; BASSLER, MORRIL, 1994; RAMIRES et al., 2010). As bandas em 1160 e $896 \mathrm{~cm}^{-1}$ presentes nos espectros da FS e FR, podem estar associadas à vibração assimétrica de ligação C-O-C e vibração de grupo $\mathrm{C} 1$ (carbono 1) da celulose, respectivamente (Figura 18d) (NELSON; O’CONNOR, 1964).

\subsubsection{Análise termogravimétrica}

\subsection{Compósitos matriz termorrígida RFF reforçados com MFS e MFR}

A Figura 42 apresenta as curvas termogravimétricas e as respectivas curvas dTG do TRFF e dos compósitos de matriz fenol-formaldeído reforçados com MFS e MFR. Entre as curvas termogravimétricas dos compósitos $\mathrm{C}_{\mathrm{RFF}} 42 \% \mathrm{MFS}$ e $\mathrm{C}_{\mathrm{RFF}} 42 \% \mathrm{MFS}$ im-ag-et, e $\mathrm{C}_{\mathrm{RFF}} 10 \% \mathrm{MFR}$ e $\mathrm{C}_{\mathrm{RFF}} 19 \% \mathrm{MFR}$, não se observou diferença significativa. Portanto, apenas será apresentada a curva do $\mathrm{C}_{\mathrm{RFF}} 42 \% \mathrm{MFS}$ e do $\mathrm{C}_{\mathrm{RFF}} 10 \% \mathrm{MFR}$, Figura 42- b e c, respectivamente.

Com base nas curvas termogravimétricas dos compósitos apresentados, percebeu-se que o primeiro evento de perda de massa está relacionado à vaporização de água. Também se observou que o TRFF apresentou uma $\mathrm{T}_{\text {onset }}$ de aproximadamente $325{ }^{\circ} \mathrm{C}$, enquanto os compósitos contendo MFS e MFR apresentaram uma $\mathrm{T}_{\text {onset }}$ de aproximadamente $290{ }^{\circ} \mathrm{C}$ e 300 ${ }^{\circ} \mathrm{C}$, respectivamente. Estas temperaturas estão associadas ao início da decomposição da fibra de sisal e rayon, respectivamente (Figura 40).

Figura 42 - Curvas TG e dTG do TRFF (a) e dos compósitos reforçados com MFS, $\mathrm{C}_{\mathrm{RFF}} 42 \% \mathrm{MFS}$ (b) e MFR, $\mathrm{C}_{\mathrm{RFF}} 10 \% \mathrm{MFR}$ (c), em atmosfera de nitrogênio com razão de aquecimento de $10{ }^{\circ} \mathrm{C} / \mathrm{min}$ e fluxo de $50 \mathrm{~mL} \mathrm{~min}^{-1}$.

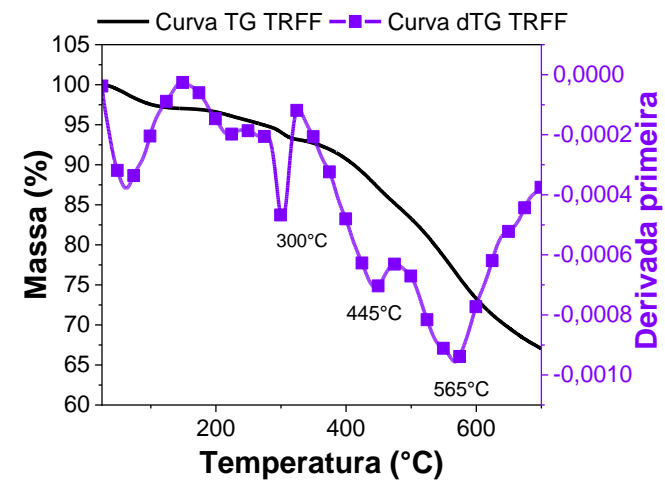

(a)

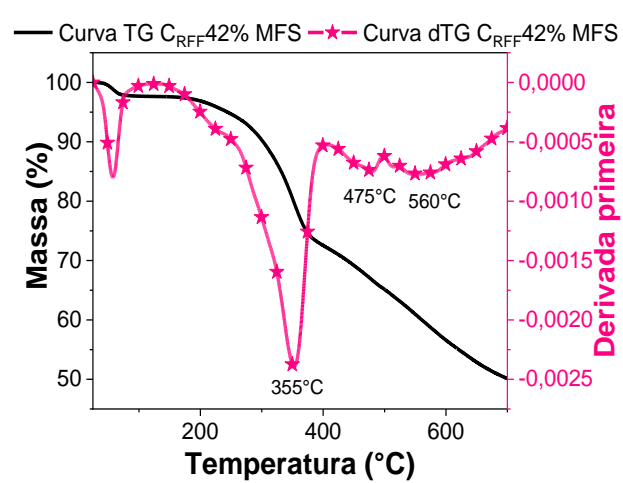

(b) 


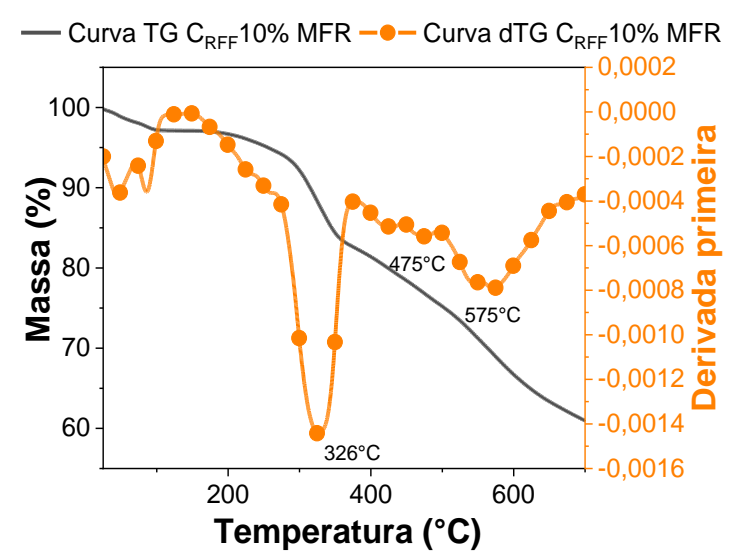

(c)

Na curva dTG do TRFF (Figura 42- a) observou-se um pico em $300{ }^{\circ} \mathrm{C}$ ( $\mathrm{T}_{\mathrm{dMÁx}}$ ) que pode estar relacionado à cura residual durante a varredura e os demais picos observados em temperaturas superiores à $400{ }^{\circ} \mathrm{C}$ estão associados à fragmentação da rede aromática fenólica.

Os picos observados nas curvas dTG dos compósitos em aproximandamente 325$350{ }^{\circ} \mathrm{C}\left(\mathrm{T}_{\mathrm{dMÁx}}\right.$ ) (Figura 42 -b e -c) estão relacionados a decomposição da celulose presente nas fibras, tanto de sisal quanto de rayon, conforme já discutidos anteriormente, e os picos acima de $400{ }^{\circ} \mathrm{C}$ observados nestas mesmas curvas referem-se à decomposição de anéis aromáticos presentes na rede fenólica a qual constitui o TRFF, como observado na Figura 42a.

\subsection{Compósitos híbridos de matriz termorrígida RFF reforçados com MFS/FMD moída}

A Figura 43 apresenta a curva termogravimétrica e a respectiva curva dTG do compósito híbrido de matriz fenol-formaldeído reforçado com MFS/FMD moída, $\mathrm{C}_{\mathrm{RFF}} 38 \% \mathrm{MFS}_{\mathrm{im}-\mathrm{ag}}$

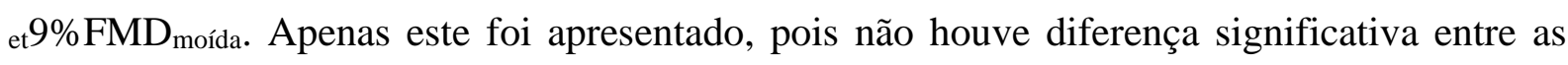
curvas temogravimétricas dos compósitos híbridos com 9 e 16\% (em massa) de FMD moída. O primeiro evento de perda de massa de todos os compósitos está relacionado à vaporização de água (Figura 43). O compósito híbrido constituído por MFS/FMD moída apresentou uma $\mathrm{T}_{\text {onset }}$ de aproximadamente $280^{\circ} \mathrm{C}$. A $\mathrm{T}_{\text {onset }}$ deste está associada à adição de FMDm nos híbridos $\left(\mathrm{C}_{\mathrm{RFF}} 38 \% \mathrm{MFS}_{\text {im-ag-et }} 9 \% \mathrm{FMD}_{\text {moída }}\right.$ e $\left.\mathrm{C}_{\mathrm{RFF}} 35 \% \mathrm{MFS}_{\text {im-ag-et }} 16 \% \mathrm{FMD}_{\text {moída }}\right)$ que possui uma $\mathrm{T}_{\text {onset }}$ de $280{ }^{\circ} \mathrm{C}$ (figura não mostrada). Vale destacar que a caracterização da FMD foi apresentada previamente (Capítulo 1), porém, a análise termogravimétrica apresentada foi realizada em atmosfera de ar sintético. 
Figura 43 - Curvas TG e dTG (primeira derivada) dos compósitos híbridos $\mathrm{C}_{\mathrm{RFF}} 38 \% \mathrm{MFS}$ im-aget $9 \% \mathrm{FMD}_{\text {moída }}$ em atmosfera de nitrogênio com razão de aquecimento de $10{ }^{\circ} \mathrm{C} / \mathrm{min}$ e fluxo de 50 $\mathrm{mL} / \mathrm{min}$.

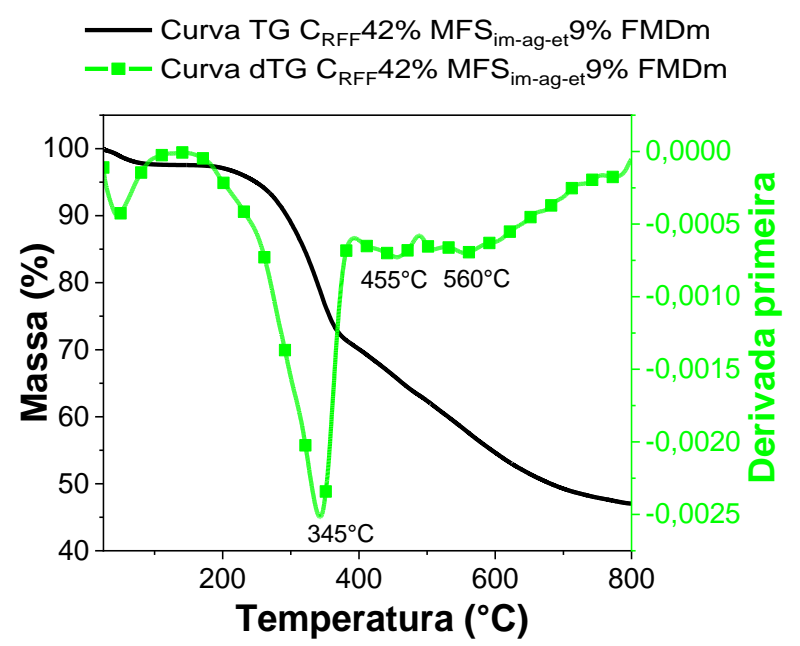

O segundo evento observado na curva dTG (Figura 43) apresentou uma $\mathrm{T}_{\mathrm{d} M A ́ x}$ de aproximadamente $345^{\circ} \mathrm{C}$, que possivelmente está relacionado à decomposição da celulose presente em ambas as fibras (sisal e FMD) utilizadas como reforço, conforme observado na Figura 40. Em todos os compósitos também se observou um terceiro e quarto eventos, ambos picos de baixa intensidade na curva dTG, com uma $\mathrm{T}_{\mathrm{dMÁx}}$ superior à 455 e $560{ }^{\circ} \mathrm{C}$, respectivamente, o qual está relacionado à quebra e decomposição de anéis aromáticos presentes na matriz termorrígida (PAIVA; FROLLINI, 2006) (Figura 42- a).

\subsubsection{Resistência ao Impacto Izod}

Os resultados de resistência ao impacto Izod dos compósitos preparados no presente capítulo foram divididos em dois subitens: os reforçados com MFS e MFR, e os híbridos constituídos por MFS/FMD moída.

\subsection{Compósitos matriz termorrígida RFF reforçados com MFS e MFR}

Na Figura 44 estão apresentados os resultados de resistência ao impacto obtidos a partir dos compósitos de matriz termorrígida fenólica reforçados com 10 e 19\% (em volume), o que se refere a compósitos com uma e duas mantas de MFR, respectivamente, e 42\% (em volume) de MFS obtidos por dois métodos de impregnação diferentes (Tabela 10). Estes métodos foram selecionados com base em experimentos preliminares.

Resumidamente, o compósito $\mathrm{C}_{\mathrm{RFF}} 42 \% \mathrm{MFS}$ foi preparado por imersão da MFS na RFF e o $\mathrm{C}_{\mathrm{RFF}} 42 \% \mathrm{MFS}_{\mathrm{im} \text {-ag-et }}$ foi preparado a partir da imersão da MFS em água por 6h, para causar a separação dos feixes de fibras e, após secagem, adição de $70 \mathrm{~mL}$ de etanol na RFF para 
redução da viscosidade da mesma, objetivando aumentar a impregnação dos feixes internos da manta (Tabela 10).

A Figura 44- a mostra que houve um aumento no valor de resistência ao impacto de todos os compósitos reforçados com MFS em comparação ao termorrígido fenólico. Estes resultados foram semelhantes aos obtidos por Ramires et al. (2010) e De Oliveira et al. (2017) ao utilizarem como reforço estrutural $30 \%$ (em massa) de fibra de sisal com comprimento de $3 \mathrm{~cm}$, $435 \mathrm{~J} \mathrm{~m}^{-1}$ e $373 \mathrm{~J} \mathrm{~m}^{-1}$, respectivamente, ambos em matriz fenólica. No entanto, no presente estudo obteve-se um elevado valor de resistência ao impacto com uma quantidade de fibras muito inferior ao utilizado pelos autores citados anteriormente. Vale destacar que $42 \%$ em volume equivale a 15\% em massa (aproximadamente) de MFS. A forma entrelaçada e orientada em que as fibras estão dispostas na manta proporcionou ao compósito uma maior resistência, mesmo tendo uma porcentagem em massa de fibras inferior aos dos demais autores, em que as fibras utilizadas eram curtas e estavam distribuídas de maneira aleatória.

Além disso, nas mantas utilizadas no presente estudo têm-se feixes de fibras alinhadas a $0^{\circ}$ e 90 que podem atuar como uma barreira impedindo a propagação transvesal da trinca, aumentando a energia de absorção do material quando submetido a este ensaio (NASCIMENTO et al., 2012; PEREIRA et al., 2017).

Figura 44 - Resistência ao impacto do termorrígido (TRFF) e dos compósitos de matriz termorrígida fenólica resol reforçados com MFS, $\mathrm{C}_{\mathrm{RFF}} 42 \% \mathrm{MFS}$ e $\mathrm{C}_{\mathrm{RFF}} 42 \% \mathrm{MFS}_{\text {im-ag-et, }}$ e $\mathrm{MFR}, \mathrm{C}_{\mathrm{RFF}} 10 \% \mathrm{MFS}$ e $\mathrm{C}_{\mathrm{RFF}}$ 19\%MFS, (a) e comparativo entre os resultados de resistência ao impacto normalizados dos compósitos reforçados com MFS e MFR (b).

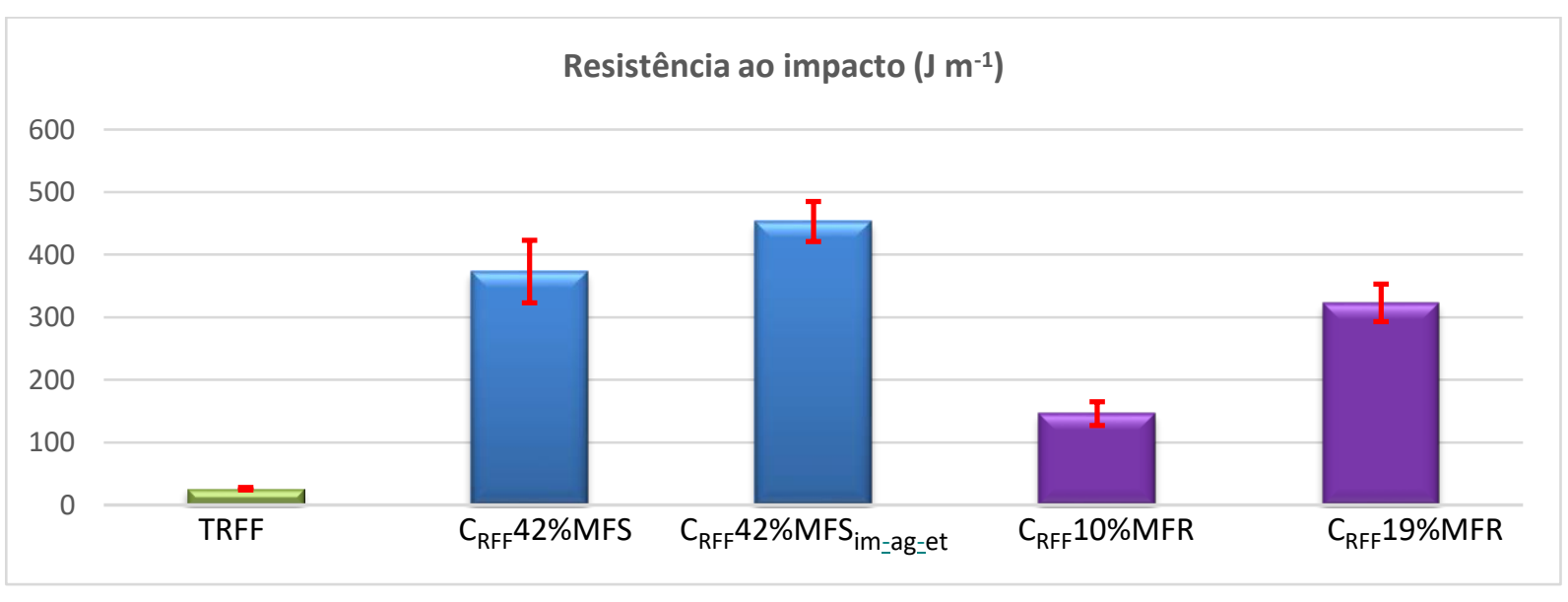

(a) 


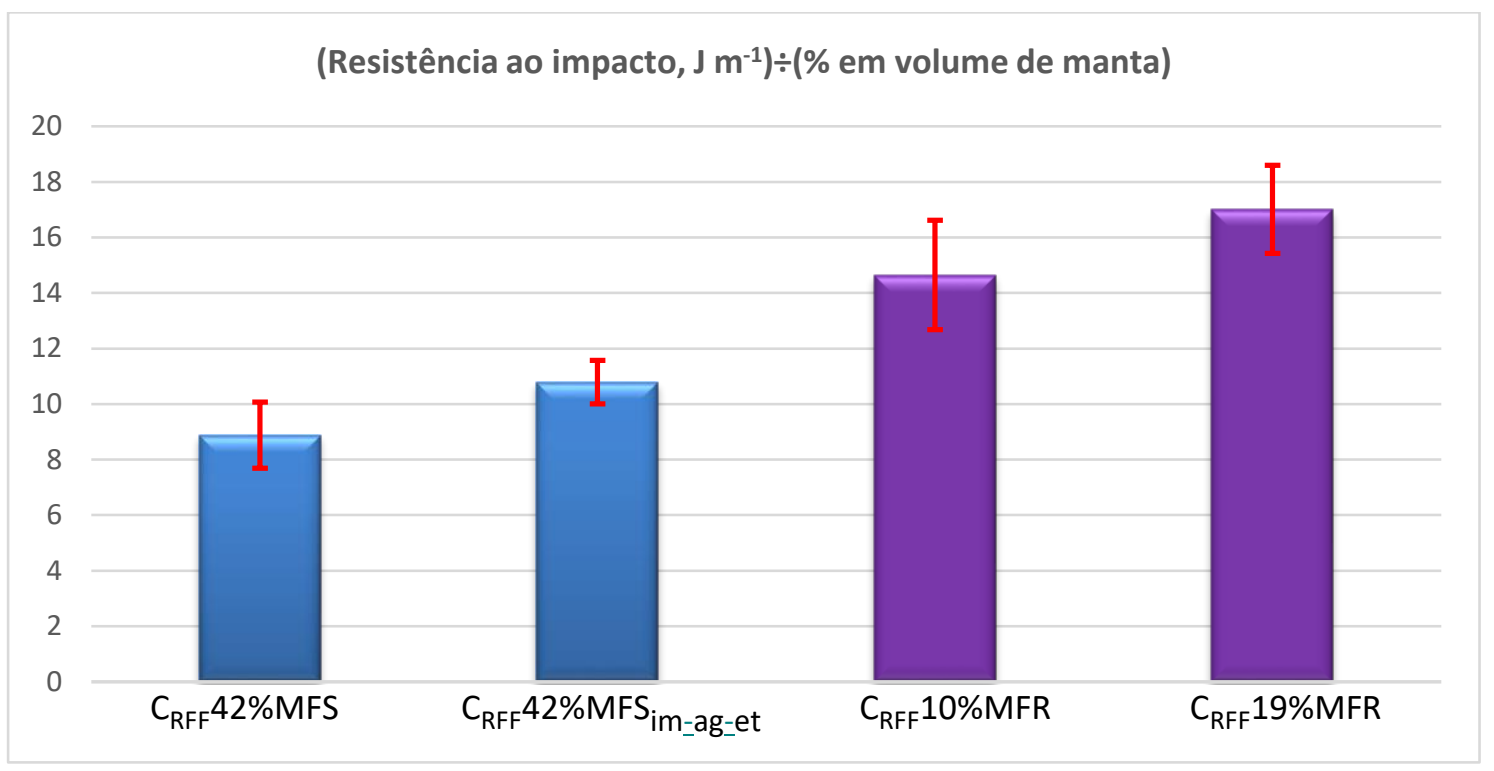

(b)

Devido as mantas de sisal e rayon corresponderem a porcentagens em volume muito diferentes nos compósitos, a Figura 44-b mostra os valores da resistência ao impacto normalizados, ou seja, os valores foram divididos por unidade de \% em volume de manta, o que permite uma melhor interpretação da ação como reforço de cada manta. Para todos os resultados de resistência ao impacto, resistência à flexão e módulo de flexão a serem mostrados neste e nos capítulos seguintes serão apresentados também os resultados normalizados.

Comparando os resultados de resistência ao impacto normalizados obtidos entre os dois métodos de impregnação (Figura 44- b), Tabela 10, que levaram a $\mathrm{C}_{\mathrm{RFF}} 42 \% \mathrm{MFS}$ e $\mathrm{C}_{\mathrm{RFF}} 42 \% \mathrm{MFS}_{\text {im-ag-et}}$, observa-se que o processo de imersão da MFS em água aliado com a redução da viscosidade com a adição de etanol, proporcionou uma melhora nesta propriedade. Isto pode ter sido ocasionado por uma maior impregnação da RFF entre os feixes de fibra da MFS. É importante destacar que esta é composta por feixes de fibras longos e densos, que estão entrelaçados entre si de forma perpendicular. Portanto, quanto menor for a viscosidade da resina polimérica, maior poderá ser a impregnação entre estes feixes de fibras.

Em relação aos compósitos reforçados com MFR, nota-se que houve um aumento significativo nos valores de resistência ao impacto à medida que se aumentou o número de camadas de manta de um para dois. Esse efeito foi semelhante ao observado por Abdellaoui et al. (2015) ao utilizar manta de fibra de juta em compósito de matriz epóxi. O uso de mantas como reforço aumenta a capacidade de carga do material, levando a compósitos mais resistentes ao impacto comparativamente a mesma matriz utilizando fibras curtas e aleatórias. Isto é ocasionado devido à tenacidade das mantas, capacidade de absorver mais energia até ruptura, e a eficiência de propagação de energia da matriz para a manta durante o ensaio de 
impacto Izod (RAJESH; PITCHAIMANI, 2017).

A forma com que a transferência de carga ocorre, da matriz para as fibras, quando o corpode-prova é atingido pelo martelo durante o ensaio interfere nas propriedades do material final. A Figura 45- a mostra que a propagação do impacto no compósito $\mathrm{C}_{\mathrm{RFF}} 42 \% \mathrm{MFS} \mathrm{S}_{\mathrm{im} \text {-ag-et }}$ não se estendeu por todo o corpo-de-prova, permanecendo ainda uma ponte de feixes de fibra. Isto indica que parte das fibras sofreram ruptura e outras apenas deformaram durante o ensaio. A mesma tendência foi observada para os outros compósitos de matriz RFF reforçados com MFS e MFR (Figura 45).

A Figura 44- b mostra que o compósito $\mathrm{C}_{\mathrm{RFF}} 19 \% \mathrm{MFR}$ apresentou uma melhor resistência ao impacto por unidade \% em volume de manta com uma porcentagem em volume inferior ao do compósito com MFS. Apesar de a fibra de sisal possuir elevada resistência (DE OLIVEIRA et al., 2017), a manta constituída por fibras de rayon atuou de forma mais eficiente como reforço, indicando elevada capacidade de absorção de energia desta manta (SHAMSUDDIN; LEE; BISMARCK, 2016).

Figura 45 - Imagens corpos-de-prova dos compóstitos $\mathrm{C}_{\mathrm{RFF}} 42 \% \mathrm{MFS}_{\text {im-ag-et }}$ (a) e $\mathrm{C}_{\mathrm{RFF}} 19 \% \mathrm{MFR}$ (b).

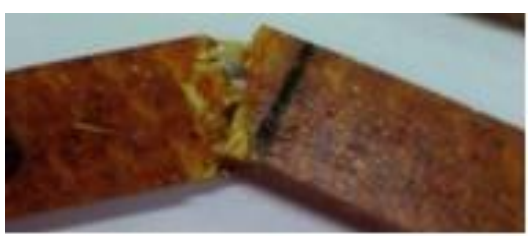

(a)

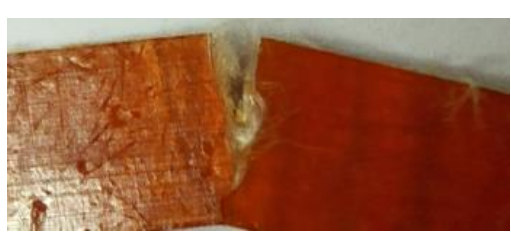

(b)

Um dos fatores que afetam o desempenho dos compósitos em relação a resistência ao impacto é a natureza da fibra, assim como sua interação com matriz (SAFRI et al., 2018). Portanto, o fato da fibra rayon ser constituída por celulose pode ter levado a maior interação entre os grupos hidroxilas presentes nesta macromolécula e os grupos hidroxilas (polares) presentes na matriz (Figura 46) (RAZERA et al., 2014; DE OLIVEIRA et al., 2017) e, consequentemente, pode levar a um aumento na adesão interfacial entre ambas e impregnação da resina pela manta de rayon (PRASHANTH et al., 2019). Outro fato importante, é que fibras mais flexíveis possuem maior capacidade de absorção de energia comparativamente às fibras mais rígidas e frágeis (BUNEA et al., 2019). Neste caso, a MFR apresenta uma maior flexibilidade se comparado a MFS. 
Figura 46 - Possível interação entre os grupos hidroxilas presentes na matriz RFF e na celulose (fibra rayon).

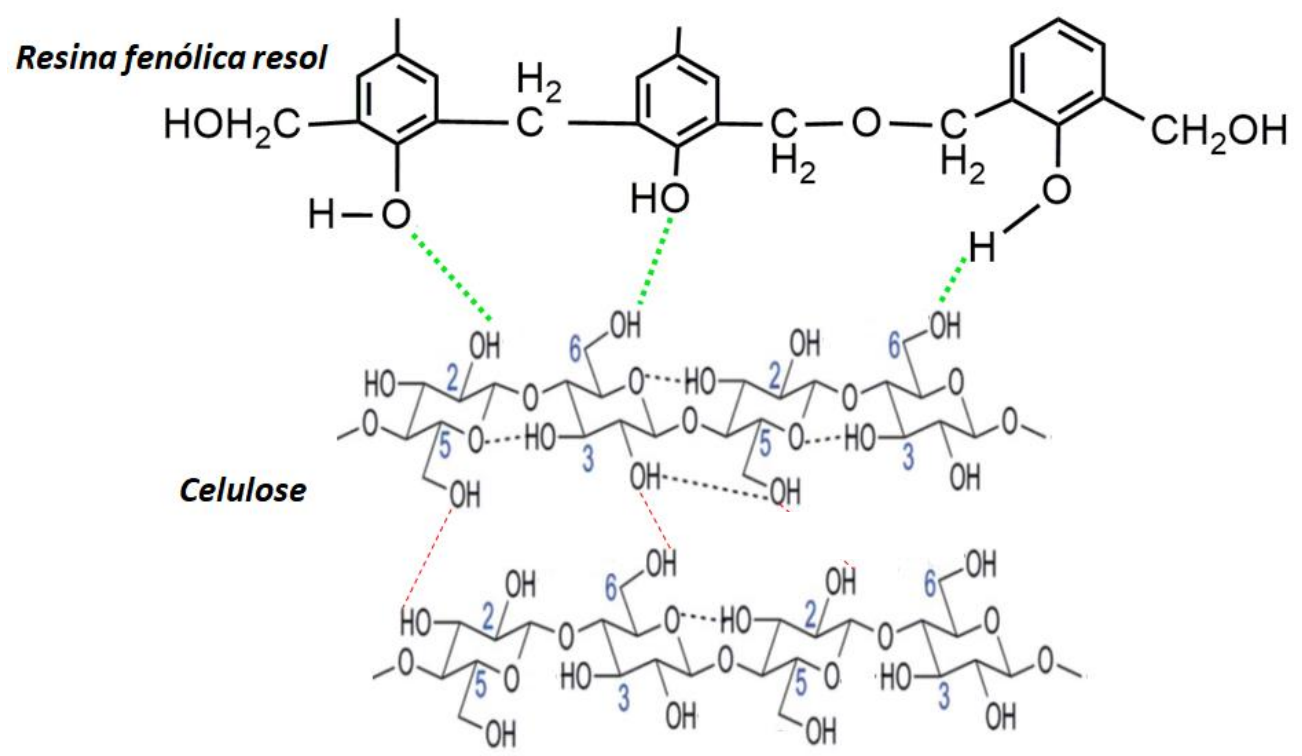

Fonte: Autoria própria

Devido à heterogeneidade da FMD em termos de comprimento, espessura, diâmetro, e a presença de silício nos poros da superfície da fibra (que pode ter prejudicado a penetração da resina fenólica), obteve-se compósitos com propriedades mecânicas aquém do esperado, conforme apresentado no Capítulo 1. Assim, foi realizado um estudo visando avaliar a influência do uso desta fibra na preparação de compósitos híbridos constituídos por MFS e FMD $_{\text {moída }}$ em matriz RFF. Os resultados referentes a estes compósitos serão apresentados a seguir.

\subsection{Compósitos híbridos de matriz termorrígida RFF reforçados com MFS/FMD moída}

Compósitos híbridos são materiais constituídos por dois ou mais tipos de fibras que combinados em uma única matriz polimérica podem fornecer propriedades mecânicas melhores ou intermediárias quando comparadas com o mesmo compósito apenas com uma fibra individual (SAFRI et al., 2018).

Os resultados de resistência ao impacto dos compósitos híbridos reforçados MFS/FMD moída 9 e 16\% (em massa) de FMD $_{\text {moída }}$ e $38 \%$ e 35\% (em volume) de MFS, $\mathrm{C}_{\mathrm{RFF}} 38 \% \mathrm{MFS}_{\text {im-ag-et }} 9 \% \mathrm{FMD}_{\text {moída }}$ e $\mathrm{C}_{\mathrm{RFF}} 35 \% \mathrm{MFS}_{\text {im-ag-et }} 16 \% \mathrm{FMD}_{\text {moída }}$, respectivamente, estão apresentados na Figura 47-a. Estes serão comparados com o resultado obtido no $\mathrm{C}_{\mathrm{RFF}} 42 \% \mathrm{MFS}_{\text {im-ag-et }}$ devido o método de impregnação utilizado em ambos ter sido o mesmo, imersão prévia da MFS em água por 6 h, objetivando causar a separação dos feixes de fibras, e 
adição de $70 \mathrm{~mL}$ de etanol na RFF para reduzir a viscosidade e facilitar a homogeneização da FMD moída na RFF (Tabela 10). Todos os compósitos híbridos apresentaram resultados de resistência ao impacto superiores ao TRFF (termorrígido não reforçado), Figura 47-a.

Figura 47 - Resultados de resistência ao impacto do termorrígido (TRFF) e dos compósitos híbridos de matriz termorrígida fenólica reforçados com MFS/FMD moída, $\mathrm{C}_{\mathrm{RFF}} 38 \% \mathrm{MFS}_{\text {im-ag-et }} 9 \% \mathrm{FMD}_{\text {mó́da }} \mathrm{e}$ $\mathrm{C}_{\mathrm{RFF}} 35 \% \mathrm{MFS}_{\text {im-ag-et }} 16 \% \mathrm{FMD}_{\text {móda }}$ (a) e comparativo entre os resultados de resistência ao impacto normalizados dos compósitos híbridos reforçados com MFS/FMD moída $_{\text {(b). }}$

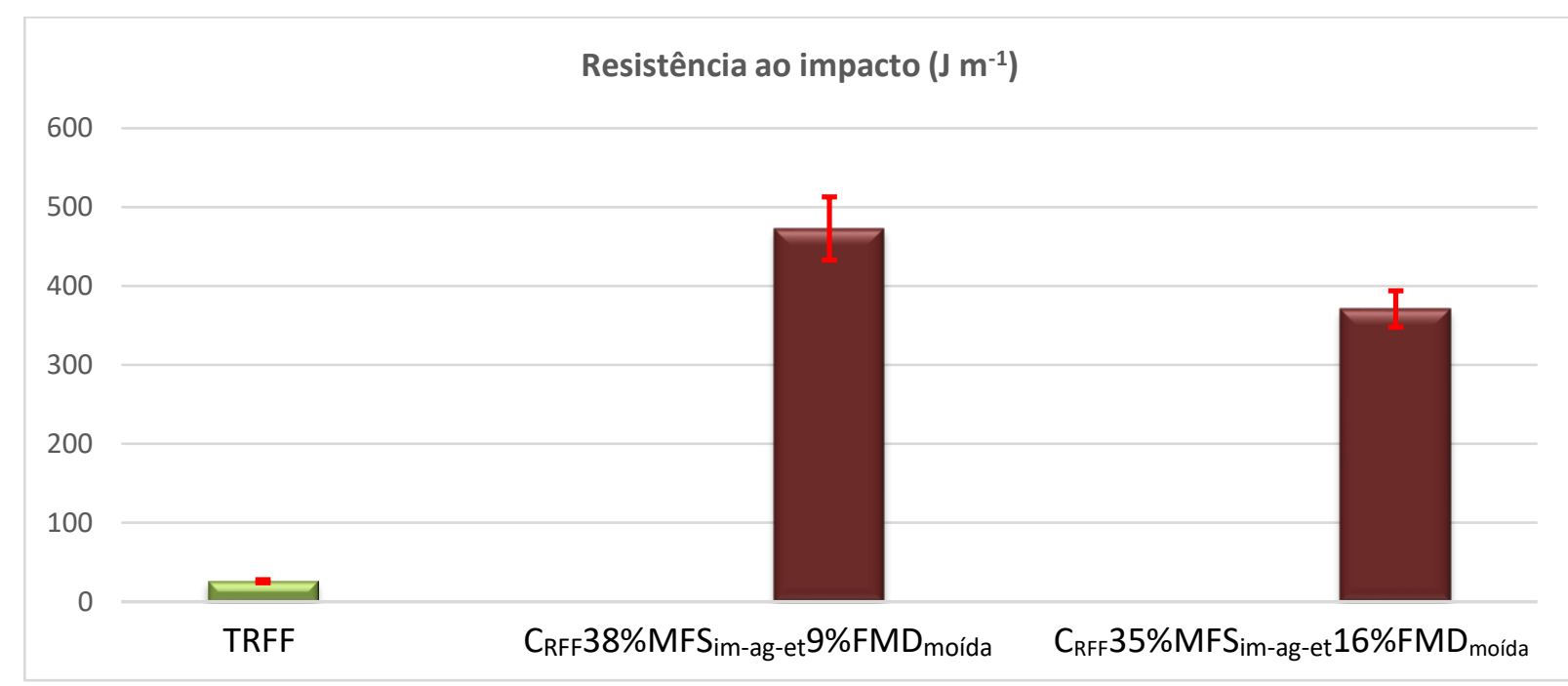

(a)

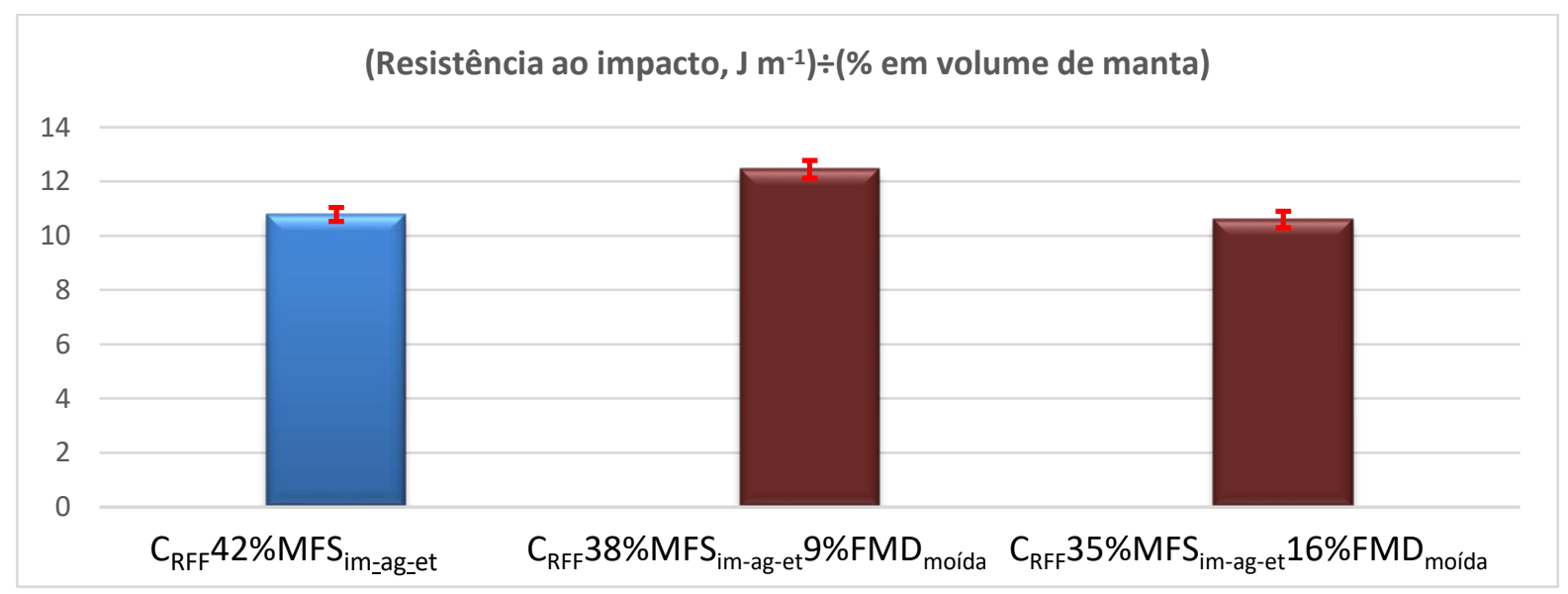

(b)

Em relação aos compósitos híbridos contendo MFS/FMD moída, as porcentagens em massa de FMD $D_{\text {moída }}$ utilizadas foram selecionadas com base em experimentos preliminares.

A Figura 47- b mostra os resultados de resistência ao impacto normalizados para os compósitos híbridos, os quais serão comparados com o compósito $\mathrm{C}_{\mathrm{RFF}} 42 \% \mathrm{MFS}$ im-ag-et. Ao comparar os resultados obtidos entre os compósitos $\mathrm{C}_{\mathrm{RFF}} 38 \% \mathrm{MFS}_{\text {im-ag-et }} 9 \% \mathrm{FMD}_{\text {moída }}$ com o $\mathrm{C}_{\mathrm{RFF}} 42 \% \mathrm{MFS}_{\mathrm{im}-\mathrm{ag}-\mathrm{et}}$, observou-se que houve um aumento da resistência ao impacto por volume de 
manta, indicando que a $\mathrm{FMD}_{\text {moída }}$ atuou como reforço adicional e não apenas como filler (enchimento/carga). A adição de $9 \%$ de $\mathrm{FMD}_{\text {moída }}$ ocasionou uma melhora nesta propriedade devido à maior absorção de energia, dificultando a iniciação e o mecanismo de fixação da trinca, assim como sua propagação no corpo-de-prova sob tensão de carga (SABA et al., 2016).

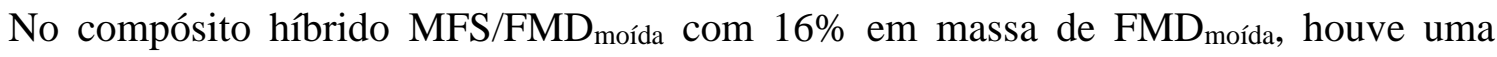
redução na resistência ao impacto e que pode estar relacionado a formação de aglomerados devido a não adequada dispersão de FMD na matriz, gerando regiões que prejudicaram a dissipação de energia da matriz para as fibras (THEN et al., 2013)

\subsubsection{Microscopia Eletrônica de Varredura (MEV)}

\subsection{Compósitos de matriz termorrígida RFF reforçados com MFS e MFR}

As Figuras 48 e 49 apresentam as micrografias das regiões de fratura obtidas após o ensaio de impacto Izod dos compósitos de matriz RFF reforçados com MFS, $\mathrm{C}_{\mathrm{RFF}} 42 \% \mathrm{MFS}$, e $\mathrm{C}_{\mathrm{RFF}} 42 \% \mathrm{MFS}_{\text {im-ag-et }}$ e dos compósitos de matriz RFF reforçado com MFR, $\mathrm{C}_{\mathrm{RFF}} 10 \% \mathrm{MFR}$ e $\mathrm{C}_{\mathrm{RFF}} 19 \% \mathrm{MFR}$, respectivamente.

As micrografias do termorrígido foram apresentadas no Capítulo 1 (Figura 31- a) e o mesmo apresentou regiões de propagação de trincas com regiões espelhadas, conferindo característica de material do tipo frágil (RAMIRES, 2010). Em todos os compósitos observouse que houve descolamento entre a fibra e a matriz (setas verdes), com regiões em que os feixes não estão recobertos pela mesma e presença de trincas que se propagaram ao redor da fibra durante o ensaio de impacto Izod (RAMIRES, 2010; MEGIATTO, 2006). Este descolamento pode estar relacionado à interface de adesão entre ambas menos intensa (ALAAEDDIN et al., 2019).

No ensaio de impacto Izod o corpo-de-prova é atingido pelo martelo em um ponto que leva à formação e propagação da trinca (setas cinzas) causando a fratura total ou parcial do material em resposta à imposição de uma tensão (CALLISTER, 2002). Um processo de fratura é iniciado pela formação e propagação da trinca. Ainda é importante destacar o fato de que nestes compósitos com MFS e MFR existem feixes de fibras alinhados à $0^{\circ}$ e $90^{\circ}$, ocorrendo rompimento parcial destes feixes e deformação de outros, permanecendo uma ponte de feixes de fibras (fiber bridging). A mesma tendência foi observada por Vieira et al. (2018) ao utilizarem manta de fibra de juta/malva como reforço em compósito de matriz epóxi. 
Figura 48 - Micrografias das superfícies fraturadas, pós-impacto, dos compósitos de matriz RFF reforçados com $42 \%$ (em volume) de MFS, $\mathrm{C}_{\mathrm{RFF}} 42 \% \mathrm{MFS}$ (a) e $\mathrm{C}_{\mathrm{RFF}} 42 \% \mathrm{MFS}_{\text {im-ag-et }}$ (b).

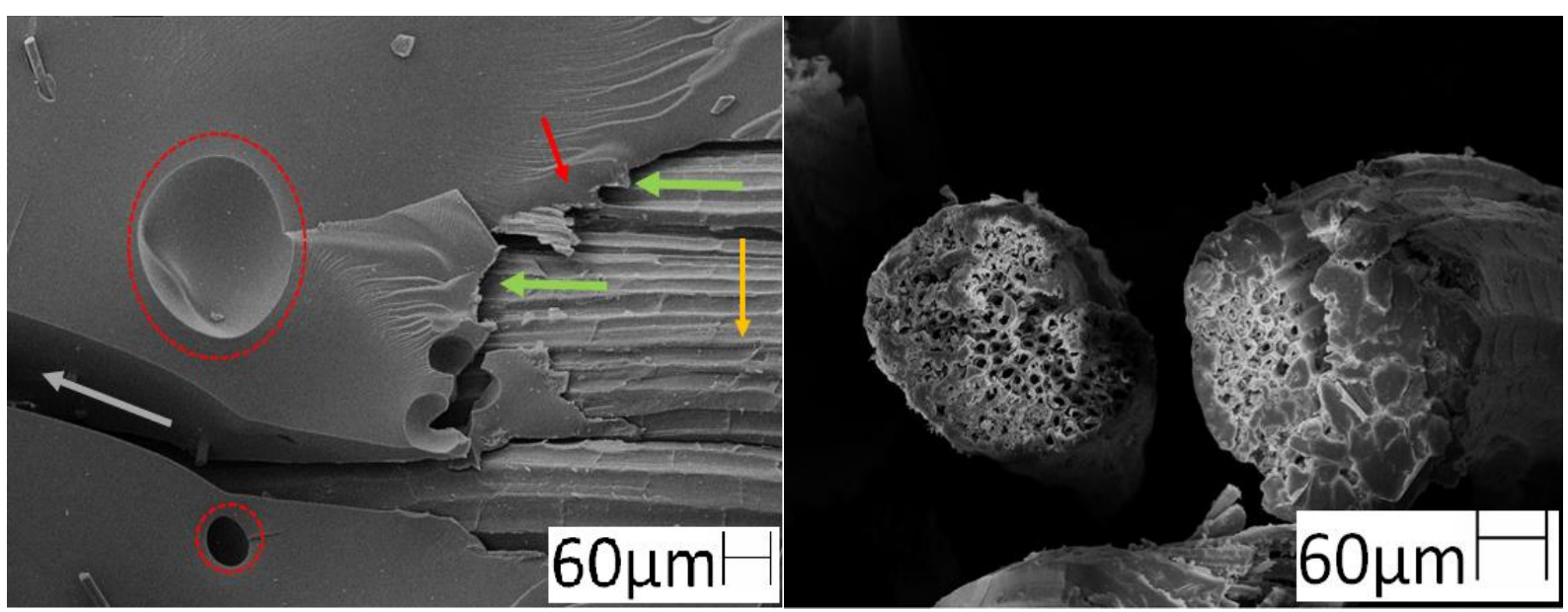

(a)

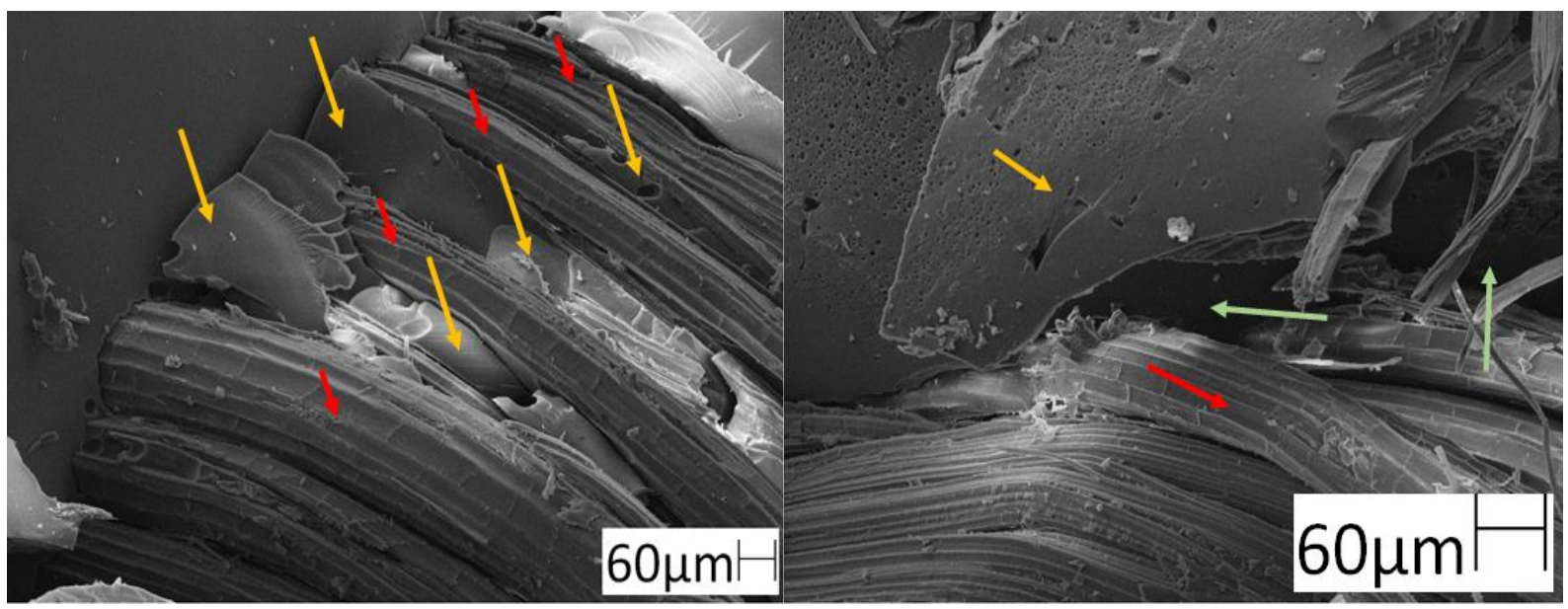

(b)

Na Figura 48- a, foi possível observar a presença de matriz (setas vermelhas) entre os feixes de fibras (setas amarelas), indicando que neste processo, imersão prévia da MFS em água e adição de etanol na RFF para reduzir a viscosidade da mesma, pode ter ocorrido uma maior impregnação de resina na região interna dos feixes. Ainda, na Figura 48-a observou-se que os feixes de fibra de sisal estão parcialmente preenchidos pela resina. 
Figura 49 - Micrografias das superfícies fraturadas, pós-impacto, dos compósitos de matriz RFF reforçados com 10\% (em volume) de MFR (a) e 19\% (em volume) de MFR (b).

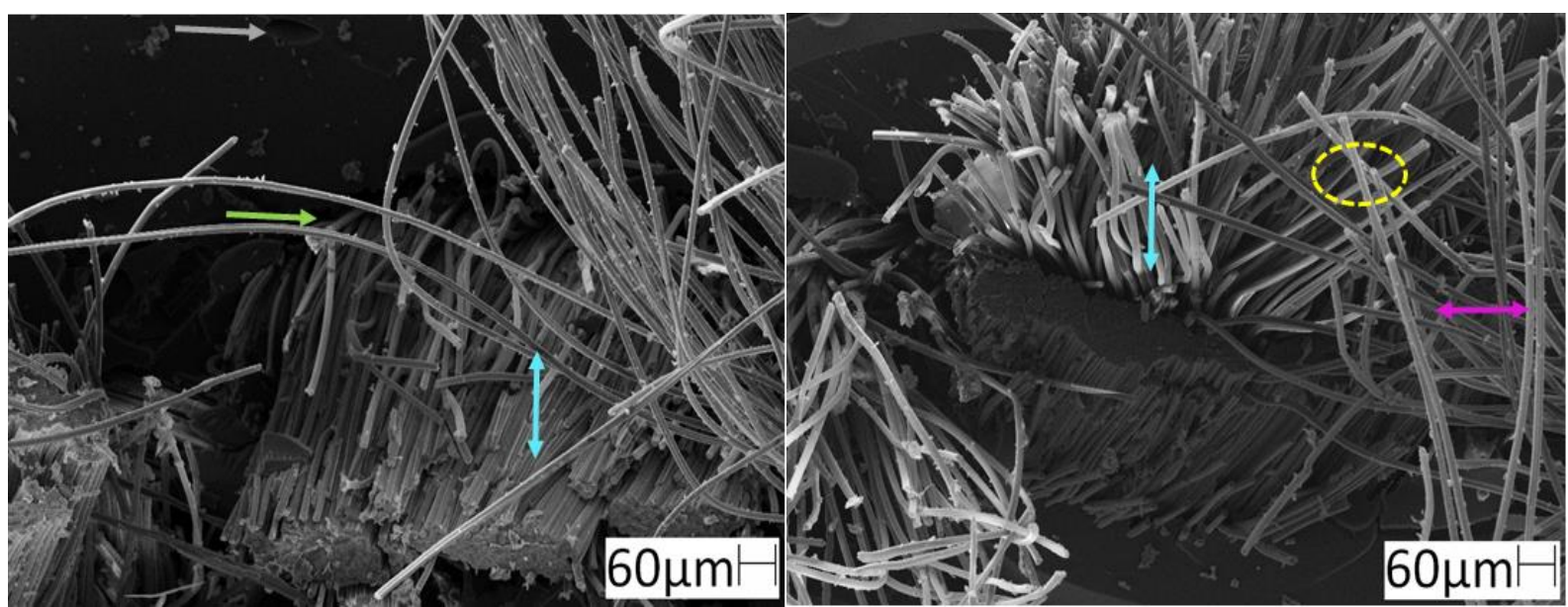

(a)

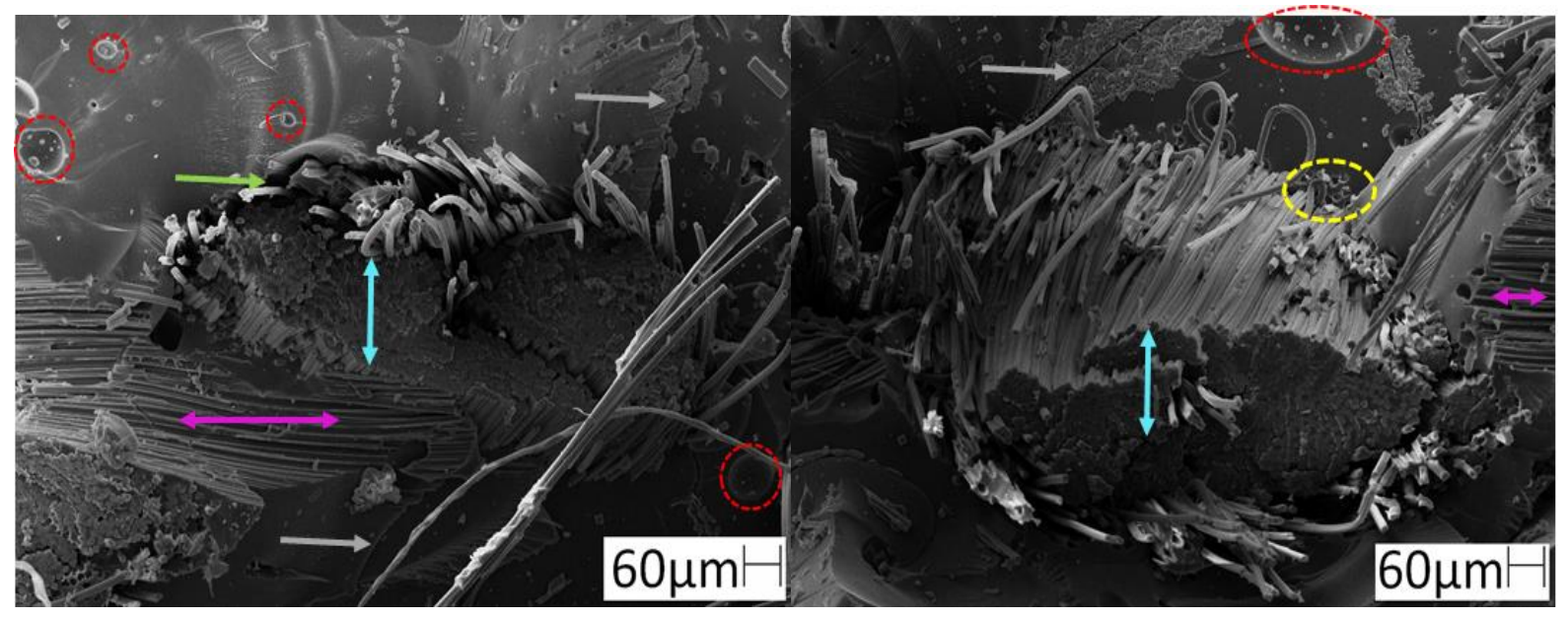

(b)

Em relação aos compósitos de matriz RFF reforçados com MFR, foram observadas regiões em que houve um sutil descolamento entre a fibra e a matriz (setas verdes) (Figura 49a e -b). Este descolamento aparentemente pode estar relacionado à propagação de trincas ao redor do feixe de fibras rayon durante o ensaio de impacto Izod (RAMIRES, 2010; MEGIATTO JUNIOR, 2006) e não à baixa adesão interfacial fibra/matriz. Também se observou que houve o rompimento parcial dos feixes da manta rayon tanto a $0^{\circ}$ (setas duplas roxas) quanto à $90^{\circ}$ (setas duplas azuis) como mostrado nas micrografias (Figura 49-a e -b), que pode ser um indicativo de boa adesão e transferência de estresse da matriz para as fibras da manta.

O fato da matriz fenólica ser constituída por anéis aromáticos de baixa polaridade e hidroxilas, os quais possuem afinidade com os grupos hidroxilas presentes na celulose (Figura 46) pode ter aumentado a interação entre ambos, melhorando assim a adesão e, consequentemente, os resultados de resistência ao impacto normalizados comparativamente aos 
compósitos reforçados com MFS (RAZERA et al., 2014; DE OLIVEIRA et al., 2017). A partir das micrografias da Figura 49 -a e -b, observa-se que houve um recobrimento dos multifilamentos que compõem um feixe de fibra rayon. Este possui uma densidade linear 1,84 $\mathrm{g} / \mathrm{cm}^{2}$ e um feixe composto por 1000 filamentos, segundo especificações da empresa Cordenka, que forneceu a manta de rayon.

\subsection{Compósitos híbridos de matriz termorrígida RFF reforçados com MFS/FMDmoída}

A Figura 50 mostra as micrografias dos compósitos híbridos de matriz RFF reforçados com MFS/FMD moída, $\mathrm{C}_{\mathrm{RFF}} 38 \% \mathrm{MFS}_{\text {im-ag-et }} 9 \% \mathrm{FMD}_{\text {moída }}$ e $\mathrm{C}_{\mathrm{RFF}} 35 \% \mathrm{MFS}_{\text {im-ag-et }} 16 \% \mathrm{FMD}_{\text {moída }}$, respectivamente.

Figura 50 - Micrografias das superfícies fraturadas, pós-impacto, dos compósitos de matriz RFF reforçados com MFS/FMD moída $_{\text {, }} \mathrm{C}_{\mathrm{RFF}} 38 \% \mathrm{MFS}_{\text {im-ag-et }} 9 \% \mathrm{FMD}_{\text {moída }}$ (a) e $\mathrm{C}_{\mathrm{RFF}} 35 \% \mathrm{MFS}_{\text {im-ag-et }} 16 \% \mathrm{FMD}_{\text {móda }}$ (b).

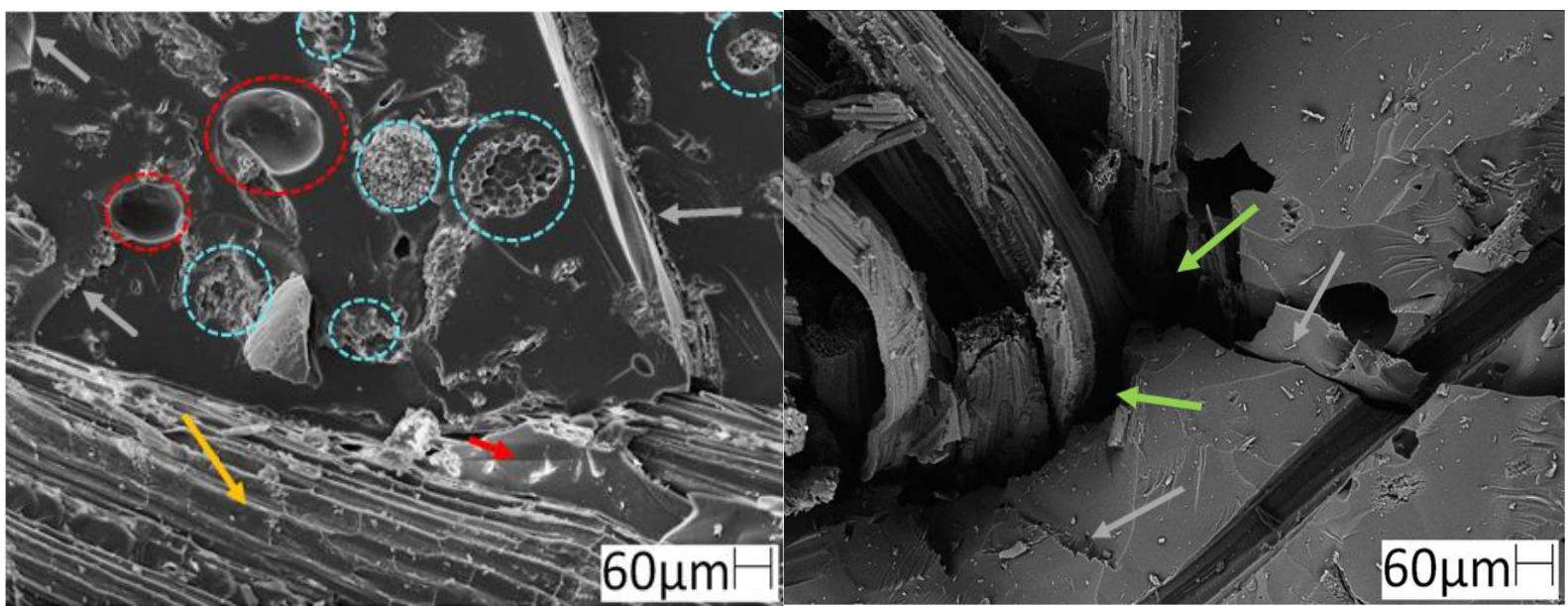

(a)

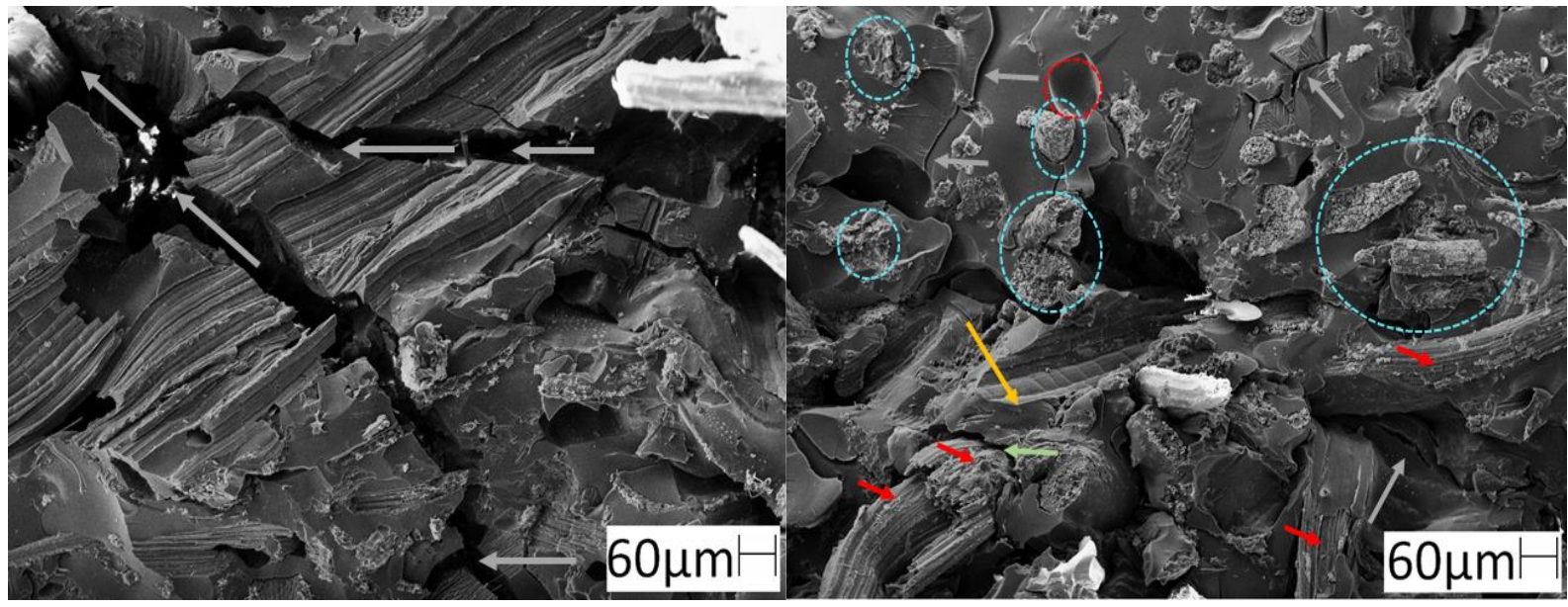

(b) 
Nestes compósitos notou-se com maior clareza a presença de trincas na matriz (setas cinzas), arrancamento das fibras (círculos amarelos), além da presença de microvazios (círculos vermelhos), os quais podem estar relacionados à vaporização da água remanescente na resina e liberação de água produzida na etapa de entrecruzamento da mesma (MEGIATTO JÚNIOR et al., 2009).

As micrografias dos compósitos MFS/FMD moída mostram que a presença de uma maior propagação de trincas que se propagaram durante o ensaio de impacto Izod foi mais evidente no compósito $\mathrm{C}_{\mathrm{RFF}} 35 \% \mathrm{MFS}_{\mathrm{im} \text {-ag-et }} 16 \% \mathrm{FMD}_{\text {moída }}$ o que corrobora com a redução da resistência ao impacto observada anteriormente para este compósito comparado ao $\mathrm{C}_{\mathrm{RFF}} 38 \% \mathrm{MFS}_{\text {im-ag- }}$ et $9 \%$ FMD moída.

\subsubsection{Ensaio de Flexão}

\subsection{Compósitos reforçados com MFS, CRFF42\%MFS e CRFF42\%MFS im-ag-et, e reforçados com MFR, CRFF10\%MFR e CRFF $19 \%$ MFR}

Os resultados de flexão do TRFF, dos compósitos de matriz RFF reforçados com MFS, $\mathrm{C}_{\mathrm{RFF}} 42 \% \mathrm{MFS}$ e $\mathrm{C}_{\mathrm{RFF}} 42 \% \mathrm{MFS}_{\text {im-ag-et, }}$ e dos compósitos reforçados com MFR, $\mathrm{C}_{\mathrm{RFF}} 10 \% \mathrm{MFR}$ e $\mathrm{C}_{\mathrm{RFF}} 19 \% \mathrm{MFR}$, estão apresentados na Figura 51. Durante os ensaios deste teste, os corpos-deprova não sofreram ruptura total devido a presença de mantas, tanto de sisal quanto de rayon, nos compósitos. Portanto, os mesmos sofreram ruptura apenas na superfície.

A Figura 51 mostra que não houve uma diferença significativa entre os valores de resistência à flexão dos compósitos reforçados com MFS preparados por dois métodos de impregnação diferentes (Tabela 10). Os compósitos $\mathrm{C}_{\mathrm{RFF}} 42 \% \mathrm{MFS}$ e $\mathrm{C}_{\mathrm{RFF}} 42 \% \mathrm{MFS}_{\text {im-ag-et }}$ não apresentaram diferenças significativas nos valores de resistência à flexão. No entanto, estes apresentaram uma redução na desta propriedade comparado ao TRFF. Vale destacar que neste ensaio a tensão submetida no corpo-de-prova pela carga de flexão é resultante da junção de forças de compressão (região superior) e tração (região inferior). Portanto, trincas que podem ser originadas em regiões específicas adjacentes à fibra devido ao estresse aplicado, podem acarretar a formação de caminhos de propagação da tensão, que levam à uma reduçao da resistência à flexão do material (ALAAEDIN et al., 2019). 
Figura 51 - Resultados de resistência à flexão dos termorrígido TRFF, compósitos reforçados com MFS, $\mathrm{C}_{\mathrm{RFF}} 42 \% \mathrm{MFS}, \mathrm{C}_{\mathrm{RFF}} 42 \% \mathrm{MFS}_{\text {im-ag-et }}$, e MFR, $\mathrm{C}_{\mathrm{RFF}} 10 \% \mathrm{MFR}$ e $\mathrm{C}_{\mathrm{RFF}} 19 \% \mathrm{MFR}$ (a), e comparativo entre os resultados de resistência à flexão normalizados dos compósitos reforçados com MFS e MFR (b).

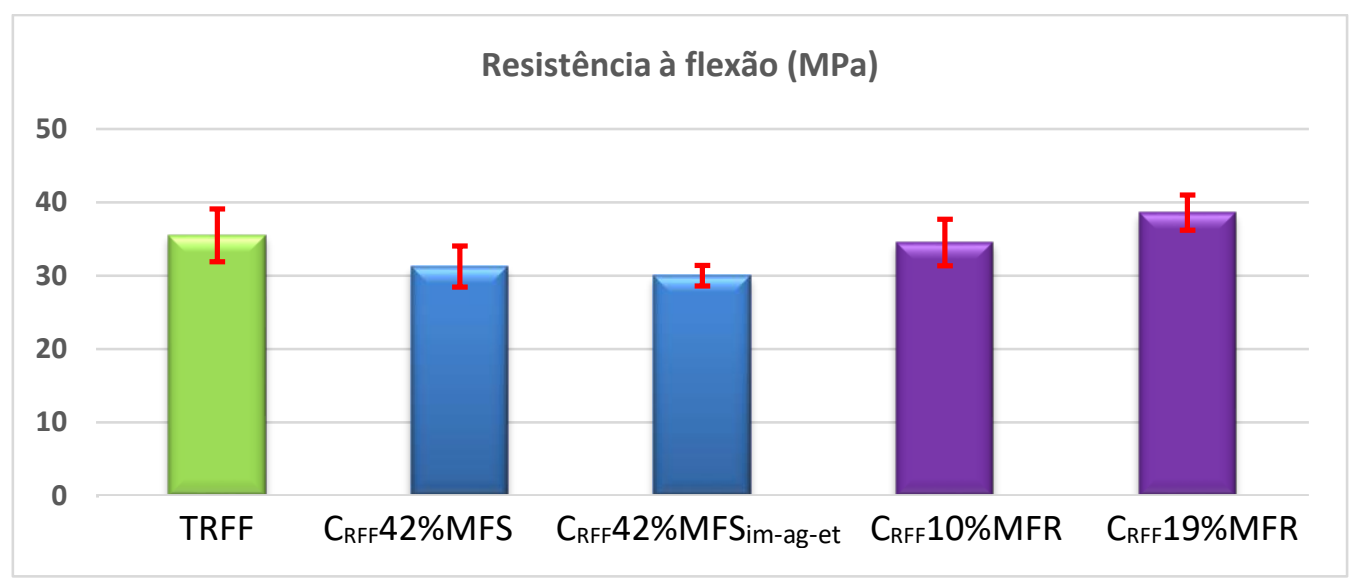

(a)

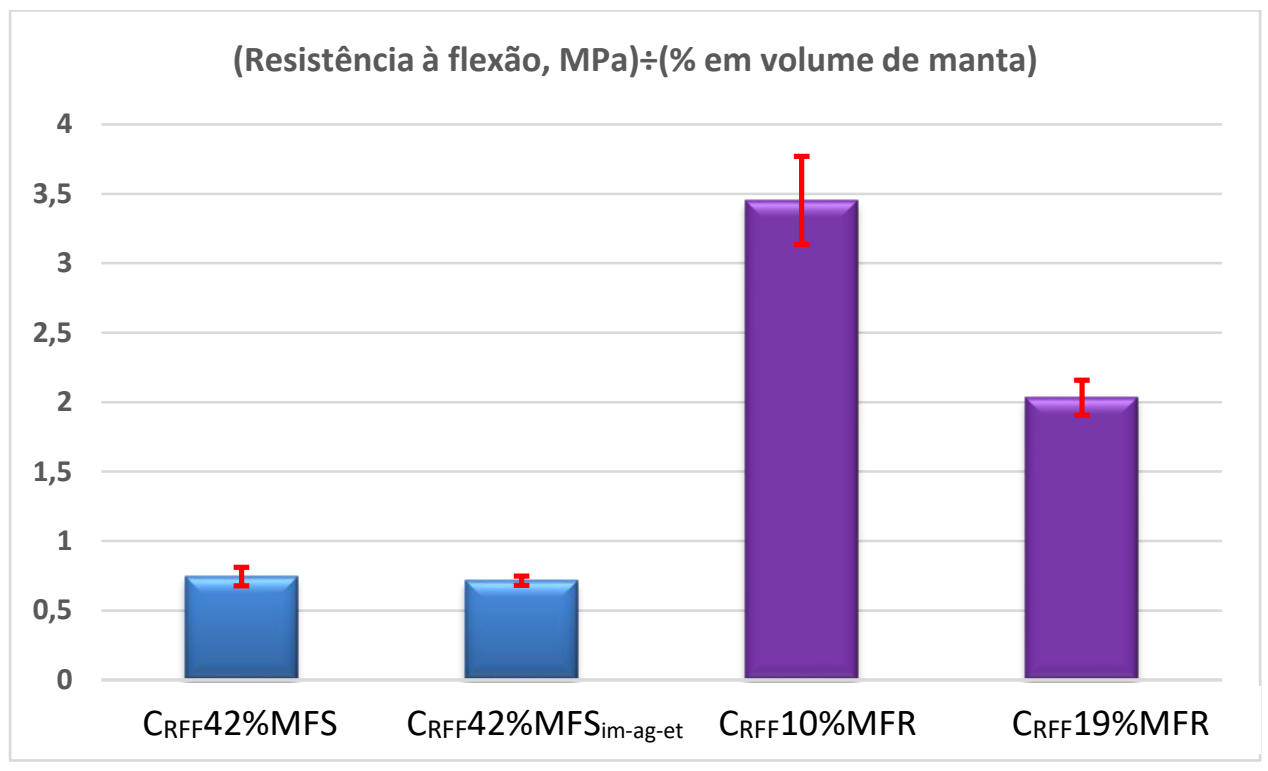

(b)

Dentre os compósitos reforçados com MFR, o $\mathrm{C}_{\mathrm{RFF}} 19 \% \mathrm{MFR}$ apresentou maior resistência à flexão comparado ao $\mathrm{C}_{\mathrm{RFF}} 10 \% \mathrm{MFR}$ e demais compósitos. Comparado ao TRFF, o $\mathrm{C}_{\mathrm{RFF}} 19 \% \mathrm{MFR}$ apresentou um aumento mesmo com a aproximação dos valores dos desvios.

Isto pode estar associado à uma maior distribuição da tensão à medida que a mesma foi aplicada no corpo-de-prova constituído por duas mantas (BLEDZKI et al., 2015; FIORE et al., 2016).

Fazendo uma breve comparação entre os valores de resistência à flexão normalizados (Figura 51- b), os quais foram obtidos dividindo a resistência à flexão por unidade de \% em em volume de manta, observou-se que o compósito com $\mathrm{C}_{\mathrm{RFF}} 10 \% \mathrm{MFR}$ apresentou maior 
resistência à flexão por unidade de \% de volume de manta, que pode estar associado à uma maior adesão neste comparado aos compósitos com MFS.

Com relação ao módulo de flexão (Figura 52- a), apenas o compósito $\mathrm{C}_{\mathrm{RFF}} 19 \% \mathrm{MFR}$ foi superior ao TRFF, indicando que neste houve um aumento da rigidez do material. No entanto, comparando os resultados de módulo de flexão normalizados (Figura 52- b), o $\mathrm{C}_{\mathrm{RFF}} 10 \% \mathrm{MFR}$ apresentou maior módulo de flexão por unidade de \% de volume de manta.

Figura 52 - Resultados de módulo de flexão do termorrígido TRFF, compósitos reforçados com MFS, $\mathrm{C}_{\mathrm{RFF}} 42 \% \mathrm{MFS}, \mathrm{C}_{\mathrm{RFF}} 42 \% \mathrm{MFS}_{\text {im-ag-et }}$, e MFR, $\mathrm{C}_{\mathrm{RFF}} 10 \% \mathrm{MFR}$ e $\mathrm{C}_{\mathrm{RFF}} 19 \% \mathrm{MFR}$ (a), e comparativo entre os resultados de módulo de flexão normalizados dos compósitos reforçados com MFS e MFR (b).

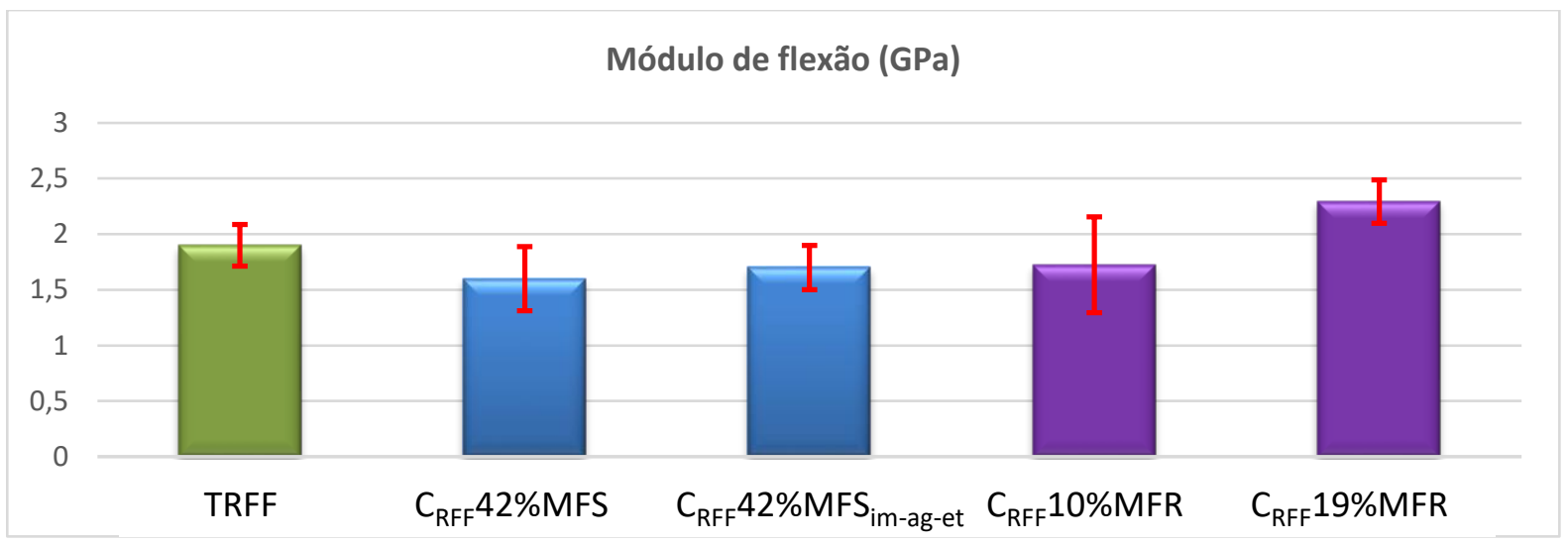

(a)

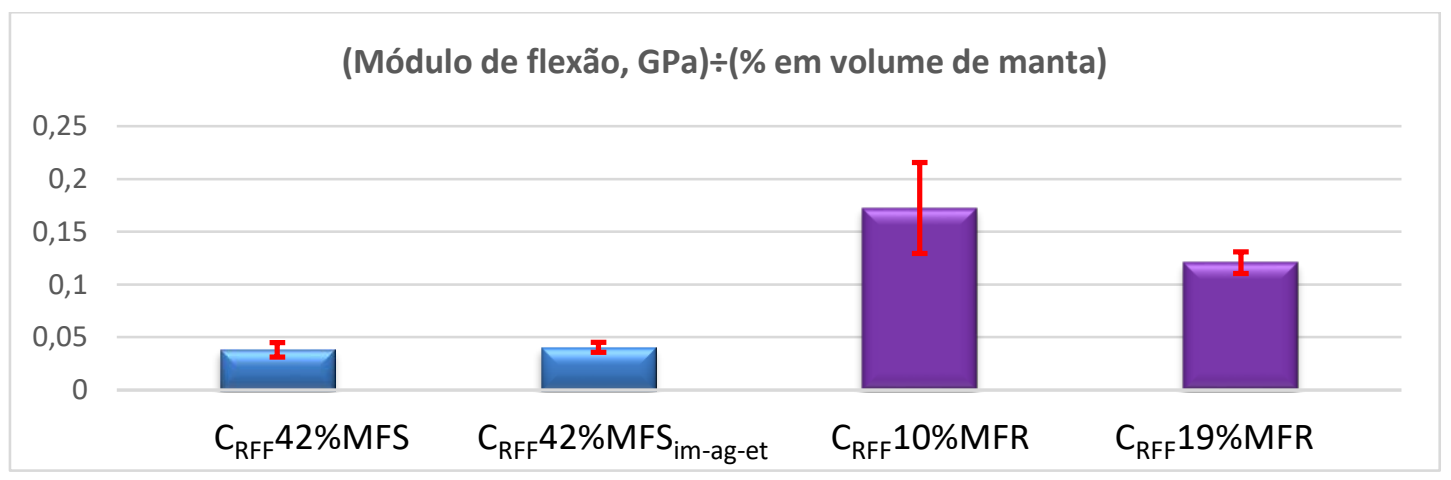

(b)

\subsection{Compósitos híbridos de matriz termorrígida RFF reforçados com MFS/FMDmoída}

A Figura 53 apresenta os resultados de resistência à flexão do termorrígido e os resultados normalizados dos compósitos híbridos reforçados por MFS/FMD moída, $\mathrm{C}_{\mathrm{RFF}} 38 \% \mathrm{MFS}_{\text {im-ag-et }} 9 \% \mathrm{FMD}_{\text {moída }}$ e $\mathrm{C}_{\mathrm{RFF}} 35 \% \mathrm{MFS}_{\text {im-ag-et }} 16 \% \mathrm{FMD}_{\text {moída. }}$

A Figura 53- a mostra que os resultados de resistência à flexão dos compósitos híbridos 
foram inferiores comparativamente ao TRFF. Apesar da inserção de FMD moída ter aumentado a resistência do material em termos de resistência ao impacto como observado anteriormente (Figura 47), a redução na resistência à flexão destes compósitos pode ter sido influenciada por fatores como: distribuição heterogênea da FMD moída, presença de vazios (LIU et al., 2006) e microtrincas no compósito. Isto pode ter levado a uma distribuição não uniforme da tensão (BLEDZKI et al., 2015; FIORE et al., 2016). Darros (2013) observou efeito semelhante na redução da resistência à flexão de compósitos de matriz epóxi reforçados com manta de côco e sisal.

No entanto, comparando os resultados normalizados destes com o compósito reforçado apenas com MFS e preparado pelo mesmo método de impregnação, $\mathrm{C}_{\mathrm{RFF}} 42 \% \mathrm{MFS}$ im-ag-et, o compósito híbrido $\mathrm{C}_{\mathrm{RFF}} 35 \% \mathrm{MFS}_{\text {im-ag-et }} 16 \% \mathrm{FMD}_{\text {moída }}$ apresentou um aumento na resistência à flexão mesmo com a aproximação dos valores dos desvios.

Figura 53 - Resultados de resistência à flexão do TRFF e dos compósitos híbridos $\mathrm{C}_{\mathrm{RFF}} 38 \% \mathrm{MFS}_{\text {im-ag- }}$ et $9 \% \mathrm{FMD}_{\text {moída }}$ e $\mathrm{C}_{\mathrm{RFF}} 35 \% \mathrm{MFS}_{\text {im-ag-et }} 16 \% \mathrm{FMD}_{\text {moída }}$ (a) e comparativo entre os resultados de resistência à flexão normalizados dos compósitos híbridos com o $\mathrm{C}_{\mathrm{RFF}} 42 \% \mathrm{MFS}_{\text {im-ag-et }}(\mathrm{b})$.

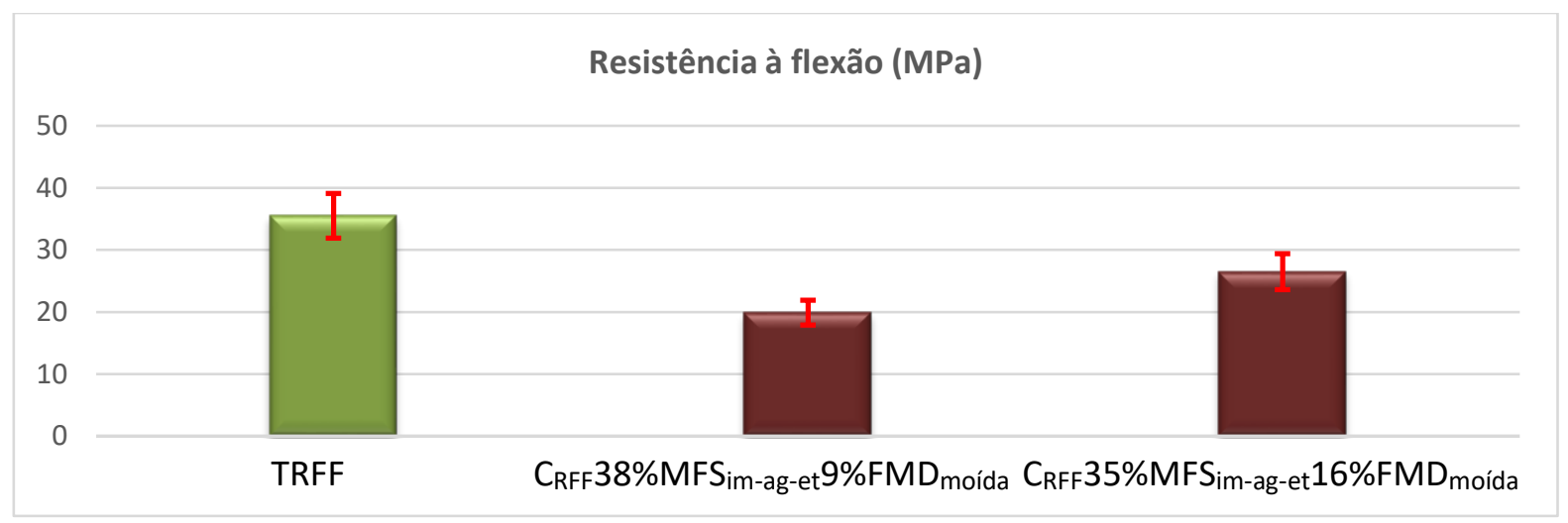

(a)

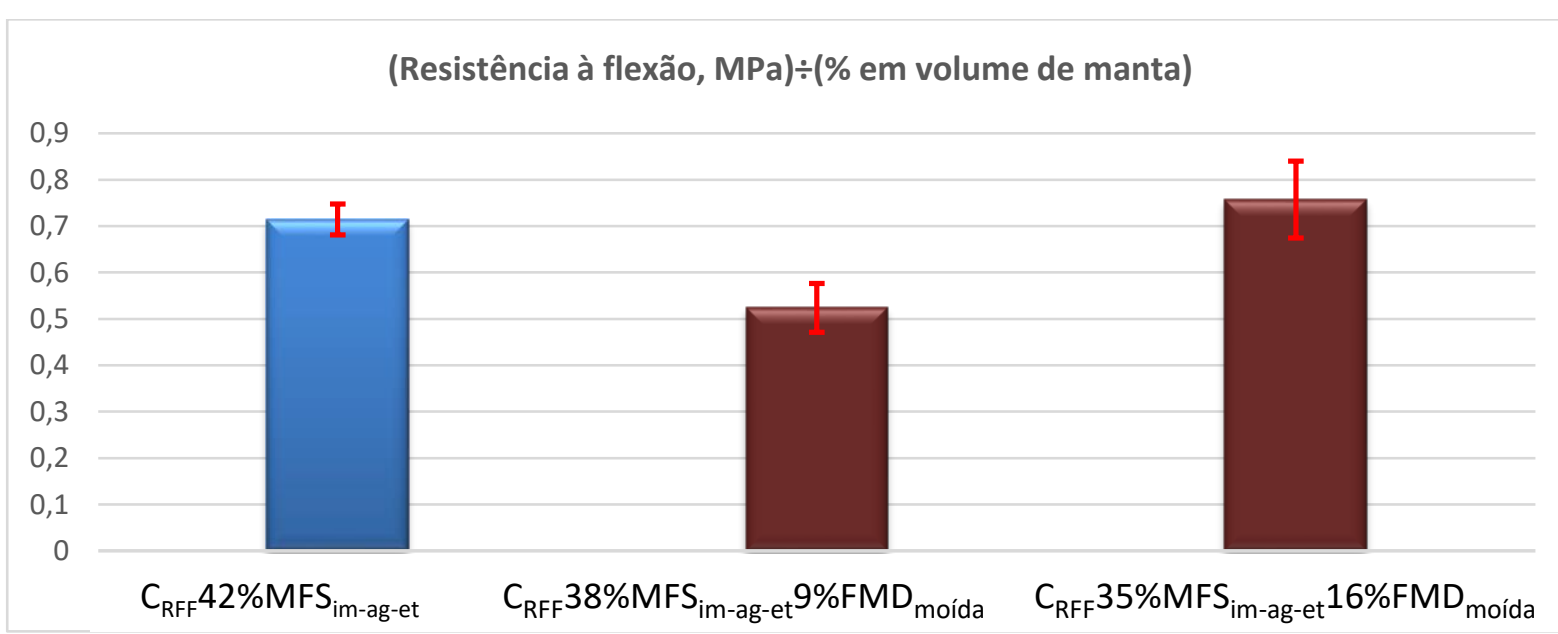

(b) 
Com base no módulo de flexão dos compósitos híbridos obtidos comparados ao TRFF (Figura 54- a), observou-se que houve um aumento desta propriedade com a inserção da $\mathrm{FMD}_{\text {moída. }}$ A mesma tendência foi observada quando se comparou os resultados de módulo de flexão normalizados com o compósito $\mathrm{C}_{\mathrm{RFF}} 42 \% \mathrm{MFS}_{\text {im-ag-et, }}$ o qual foi preparado pelo mesmo método de impregnação. Um aumento no módulo de flexão está associado à um aumento da rigidez do material (FIORE et al., 2016).

Figura 54 - Resultados de módulo de flexão do TRFF e dos compósitos híbridos $\mathrm{C}_{\mathrm{RFF}} 38 \% \mathrm{MFS}_{\text {im-ag- }}$ et $9 \% \mathrm{FMD}_{\text {moída }}$ e $\mathrm{C}_{\mathrm{RFF}} 35 \% \mathrm{MFS}_{\text {im-ag-et }} 16 \% \mathrm{FMD}_{\text {moída }}$ (a) e comparativo entre os resultados de módulo de flexão normalizados dos compósitos híbridos com o $\mathrm{C}_{\mathrm{RFF}} 42 \% \mathrm{MFS}_{\text {im-ag-et }}(\mathrm{b})$.

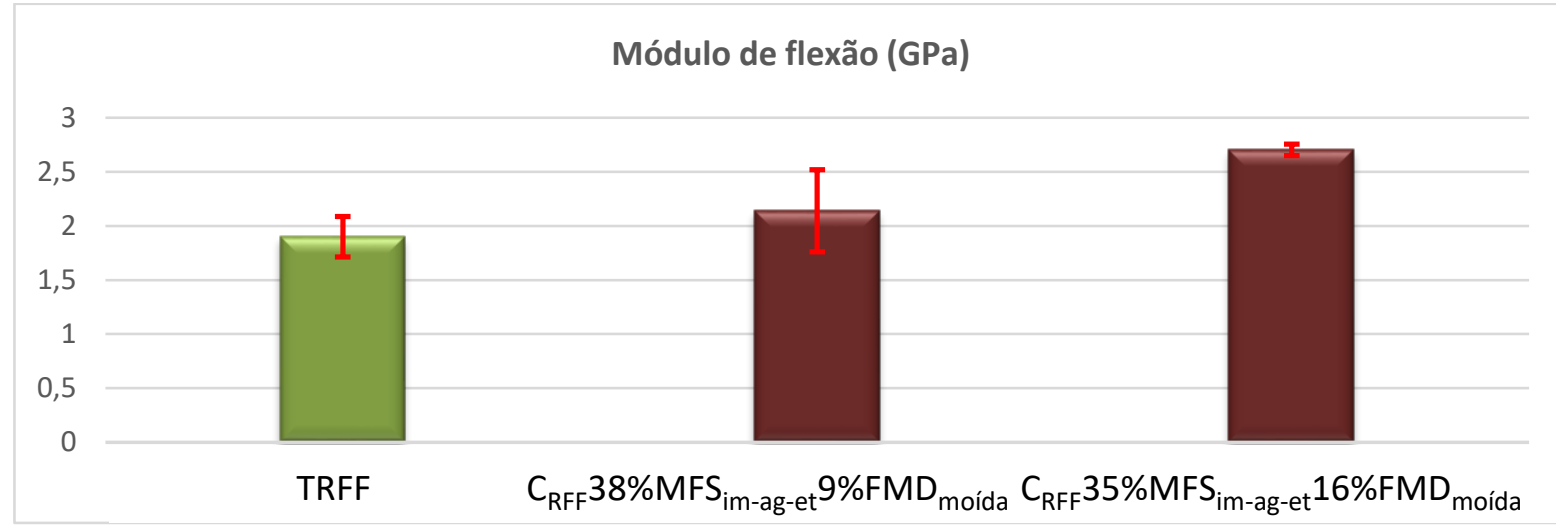

(a)

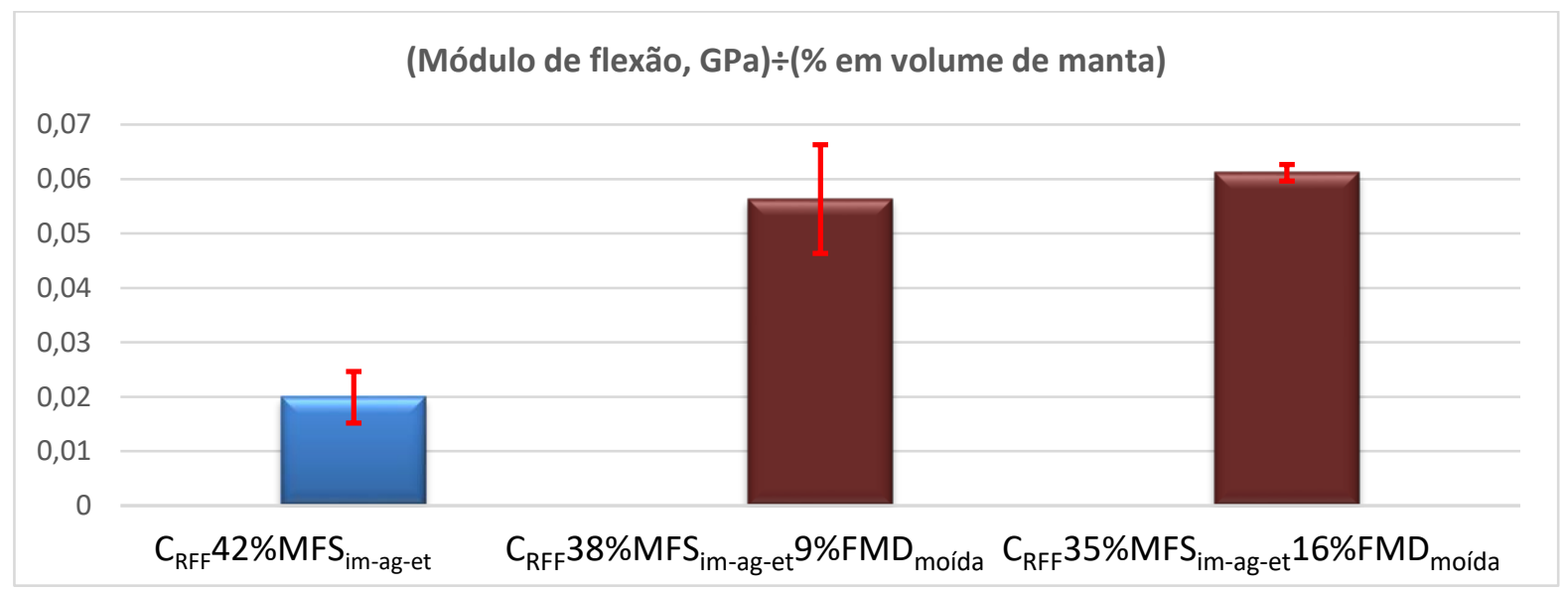

(b)

Entre os compósitos híbridos $\mathrm{C}_{\mathrm{RFF}} 38 \% \mathrm{MFS}_{\text {im-ag-et }} 9 \% \mathrm{FMD}_{\text {moída }}$ e $\mathrm{C}_{\mathrm{RFF}} 35 \% \mathrm{MFS}_{\text {im-ag- }}$ et $16 \% \mathrm{FMD}_{\text {moída }}$ houve um aumento nesta propriedade mesmo com a aproximação dos valores dos desvios. Neste caso, a presença de uma maior porcentagem em massa de FMD na matriz permitiu a obtenção de uma compósito mais rígido. 


\subsubsection{Análise dinâmico-mecânica (DMA)}

\subsection{Compósitos matriz termorrígida RFF reforçados com MFS e MFR}

A Figura 55 apresenta as curvas de módulo de armazenamento (E') (a) e $\tan \delta$ versus temperatura (b) do termorrígido fenol-formaldeído (TRFF) e dos compósitos reforçados com MFS e MFR. Como apenas os compósitos $\mathrm{C}_{\mathrm{RFF}} 42 \% \mathrm{MFS}$ e $\mathrm{C}_{\mathrm{RFF}} 42 \% \mathrm{MFS}$ im-ag-et foram utilizados como padrão de comparação, dentre os métodos de impregnação utilizados, para preparação dos compósitos híbridos MFS/FMD moída, apenas os resultados de DMA referentes a estes serão apresentados a seguir.

As curvas da Figura 55- a, mostraram que a presença de mantas nos compósitos implicou em uma redução em E', comparativamente ao TRFF, o que indica menor grau de entrecruzamento na matriz devido a presença do reforço, assim como pode estar relacionado a uma transferência de carga parcial da matriz RFF para a MFS, que levou à um menor armazenamento de energia pelo sistema (LUZ et al., 2018). Ainda, a presença de vazios pode ter levado à redução de E' na maior parte dos compósitos comparativamente ao termorrígido (MEGIATTO JUNIOR, 2006; KAW, 2006).

Figura 55 - Curvas DMA- Módulo de armazenamento (E') (a) e tan $\delta$ versus temperatura (b) do termorrígido fenólico (TRFF) e dos compósitos reforçados com MFS, $\mathrm{C}_{\mathrm{RFF}} 42 \% \mathrm{MFS}$ e $\mathrm{C}_{\mathrm{RFF}} 42 \% \mathrm{MFS}_{\text {im-ag-et }}$, e MFR, $\mathrm{C}_{\mathrm{RFF}} 10 \% \mathrm{MFR}$ e $\mathrm{C}_{\mathrm{RFF}} 19 \% \mathrm{MFR}$.

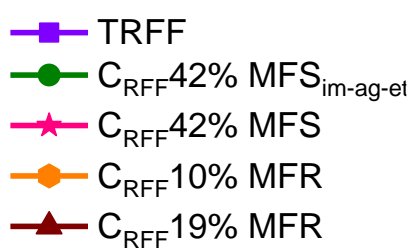

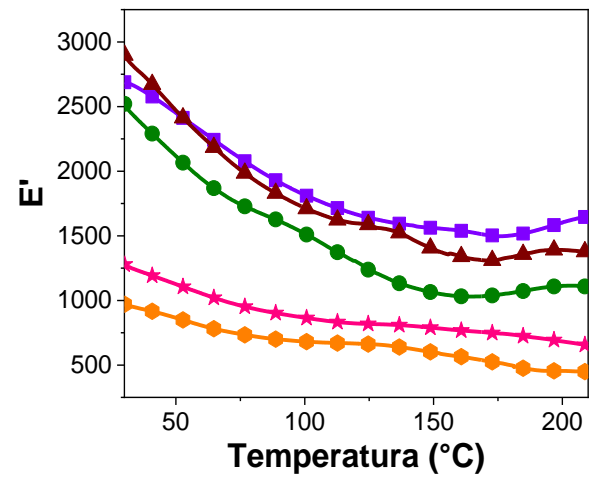

(a)

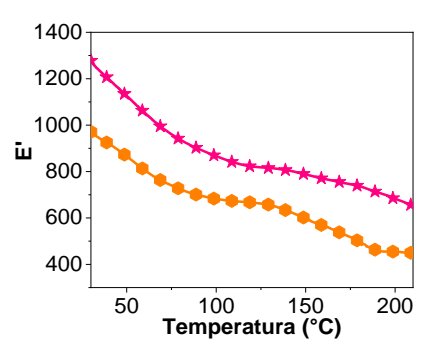

(a') 


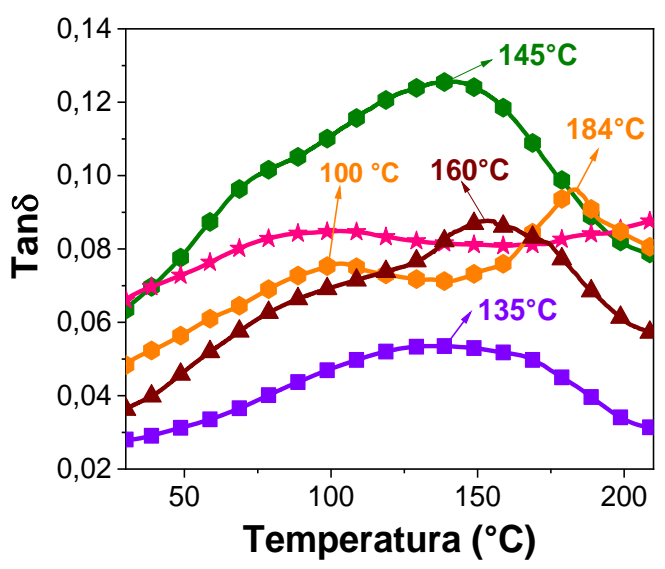

(b)

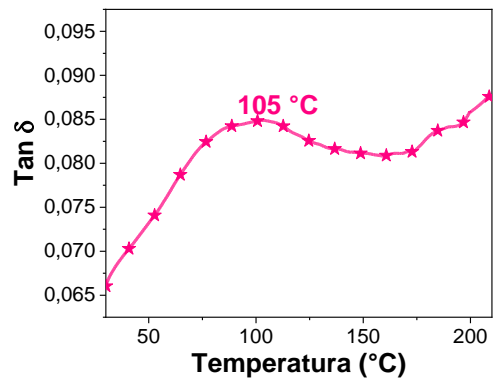

(b')

Ao comparar as curvas de E' dos compósitos $\mathrm{C}_{\mathrm{RFF}} 42 \% \mathrm{MFS}$ e $\mathrm{C}_{\mathrm{RFF}} 42 \%$ MFSimaget, vale destacar que estes só diferem entre si quanto ao método de impregnação utilizado na preparação dos mesmos, notou-se que o compósito $\mathrm{C}_{\mathrm{RFF}} 42 \% \mathrm{MFS}_{\text {im-ag-et }}$ apresentou valor de $\mathrm{E}$ ' maior quando comparado com o $\mathrm{C}_{\mathrm{RFF}} 42 \% \mathrm{MFS}$. A melhor impregnação leva a interações fibra/matriz mais intensa na interface, o que reduz a movimentação dos segmentos das cadeias, aumentando a rigidez do material (RAMIRES et al., 2010; SABA et al., 2017).

A Figura 55- b apresenta as curvas $\tan \delta$ versus temperatura. Fatores como tipo e distribuição de fibra na matriz, assim como vazios e interação fibra-matriz, interferem diretamente no valor do tan $\delta$ (ASIM et al., 2019). A Figura 55-b mostra que, com exceção de $\mathrm{C}_{\mathrm{RFF}} 42 \% \mathrm{MFS}$ e $\mathrm{C}_{\mathrm{RFF}} 10 \% \mathrm{MFR}$, os compósitos apresentaram temperaturas de pico $\tan \delta$ maior que o TRFF, indicando que as interações fibra/matriz na interface para esses compósitos diminuiu a mobilidade de segmentos da matriz e aumentou o valor de $\mathrm{T}_{\mathrm{g}}$. Com relação a $\mathrm{C}_{\mathrm{RFF}} 42 \% \mathrm{MFS}$ e $\mathrm{C}_{\mathrm{RFF}} 10 \% \mathrm{MFR}$, o menor grau de entrecruzamento indicado pelos valores de $\mathrm{E}^{\prime}$ levaram a segmentos mais extensos, com maior mobilidade, e menor $\mathrm{T}_{\mathrm{g}}$. O pico a $184{ }^{\circ} \mathrm{C}$ observado para $\mathrm{C}_{\mathrm{RFF}} 10 \% \mathrm{MFR}$ pode corresponder a entrecruzamento residual ocorrido durante a varredura, o que leva a maior $\mathrm{T}_{\mathrm{g}}$.

Com base na Figura 55-b, observou-se que todos os compósitos apresentaram $\tan \delta$ maior que o TRFF. Entre os compósitos reforçados com MFS, o compósito $\mathrm{C}_{\mathrm{RFF}} 42 \% \mathrm{MFS}_{\text {im-ag-et }}$ apresentou menor $\tan \delta$, possivelmente devido à maior impregnação neste comparado ao $\mathrm{C}_{\mathrm{RFF}} 42 \% \mathrm{MFS}$.

Devido estes materias se decomporem em temperaturas superiores a $250{ }^{\circ} \mathrm{C}$ (curvas termogravimétricas- Figura 42), as temperaturas mostradas nas curvas tan $\delta$ estão associadas à $\mathrm{T}_{\mathrm{g}}$. 


\subsection{Compósitos híbridos de matriz termorrígida RFF reforçados com MFS/FMD moída}

A Figura 56 apresenta as curvas de módulo de armazenamento (E') (a) e $\tan \delta$ versus temperatura (b) do termorrígido fenol-formaldeído (TRFF) e dos compósitos híbridos reforçados com MFR/FMD moída. O compósito híbrido constituído por $16 \%$ de FMD $_{\text {moída }}$ apresentou um pequeno aumento em E' quando comparado ao TRFF, e um aumento mais significativo quando comparado aos compósitos $\mathrm{C}_{\mathrm{RFF}} 42 \% \mathrm{MFS}$ im-ag-et $\mathrm{e}$ $\mathrm{C}_{\mathrm{RFF}} 38 \% \mathrm{MFS}_{\text {im-ag-et }} 9 \% \mathrm{FMD}_{\text {moída, }}$, Figura 56-a, indicando um aumento da rigidez do material devido à presença de maior porcentagem em massa de $\mathrm{FMD}_{\text {moída. }}$

Já o compósito híbrido $\mathrm{C}_{\mathrm{RFF}} 38 \% \mathrm{MFS}_{\text {im-ag-et }} 9 \% \mathrm{FMD}_{\text {moída }}$ apresentou uma redução de E' comparado ao TRFF e ao compósito controle $\left(\mathrm{C}_{\mathrm{RFF}} 42 \% \mathrm{MFS}_{\text {im-ag-et }}\right)$, indicando menor grau de entrecruzamento na matriz, e/ou uma transferência de carga parcial da matriz para o reforço, levando à um menor armazenamento de energia pelo sistema (LUZ et al., 2018), assim como devido a influência da presença de vazios (MEGIATTO JUNIOR, 2006; KAW, 2006), como já mencionado.

Figura 56 - Curvas DMA- Módulo de armazenamento (E') (a) e Tan $\delta$ versus temperatura (b) do termorrígido fenólico (TRFF) e dos compósitos reforçados com MFS, $\mathrm{C}_{\mathrm{RFF}} 42 \% \mathrm{MFS}_{\text {im-ag-et }} \mathrm{e}$ híbridos reforçados com MFS/FMD moída, $_{\text {RFF }} 38 \% \mathrm{MFS}_{\text {im-ag-et }} 9 \% \mathrm{FMD}_{\text {moída }}$ e $\mathrm{C}_{\mathrm{RFF}} 35 \% \mathrm{MFS}_{\text {im-ag-et }} 16 \% \mathrm{FMD}_{\text {moída. }}$

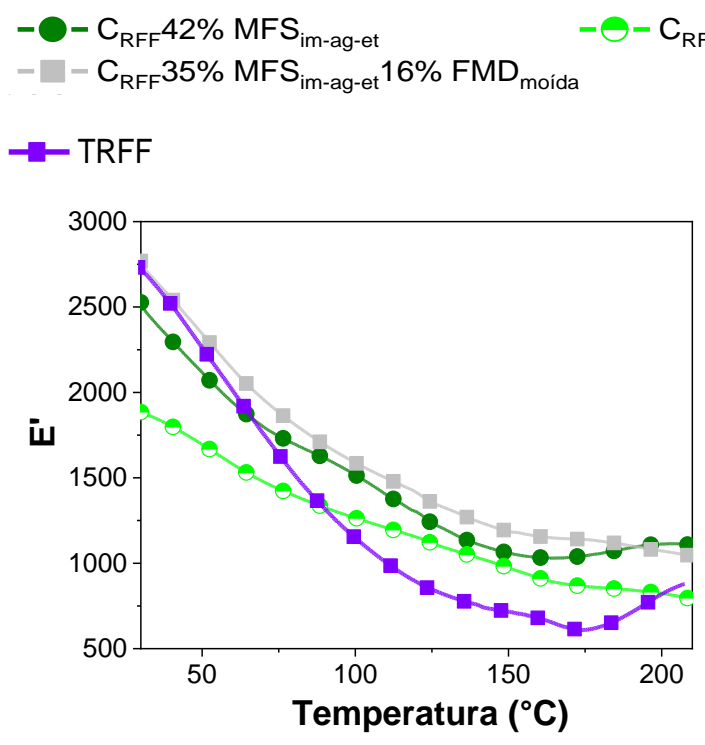

(a)

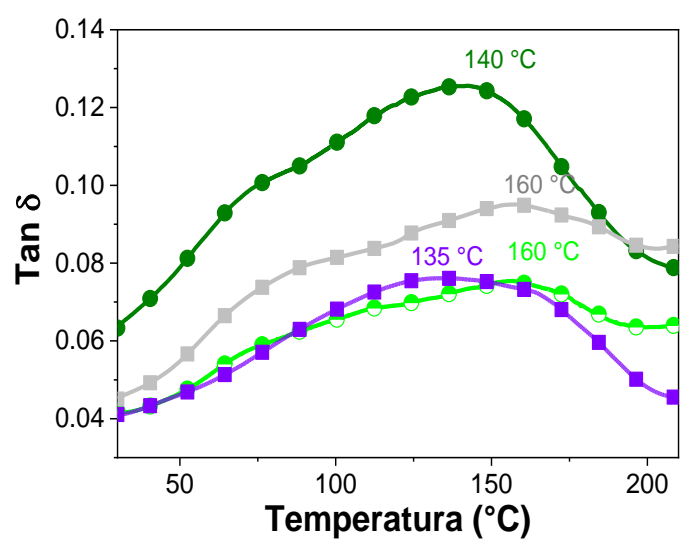

(b)

Ao comparar as curvas tan $\delta$ dos compósitos híbridos constituídos por MFS/FMD moída, observou-se que os compósitos $\mathrm{C}_{\mathrm{RFF}} 38 \% \mathrm{MFS}_{\text {im-ag-et }} 9 \% \mathrm{FMD}_{\text {moída }}$ e $\mathrm{C}_{\mathrm{RFF}} 35 \% \mathrm{MFS}_{\text {im-ag- }}$ 
et $16 \% \mathrm{FMD}_{\text {moída }}$ apresentaram intensidade do pico tan $\delta$ inferior ao do compósito $\mathrm{C}_{\mathrm{RFF}} 42 \% \mathrm{MFS}_{\text {im-ag-et. }}$ Parte da carga aplicada a um polímero pode ser dissipada por mecanismos de dissipação de energia, por exemplo devido a movimentos de segmentos. Um aumento ou diminuição na intensidade do pico tan $\delta$ indica que o material tem maior ou menor potencial de dissipação de energia. Em compósitos, a movimentação de segmentos da estrutura química da matriz é impactada pelas interações entre eles e os demais constituintes do material. Interações intermoleculares mais intensas entre segmentos e componentes diminui a mobilidade dos primeiros, diminuindo assim o potencial de diminuição de energia via movimento de segmentos e, portanto, a intensidade do pico tan $\delta$.

No caso de $\mathrm{C}_{\mathrm{RFF}} 38 \% \mathrm{MFS}_{\text {im-ag-et }} 9 \% \mathrm{FMD}_{\text {moída }}$ e $\mathrm{C}_{\mathrm{RFF}} 35 \% \mathrm{MFS}_{\text {im-ag-et }} 16 \% \mathrm{FMD}_{\text {moída, além de }}$

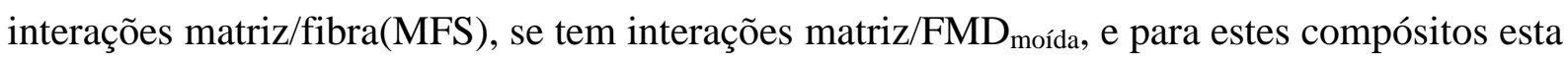
última interação pode ter contribuído para a diminuição na intensidade dos picos, embora não se observe correlação entre o aumento da porcentagem de $\mathrm{FMD}_{\text {moída }}$ de $9 \%$ para $16 \%$ e a intensidade dos picos.

As temperaturas indicadas nas curvas tan $\delta$ estão associadas à $T_{g}$, pois sabe-se, com base nas curvas termogravimétricas apresentadas anteriormente (Figuras- 41 e 42), que estes materias se decompõem em temperaturas superiores a $250{ }^{\circ} \mathrm{C}$.

Ainda com base na curva $\tan \delta$ (Figura 56- b), observou-se que houve um aumento da $\mathrm{Tg}$ nos compósitos híbridos tanto comparados com o $\mathrm{C}_{\mathrm{RFF}} 42 \% \mathrm{MFS}_{\text {im-ag-et }}$ quanto com TRFF (Figura 55- b). As propriedades dos compósitos são fortemente influenciadas pelas interações entre os fillers (enchimentos), a FMD moída, e/ou agente de reforço, a MFS, no caso, e a matriz polimérica que, consequentemente, influenciam na mobilidade destes segmentos (PRASOB; SASIKUMAR, 2019). Não se observou correlação entre o aumento da porcentagem de FMD $_{\text {moída }}$ de $9 \%$ para $16 \%$ e os valores de $\mathrm{T}_{\mathrm{g}}$.

\subsection{Conclusões parcíaís}

A utilização de manta de fibra de sisal e rayon como reforço em compósitos de matriz fenol-formaldeído se mostrou uma alternativa satisfatória, pois foi possível a obtenção de compósitos com boas propriedades mecânicas com uma porcentagem em massa de fibra pequena, 15, 6 e 11\% para os compósitos $\mathrm{C}_{\mathrm{RFF}} 42 \% \mathrm{MFS}, \mathrm{C}_{\mathrm{RFF}} 10 \% \mathrm{MFR}$ e $\mathrm{C}_{\mathrm{RFF}} 19 \% \mathrm{MFR}$, respectivamente. Estas porcentagens em massa equivalem às porcentagens em volume de 42 , 10 e $19 \%$, respectivamente.

Dentre os métodos de impregnação considerados para os compósitos com MFS, a junção 
de imersão da MFS em água por 6 h, e redução da viscosidade da RFF através da adição de 70 $\mathrm{mL}$ de etanol, foi o que proporcionou melhor resultado de resistência ao impacto, $453 \mathrm{~J} \mathrm{~m}^{-1}$ $\left(\mathrm{C}_{\mathrm{RFF}} 42 \% \mathrm{MFS}_{\mathrm{im}-\mathrm{ag} \text {-et }}\right)$. Ainda, observou-se que a $\mathrm{FMD}_{\text {moída }}$ atuou como reforço adicional no compósito híbrido constituído por MFS/FMD moída contendo $9 \%$ (em massa) de FMD moída, quando comparados os resultados de resistência ao impacto, resistência à flexão e módulo de flexão (por unidade de porcentagem de volume de manta) do compósito reforçado apenas com MFS, e produzido pelo mesmo método de impregnação.

Métodos alternativos de impregnação da MFS e inserção da FMD moída na matriz ainda precisam ser avaliados com o objetivo de reduzir a quantidade de vazios e, assim, conseguir melhorar as propriedades do material como um todo, como módulo de armazenamento, comparados ao TRFF. 


\section{Capítulo 3}

\section{Sintese de resina fenol-glutaraldeído: obtenção de compósitos de matriz termorrígida reforçados com manta de sísal, manta de rayon, e hibrido constítuído por manta de sísal e fíbra do mesocarpo do dendề moída}

\subsection{Introdução}

Neste capítulo relatou-se a preparação de compósitos de matriz termorrígida fenolglutaraldeído, sintetizada em meio básico, reforçados com MFS, MFR e híbrido

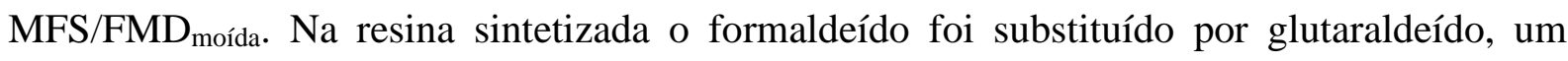
dialdeído, sendo que na reação deste com fenol em meio básico ocorre a inserção de grupos hidroxialquila (- $\mathrm{CHOHCH}_{2} \mathrm{CH}_{2} \mathrm{CH}_{2} \mathrm{COH}$ ) nas posições menos impedidas dos anéis aromáticos, prosseguindo com a formação do pré-polímero fenol-glutaraldeído (DA SILVA et al., 2013).

A fim de avaliar a influência da substituição do formaldeído por glutaraldeído nas propriedades do compósito final, foram preparadados compósitos com MFS, MFR e híbrido de MFS/FMD moída. A porcentagem em volume das mantas foram as usadas no Capítulo 2, $42 \%$ e 19\% em volume de MFS e MFR, respectivamente, e o híbrido foi preparado com 35\% em volume de MFS e $16 \%$ em massa de FMD moída.

Os compósitos foram preparados por moldagem com compressão, sendo o ciclo de moldagem baseado em trabalhos anteriores desenvolvidos no grupo MacromoLignocell (RAZERA; FROLLINI, 2004; RAMIRES, 2010; DE OLIVEIRA, 2010).

\subsection{Experimental}

\subsubsection{Materiais}

Foi utilizado para a síntese do pré-polímero o glutaraldeído (solução 25\%, Êxodo), fenol e hidróxido de sódio conforme descrito no 1.2.1 do Capítulo 1. Os demais materias e reagentes utilizados foram apresentados nos itens 1.2.1 e 2.2.1 dos Capítulos 1 e 2, respectivamente. 


\subsubsection{Métodos}

3.2.2.1 Caracterização das fibras que compõem as mantas utilizadas como reforço, MFS e MFR, e FMD moída

As caracterizações das fibras utilizadas neste Capítulo 3 como reforço foram apresentadas nos Capítulos 1 e 2.

\subsubsection{Síntese de resina fenol-glutaraldeído para preparação de compósitos reforçados por mantas e FMD moída}

\subsection{Síntese da resina (pré-polímero) fenol-glutaraldeído resol (RFG)}

A reação de síntese do pré-polímero foi realizada conforme descrito no item 1.2.2.2.1 no Capítulo 1. As condições foram baseadas em Da Silva (2011). O pré-polímero foi preparado utilizando uma proporção em massa de fenol: glutaraldeído (solução a 25\%): KOH de 1,0:3,4:0,06, respectivamente. A reação foi realizada durante $5 \mathrm{~h}$, a $97^{\circ} \mathrm{C}$. Ao término da reação, deixou-se o sistema resfriar até a temperatura ambiente, mediu-se o pH e ajustou-se o mesmo para 7,0 adicionando $\mathrm{HCl}(37 \%)$.

\subsubsection{Preparação dos compósitos reforçados com fibra vegetal}

\subsection{Adição do agente acelerador de cura}

A adição do agente de cura, resorcina, foi realizado de acordo com o descrito no item

\subsubsection{1 do Capítulo 1.}

\subsection{Incorporação do reforço}

Os compósitos de matriz RFG foram preparados utilizando MFS, MFR e híbrido

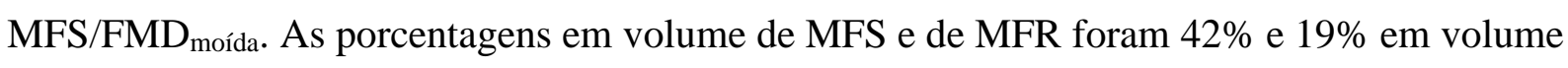
de MFS e MFR, respectivamente. Dentre os compósitos de matriz RFF preparados com MFR apresentados no Capítulo 2, $\mathrm{C}_{\mathrm{RFF}} 10 \% \mathrm{MFR}$ e $\mathrm{C}_{\mathrm{RFF}} 19 \% \mathrm{MFR}$, apenas foi preparado o compósito com duas MFR (19\% em volume) em matriz RFG, pois esta foi a porcentagem em volume que apresentou melhor resultado de resistência ao impacto.

Em relação ao compósito híbrido constituído por MFS e FMD moída, a porcentagem em massa utilizada de FMD $_{\text {moída }}(16 \%)$ foi baseada em experimento preliminar a partir das porcentagens em massa utilizadas anteriormente no Capítulo 2. Os modos de preparação dos compósitos citados estão apresentados na Tabela 16. A \% indicada de MFS e MFR nos códigos dos compósitos de matriz RFG é em volume. O compósito híbrido contém 35\% (em volume) 
de MFS e $16 \%$ (em massa) de FMD moída.

Tabela 16 - Modo de preparo dos compósitos de matriz RFG reforçados com MFS e MFR, e híbrido MFS/FMD moída.

Compósitos de matriz RFG reforçados com MFS e MFR

\begin{tabular}{|c|c|}
\hline Compósitos & Modo de preparação \\
\hline $\mathrm{C}_{\mathrm{RFG}} \mathbf{4 2 \% \mathrm { MFS }}$ & Imersão da MFS na RFG \\
\hline $\mathrm{C}_{\mathrm{RFG}} 19 \% \mathrm{MFR}$ & $\begin{array}{l}\text { Imersão das duas mantas usadas, intercalando as camadas } \\
\text { de resina e das mantas }\end{array}$ \\
\hline \multicolumn{2}{|c|}{ 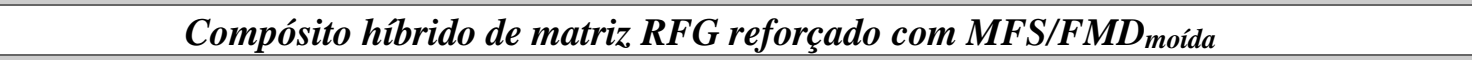 } \\
\hline $\mathrm{C}_{\mathrm{RFG}} 35 \% \mathrm{MFS16 \% FMDmoída}$ & $\begin{array}{l}\text { 16\% FMD moída em massa } \\
\text { A MFS foi pré-impregnada com parte da resina. } \\
\text { FMD moída foi misturada com RFG. Após } \\
\text { homogeneização, espalhou-se uma parte da mistura na } \\
\text { parte inferior do molde, colocou-se a MFS pré- } \\
\text { impregnada e adicionou-se o restante da mistura } \\
\text { RFG+FMD }{ }_{\text {moída. }}\end{array}$ \\
\hline
\end{tabular}

\subsection{Moldagem do termorrígido e dos compósitos}

O termorrígido e os compósitos contendo resina fenólica foram moldados por compressão e aquecimento controlados, em molde portátil, como descrito no item 1.2.2.3.3 do Capítulo 1. O ciclo seguido para a cura dos compósitos de matriz RFG está apresentado na Tabela 17.

Tabela 17 - Ciclo de cura para a obtenção do termorrígido e compósitos de matriz fenolglutaraldeído.

$$
\text { Temperatura }\left({ }^{\circ} \mathbf{C}\right) \quad \text { Tempo }(\min ) \quad \text { Força (ton) }
$$

\begin{tabular}{ccc}
\hline 115 & 180 & 0 \\
\hline 125 & 210 & $0-10$ \\
150 & 210 & $10-16$
\end{tabular}

O ciclo foi baseado em experimentos de Da Silva (2011) e em experimentos preliminares realizados com molde aberto em que se observou como ocorria o avanço da reação em termos de tempo e temperatura, com base na viscosidade da resina. Após 180 min do início do ciclo a $125{ }^{\circ} \mathrm{C}$, observou-se o início do ponto de gelificação da resina RFG. Neste ponto a resina encontra-se no estágio intermediário entre líquido e sólido, ou seja, encontra-se na forma de gel (há um aumento significativo da viscosidade) (MEGIATTO JÚNIOR, 2006). A partir disso, a pressão foi exercida aos poucos para evitar perdas de resina devido a vazamentos. Após algum 
tempo de permanência a $150{ }^{\circ} \mathrm{C}$ foi observado início do entrecruzamento, avaliado com molde aberto.

\subsubsection{Caracterização do pré-polímero, do termorrígido e dos compósitos}

\subsection{Espectroscopia na região do infravermelho por transformada de Fourier} (FTIR)

Os espectros de FTIR do pré-polímero RFG e dos compósitos foram obtidos de acordo com o descrito no item 1.2.2.4.1 do Capítulo 1.

\subsection{Cromatografia por exclusão de tamanho (SEC)}

A análise de SEC do pré-polímero RFG foi realizada de acordo com o que foi descrito no item 1.2.2.4.2 do Capítulo 1.

\subsection{Ressonância magnética nuclear $\mathrm{de}^{13} \mathrm{C}$}

A análise de RMN do pré-polímero RFG foi realizada de acordo com o que foi descrito no item 1.2.2.4.4 do Capítulo 1.

\subsection{Análise termogravimétrica (TGA)}

A análise termogravimétrica do pré-polímero e dos compósitos foi realizada de acordo com o que foi descrito no item 2.2.2.5.5 do Capítulo 2 .

\subsection{Resistência ao impacto}

Os ensaios de impacto Izod dos compósitos foram realizados de acordo com o descrito no item 1.2.2.4.5 do Capítulo 1.

\subsection{Microscopia Eletrônica por Varredura (MEV)}

A análise de microscopia eletrônica de varredura dos compósitos após fratura no ensaio de impacto Izod foi realizada de acordo com o que foi descrito no item 1.2.2.4.6 do Capítulo 1.

\subsection{Ensaio de resistência à flexão}

O ensaio de resitência à flexão dos compósitos foi realizado de acordo com o descrito no item 1.2.2.4.7 do Capítulo 1. 
A análise de DMA dos compósitos foi realizada de acordo com o descrito no item

\subsubsection{6 do Capítulo 2.}

\subsection{Resultados e discussão}

\subsubsection{Caracterização do pré-polímero, termorrígido e compósitos}

\subsubsection{Espectroscopia na região do infravermelho por transformada de Fourier (FTIR)}

A Figura 57 apresenta os espectros de FTIR da resina RFG, do termorrígido e dos compósitos de matriz RFG.

Figura 57 - Espectros na região do infravermelho da resina RFG, do termorrígido (TRFG), e dos compósitos reforçados com MFS, $\mathrm{C}_{\mathrm{RFG}} 42 \% \mathrm{MFS}$, MFR, $\mathrm{C}_{\mathrm{RFG}} 19 \% \mathrm{MFR}$, e híbrido MFS/FMD móda $_{\text {, }}$ $\mathrm{C}_{\mathrm{RFG}} 35 \% \mathrm{MFS} 16 \% \mathrm{FMD}_{\text {moída. }}$
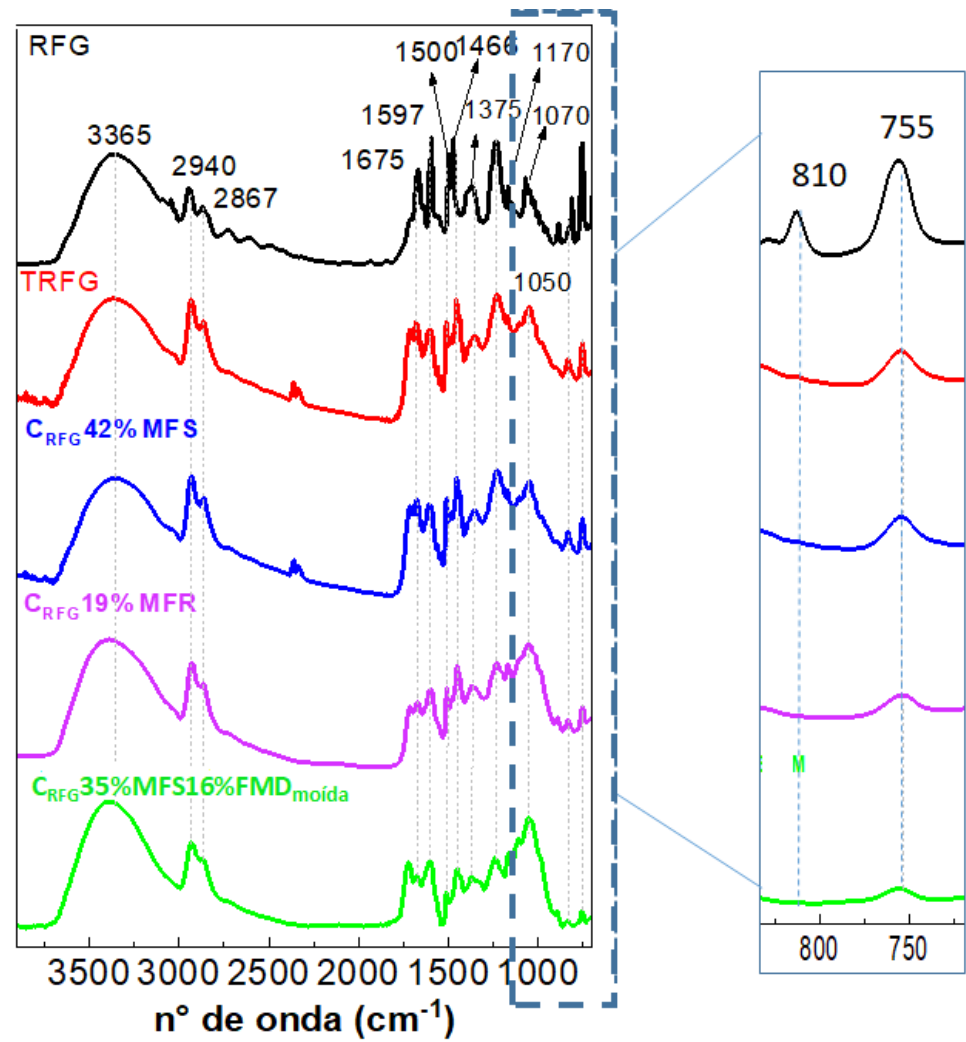

As bandas intensas observadas $3365 \mathrm{~cm}^{-1}$ nos espectros da RFG e do termorrígido estão relacionados ao estiramento ou à deformação axial de grupos hidroxilas alcoólico e fenólico presentes na estruturura de ambas. Já nos espectros dos compósitos esta mesma banda pode ser atribuída também a grupos hidroxilas provenientes de constituites das fibras lignocelulósicas como, hemiceluloses, celulose e lignina.

As bandas observadas em 2940 e $2867 \mathrm{~cm}^{-1}$, no caso da resina RFG e do termorrígido, estão relacionadas à ligação $\mathrm{C}-\mathrm{H}$ de grupos saturados provenientes da inserção da cadeia 
hidroxialquílica (- $\left.\mathrm{CHOHCH}_{2} \mathrm{CH}_{2} \mathrm{CH}_{2} \mathrm{COH}\right)$ proveniente do glutaraldeído durante a síntese, conforme apresentado na Figura 8- a. Esta resina foi obtida a partir da reação de alquilação do fenol através da substituição do formaldeído por glutaraldeído. Nos compósitos, os grupos saturados também podem estar associados às cadeias carbônicas da celulose e de hemiceluloses presentes nas fibras.

Em $1715 \mathrm{~cm}^{-1}$ (Figura 57) observa-se uma banda referente à deformação axial de ligação $\mathrm{C}=\mathrm{O}$ presente no TRFG e nos demais compósitos. Em aproximadamente 1675-1510 $\mathrm{cm}^{-1}$ observa-se uma banda referente ao estiramento (deformação axial) das ligações $\mathrm{C}=\mathrm{C}$ do anel aromático, a qual pode ser proveniente tanto da matriz quanto da lignina presente na fibra de sisal e dendê, no caso dos compósitos $\mathrm{C}_{\mathrm{RFG}} 42 \% \mathrm{MFS}$ e $\mathrm{C}_{\mathrm{RFG}} 35 \% \mathrm{MFS} 16 \% \mathrm{FMD}_{\text {moída }}$ (SILVERSTEIN; BASSLER, MORRIL, 1994; BYKOV, 2008).

Tabela 18 - Possíveis atribuições das principais bandas de absorção observadas nos compósitos de matriz termorrígida RFG reforçados com MFS, MFR e híbrido MFS/FMD moída.

\begin{tabular}{|c|c|}
\hline \multicolumn{2}{|r|}{ Resina Fenólica RFG e TRFG } \\
\hline $\mathrm{n}^{\circ}$ de onda $\left(\mathrm{cm}^{-1}\right)$ & Atribuição \\
\hline 3380 & Deformação axial simétrica de grupos $\mathrm{OH}$ alcoólicos e fenólicos \\
\hline 2934-2860 & Vibração de estiramento de $\mathrm{CH}_{2}$ de grupos metila e metileno \\
\hline 1715 & Deformação axial de ligação $C=O$ \\
\hline 1675- 1515 & Deformação fora do plano de $C=C$ aromáticos \\
\hline 1455 & Deformação angular de ligação $\mathrm{C}$ - $\mathrm{H}$ de grupos metileno \\
\hline 1356 & Estiramento de grupo $\mathrm{CH}_{3}$ \\
\hline 1228 & Deformação axial da ligação $\mathrm{C}-\mathrm{O}-\mathrm{C}$ de éter em $-\mathrm{CH}_{2}-\mathrm{O}-\mathrm{CH}_{2^{-}}$ \\
\hline 1050 & $\begin{array}{c}\text { Vibração de estiramento assimétrico } \mathrm{C}-\mathrm{O}-\mathrm{C} \text { de éter alifático (ponte éter- } \\
\text { metileno) }\end{array}$ \\
\hline 1016-1010 & Estiramento da ligação $-\mathrm{C}$-O do grupo hidroximetila \\
\hline 810 & $\begin{array}{c}\text { Deformação angular da ligação } C \text {-H fora do plano em anéis unidos por } \\
\text { ligações orto-para }\end{array}$ \\
\hline 755 & $\begin{array}{c}\text { Deformação angular da ligação } C \text {-H fora do plano em anéis unidos por } \\
\text { ligações orto-orto. }\end{array}$ \\
\hline \multicolumn{2}{|r|}{ Compósitos com matriz de RFG } \\
\hline $\mathrm{n}^{\circ}$ de onda $\left(\mathrm{cm}^{-1}\right)$ & Atribuição \\
\hline 3345-3290 & Deformação axial simétrica de grupos $\mathrm{OH}$ alcoólicos e fenólicos \\
\hline 2960-2850 & Vibração de estiramento de $\mathrm{CH}_{2}$ de grupos metila e metileno \\
\hline 1610-1510 & Deformação fora do plano de $C=C$ aromáticos \\
\hline 1465 & Deformação angular de ligação $\mathrm{C}$ - $\mathrm{H}$ de grupos metileno \\
\hline 1365 & Estiramento $\mathrm{C}$ - $\mathrm{H} \mathrm{em} \mathrm{CH}_{3}$ \\
\hline 1250-1227 & OH fenólico \\
\hline 1050 & Deformação axial da ligação $\mathrm{C}-\mathrm{O}-\mathrm{C}$ \\
\hline 755 & $\begin{array}{c}\text { Deformação angular da ligação } C \text { - } H \text { fora do plano em anéis unidos por } \\
\text { ligações orto-orto. }\end{array}$ \\
\hline
\end{tabular}




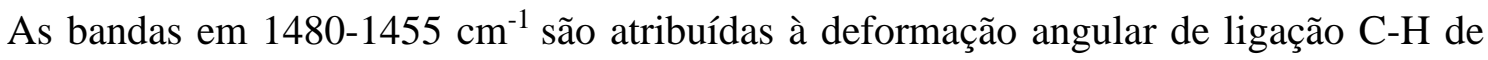
grupos metileno, as quais podem ser provenientes do processo de condensação e entrecruzamento do pré-polímero RFG antes e durante a moldagem do compósito, respectivamente (Figura 8- b). Em 1220 e $1050 \mathrm{~cm}^{-1}$ observou-se bandas referentes às hidroxilas fenólicas e deformação axial de ligação C-O de fenol (RAMIRES, 2010; RAZERA, 2006; MEGIATTO JÚNIOR, 2009).

As bandas em 810 e $755 \mathrm{~cm}^{-1}$, observadas apenas no espectro da RFG (Figura 57) podem ser referentes à deformação angular da ligação $\mathrm{C}-\mathrm{H}$ fora do plano em anéis unidos por ligações orto-para e orto-orto, respectivamente. A maior intensidade da banda em $755 \mathrm{~cm}^{-1}$ pode estar associada à formação de ligações orto-orto durante o processo de crescimento da cadeia do prépolímero (RAMIRES, 2010). O mesmo foi observado no espectro de FTIR da resina RFF (Figura 26). No espectro do TRFG e dos compósitos, verificou-se o desaparecimento da banda em $810 \mathrm{~cm}^{-1}$, que pode estar relacionado à formação de ligações orto-para durante o processo de entrecruzamento (RAMIRES, 2010; DA SILVA, 2011).

\subsubsection{Determinação da massa molar média por cromatografia de exclusão por tamanho do pré-polímero RFG (SEC)}

A Tabela 19 mostra as massas molares médias e a polidispersividade da RFG calculada a partir do cromatograma (não mostrado).

A resina RFG apresentou maior uma solubilidade após a adição de duas gotas de $\mathrm{HCl}$ concentrado ao THF. Este mesmo efeito também foi observado com a resina RFF, conforme já mencionado Capítulo 1.

O pré-polímero (RFG) obtido possui frações com valores de $\bar{M} w$ entre aproximadamente 972 e $354\left(\mathrm{gmol}^{-1}\right)$ (Tabela 19).

Tabela 19: Valores de massa molar ponderal média $(\bar{M} \mathrm{w})$, massa molar numérica média $(\bar{M} \mathrm{n})$ e polidispersividade $(\bar{M} \mathrm{w} / \bar{M} \mathrm{n})$ da resina fenol-glutaraldeído.

\section{Resina fenol-glutaraldeído}

\begin{tabular}{cccc}
\hline Picos & $\overline{\mathbf{M}} \boldsymbol{w}\left(\mathbf{g} \mathbf{m o l}^{-\mathbf{1}}\right)$ & $\overline{\mathbf{M}} \boldsymbol{n}\left(\mathbf{g ~ m o l}^{-\mathbf{1}}\right)$ & $\overline{\mathbf{M}} \boldsymbol{w} / \overline{\mathbf{M}} \boldsymbol{n}$ \\
\hline $\mathbf{1}$ & 972 & 872 & 1,1 \\
$\mathbf{2}$ & 497 & 491 & 1,0 \\
\hline $\mathbf{3}$ & 354 & 352 & 1,0 \\
\hline Média & 682 & 560 & 1,2 \\
\hline
\end{tabular}


O pré-polímero RFG é representado pelas frações 1 e 2, pois foram obtidos picos mais representativos da fração macromolecular. O pico indicado por 3 corresponde a oligômeros, que reagiram durante entrecruzamento, na formação do termorrígido (Figura 8- b e -c). Ao comparar os valores de $\bar{M} w$ desta resina com a RFF (Tabela 9 -Capítulo 1), observou-se que a RFG apresentou $\bar{M} w$ semelhante. No entanto, a inserção de segmentos mais extensos na RFG comparativament à RFF (inserção de $-\mathrm{CH}_{2} \mathrm{OH}$ ), conferiu a mesma aspecto visual menos viscoso.

A temperatura em que se observou o início da gelificação (baseado em experimento preliminar com molde aberto) desta resina, $125{ }^{\circ} \mathrm{C}$, foi superior à da RFF (resina fenolformaldeído) (95-105 ${ }^{\circ} \mathrm{C}$ ), o que pode estar associado com o maior tamanho da cadeia proveniente do glutaraldeído (- $\mathrm{CHOHCH}_{2} \mathrm{CH}_{2} \mathrm{CH}_{2} \mathrm{COH}$ ) comparativamente à do formaldeído (- $\left.\mathrm{CH}_{2} \mathrm{OH}\right)$, e que levou a menor reatividade, e menor massa molar média, como mencionado.

A baixa viscosidade da resina RFG permitiu sua utilização sem necessidade de adição de etanol para redução de viscosidade para aumentar a impregnação, conforme realizado para a resina RFF apresentado no Capítulo 2.

\subsubsection{Ressonância magnética nuclear $\operatorname{de}^{13} \mathrm{C}$}

A Figura 58 apresenta o espectro de $\mathrm{RMN}-{ }^{13} \mathrm{C}$ e a Tabela 20 apresenta as possíveis atribuições para a resina fenol-glutaraldeído. A Figura 58 mostra sinais entre 17-19 ppm, que podem ser atribuídas ao carbono secundário da cadeia hidroxialquílica (- $\mathrm{CHOHCH}_{2} \mathrm{CH}_{2} \mathrm{CH}_{2} \mathrm{COH}$ ) inserida no anel fenólico (Figura 8) (WU et al., 2017a). O sinal residual do solvente foi observado entre 39,1-40,4 ppm. Em 40,5 ppm observou-se sinal característico de ponte metileno. Em 42 ppm observou-se sinal que pode ser referente à carbono secundário de fenol hidroxialquilado ou de fenóis hidroxialquilados condensados (WU et al., 2017a). O sinal em 70,7 ppm pode ser referente ao carbono secundário ligado ao anel aromático de fenol hidroxialquilado condensado. Estes são formados durante a etapa de polimerização da resina para obtenção do pré-polímero (Figura 8). 
Figura 58 - Espectro de $\mathrm{RMN}-{ }^{13} \mathrm{C}$ da resina fenol-glutaraldeído (solvente DMSO-d6, 20000 varreduras).

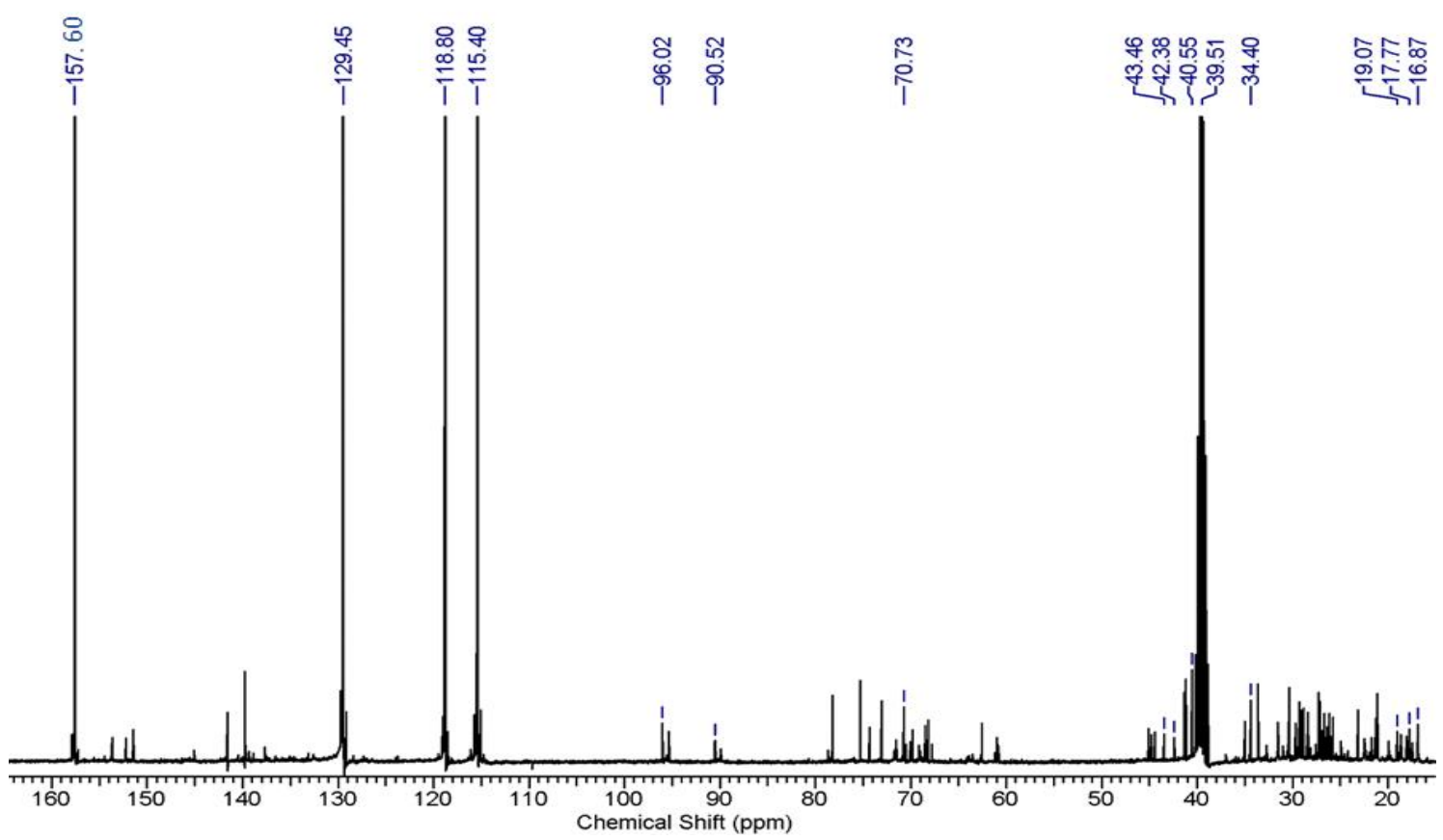

Tabela 20: Picos presentes no espectro de $\mathrm{RMN}-{ }^{13} \mathrm{C}$ da $\mathrm{RFG}$.

\begin{tabular}{|c|c|}
\hline \multicolumn{2}{|r|}{ Picos presentes nos espectros de $R M N^{13} \mathrm{C}$ da $\mathrm{RFG}$} \\
\hline $\begin{array}{l}\text { Deslocamento } \\
\text { químico (ppm) }\end{array}$ & Possíveis atribuições \\
\hline 17-19 & Fenol-CH $(\mathrm{OH}) \mathrm{CH}_{2} \mathrm{CH}_{2} \mathrm{CH}_{2} \mathrm{CHO}$ ou Fenol- $\mathrm{CH}(\mathrm{OH}) \mathrm{CH}_{2} \mathrm{CH}_{2} \mathrm{CH}_{2} \mathrm{CH}(\mathrm{OH})$ \\
\hline 34,4 & $\mathrm{CH}_{2}$ de grupo metileno entre dois anéis aromáticos na posição orto-para \\
\hline 40,5 & $-\mathrm{CH}_{2}$ - de grupo metileno \\
\hline 42 & $\begin{array}{c}\text { Fenol-CH(OH)CH} \mathrm{CH}_{2} \mathrm{CH}_{2} \mathrm{CH}_{2} \mathrm{CHO} \text { ou } \\
\text { Fenol- } \mathrm{CH}(\mathrm{OH}) \mathrm{CH}_{2} \mathrm{CH}_{2} \mathrm{CH}_{2} \mathrm{CH}(\mathrm{OH}) \text {-fenol }\end{array}$ \\
\hline $\mathbf{7 0 , 7}$ & Fenol- $\mathrm{CH}(\mathrm{OH}) \mathrm{CH}_{2} \mathrm{CH}_{2} \mathrm{CH}_{2} \mathrm{CH}(\mathrm{OH})-\mathrm{Ph}$ \\
\hline 90-100 & $\mathrm{CHO}\left(\mathrm{CH}_{2}\right)_{3}(\mathrm{CH})(\mathrm{OH})_{2}$ \\
\hline 115,4 & Carbono $\mathrm{C}_{1}$ de anel aromático \\
\hline 118,8 & Carbono orto não substituído \\
\hline 129,4 & Carbono orto substituído \\
\hline 157,8 & Carbono na posição para do anel fenólico substituído \\
\hline
\end{tabular}

(REFERÊNCIA: RAMIRES, 2010; WU et al., 2017).

Os sinais entre 115,4 e 157,8 são referentes à carbonos aromáticos.

\subsubsection{Análise termogravimétrica}

\subsection{Resina RFG}

A Figura 59 apresenta a curva termogravimétrica e a respectiva derivada primeira da resina fenol-glutaraldeído (RFG). O primeiro evento, referente ao pico intenso observado na 
curva dTG em aproximadamente $120^{\circ} \mathrm{C}\left(\mathrm{T}_{\mathrm{dMÁx}}\right)$, pode ser atribuído às etapas de condensação do pré-polímero ao ser submetido à aquecimento durante a varredura, as quais foram acompanhadas por liberação de água (OLIVEIRA, 2010). A temperatura do pico praticamente coincide com a temperatura observada para o início da gelificação da resina $\left(125^{\circ} \mathrm{C}\right)$.

Figura 59 - Curvas TG e dTG (primeira derivada) da resina fenol-glutaraldeído (RFG) em atmosfera de nitrogênio com razão de aquecimento de $10{ }^{\circ} \mathrm{C} / \mathrm{min}$ e fluxo de $50 \mathrm{~mL} / \mathrm{min}$.

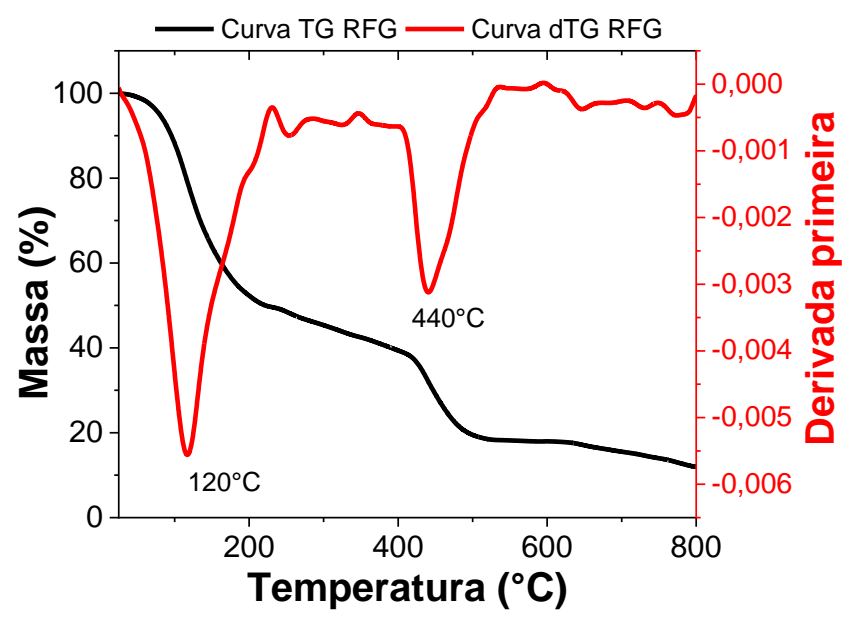

O segundo evento observado na curva dTG da RFG a $440{ }^{\circ} \mathrm{C}\left(\mathrm{T}_{\mathrm{dMÁx}}\right.$ ) (Figura 59) pode ser atribuído as decomposições da rede aromática (WANG et al., 2014).

\subsection{Termorrígido TRFG e compósitos de matriz RFG reforçados com MFS, MFR e híbrido MFS/ FMDmmoída}

A Figura 60 apresenta as curvas termogravimétricas e as respectivas curvas derivadas para o termorrígido (TRFG) e os compósitos $\mathrm{C}_{\mathrm{RFG}} 42 \% \mathrm{MFS}, \mathrm{C}_{\mathrm{RFG}} 19 \% \mathrm{MFR}$, e híbrido MFS/FMD moída, $_{\text {RFG }}$ 35\%MFS16\%FMD moída. A Figura 60 mostra que as amostras apresentaram uma perda de massa de 7-10\% referente à perda de umidade residual. O TRFG apresentou uma $\mathrm{T}_{\text {onset }}$ de $182{ }^{\circ} \mathrm{C}$, enquanto os compósitos $\mathrm{C}_{\mathrm{RFG}} 42 \% \mathrm{MFS}, \mathrm{C}_{\mathrm{RFG}} 19 \% \mathrm{MFR}$ e híbrido $\mathrm{C}_{\mathrm{RFG}} 35 \% \mathrm{MFS} 16 \% \mathrm{FMD}_{\text {moída }}$ apresentaram $\mathrm{T}_{\text {onset }}$ de 240,260 e $270{ }^{\circ} \mathrm{C}$.

O segundo e terceiro eventos observados na curva dTG (Figura 60) do TRFG apresentaram uma $\mathrm{T}_{\mathrm{dMÁx}}$ de $383{ }^{\circ} \mathrm{C}$ e $450{ }^{\circ} \mathrm{C}$, respectivamente, possivelmente relacionado à quebra de ligações C-C e decomposição de anéis aromáticos. Nos compósitos se observou uma $\mathrm{T}_{\mathrm{dMÁX}}$ no segundo evento na curva dTG entre 315 e $337^{\circ} \mathrm{C}$, que possivelmente está relacionado à decomposição da celulose presente em ambas as fibras utilizadas como reforço, conforme observado na Figura 40. 
Figura 60 - Curvas TG e dTG (primeira derivada) do termorrígido TRFG (a), e dos compósitos $\mathrm{C}_{\mathrm{RFG}} 42 \% \mathrm{MFS}$ (b), $\mathrm{C}_{\mathrm{RFG}} 19 \% \mathrm{MFR}$ (c) e híbrido $\mathrm{C}_{\mathrm{RFG}} 35 \% \mathrm{MFS} 16 \% \mathrm{FMD}_{\text {moída }}$ (d), em atmosfera de nitrogênio com razão de aquecimento de $10{ }^{\circ} \mathrm{C} / \mathrm{min}$ e fluxo de $50 \mathrm{~mL} \mathrm{~min}{ }^{-1}$.

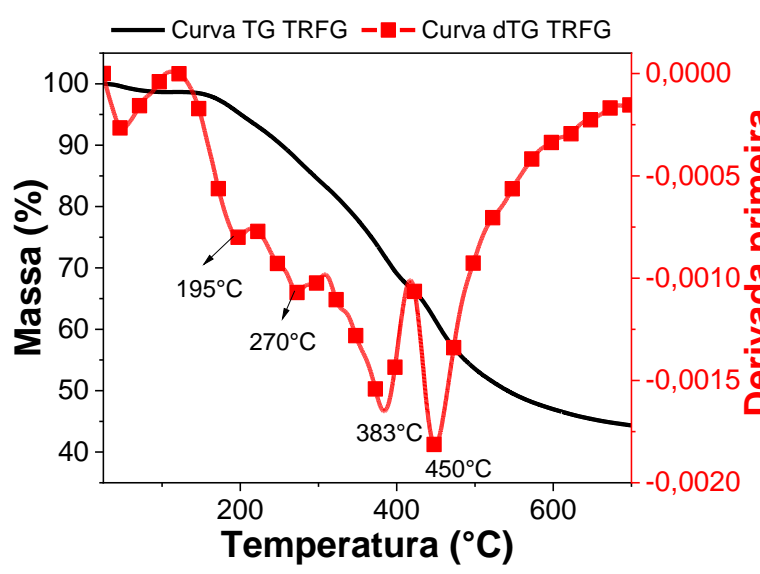

(a)

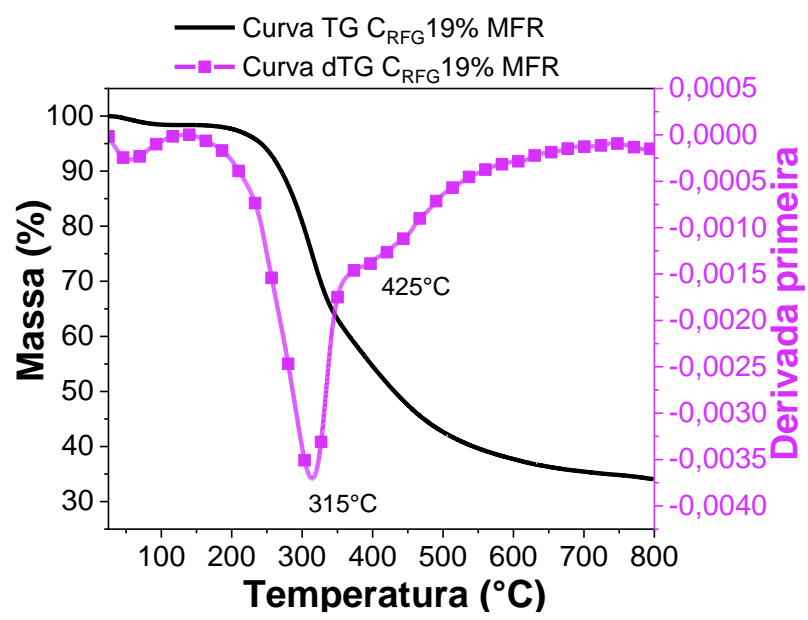

(c)

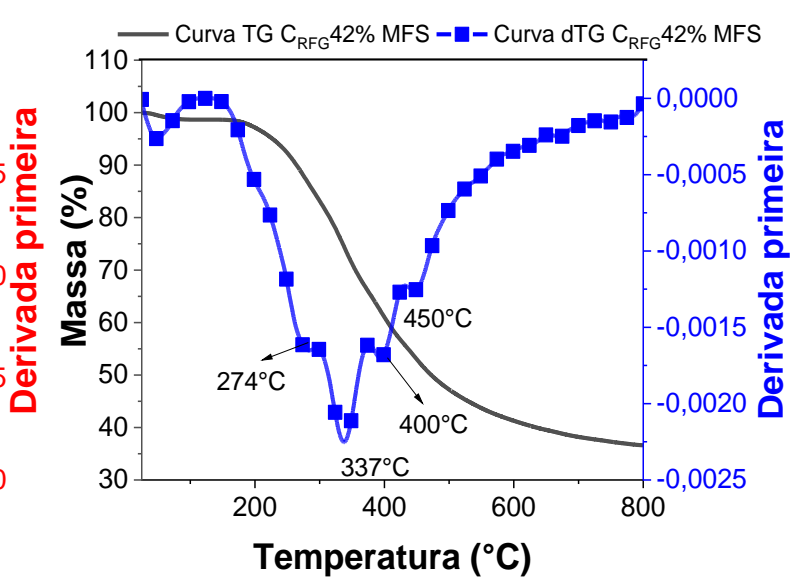

(b)

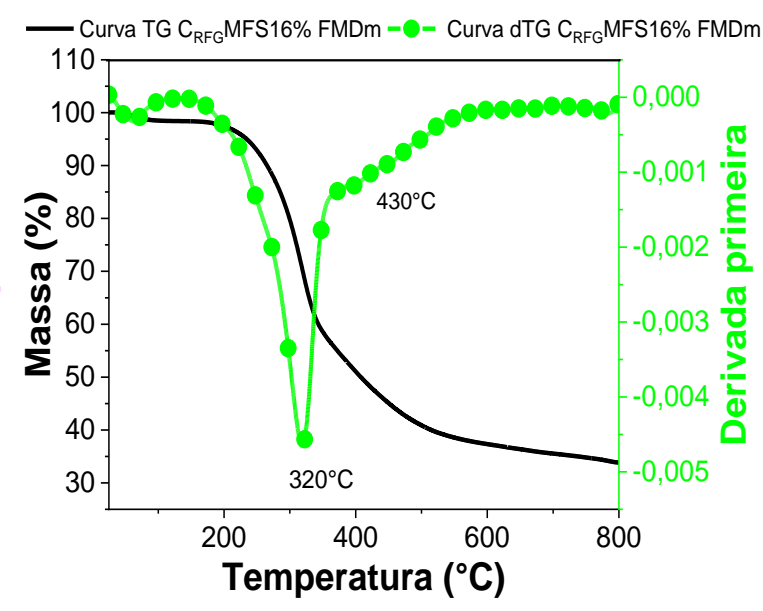

(d)

Em todos os compósitos também se observou um quarto evento (pico de baixa intensidade) na curva dTG com uma $\mathrm{T}_{\mathrm{dMÁx}}$ entre 425 e $450{ }^{\circ} \mathrm{C}$, que pode estar relacionado à degradação de anéis aromáticos presentes na matriz termorrígida (PAIVA; FROLLINI, 2006) (Figura 60- a).

\subsubsection{Impacto Izod do termorrígido TRFG e dos compósitos de matriz RFG reforçados com MFS, MFR e híbrido MFS/FMDmoída}

Os valores de resistência ao impacto dos compósitos de matriz RFG reforçados com MFS, $\mathrm{C}_{\mathrm{RFG}} 42 \% \mathrm{MFS}, \mathrm{MFR}, \mathrm{C}_{\mathrm{RFG}} 19 \% \mathrm{MFR}$, e híbrido MFS/FMD moída, $\mathrm{C}_{\mathrm{RFG}} 35 \% \mathrm{MFS16 \% FMD}$ moída, estão apresentados na Figura 61. A porcentagem de manta de fibra apresentada no código da

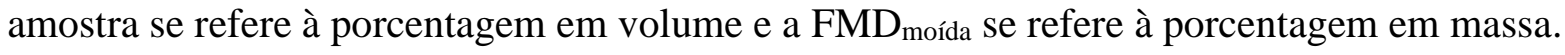


A Figura 61 mostra que houve uma melhora considerável nesta propriedade com a inserção tanto de manta de sisal quanto de rayon, quando comparados ao TRFG, o qual apresentou resistência ao impacto inferior ao TRFF, 8,0 $\pm 1,4 \mathrm{~J} \mathrm{~m}^{-1}$ contra 26,0 $\pm 2 \mathrm{~J} \mathrm{~m}^{-1}$, respectivamente.

Figura 61 - Resultados de resistência ao impacto do termorrígido TRFG, e dos compósitos $\mathrm{C}_{\mathrm{RFG}} 42 \% \mathrm{MFS}, \mathrm{C}_{\mathrm{RFG}} 19 \% \mathrm{MFR}$ e $\mathrm{C}_{\mathrm{RFG}} 35 \% \mathrm{MFS} 16 \% \mathrm{FMD}_{\text {mó́da }}$ (a), e comparativos entre os resultados de resistência ao impacto normalizados dos compósitos $\mathrm{C}_{\mathrm{RFG}} 42 \% \mathrm{MFS}, \mathrm{C}_{\mathrm{RFG}} 19 \% \mathrm{MFR}$ e $\mathrm{C}_{\mathrm{RFG}} 35 \% \mathrm{MFS} 16 \% \mathrm{FMD}_{\text {moída. }}$

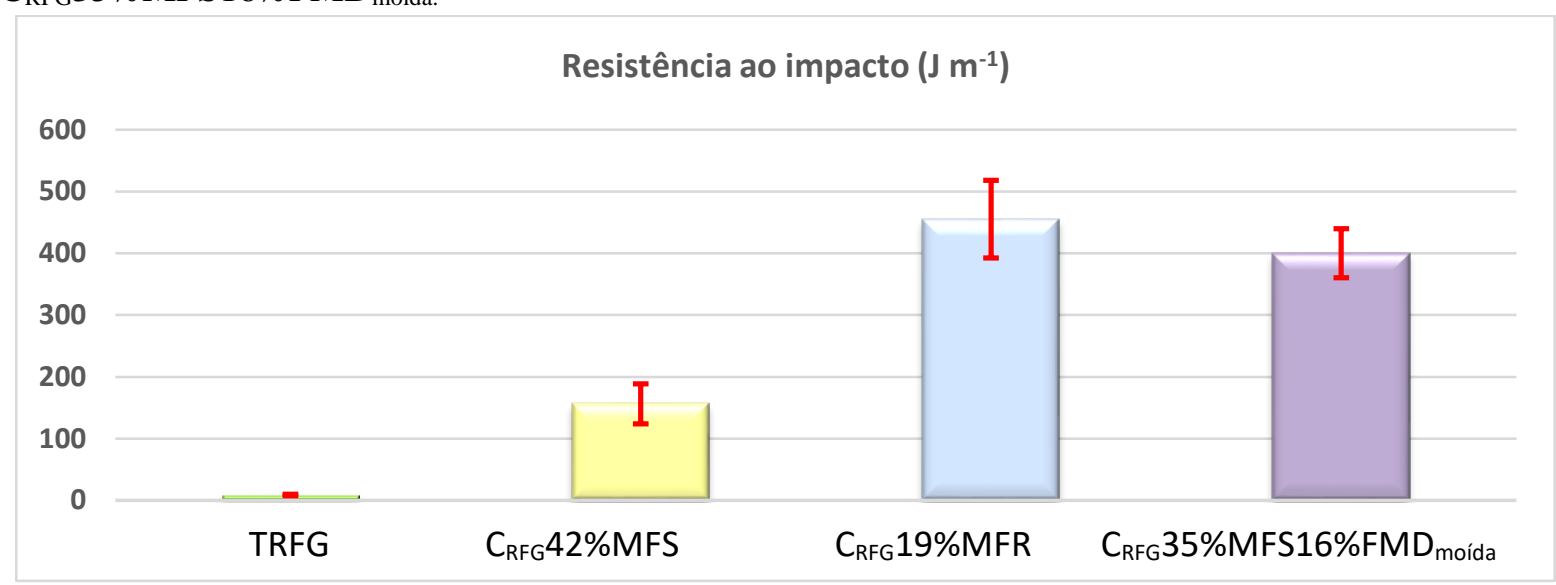

(a)

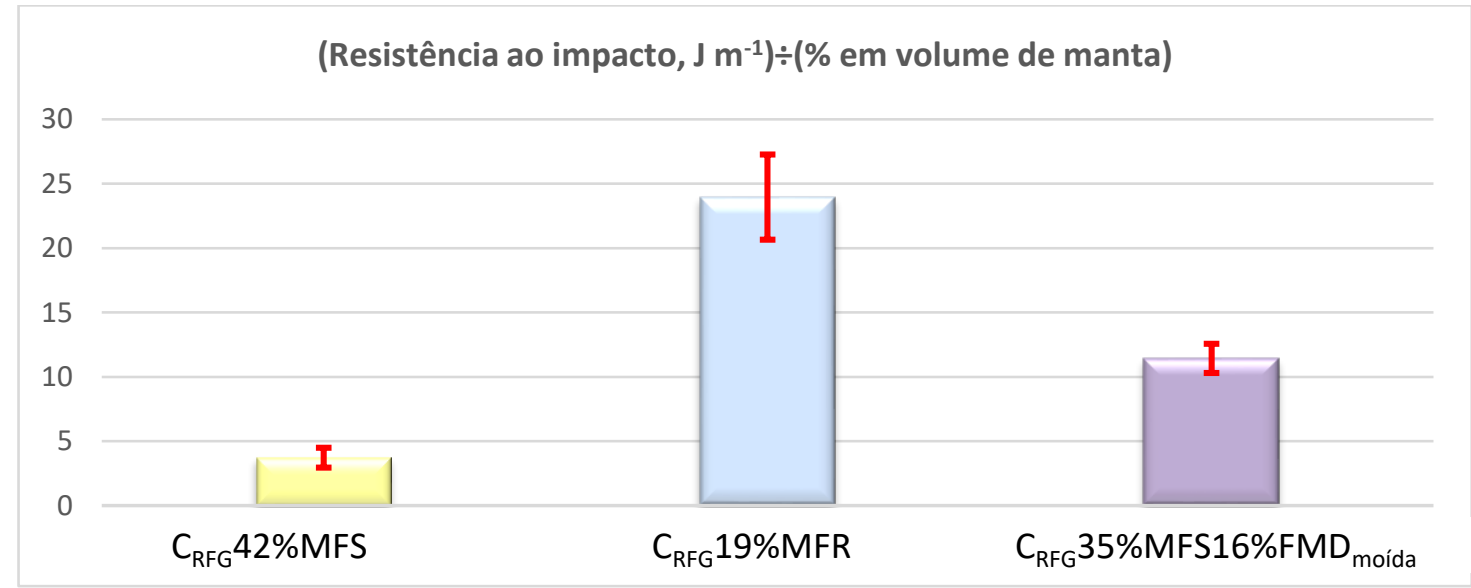

(b)

Ao comparar os resultados de resistência ao impacto do compósito $\mathrm{C}_{\mathrm{RFG}} 42 \% \mathrm{MFS}$ com o seu respectivo híbrido, $\mathrm{C}_{\mathrm{RFG}} 35 \% \mathrm{MFS} 16 \% \mathrm{FMD}_{\text {moída }}$, observou-se uma melhora significativa na resistência ao impacto, que pode ter sido ocasionado pela melhor transferência de carga da matriz para o reforço quando $\mathrm{FMD}_{\text {moída }}$ estava presente.

$\mathrm{O}$ resultado de resistência ao impacto do compósito $\mathrm{C}_{\mathrm{RFG}} 19 \% \mathrm{MFR}, 455 \pm 62 \mathrm{~J} \mathrm{~m}^{-1}$, foi superior ao mesmo compósito obtido com a matriz RFF, $323 \pm 30 \mathrm{~J} \mathrm{~m}^{-1}$ (Figura 44- a), 
conforme apresentado no Capítulo 2. Mesma tendência foi observada no resultado de resistência ao impacto normalizado. Isto tanto pode estar relacionado à uma maior molhabilidade das mantas de rayon devido a menor viscosidade desta resina comparativamente à RFF, conforme mencionado anteriormente na análise de SEC, quanto à uma maior adesão na interface fibra/matriz. A matriz RFG é rica em grupos hidroxilas polares que podem interagir através de ligações hidrogênio com a hidroxilas presentes na celulose (DE OLIVEIRA et al., 2017; DA SILVA et al., 2018). O compósito $\mathrm{C}_{\mathrm{RFG}} 42 \% \mathrm{MFS}$ apresentou uma redução da resistência ao impacto, $156 \pm 32 \mathrm{~J} \mathrm{~m}^{-1}$ (Figura 61- a), comparativamente ao mesmo compósito obtido em matriz RFF, $373 \pm 50 \mathrm{~J} \mathrm{~m}^{-1}$ (Figura 44- a). Esta redução pode estar associada à maior fragilidade da matriz RFG que dificultou a transferência de estresse da matriz para a MFS.

Também foi preparado um compósito híbrido constituído por MFS/FMD moída em matriz RFG. A menor viscosidade desta resina permitiu a utilização de uma maior porcentagem em massa $(16 \%)$ de FMD $_{\text {moída }}$ sem a necessidade de adição de etanol na resina para facilitar a homogeneização da fibra moída na matriz, e a impregnação da MFS na preparação do compósito híbrido $\mathrm{C}_{\mathrm{RFF}} 35 \% \mathrm{MFS16 \%} \mathrm{FMD}_{\text {moída }}$. Comparando os resultados de resistência ao impacto deste, $400 \pm 69 \mathrm{~J} \mathrm{~m}^{-1}$ (Figura 61- a), e do mesmo compósito híbrido em matriz RFF, $373 \pm 29 \mathrm{~J} \mathrm{~m}^{-1}$, (Figura 47- a), observou-se que ambos não apresentaram diferença significativa entre si.

Observou-se que o compósito $\mathrm{C}_{\mathrm{RFG}} 19 \% \mathrm{MFR}$ apresentou uma maior resistência ao impacto por unidade de porcentagem em volume de manta comparativamente ao compósito $\mathrm{C}_{\mathrm{RFG}} 42 \% \mathrm{MFS}$, o que também foi observado para o valor total da resistência ao impacto. A menor viscosidade da resina RFG pode ter aumentado a molhabilidade das mantas pela resina e a adesão fibra/matriz na interface. Assim, a carga recebida pela matriz foi eficientemente transferida para as duas mantas, levando a uma maior absorção do impacto quando o corpo-deprova foi atingido pelo martelo durante o ensaio (RAJESH; PITCHAIMANI, 2017).

Neste compósito, $\mathrm{C}_{\mathrm{RFG}} 19 \% \mathrm{MFR}$, observou-se delaminação, ou seja, o corpo-de-prova se separou na interface em duas lâminas. Contudo, a matriz localizada na interface matriz-MFR permaneceu aderida a mesma. No compósito $C_{\text {RFF }} 19 \%$ MFR não se observou delaminação, apenas ruptura parcial do corpo-de-prova.

\subsubsection{Microscopia eletrônica de varredura do termorrígido TRFG e dos compósitos de matriz RFG reforçados com MFS, MFR e híbrido MFS/FMD moída}

A Figura 62 apresenta as micrografias das superfícies de após o ensaio de impacto Izod do TRFG e dos compósitos de matriz RFG reforçados com MFS, $\mathrm{C}_{\mathrm{RFG}} 42 \% \mathrm{MFS}$, e seu 
respectivo híbrido, $\mathrm{C}_{\mathrm{RFG}} \mathrm{MFS} 16 \% \mathrm{FMD}_{\text {moída }}$ e do compósito reforçado com MFR, $\mathrm{C}_{\mathrm{RFG}} 19 \% \mathrm{MFR}$. A análise de MEV dos compósitos $\mathrm{C}_{\mathrm{RFG}} 42 \% \mathrm{MFS}$ e $\mathrm{C}_{\mathrm{RFG}} 19 \% \mathrm{MFR}$ foi realizada tanto na superfície de fratura quanto na região da superfície de interface fibra-matriz, como indicado nas micrografias (Figura 62- b e -c), devido a problemas de quebra da matriz durante a preparação dos copos-de-prova para análise. No compósito híbrido a análise foi realizada apenas na região de fratura após ensaio de impacto Izod.

Na Figura 62-a observa-se que o termorrígido TRFG apresentou regiões de propagação de trincas com regiões espelhadas, o que caracteriza material do tipo frágil (RAMIRES, 2010). Isto também foi observado para o TRFF, conforme apresentado no Capítulo 1. Na Figura 62b observou-se a presença de matriz (setas vermelhas) aderida à superfície da fibra (seta amarelas), indicando que apesar da baixa resistência ao impacto obtido no compósito $\mathrm{C}_{\mathrm{RFG}} 42 \% \mathrm{MFS}$ comparativamente ao compósito híbrido $\mathrm{C}_{\mathrm{RFG}} 35 \% \mathrm{MFS} 16 \% \mathrm{FMD}_{\text {moída, }}$ havia adesão entre ambas.

Figura 62 - Micrografias das superfícies fraturadas, pós-impacto, do termorrígido TRFG (a), dos compósitos reforçados com MFS, $\mathrm{C}_{\mathrm{RFG}} 42 \% \mathrm{MFS}$ (b), MFR, $\mathrm{C}_{\mathrm{RFG}} 19 \% \mathrm{MFR}$ (c), e compósito híbrido

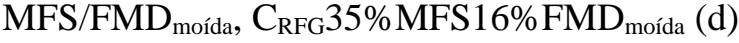

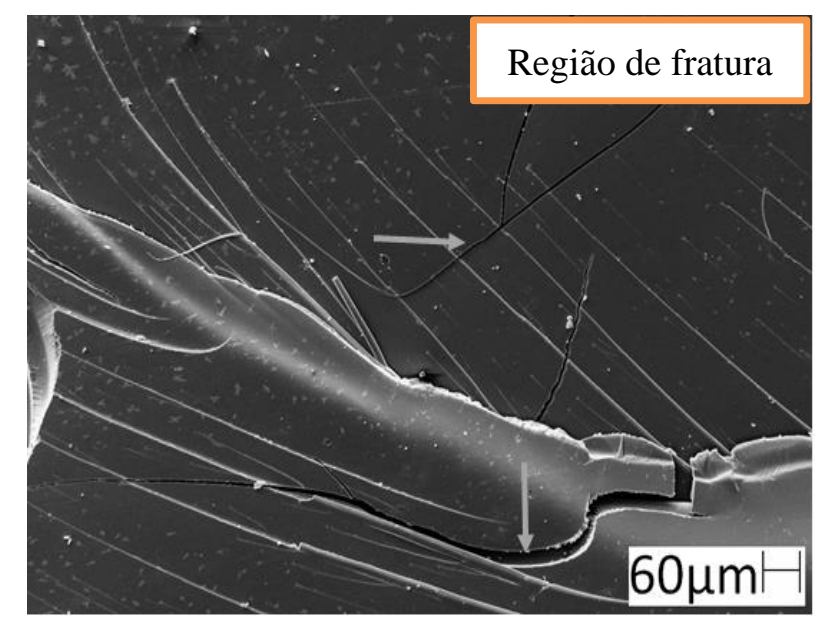

(a) 


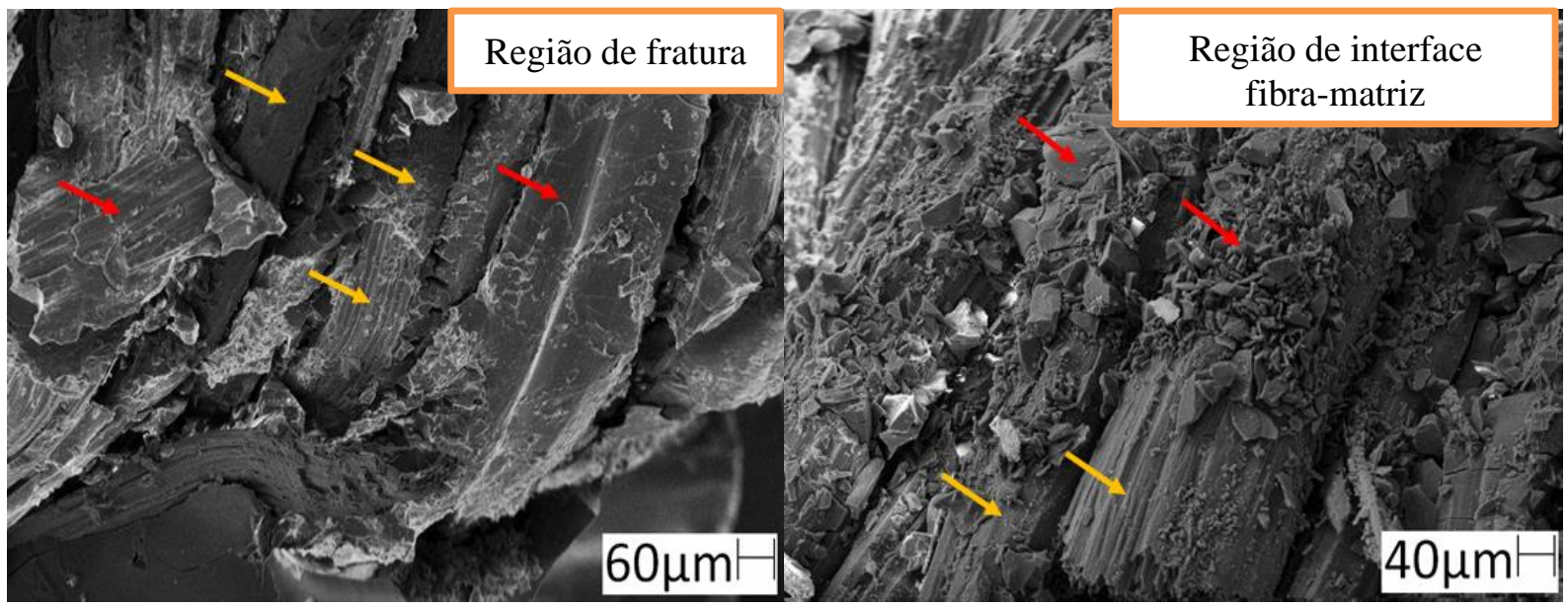

(b)

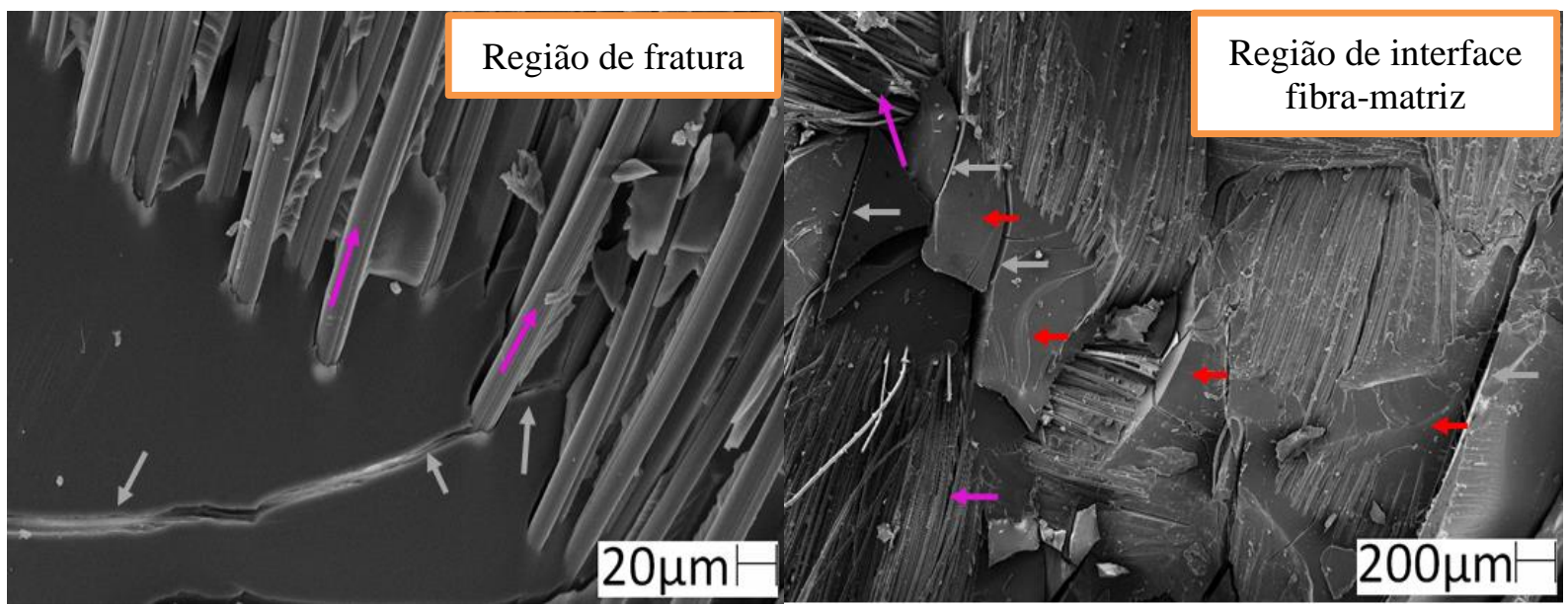

(c)

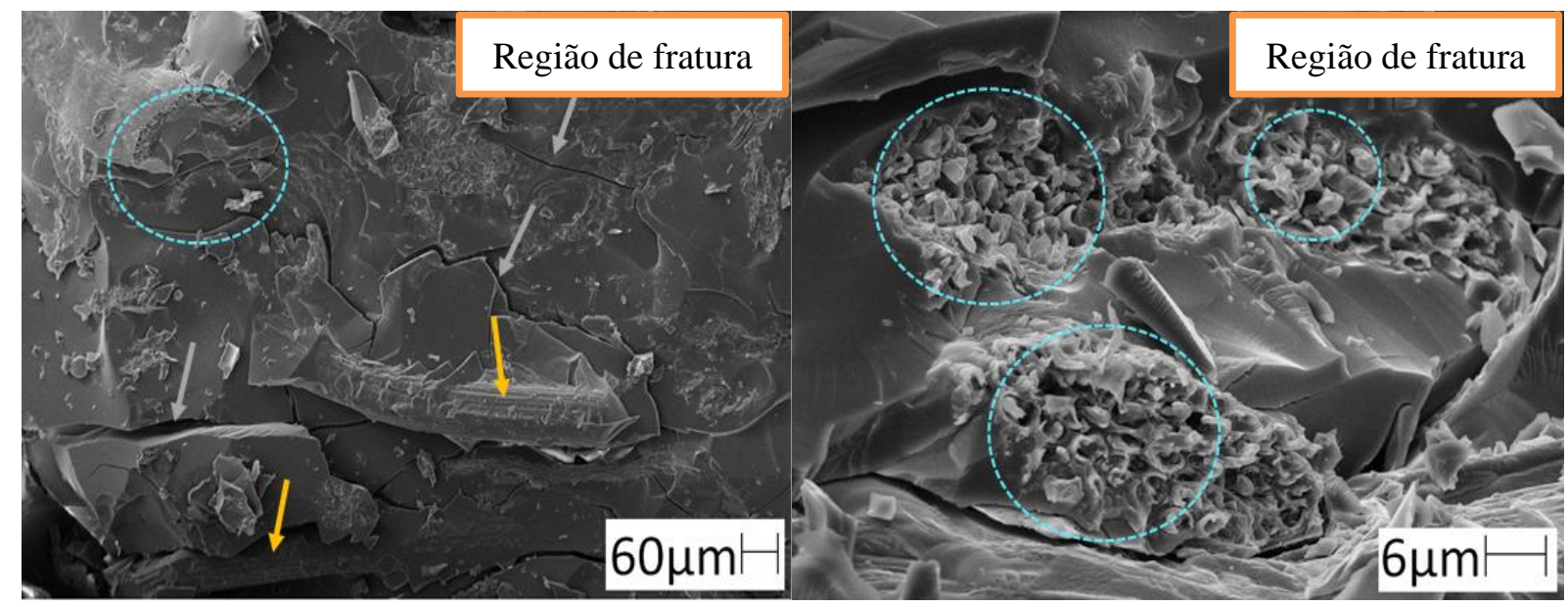

(d)

A presença de trincas que se propagaram ao redor da fibra rayon (setas cinzas) durante o ensaio de impacto Izod foi evidente na região de fratura do compósito $\mathrm{C}_{\mathrm{RFG}} 19 \% \mathrm{MFR}$ (Figura 62- b) (RAMIRES, 2010; MEGIATTO JÚNIOR, 2006), que apresentou delaminação. No entanto, não se observou um descolamento significativo ou arracamento fibra (pull out) da fibra 
da matriz.

Tanto no compósito $\mathrm{C}_{\mathrm{RFF}} 19 \% \mathrm{MFR}$ como no $\mathrm{C}_{\mathrm{RFG}} 42 \% \mathrm{MFS}$, as fibras da manta apenas sofreram deformação permancendo uma ponte de feixes de fibras (fiber bridging). No

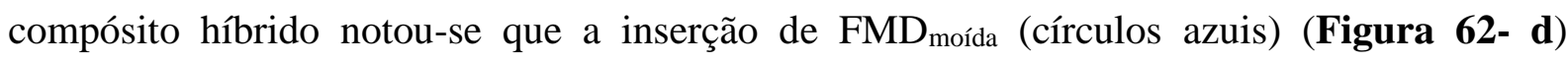
aumentou a resistência da matriz, conforme apresentado anteriormente (item 3.3.1.5). A $\mathrm{FMD}_{\text {moída }}$ no compósito $\mathrm{C}_{\mathrm{RFG}} 35 \% \mathrm{MFS} 16 \% \mathrm{FMD}_{\text {moída }}$ permaneceu aderida à matriz na região de fratura do corpo-de-prova. A inserção de FMDm na matriz neste compósito híbrido deixou a mesma menos frágil, e, possivelmente, pode ter melhorado a transferência de carga da matriz para as fibras, FMD moída e MFS, conforme observado anteriormente no resultado de resistência ao impacto (Figura 61- a). Um processo de fratura é iniciado pela formação e propagação da trinca, porém, neste caso, a propagação transversal da trinca foi interrompida pela manta e a trinca propagou apenas na interface (NASCIMENTO et al., 2012; PEREIRA et al., 2017).

\subsubsection{Resistência à flexão}

Os resultados de flexão dos compósitos de matriz RFG reforçados com MFS, $\mathrm{C}_{\mathrm{RFG}} 42 \% \mathrm{MFS}, \mathrm{MFR}, \mathrm{C}_{\mathrm{RFG}} 19 \% \mathrm{MFR}$, e híbrido $\mathrm{C}_{\mathrm{RFG}} 38 \% \mathrm{MFS} 16 \% \mathrm{FMD}_{\text {moída, estão }}$ apresentados na Figura 63. É importante destacar que assim como os compósitos de matriz RFF reforçados com mantas e híbrido, os corpos-de-prova dos compósitos obtidos neste capítulo também não sofreram ruptura completa.

Figura 63 - Resultados de resistência à flexão (a), comparativo entre os resultados resistência à flexão normalizados(b), resultados de módulo de flexão (c) e comparativo entre os resultados de módulo de flexão normalizados dos compósitos $\mathrm{C}_{\mathrm{RFG}} 42 \% \mathrm{MFS}, \mathrm{C}_{\mathrm{RFG}} 19 \% \mathrm{MFR}$ e $\mathrm{C}_{\mathrm{RFG}} 35 \% \mathrm{MFS} 16 \% \mathrm{FMD}_{\text {móda }}$ (d).

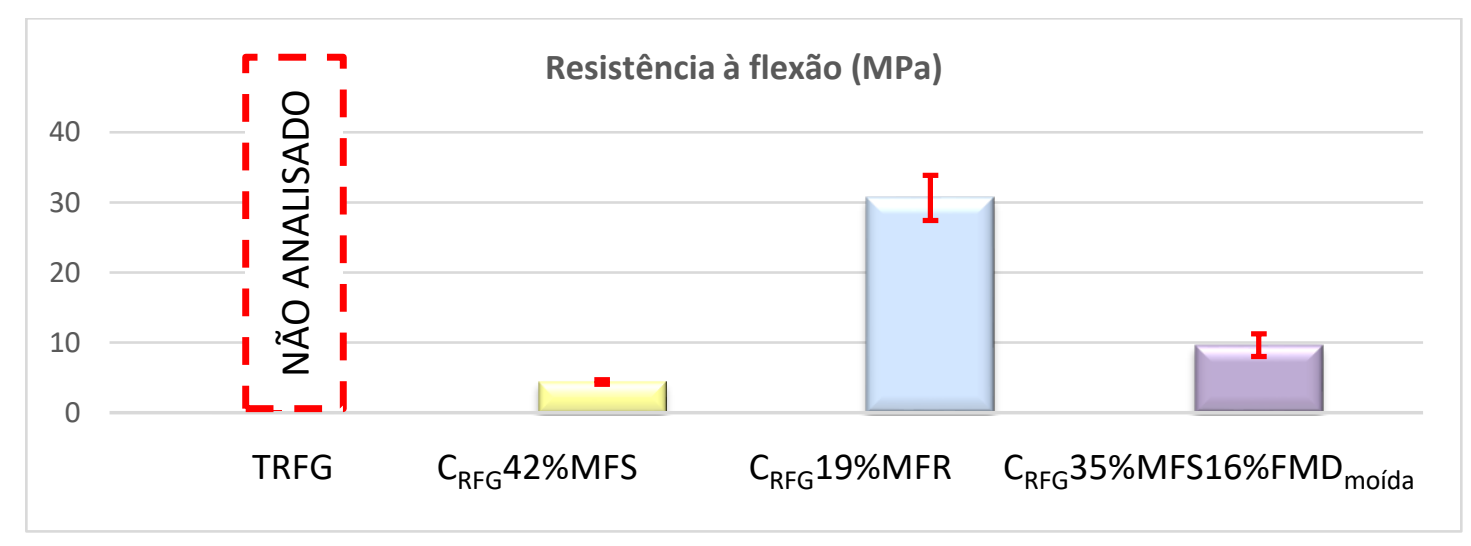

(a) 


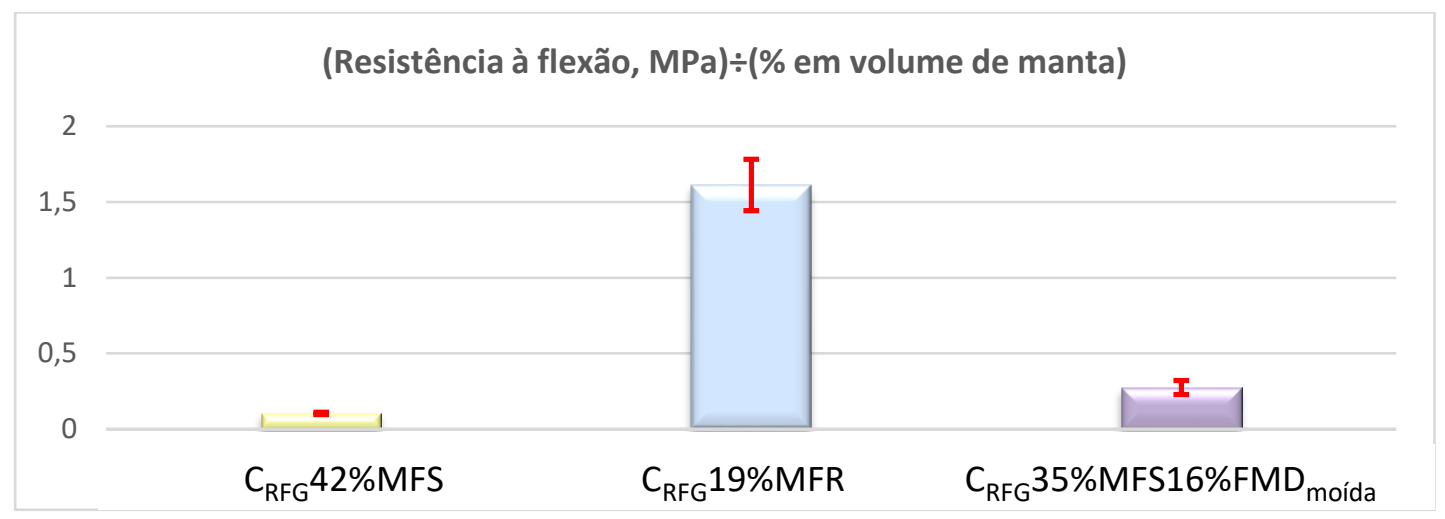

(b)

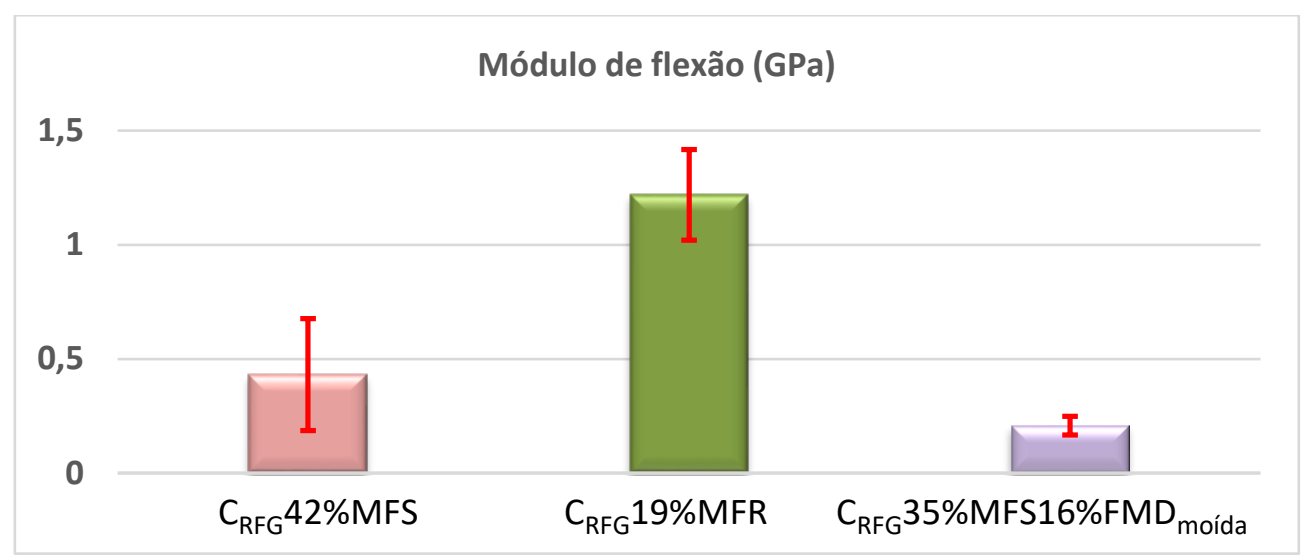

(c)

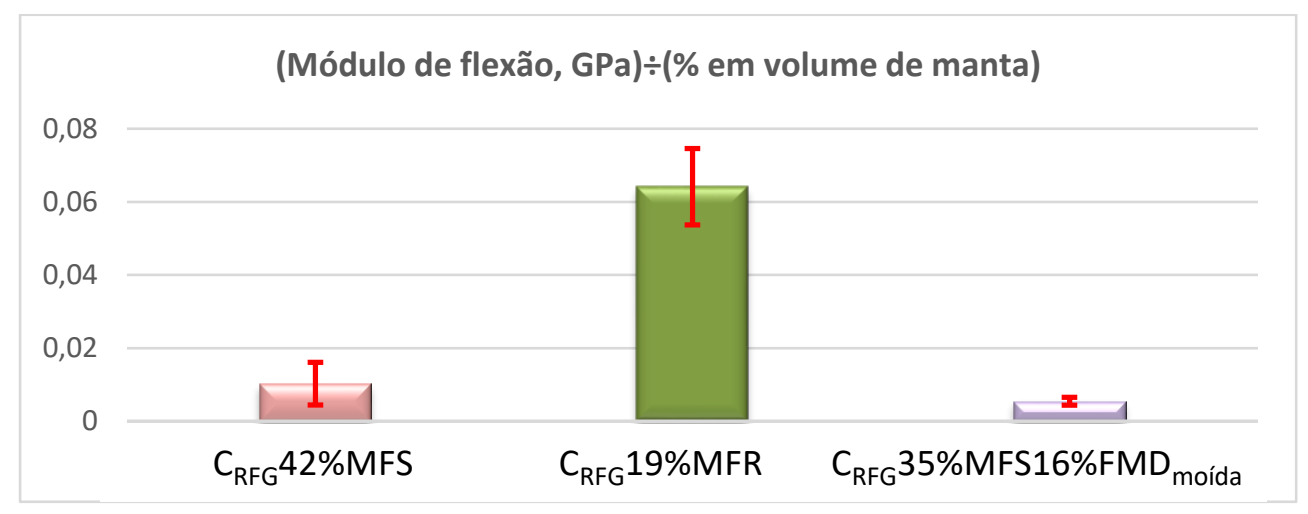

(d)

Devido à fragilidade do termorrígido não reforçado (TRFG) não foi possível a obtenção de corpos-de-prova para realização deste ensaio. A Figura 63 mostra que a inserção de mantas levou a um aumento considerável na resistência à flexão do material, pois foi possível realizar o ensaio. A adição de $\mathrm{FMD}_{\text {moída }}$ na matriz (compósito $\mathrm{C}_{\mathrm{RFG}} 38 \% \mathrm{MFS} 16 \% \mathrm{FMD}_{\text {moída) }}$ comparativamente ao $\mathrm{C}_{\mathrm{RFG}} 42 \% \mathrm{MFS}$, levou à um aumento resistência à flexão. Ao comparar os resultados de resistência à flexão normalizados (por unidade de procentagem em volume de manta), foi possível observar que o $\mathrm{C}_{\mathrm{RFG}} 19 \% \mathrm{MFR}$ apresentou melhor resultado. Como no 
compósito $\mathrm{C}_{\mathrm{RFG}} 42 \% \mathrm{MFS}$ havia predominância de matriz nas superfícies superior e inferior, este compósito foi influenciado pelas propriedades de superfície da mesma (DE OLIVEIRA et al., 2017), enquanto no compósito $\mathrm{C}_{\mathrm{RFG}} 19 \% \mathrm{MFR}$, contendo duas mantas de rayon, a matriz ficou distribuída entre as duas mantas e as superfícies, o que levou a melhor transferência de carga da matriz para as mantas.

Ao compararmos os resultados de resistência à flexão do compósito $\mathrm{C}_{\mathrm{RFG}} 19 \% \mathrm{MFR}, 26,5 \mathrm{MPa}$ (Figura 63- a), com o $\mathrm{C}_{\mathrm{RFF}} 19 \% \mathrm{MFR}, 38,5 \mathrm{MPa}$, apresentado no Capítulo 2, possivelmente a maior fragilidade da matriz RFG em relação à RFF causou a redução observada no $\mathrm{C}_{\mathrm{RFG}} 19 \% \mathrm{MFR}$. A mesma tendência foi observada para os demais compósitos.

Os resultados de módulo de flexão normalizados (Figura 63- d) mostram a mesma tendência dos resultados de resistência à flexão, indicando que o compósito $\mathrm{C}_{\mathrm{RFG}} 19 \% \mathrm{MFR}$ apresentou maior rigidez comparado ao $\mathrm{C}_{\mathrm{RFG}} 42 \% \mathrm{MFS}$ e ao $\mathrm{C}_{\mathrm{RFG}} 35 \% \mathrm{MFS} 16 \% \mathrm{FMD}_{\text {moída. }}$

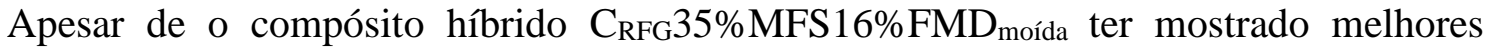
resultados de resistência ao impacto (Figura 61- a) e flexão (Figura 63- a), comparado ao $\mathrm{C}_{\mathrm{RFG}} 42 \% \mathrm{MFS}$, o híbrido apresentou menor módulo de flexão por unidade de porcentagem de volume de manta (Figura 63- d). A presença de defeitos como vazios e microtrincas na interface de adesão entre a FMD moída/MFS/matriz podem ter levado à uma distribuição não uniforme da tensão à medida que a mesma foi aplicada no corpo-de-prova (BLEDZKI et al., 2015; FIORE et al., 2016). Liu et al. (2006) observaram uma redução tanto da resistência à flexão quanto no modulo de flexão à medida que aumentou a quantidade de vazios.

Ao se comparar os resultados de módulo de flexão dos compósitos de matriz RFG (Figura 63- c) com os respectivos em matriz RFF (Figuras 52- a e 53- a), observou-se uma uma redução desta propriedade nos compósitos de matriz RFG. A mesma tendência foi observada nos resultados de flexão, conforme mencionado anteriormente.

\subsubsection{Análise dinâmico mecânica do termorrígido TRFG e dos compósitos de matriz RFG reforçados com MFS, MFR e híbrido MFS/FMD móda}

A Figura 64 apresenta as curvas de módulo de armazenamento (E') (a) e $\tan \delta$ (b) versus temperatura dos compósitos de matriz RFG reforçados com MFS, $\mathrm{C}_{\mathrm{RFG}} 42 \% \mathrm{MFS}$, MFR, $\mathrm{C}_{\mathrm{RFG}} 19 \% \mathrm{MFR}$, e híbrido $\mathrm{C}_{\mathrm{RFG}} 35 \% \mathrm{MFS} 16 \% \mathrm{FMD}_{\text {moída }}$. 
Figura 64 - Curvas DMA- Módulo de armazenamento (E') (a) e Tan $\delta$ (b) do termorrígido fenólico versus temperatura (TRFG) e dos compósitos matriz RFG reforçados com MFS, $\mathrm{C}_{\mathrm{RFG}} 42 \% \mathrm{MFS}$, MFR, $\mathrm{C}_{\mathrm{RFG}} 19 \% \mathrm{MFR}$, e híbrido $\mathrm{C}_{\mathrm{RFG}} 35 \% \mathrm{MFS} 16 \% \mathrm{FMD}_{\text {moída. }}$

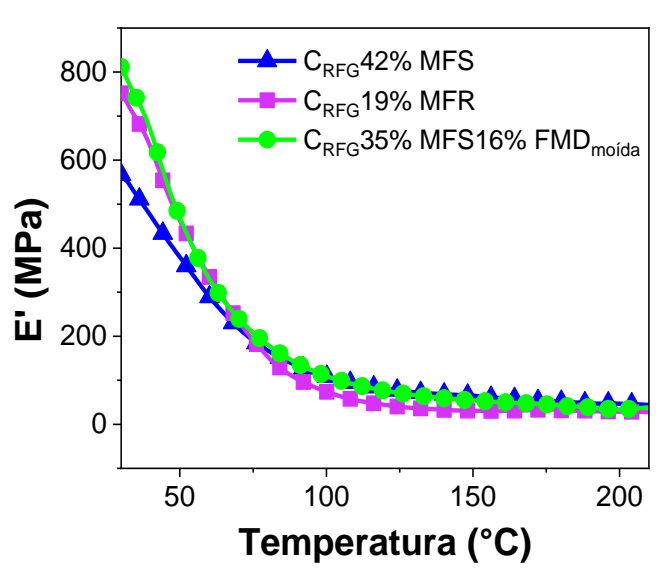

(a)

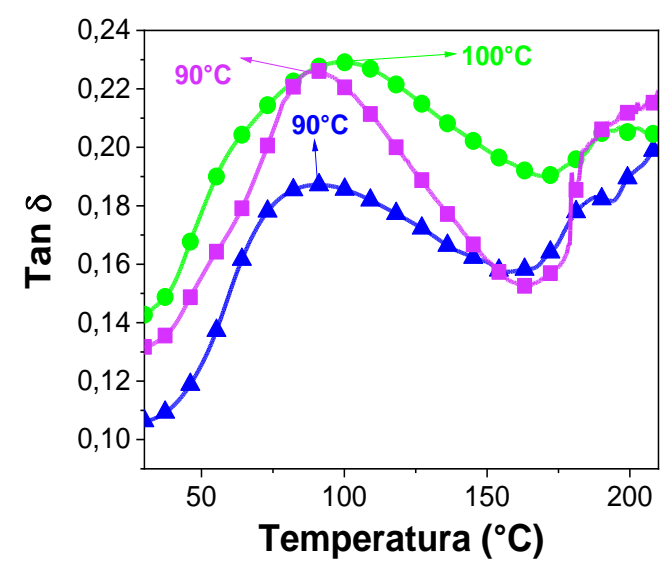

(b)

Devido a fragilidade do TRFG não foi a possível a realização desta análise para o termorrígido não reforçado.

Os compósitos apresentaram baixos valores de $\mathrm{E}^{\prime}$ entre si, Figura 64-a, sendo que o $\mathrm{C}_{\mathrm{RFG}} 19 \% \mathrm{MFR}$ e o $\mathrm{C}_{\mathrm{RFG}} 35 \% \mathrm{MFS} 16 \% \mathrm{FMD}_{\text {moída }}$ apresentaram valores próximos. Comparando com os mesmos compósitos de matriz RFF (Figura 55- a e 56- a), os compósitos de matriz RFG apresentaram menores valores em E'. Este resultado pode ser atribuído a um menor grau de entrecruzamento destes compósitos, e também a maior mobilidade de segmentos introduzidos pela reação com glutaraldeido (- $\left.\mathrm{CHOHCH}_{2} \mathrm{CH}_{2} \mathrm{CH}_{2} \mathrm{COH}-\right)$, comparativamente aos grupos $-\mathrm{CH}_{2}$ - introduzidos quando formaldeído foi o reagente. A maior mobilidade de segmentos leva à uma maior dissipação de energia na transferência de esforço na inteface fibra/matriz e, consequentemente, ocasiona a redução no módulo de armazenamento (RAMIRES, 2010; COSTA et al., 2016).

A baixa resistência ao impacto do TRFG (não reforçado) (Figura 61- a) comparado à do TRFF, possivelmente pode estar associada à essa maior mobilidade dos segmentos na matriz TRFG.

A Figura 64- b apresenta as curvas Tan $\delta$ versus temperatura dos compósitos de matriz RFG. Os compósitos $\mathrm{C}_{\mathrm{RFG}} 42 \% \mathrm{MFS}, \mathrm{C}_{\mathrm{RFG}} 19 \% \mathrm{MFR}$ e $\mathrm{C}_{\mathrm{RFG}} 35 \% \mathrm{MFS} 16 \% \mathrm{FMD}_{\text {moída }}$ apresentaram $\mathrm{T}_{\mathrm{g}}$ (picos observados nas curvas $\operatorname{Tan} \delta$ ) de aproximadamente 90, 90 e $100{ }^{\circ} \mathrm{C}$, respectivamente. A maior $\mathrm{T}_{\mathrm{g}}$ de $\mathrm{C}_{\mathrm{RFG}} 35 \% \mathrm{MFS} 16 \% \mathrm{FMD}_{\text {moída }}$ indica que componentes de FMD $_{\text {moída }}$ interagiram em nível molecular com a matriz, diminuindo a mobilidade dos 
segmentos. Como as temperaturas de decomposição destes materiais ocorrem acima de $240{ }^{\circ} \mathrm{C}$ (Figura 59), a temperatura indicada nos picos das curvas Tan $\delta$ estão relacionadas à $T_{g}$.

A $\mathrm{T}_{\mathrm{g}}$ dos compósitos de matriz RFG foram inferiores às dos compósitos de matriz RFF, que variaram de 140 a $184{ }^{\circ} \mathrm{C}$, com exceção do $\mathrm{C}_{\mathrm{RFF}} 42 \% \mathrm{MFS}$ que apresentou valor $\mathrm{Tg}$ de $105{ }^{\circ} \mathrm{C}$. Isto pode estar relacionado ao menor grau de entrecruzamento indicado pelos valores de E' (Figura 63- a), como também a maior extensão dos segmentos introduzidos pela reação com glutaraldeído e, portanto, maior mobilidade, comparativamente ao formaldeído, como mencionado.

\subsection{Conclusões parcíaís}

O grau de entrecruzamento da matriz TRFG possivelmente influenciou nesta propriedade, pois apesar dos compósitos $\mathrm{C}_{\mathrm{RFG}} 19 \% \mathrm{MFR}$ e $\mathrm{C}_{\mathrm{RFG}} 35 \% \mathrm{MFS} 16 \% \mathrm{FMD}_{\text {moída }}$ terem apresentado elevados valores de resistência ao impacto, $455 \pm 62 \mathrm{~J} \mathrm{~m}^{-1}$ e $400 \pm 69 \mathrm{~J} \mathrm{~m}^{-1}$, respectivamente, os mesmos apresentaram menores valores de E' (observados na análise de DMA) quando comparados com os respectivos compósitos em matriz RFF.

A menor viscosidade da resina RFG influenciou positivamente no aumento da molhabilidade das mantas rayon ( $\left.\mathrm{C}_{\mathrm{RFG}} 19 \% \mathrm{MFR}\right)$, assim como a inserção de glutaraldeído na resina fenol-glutaraldeído pode ter ocasionado uma maior adesão/interação entre esta e os grupos hidroxilas presentes na manta rayon, proporcionando a obtenção de melhor resultado de resistência ao impacto comparativamente ao $\mathrm{C}_{\mathrm{RFF}} 19 \% \mathrm{MFR}$ (Capítulo 2).

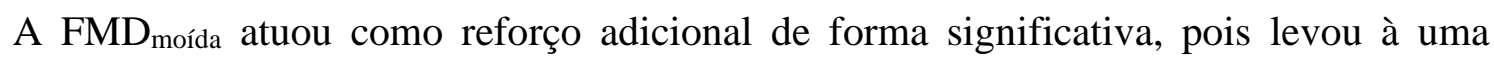
melhora significativa na propriedade do material, de $156\left(\mathrm{C}_{\mathrm{RFG}} 42 \% \mathrm{MFS}\right)$ para $440 \mathrm{~J} \mathrm{~m}^{-1}$

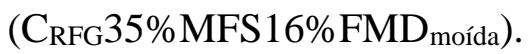

A utilização da resina fenol-glutaraldeído como matriz polimérica na preparação de compósitos se mostrou bastante satisfatória em compósitos que contenham mais de uma manta rayon e MFS/FMD moída como reforço, pois as regiões em que há predominância de matriz no compósito apenas com MFS foram prejudicadas devido à fragilidade da matriz e reduziu a transferência de estresse da matriz para as fibras. 


\section{Capítulo 4}

\section{Síntese de resina lignofenólica: obtenção de} compósitos de matriz termorrígida reforçados com manta de sisal, manta de rayon, e híbrído constituído por manta de sisal e fíbra do mesocarpo do dendê moída

\subsection{Introdução}

A substituição de matérias-primas não renováveis por materiais originados a partir de fontes naturais vem sendo um dos assuntos de grande interesse por parte das indústrias nos últimos anos, visando reduzir o impacto ambiental, o que também alcança a área de síntese de resinas.

Visando a redução e/ou susbtituição total do uso de fenol na síntese de resinas fenólicas, tem-se a lignina como fonte de anéis aromáticas neste tipo de aplicação. A lignina é uma macromolécula fenólica de estrutura tridimensional complexa e amorfa, a qual pode ser obtida a partir da biomassa lignocelulósica.

Neste capítulo relata-se a preparação de compósitos de matriz termorrígida lignina Kraft-fenol-formaldeído, a partir de resina sintetizada em meio básico, reforçados com MFR e

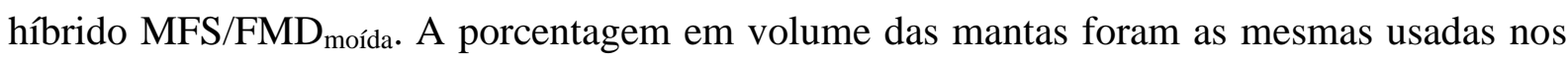
Capítulos 2 e 3, 19\% (em volume) de MFR, e o híbrido foi preparado com 38\% (em volume) de MFS e $9 \%$ (em massa) de FMD $_{\text {moída. }}$ Foi escolhida a porcentagem de 19\% de MFR, por esta levar ao melhor resultado de resistência ao impacto comparado ao compósito com 10\% de MFR, ambos apresentados no Capítulo 2. Em relação ao compósito com híbrido constituído por

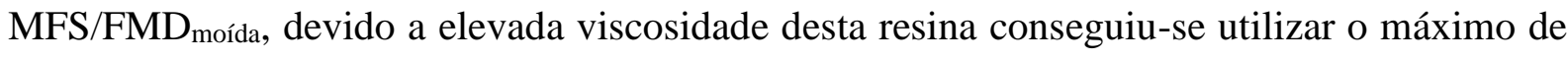
9\% de porcentagem em massa. Esta porcentagem foi baseada nos resultados de resistência ao impacto dos compósitos de matriz fenol-formaldeído reforçados com MFS/FMD moída apresentados no Capítulo 2 
A fragilidade da matriz lignina Kraft-fenol-formaldeído, impossibilitou a obtenção de compósitos apenas reforçados com MFS, pois durante o processo de corte as superfícies dos mesmos apresentaram muitas rachaduras.

Os compósitos foram preparados por moldagem com compressão, em que o ciclo de moldagem foi baseado em trabalhos anteriores desenvolvidos no grupo MacromoLignocell, (RAZERA; FROLLINI, 2004; RAMIRES, 2010; DE OLIVEIRA, 2010; DA SILVA et al., 2018), conforme já mencionado.

\subsection{Experimental}

\subsubsection{Materiais}

A lignina Kraft utilizada no presente estudo foi obtida da madeira de eucalipto, e foi cedida gentilmente pela indústria Suzano Papel e Celulose (Limeira-SP). Os demais materias e reagentes utilizados foram apresentados nos itens 1.2.1 e 2.2.1 do Capítulo 1 e 2, respectivamente.

\subsubsection{Métodos}

4.2.2.1 Caracterização das fibras que compõem as mantas utilizadas como reforço, MFS e MFR, e FMDmoída

A caracterização das fibras utilizadas neste Capítulo 4 como reforço foi apresentada nos Capítulos 1 e 2. Alguns dos resultados de caracterização da lignina Kraft purificada também foram apresentados previamente por Cassales (2019): análise emelentar, teor de lignina Klason, determinação da massa molar e análise termogravimétrica.

\subsubsection{Purificação da lignina kraft}

Previamente à realização da síntese da resina RLKFF, a lignina Kraft (LK) foi purificada em água a $70{ }^{\circ} \mathrm{C}$ por $1 \mathrm{~h}$ e a razão de lignina:água foi de 1:10 (m/v) em sistema com agitação mecânica. Esta condição foi selecionada baseando-se em experimentos preliminares.

\subsubsection{Síntese de resina lignofenólica}

\subsection{Síntese da resina (pré-polímero) lignina Kraft : fenol : formaldeído (RLKFF)}

A reação de síntese do pré-polímero foi realizada conforme descrito anteriormente no item 1.2.2.2.1 no Capítulo 1, baseada nas condições de Da Silva (2011). O pré-polímero foi preparado utilizando uma proporção em massa de 0,3: 0,7: 1,38: 0,06 de fenol: lignina Kraft: 
formaldeído (solução a 37\%): $\mathrm{KOH}$, respectivamente. A proporção de lignina Kraft: fenol utilizada no presente estudo foi baseada em experimentos preliminares. Inicialmente foi realizada a solubilização prévia da lignina por 30 min com agitação mecânica em solução de $\mathrm{KOH}$ pH 9. A proporção de lignina: solução de $\mathrm{KOH}$ foi 1:2,5 em massa. Em seguida, adicionou-se o formaldeído e a mistura ficou em agitação por mais $45 \mathrm{~min}$. Aqueceu-se então a mistura por $1 \mathrm{~h}$ à $93-95{ }^{\circ} \mathrm{C}$. Ao término desta etapa, o sistema foi resfriado até $60{ }^{\circ} \mathrm{C}$ e adicionou-se o fenol. Em seguida, iniciou-se o aquecimento novamente até atingir $85^{\circ} \mathrm{C}$ por 30 min. Ao fim deste tempo, a reação retornou a $70{ }^{\circ} \mathrm{C}$ e a mesma foi mantida nesta temperatura por 1 h. Ao término da reação, deixou-se o sistema resfriar até a temperatura ambiente, mediuse o $\mathrm{pH}$ e, ajustou-se o mesmo para 7,0 adicionando $\mathrm{HCl}(37 \%)$.

\subsubsection{Preparação dos compósitos de matriz lignofenólica reforçado com MFR e MFS/FMDmoída}

\subsection{Adição do agente acelerador de cura}

Devido à elevada viscosidade desta resina, foram adicionados $70 \mathrm{~mL}$ de etanol à mesma previamente à adição do agente de cura. Este foi adicionado de acordo com o descrito no item 2.2.2.3.1 do Capítulo 2.

\subsection{Incorporação do reforço}

A Tabela 21 apresenta o modo de preparação dos compósitos de matriz RKLFF reforçados com MFR e híbrido MFS/FMD moída.

Tabela 21: Modo de preparo dos compósitos de matriz RLKFF reforçados com MFR, e híbrido MFS/FMD moída.

\begin{tabular}{|c|c|}
\hline \multicolumn{2}{|c|}{ Compósito de matriz RLKFF com MFR } \\
\hline Compósitos & Modo de preparação \\
\hline $\mathrm{C}_{\text {RLKFF }} 19 \% \mathrm{MFR}$ & $\begin{array}{l}\text { Adição de } 50 \mathrm{~mL} \text { de etanol à RLKFF; } \\
\text { Intercalou-se as camadas de MFR (previamente } \\
\text { pinceladas com resina) e resina }\end{array}$ \\
\hline \multicolumn{2}{|c|}{ Compósito híbrido de matriz RLKFF reforçado com MFS/FMDmoída } \\
\hline C $_{\text {RLKFF }} 38 \%$ MFS9\%FMDmoída & $\begin{array}{l}9 \% \mathrm{FMD}_{\text {moída }} \text { em massa } \\
\text { A MFS foi pré-impregnada com parte da resina. Em } \\
\text { seguida, realizou-se a mistura da FMD } \text { moída } \text { com o restante } \\
\text { de RLKFF. Após homogeneização, espalhou-se uma } \\
\text { parte da mistura no molde inferior, colocou-se a MFS pré- } \\
\text { impregnada, e adicionou-se o restante da mistura } \\
\text { RLKFF+FMD }\end{array}$ \\
\hline
\end{tabular}


A porcentagen em volume de MFR foi a mesma utilizada no Capítulo 3, $19 \%$ em volume de MFR, ou seja, usando duas mantas, pois esta foi a porcentagem em volume que apresentou melhor resultado de resistência ao impacto. Em relação ao compósito híbrido constituído por MFS e $\mathrm{FMD}_{\text {moída }}$, a porcentagem em massa utilizada de $\mathrm{FMD}_{\text {moída }}$ foi de $9 \%$. Devido à maior viscosidade da resina RLKFF (mesmo após adição de etanol) não foi possível adicionar porcentagem em massa superior a esta. A adição de etanol na resina RLKFF ficou limitada a $70 \mathrm{~mL}$, pois a resina ao ser colocada no molde pré-aquecido reagia rapidamente e formava uma película na parte inferior, o que impedia a evaporação do solvente.

\subsection{Moldagem do termorrígido e dos compósitos}

O termorrígido e os compósitos contendo resina fenólica foram moldados por compressão e aquecimento controlados, em molde portátil como descrito nos itens 2.2.2.4 e 3.2.2.3.3 dos Capítulos 2 e 3. O ciclo seguido para a cura dos compósitos de matriz RLKFF está apresentado na Tabela 22.

Tabela 22: Ciclo de cura para a obtenção do termorrígido e compósitos de matriz lignofenólica.

\begin{tabular}{ccc}
\hline Temperatura $\left({ }^{\circ} \mathbf{C}\right)$ & Tempo (min) & Força (ton) \\
\hline 50 & 15 & 0 \\
\hline 65 & 60 & 0 \\
\hline 75 & 60 & 0 \\
\hline 85 & 90 & 0 \\
\hline 95 & 30 & 10 \\
\hline 105 & 30 & 14 \\
\hline 115 & 60 & 16 \\
\hline 125 & 90 & 16 \\
\hline
\end{tabular}

Os ciclos de cura adotados foram baseados em estudos prévios (PAIVA; FROLLINI, 2006; RAMIRES, 2010) com adaptações. Nestes a moldagem iniciou-se após 60 min com molde aberto e aquecido a $65^{\circ} \mathrm{C}$ para eliminação do etanol, o que foi observado pela redução da viscosidade da resina. A pressão foi elevada (até força $=10$ ton) a $95^{\circ} \mathrm{C}$, pois verificou-se visualmente, em teste preliminar com o molde aberto, que esta era a temperatura aproximada do início do ponto de gelificação desta resina, a qual prosseguiu até aproximadamente $105^{\circ} \mathrm{C}$. 


\subsubsection{Caracterização da LK, pré-polímero, do termorrígido e dos compósitos}

\subsection{Determinação do teor de lignina Klason total}

O teor de lignina Klason total foi realizado de acordo com o descrito no item 1.2.2.1.1.3 do Capítulo 1.

\subsection{Análise elementar, determinação de açucares residual e cinzas}

O teor de carbono, hidrogênio, nitrogênio e enxofre da lignina Kraft antes e depois da purificação foi avaliado em equipamento da CE Instruments equipado com software Eager 200 no Departamento de Química da Universidade Federal de São Carlos (UFSCAR). A análise de cinzas foi realizada de acordo com o descrito no item 1.2.2.1.1.2 do Capítulo 1.

A análise de açúcares residuais do licor obtido na análise de lignina Klason da lignina kraft bruta e purificada foi realizada em cromatógrafo líquido Shimadzu com índice (RID-A Shimadzu) e coluna Aminex HPX9287H $(300 \times 7,8$ mm BIO-RAD). D-glicose (SigmaAldrich), d-xilose (Sigma-Aldrich), 1-arabinose (Sigma-Aldrich) ácido fórmico (49-51\%, Sigma-Aldrich), ácido acético (49-51\%, Sigma-Aldrich ) foram utilizados como padrão e a mistura eluente de ácido sulfúrico $0,005 \mathrm{~mol} \mathrm{~L}^{-1}$ (Merck Chemicals) com uma taxa de fluxo de $0,6 \mathrm{~mL} \min ^{-1} \mathrm{a} 45^{\circ} \mathrm{C}$.

\subsection{Espectroscopia na região do infravermelho por transformada de Fourier} (FTIR)

Os espectros de FTIR da lignina Kraft purificada, do pré-polímero RLKFF e dos compósitos foram obtidos de acordo com o descrito no item 1.2.2.4.1 do Capítulo 1.

\subsection{Cromatografia por exclusão de tamanho (SEC)}

Previamente a realização da análise SEC da lignina Kraft purificada, a mesma foi acetilada objetivando aumentar sua solubilidade no eluente utilizado para análise, THF. O processo de acetilação foi realizado em uma mistura de piridina/anidrido acético $(1: 1 \mathrm{v} / \mathrm{v})$, durante $24 \mathrm{~h}, 60^{\circ} \mathrm{C}$ (Figura 16). A etapa seguinte consistiu na reação entre o anidrido acético, que não reagiu, com metanol $(50 \mathrm{~mL})$ a $80^{\circ} \mathrm{C}$ durante $3 \mathrm{~h}$ em sistema com refluxo. A partir desta reação formou-se acetato de metila que foi evaporado em seguida. A eliminação da piridina foi realizada por co-destilação com tolueno em rotaevaporador $(2 \times 10 \mathrm{~mL})$. A eliminação do tolueno foi realizada por co-destilação com metanol em rotaevaporador. A última etapa foi a evaporação do metanol e separação da fração sólida, a qual foi seca em estufa e armazenada em dessecador (HOAREAU, 2005).

A análise SEC da lignina Kraft purificada acetilada seguiu o procedimento descrito no 
item 1.2.2.4.2 do Capítulo 1, e a do pré-polímero RLKFF foi realizada de acordo com o que foi descrito nos itens 1.2.2.4.2 e 3.2.2.4.2 do Capítulo 1 e 3.

\section{2.2.5.5 Ressonância magnética nuclear}

A lignina Kraft purificada acetilada foi dissolvida em DMSO- $d 6$ e piridina- $d 5$ na proporção de 4:1 (v/v), com auxílio de agitação magnética. A acetilação da lignina é imprescindível na análise de RMN, pois minimiza a agregação causada pelas interações intermoleculares entre os grupos hidroxila. Para caracterização desta lignina em termos de predominância dos constituintes principais, foi realizado experimento bidimensional heteronuclear de $g$ HSQC. Para o $g$ HSQC foram adquiridos 64 transientes, com um tempo de espera em cada aquisição de 0,5 s, janela em F1 de 200 ppm e em F2 de 16 ppm, com números de pontos em F1 de 256 e F2 de 962. Os sinais do DMSO, com o ${ }^{1} \mathrm{H}$ em 2,5 ppm e o ${ }^{13} \mathrm{C}$ em 39,51, foram utilizados como referência para a atribuição dos sinais.

A análise de RMN do pré-polímero RLKFF foi realizada de acordo com o que foi descrito no item 1.2.2.4.4 do Capítulo 1.

\subsection{Resistência ao impacto}

O ensaio de impacto Izod dos compósitos foi realizado de acordo com o descrito no item

\subsubsection{5 do Capítulo 1.}

\subsection{Microscopia Eletrônica por Varredura (MEV)}

A análise de microscopia eletrônica de varredura dos compósitos após fratura no ensaio de impacto Izod foi realizada de acordo com o que foi descrito no item 1.2.2.4.6 do Capítulo 1.

\subsection{Ensaio de resistência à flexão}

O ensaio de resistência à flexão dos compósitos foi realizado de acordo com o descrito no item 1.2.2.4.7 do Capítulo 1.

\subsection{Análise termogravimétrica (TGA)}

A análise termogravimétrica do pré-polímero e dos compósitos foi realizada de acordo com o que foi descrito no item 2.2.2.5.5 do Capítulo 2.

\subsection{Análise dinâmico mecânica (DMA)}


A análise de DMA dos compósitos foi realizada de acordo com o descrito no item

\subsubsection{8 do Capítulo 1.}

\subsection{Resultados e discussão "}

4.3.1 Caracterização da lignina Kraft, resina lignina-fenol-formaldeído e dos compósitos de matriz RLKFF reforçados com MFS, MFR e híbrido MFS/FMD moída

\subsubsection{Purificação, teor de impurezas, teor de lignina Klason total e análise elementar da lignina Kraft}

A purificação da lignina previamente à sua utilização em processos de síntese é imprescindível, pois as impurezas como, cinzas e açúcares residuais, presentes na lignina podem reduzir a sua reatividade (GOSSELINK et al., 2004; DWIATMOKO et al., 2014). Os resultados referentes ao teor de impurezas como cinzas e açúcares, teor de lignina Klason total e análise elementar da lignina Kraft antes e após a purificação estão apresentados na Tabela 23.

Tabela 23: Resultados de teor de lignina klason, umidade, açúcares e análise elementar da lignina Kraft antes e após etapa de purificação.

\section{Presente estudo}

\begin{tabular}{|c|c|c|c|c|c|}
\hline & $\begin{array}{c}\text { Lignina } \\
\text { Kraft } \\
\text { bruta }\end{array}$ & $\begin{array}{l}\text { Lignina } \\
\text { Kraft } \\
\text { purificada }\end{array}$ & $\begin{array}{l}\text { Gordobil } \\
\text { et al. } 2016\end{array}$ & $\begin{array}{l}\text { Hermiati et } \\
\text { al. } 2017\end{array}$ & $\begin{array}{l}\text { Domínguez- } \\
\text { Robles et } \\
\text { al., } 2018\end{array}$ \\
\hline & $\begin{array}{l}\text { Madeira de } \\
\text { eucalipto }\end{array}$ & $\begin{array}{l}\text { Madeira de } \\
\text { eucalipto }\end{array}$ & $\begin{array}{l}\text { Lignina } \\
\text { Kraft de } \\
\text { eucalipto }\end{array}$ & $\begin{array}{c}\text { Lignina } \\
\text { Kraft } \\
\text { Acacia } \\
\text { mangium }\end{array}$ & $\begin{array}{c}\text { Lignina } \\
\text { Kraft de } \\
\text { madeira } \\
\text { macia }\end{array}$ \\
\hline $\begin{array}{c}\text { Umidade } \\
(\%)\end{array}$ & $7,8 \pm 0,6$ & $3,8 \pm 0,2$ & NI & NI & NI \\
\hline Cinzas (\%) & $1,8 \pm 0,1$ & $0,1 \pm 0,4$ & 22,4 & 8,25 & 2,7 \\
\hline C (\%) & 56,3 & 61,3 & 49,8 & 49,7 & 66,9 \\
\hline H (\%) & 5,1 & 5,6 & 5,0 & 5,4 & 5,5 \\
\hline $\mathbf{N}(\%)$ & 0,7 & 0,7 & 0,11 & 0,12 & 0,15 \\
\hline $\mathrm{S}(\%)$ & 2,5 & 1,8 & 0,78 & 2,77 & 1,45 \\
\hline O*(\%) & 33,5 & 30,4 & 44,3 & 42 & NI \\
\hline $\begin{array}{c}\text { Açúcares } \\
(\%)\end{array}$ & $\begin{array}{c}5,500 \\
\pm 0,005 \\
\end{array}$ & $\begin{array}{c}4,980 \\
\pm 0,003 \\
\end{array}$ & 2,2 & NI & NI \\
\hline LKT* & $88,4 \pm 2,2$ & $94,1 \pm 1,4$ & 65 & 60,4 & 92,3 \\
\hline
\end{tabular}

*LKT-lignina klason total/ NI- não informado pelo autor 
Houve um aumento no teor de lignina Klason e uma redução nos teores de cinzas e açúcares após a etapa de purificação da lignina Kraft, indicando remoção de impurezas. É importante frisar que estes resultados também foram apresentados na tese de Cassales (2019).

A diferença no teor de açúcares solúveis foi de apenas 0,5\% comparado à lignina Kraft bruta. A lignina utilizada no presente estudo foi obtida através do processo Kraft Lignoboost. O processo Kraft consiste na dissolução da lignina e hemiceluloses submetendo a biomassa a um tratamento alcalino com hidróxido de sódio e um sal de sulfeto, geralmente sulfeto de sódio, que leva à clivagem das ligações $\alpha-\mathrm{O}-4, \alpha-\mathrm{O}-\mathrm{H}$ e $\beta-\mathrm{O}-4$ (Figura 65) da lignina e do complexo lignina-carboidrados (LIITIA et al., 2003; GALKIN; SAMEC, 2016; CARVAJAL; GÒMEZ; CARDONA, 2016). A diferença do processo Kraft "tradicional” para o Kraft Lignoboost, é que a lignina deste é precipitada em duas etapas: redução do $\mathrm{pH}$ do meio usando $\mathrm{CO}_{2}$ seguido de ressuspensão e precipitação com ácido sulfúrico. No processo Kraft tradicional a lignina é precipitada em apenas uma etapa através da adição de ácido sulfúrico (redução do pH) no licor negro (rico em açúcares solúveis e lignina) (WALLMO et al., 2018).

No entanto, nem todas as ligações do complexo lignina-carboidrados são clivadas durante o processo de extração e a lignina ainda pode conter açucares ligados a ela. Ainda, durante a etapa de precipitação, alguns açúcares podem sofrer ressuspensão e permanecerem associados à lignina, mesmo que não seja através de ligações covalentes (CONSTANT et al., 2016).

Com relação à análise elementar, o aumento nos teores de carbono e hidrogênio foi consequência da remoção de impurezas inorgânicas. Também se observou uma significativa redução do teor de enxofre na lignina Kraft após a purificação.

Figura 65 - Esquema da clivagem das ligações $\alpha-\mathrm{O}-\mathrm{H}$ da lignina com formação de intermediário metileno quinona.

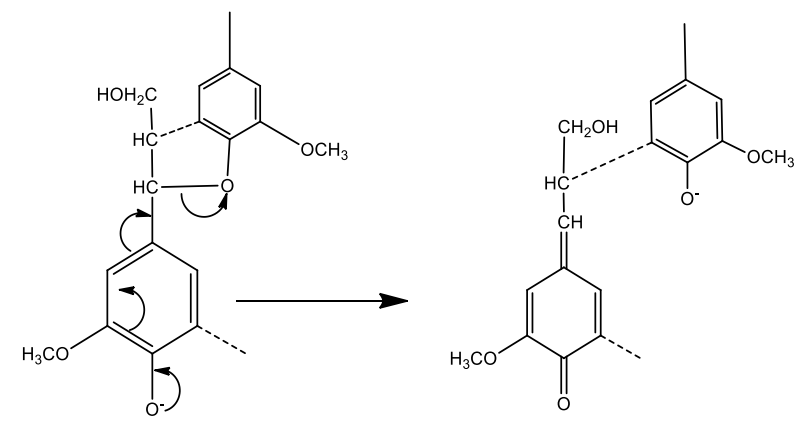

Fonte: GALKIN; SAMEC, 2016

A presença do enxofre na estrutura química da lignina Kraft é proveniente do sal de 
sulfeto utilizado no processo de dissolução da lignina (GALKIN; SAMEC, 2016; GORDOBIL et al., 2018). No entanto, o enxofre eliminado durante a purificação é referente ao ácido sulfúrico residual utilizado na etapa de precipitação, e que não foi removido completamente na etapa de lavagem da lignina Kraft.

Fazendo uma breve comparação entre os teores de açúcares, lignina klason e enxofre encontrados na literatura para a lignina Kraft (Tabela 23), foi possível observar que existem variações entre as porcentagens. Os teores de cinzas obtidos no presente estudo foram inferiores aos encontrados literatura, conforme apresentado na Tabela 23. O teor de cinzas é influenciado tanto pela matéria-prima a partir da qual a lignina é obtida, como também pela concentração de sal e tipo de processo de polpação utilizado. Domingues-Robles obtiveram lignina de palha de trigo obtida a partir do processo soda com $29,3 \%$ de material inorgânico, enquanto, a lignina kraft obtida pelo mesmo autor, porém, de um processo e de uma fonte diferente apresentou 2,7\% de material inorgânico (Tabela 23), indicando a influência da fonte que gerou a lignina, assim como do processo de extração.

Apenas a lignina Kraft obtida após purificação foi utilizada para síntese de resina lignofenólica e, portanto, os resultados de caracterização que serão apresentados a seguir serão referentes a esta lignina.

\subsubsection{Espectroscopia na região do infravermelho da lignina Kraft, da resina RLKFF, termorrígido TRLKFF e compósitos}

A lignina é uma macromolécula fenólica rica em anéis aromáticos e de estrutura tridimensional bastante complexa considerada uma promissora substituinte do fenol em resinas fenólicas (PAIVA; FROLLINI, 2006; RAMIRES et al., 2010; ZHAO et al., 2016; STUCKER et al., 2016). A Figura 66 apresenta o espectro da lignina Kraft utilizada no presente trabalho como substituinte parcial do fenol, da resina lignina Kraft fenol-formaldeído (RLKFF), do termorrígido (TRLKFF) e dos compósitos reforçados com MFR, $\mathrm{C}_{\mathrm{RLKFF}} 19 \% \mathrm{MFR}$, e híbrido

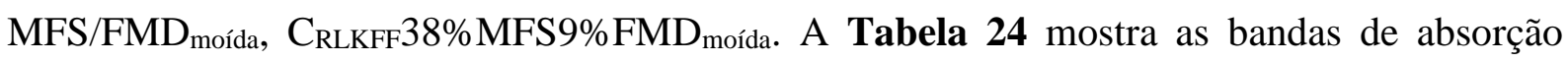
observadas na região de infravermelho obtidas.

Ao comparar os espectros observados na Figura 66, notou-se em todos uma banda intensa em aproximadamente $3420 \mathrm{~cm}^{-1}$ referente a estiramento ou deformação axial de grupos hidroxilas alcoólico e fenólico provenientes da lignina e do fenol.

Em 2945-2840 cm-1 observaram-se bandas referentes à deformação axial C-H de grupos saturados. Durante a síntese da resina, a primeira etapa da reação é a hidroximetilação da lignina, ou seja, inserção de grupos hidroximetila $\left(-\mathrm{CH}_{2}-\mathrm{OH}\right)$ na posição orto em relação ao 
grupo hidroxila do anel aromático (SAUNDERS, 1988; EL MANSOURI; YUAN; HUANG, 2011; ABDELWAHAB; NASSAR, 2011), conforme apresentado na Figura 66. Nos espectros de lignina e da resina RLKFF observou-se uma banda em $1715 \mathrm{~cm}^{-1}$ que está associdado à deformação axial de grupos carbonila conjugados.

No espectro do compósito $\mathrm{C}_{\mathrm{RLKFF}} 38 \% \mathrm{MFS} \% \mathrm{FMD}_{\text {moída }}$ observou-se uma banda em $1730 \mathrm{~cm}^{-1}$ possivelmente referente à estiramento de ligações $\mathrm{C}=\mathrm{O}$ de grupos éster e ácidos fenólicos que estão presentes em extrativos e hemiceluloses, e lignina, respectivamente, encontrados nas fibras de sisal e FMD moída (MAHMUD et al., 2013; THEN et al., 2014; PHITSUWAN et al., 2017), já que esta banda estava ausente no espectro do TRLKFF.

Figura 66 - Espectros na região de infravermelho da lignina Kraft, da resina RLKFF, termorrígido TRLKFF, e dos compósitos de matriz RLKFF reforçados com MFR, C $_{\text {RLKFF }} 19 \%$ MFR, e híbrido MFS/FMD ${ }_{\text {moída }}, \mathrm{C}_{\mathrm{RLKFF}} 38 \% \mathrm{MFS} 9 \% \mathrm{FMD}_{\text {moída. }}$

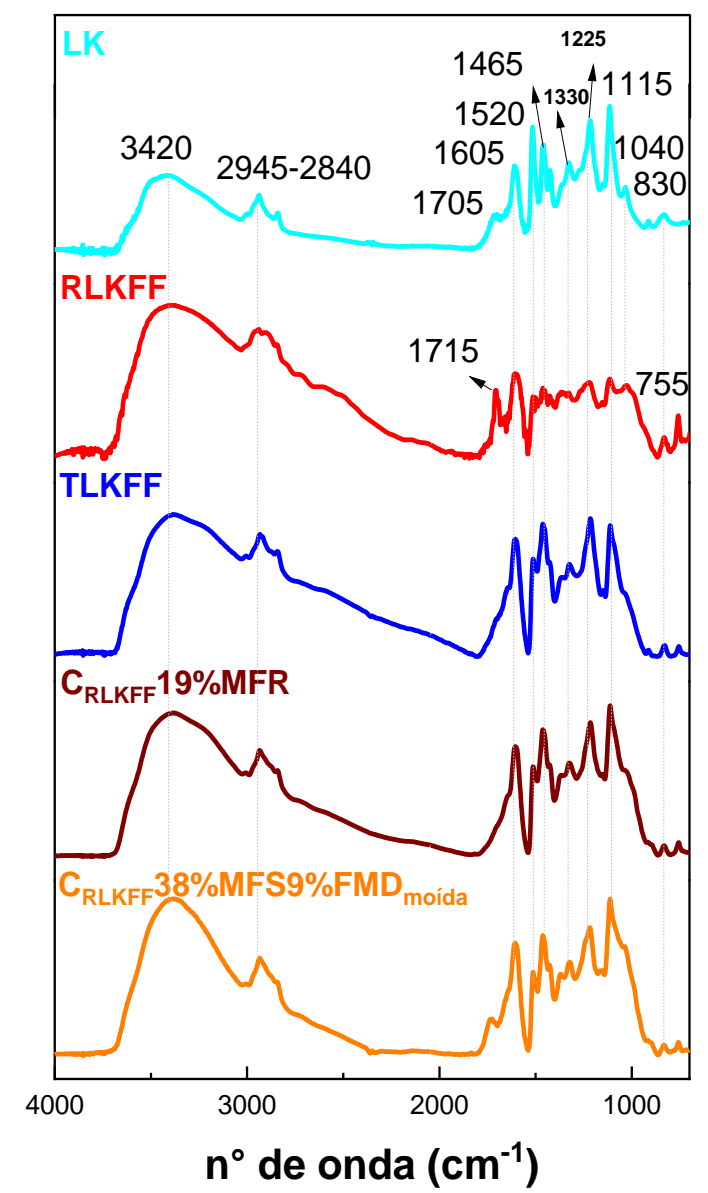

No espectro do compósito C $_{\text {RLKFF }} 19 \%$ MFR esta banda também não foi observada, assim como no espectro da fibra rayon (Figura 34- Capítulo 2). Como esta é formada a partir da polpa celulósica mercerizada, possivelmente houve a eliminação de hemiceluloses e extrativos 
durante a polpação (ORUE et al., 2015; THEN et al., 2015; BOSSUNIA et al., 2016; SENTHAMARAIKANNANA; KATHIRESAN, 2018).

Em todos os espectros em aproximadamente $1605 \mathrm{~cm}^{-1}$ (Figura 66), notou-se uma banda referente ao estiramento (deformação axial) das ligações $\mathrm{C}=\mathrm{C}$ de anéis aromáticos provenientes da lignina. No espectro da lignina observou-se uma banda em $1460 \mathrm{~cm}^{-1}$ que está associada à deformação assimétrica de ligação $\mathrm{C}-\mathrm{H}$ em $-\mathrm{CH}_{2}$ - Nos espectros da resina RLKFF, do termorrígido TRLKFF e no dos demais compósitos esta banda pode estar relacionada à deformação de $\mathrm{C}-\mathrm{H}$ de pontes metileno, as quais são formadas na condensação entre os monômeros de lignina hidroximetilado (ABDELWAHAB; NASSAR, 2011) e no entrecruzamento da resina durante a moldagem originando uma estrutura termorrígida (FENG et al., 2015).

A lignina Kraft apresentou bandas referentes à deformação de ligação presentes em estruturas siringila, 1329 e $1115 \mathrm{~cm}^{-1}$ (AHUJA, KAUSHIK, SINGH 2018; MARTÍNSAMPEDRO et al., 2019) e guaiacila, $1225 \mathrm{~cm}^{-1}$ (MARTÍN-SAMPEDRO et al., 2019) (Figura 66), em sua composição, sendo esta última mais reativa frente ao formaldeído (Figura 67). A reatividade da lignina é dependente da proporção em que seus constituintes estão presentes. A estrutura menos reativa é a siringila, pois esta possui as posições C3 e C5 do anel aromático impedidas estericamente por grupos metoxilas. A guaiacila e a p-hidroxifenila possuem apenas uma das posições (C3 ou C5) impedidas, e ambas posições livres para reagir com formaldeído, respectivamente (EL MANSOURI et al., 2006; RAMIRES et al., 2010) (Figura 11- b). Ligninas típicas de eucalipto (hardwood) têm como predominância, geralmente, de estruturas do tipo siringila e guaiacila (GOSSELINK, 2011).

Figura 67 - Esquema da reação de hidroximetilação da lignina contendo estrutura guaiacila.

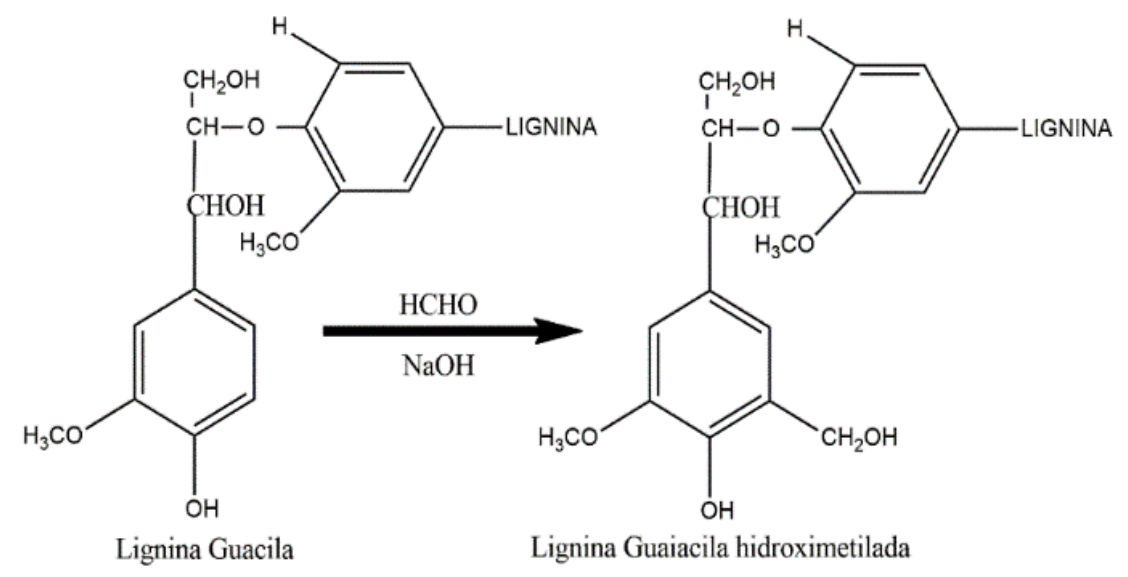

Fonte: Ramires e Frollini (2010). 
Tabela 24 - Principais bandas de absorção observadas na lignina kraft, na resina RLKFF, no termorrígo TRLKFF e nos compósitos de matriz termorrígida RLKFF reforçados com MFR, $\mathrm{C}_{\mathrm{RLKFF}} 19 \% \mathrm{MFR}$, e híbrido MFS/FMD moída, $\mathrm{C}_{\mathrm{RLKFF}} 38 \%$ MFS9\%FMD moída.

\begin{tabular}{|c|c|}
\hline & Lignina Kraft \\
\hline $\mathrm{n}^{\circ}$ de onda $\left(\mathrm{cm}^{-1}\right)$ & Possível atribuição \\
\hline 3420 & Deformação axial $\mathrm{O}-\mathrm{H}$ \\
\hline 2945-2840 & Deformação axial $\mathrm{C}-\mathrm{H}$ em $-\mathrm{CH}_{3} e-\mathrm{CH}_{2^{-}}$ \\
\hline 1705 & Estiramento de lifgação $C=O$ de dos grupos carbonila conjugados \\
\hline 1612 & Vibração $C=C$ de anel aromático \\
\hline 1520 & Vibração $C=C$ de anel aromático \\
\hline 1465 & Vibração de ligação $\mathrm{C}$-H em grupos metoxilas $\left(-\mathrm{OCH}_{3}\right)$ \\
\hline 1330 & Estiramento de ligação $C$-O de anel siringila \\
\hline 1225 & $\begin{array}{c}\text { Deformação de vibrações de ligações } \mathrm{C} \text {-H em anel aromático tipo } \\
\text { guaiacila }\end{array}$ \\
\hline 1115 & $\begin{array}{c}\text { Deformação de vibrações de ligações } \mathrm{C} \text { - } \mathrm{H} \text { em anel aromático tipo } \\
\text { siringila e deformação de vibração de ligação } \mathrm{C} \text {-O em álcool } \\
\text { primário }\end{array}$ \\
\hline 1030 & $\begin{array}{c}\text { Deformação de vibrações de ligaçães } C \text {-H no plano em anel } \\
\text { aromático tipo guaiacilal deformação de vibração de ligação } C-O \\
\text { em álcool primário }\end{array}$ \\
\hline \multirow[t]{2}{*}{830} & Vibração C-H na posição 2 e 6 de anel guaiacila \\
\hline & Resina RLKFF e Compósitos* \\
\hline $\mathrm{n}^{\circ}$ de onda $\left(\mathrm{cm}^{-1}\right)$ & Atribuição \\
\hline 3415 & Deformação axial $O-H$ \\
\hline 2944 & Deformação axial $\mathrm{C}$ - $\mathrm{H}$ em $\mathrm{CH}_{3}$ e $\mathrm{CH}_{2}$ em grupos metileno \\
\hline $1730 * *$ & $C=O$ de éster e ácido fenólico \\
\hline $1605 / 1515$ & Vibração $C=C$ de anel aromático \\
\hline 1466 & Deformação angular de ligação $\mathrm{C}$ - $\mathrm{H}$ de grupos metileno \\
\hline 1225 & $\begin{array}{c}\text { Vibração de } \mathrm{C} \text {-OH fenólico e } \mathrm{C} \text {-O de anel aromático } \\
\text { de unidades siringila e guaiacila }\end{array}$ \\
\hline 1115 & Estiramento da ligação-C-O do grupo hidroximetila \\
\hline 1030 & Deformação axial simétrica de ligação $\mathrm{C}-\mathrm{O}-\mathrm{C}$ de grupos $-\mathrm{OCH}_{3}$ \\
\hline 755 & Deformação angular da ligação $C$-H fora do plano \\
\hline
\end{tabular}

(REFERÊNCIAs: POLJANŠEK E KRAJNC (2005), TEJADO et al. (2007), SILVERSTEIN et al. (1994) e RAMIRES (2010), HERMINIAT et al. (2017)).

A banda em $755 \mathrm{~cm}^{-1}$ observada no espectro da resina RLKFF pode ser atribuída à ligação entre lignina e fenol na posição orto ou entre gupos hidroxila da cadeia lateral da lignina (ALONSO et al., 2005). Já que a lignina, geralmente possui a posição para ocupada por cadeia alifática (RAMIRES, 2010).

4.3.1.3 Determinação da massa molar média por cromatografia de exclusão por tamanho da lignina Kraft e da resina RLKFF 
A determinação da massa molar média da lignina é importante pois a partir desta é possível se ter conhecimento das diferentes frações que a compõem e que, consequentemente, influenciam na sua reatividade. Previamente à realização desta análise, a lignina kraft obtida após a etapa de purificação foi acetilada para aumentar a sua solubilidade no eluente da análise, THF, no caso. Ainda a acetilação da lignina ajuda a evitar que a molécula se agregue através de interações moleculares entre os grupos hidroxilas, acarretando em um cromatograma que reflete a real massa molar média desta macromolécula. A Tabela 25 mostra as massas molares médias e a polidispersividade obtidos por exclusão por tamanho da resina RLKFF.

Tabela 25 - Massa molar ponderal média $(\bar{M} w)$, massa molar numérica média $(\bar{M} n)$ e polidispersividade $(\bar{M} w / \bar{M} n)$ por picos e total da lignina kraft após purificação e acetilação e da resina lignina Kraft-fenolformaldeído.

\begin{tabular}{cccc}
\hline \multirow{2}{*}{ Picos } & \multicolumn{3}{c}{ Resina lignina Kraft-fenol-formaldeído } \\
& $\overline{\boldsymbol{M}} \boldsymbol{w}\left(\mathrm{gmol}^{-\mathbf{1}}\right)$ & $\overline{\mathbf{M}} \boldsymbol{n}\left(\mathrm{gmol}^{-\mathbf{}}\right)$ & $\overline{\boldsymbol{M}} \boldsymbol{w} / \overline{\mathbf{M}} \boldsymbol{n}$ \\
\hline $\mathbf{1}$ & 2797 & 1861 & 1,5 \\
\hline $\mathbf{2}$ & 642 & 638 & 1,0 \\
$\mathbf{3}$ & 474 & 471 & 1,0 \\
\hline $\mathbf{4}$ & 258 & 256 & 1,0 \\
\hline Média & $\mathbf{2 6 3 9}$ & $\mathbf{2 3}$ & $\mathbf{1 1 3}$ \\
\hline
\end{tabular}

A lignina Kraft apresentou uma das frações com $\overline{\mathrm{M}} \mathrm{w}$ em torno de $4000 \mathrm{~g} \mathrm{~mol}^{-1}$, enquanto as demais variaram entre 988 e $305 \mathrm{~g} \mathrm{~mol}^{-1}$, apresentando um valor médio total de $2544 \mathrm{~g} \mathrm{~mol}^{-1}(\overline{\mathrm{M}} \mathrm{w}), 975 \mathrm{~g} \mathrm{~mol}^{-1}$ ( $\overline{\mathrm{M}} \mathrm{n}$ ) e 2,6 (índice de polidispersividade), sendo a primeira citada fração mencionada superior à maior fração molar encontrada na resina RLKFF, Tabela 25.

Os valores de $\overline{\mathrm{M}}$ w e $\overline{\mathrm{M}} n$ da lignina kraft são referentes a fração solúvel em THF, sendo que apenas pequena fração não foi dissolvida, provavelmente correspondendo a contaminantes não eliminados durante a etapa de purificação. Durante o processo kraft a dissolução da lignina ocorre a partir da reação de ânions hidróxido e hidrossulfeto $\left(\mathrm{HS}^{-}\right)$que, consequentemente, resulta na obtenção de fragmentos solúveis em álcali. De maneira geral, estes dois tipos de reação podem ocorrer: (1) reações de degradação que levam a obtenção de fragmentos menores de lignina; e (2) reações de condensação entre os fragmentos de lignina obtidos (resultando em fragmentos maiores) (AZADI et al., 2013). Vale salientar que as ligações C-C presentes na estrutura da protolignina não são quebradas durante a extração na polpação Kraft devido sua elevada estabilidade e ligninas que possuem unidade guaiacila podem apresentar massas 
molares maiores comparativamente à lignina com predominância de estruturas siringila (TEJADO et al., 2007).

Em meio básico, com aquecimento, durante a síntese da resina RLKFF, pode ter ocorrido despolimerização da lignina, através da clivagem de ligações éter levando a frações de menor massa molar (EL MANSOURI et al., 2011), as quais reagiram com formaldeído e após hidroximetilação reagiram com o fenol, gerando o pré-polímero.

\subsubsection{Ressonância magnética nuclear}

\subsection{Lignina kraft}

A Figura 68- a mostra o espectro de $g \mathrm{HSQC}$ (Heteronuclear Single Quantum Coherence), o qual correlaciona os sinais/cross-peaks obtidos nos espectros de ${ }^{1} \mathrm{H}-{ }^{13} \mathrm{C}$, da lignina Kraft, utilizada no presente estudo, purificada e acetilada.

A reatividade da lignina em processos de síntese de resinas lignina-aldeído e/ou ligninafenol-aldeído está diretamente relacionada com a presença de hidroxilas fenólicas presentes na estrutura da mesma, pois são responsáveis pela ativação do anel aromático na posição orto (Figura 68- b). Quanto maior o teor de hidroxilas fenólicas e menor o teor de metoxilas $\left(-\mathrm{OCH}_{3}\right)$, mais reativa a lignina pode ser neste tipo de aplicação (EL MANSOURI; SALVADÓ, 2006). As hidroxilas fenólicas são originadas a partir da clivagem das ligações $\beta$-aril-éter ( $\beta$ O-4), as quais são mais extensamente clivadas durante a despolimerização da lignina in natura na polpação Kraft (KRINGSTAD; MORCK, 1983). Também podem ser formadas a partir da desmetilação, o qual ocorre clivagem das ligações $-\mathrm{OCH}_{3}$ e substituição por átomos de hidrogênio.

Figura 68 - Espectro bidimensional heteronuclear de gHSQC ${ }^{1} \mathrm{H}^{13} \mathrm{C}$ da região aromática (a), alifática (b) e constuintes principais e possíveis subunidades identificados na lignina Kraft (c).

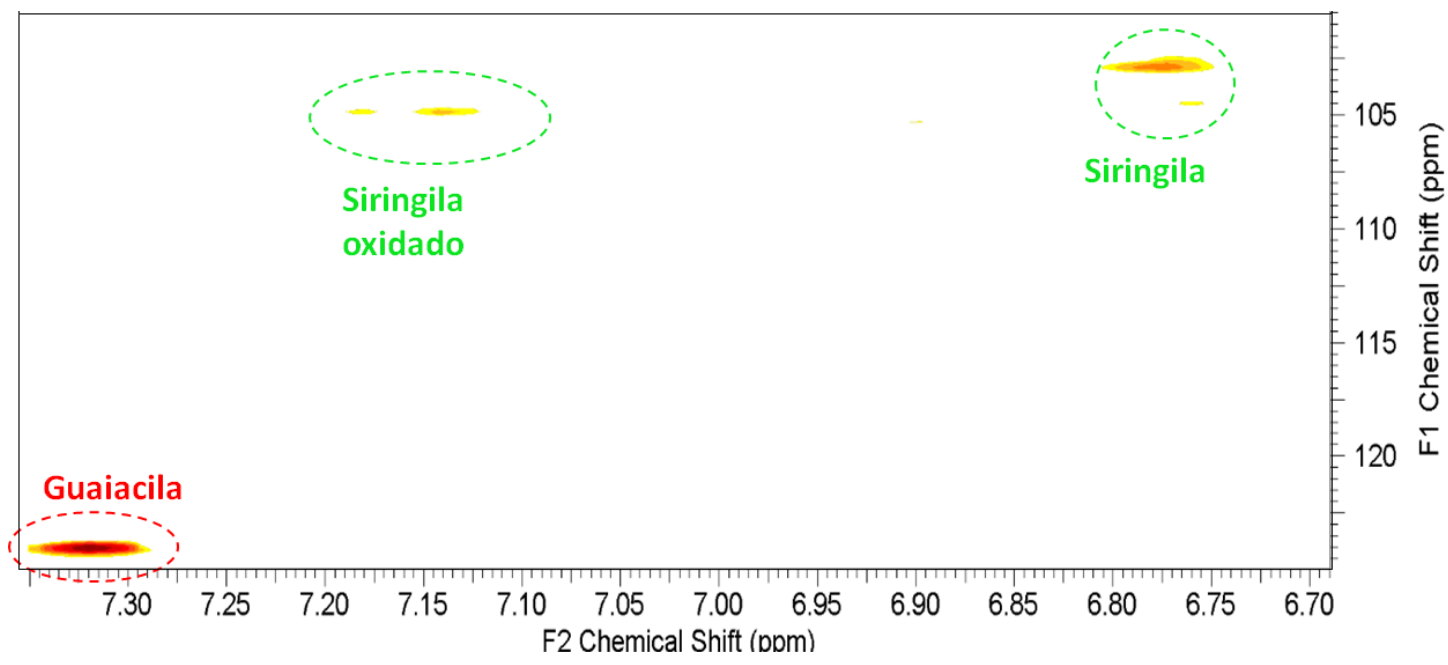


(a)

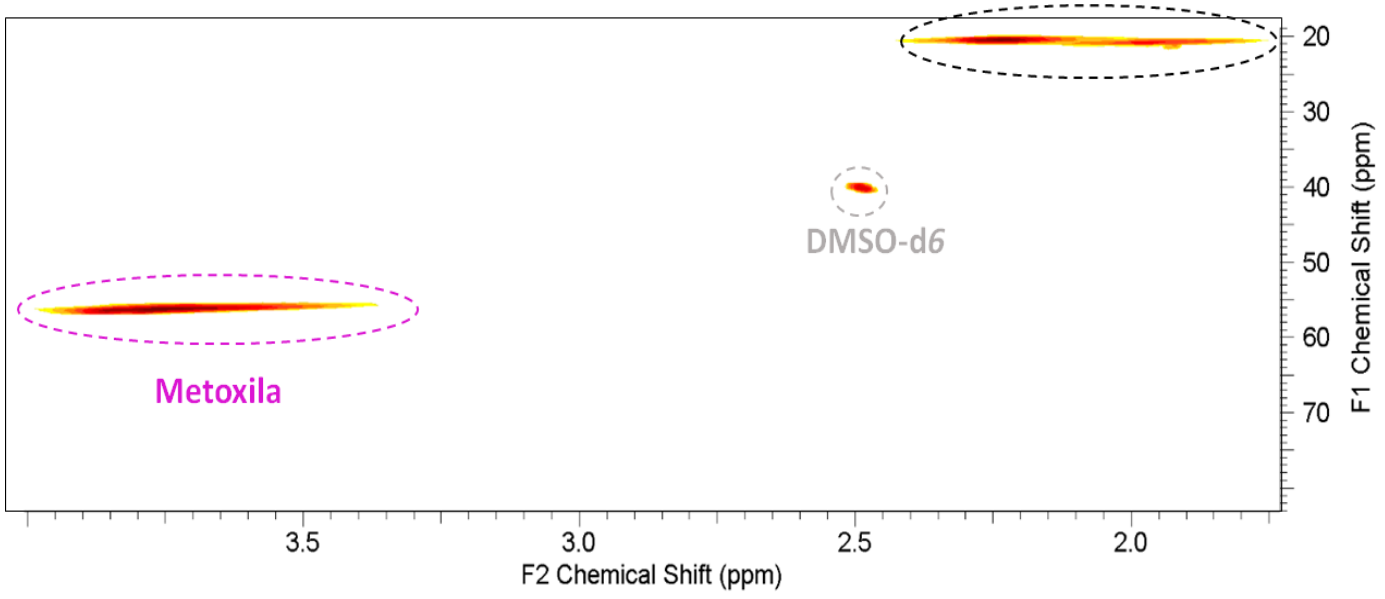

(b)<smiles>CCc1ccc(O)c(I)c1</smiles>

p-hidroxifenila Guaiacila Siringila<smiles>COc1cc(C(=O)O)cc(OCCOc2c(OC)cc(C(=O)C(C)C)cc2OC)c1OC</smiles>

Siringila oxidado

(c)

A Tabela 26 apresenta os cross-peaks $\left(\delta_{\mathrm{C}} / \delta_{\mathrm{H}}\right)$ obtidos, e mostra em 56/3,69 ppm a presença de metoxilas $\left(-\mathrm{OCH}_{3}\right)$. A presença deste grupo está relacionada às estruturas guaiacila e siringila. Em 103 / 6,8 ppm observou-se sinal referente às unidades siringila. Estas são as mais impedidas estericamente por possuírem as posições C3 e C5 ligada a grupo metoxila (Figura 68- b) (EL MANSOURI et al., 2011; RAMIRES et al., 2011).

Em 123,97/7,34 ppm observou-se cross-peak que pode ser atribuído à estrutura guaiacila. Com base nos sinais identificados foi possível observar que a lignina Kraft utilizada no presente estudo possui predominância de estruturas siringila e guiacila, o que levou a redução de sua reatividade. Como consequência, somente foi possível a obtenção de uma resina com $70 \%$ de substituição de fenol por lignina kraft, e não substituição total. Fernandes-Costas et al. (2014) 
também observou predominância de estruturas siringila e guaiacila ao analisar ligninas Kraft obtidas a partir de eucalytus globulus.

Tabela 26 - Atribuição dos sinais dos espectros de $g \mathrm{HSQC}\left({ }^{13} \mathrm{C}-{ }^{1} \mathrm{H}\right)$ das unidades constituintes da lignina kraft.

\begin{tabular}{|c|c|c|c|}
\hline $\begin{array}{l}\text { Deslocamento } \\
\text { químico } \\
(\mathbf{p p m})\end{array}$ & Literatura* & $\begin{array}{l}\text { Possíveis } \\
\text { atribuições }\end{array}$ & Referência \\
\hline $55,98 / 3,69$ & $\begin{array}{l}56-55,5 / \\
3,81-3,74\end{array}$ & Metoxila & $\begin{array}{l}\text { Liu et al. (2019); Shao et al. (2018); Martín-Sanpedro } \\
\text { et al. (2019) }\end{array}$ \\
\hline $102,82 / 6,8$ & $103,8 / 6,7$ & Siringila & Rencoret et al., 2008 \\
\hline $104,84 / 7,14$ & $\begin{array}{c}106,7 / 7,36- \\
7,21\end{array}$ & $\begin{array}{l}\text { Siringila } \\
\text { oxidado }\end{array}$ & Ibarra et al., 2007; Rencoret et al., 2008 \\
\hline $123,97 / 7,34$ & $\begin{array}{l}122,3-121,0 \\
/ 7,3-6,9\end{array}$ & Guaiacila & Rutkowska et al., 2009; Fernández-Costas et al., 2014 \\
\hline
\end{tabular}

Ramires et al. (2010) obtiveram êxito ao substituir 100\% do fenol por lignina organossolve, obtida do bagaço de cana-de-açúcar, em síntese de resina lignofenólica. No entanto, a lignina utilizada pelos autores apresentou picos (espectro de $\mathrm{RMN}^{31} \mathrm{P}$ ) característicos de estruturas p-hidroxifenila, guaiacila e siringila, confirmando a maior proporção de estruturas $p$-hidroxifenila, do tipo HGS, típica de plantas anuais, comparativamente a outras plantas. Esta lignina possui maior reatividade quando comparada à lignina kraft (obtida de eucaliptus) utilizada no presente estudo, a qual foi usada devido a disponibilidade, pelo menos até o momento, significativamente maior que a organossolve obtida de bagaço de cana de açúcar.

\subsection{Resina RLKFF}

A Figura 69 apresenta o espectro de $\mathrm{RMN}-{ }^{13} \mathrm{C}$ da resina lignina-fenol-formaldeído. Ao se comparar este com o da resina fenol-formaldeído (Item 1.3.2.2- Capítulo 1), foi possível observar que alguns sinais foram semelhantes e, portanto, apenas os sinais adicionais serão apresentados na Tabela 27. O sinal em 31 ppm está relacionado ao carbono de pontes metilênicas (- $\left.\mathrm{CH}_{2}-\right)$ entre as unidades fenólicas (YANG et al., 2015; PINHEIRO et al., 2017). Em 56,4 ppm observou-se sinal referente ao carbono de grupos metoxila provenientes de estruturas guaiacila e siringila, as quais foram as estruturas predominantes na lignina kraft utilizada no presente estudo, conforme apresentado no espectro de $g$ HSQC da mesma (Figura 68). Em 60,0 e 63,3 ppm observou-se sinais referentes ao carbono de grupos hidroximetila 
ligados às posições orto e para do anel aromático, respectivamente (YANG et al., 2015).

Figura 69 - Espectro de $\mathrm{RMN}-{ }^{13} \mathrm{C}$ da resina lignina-fenol-formaldeído.

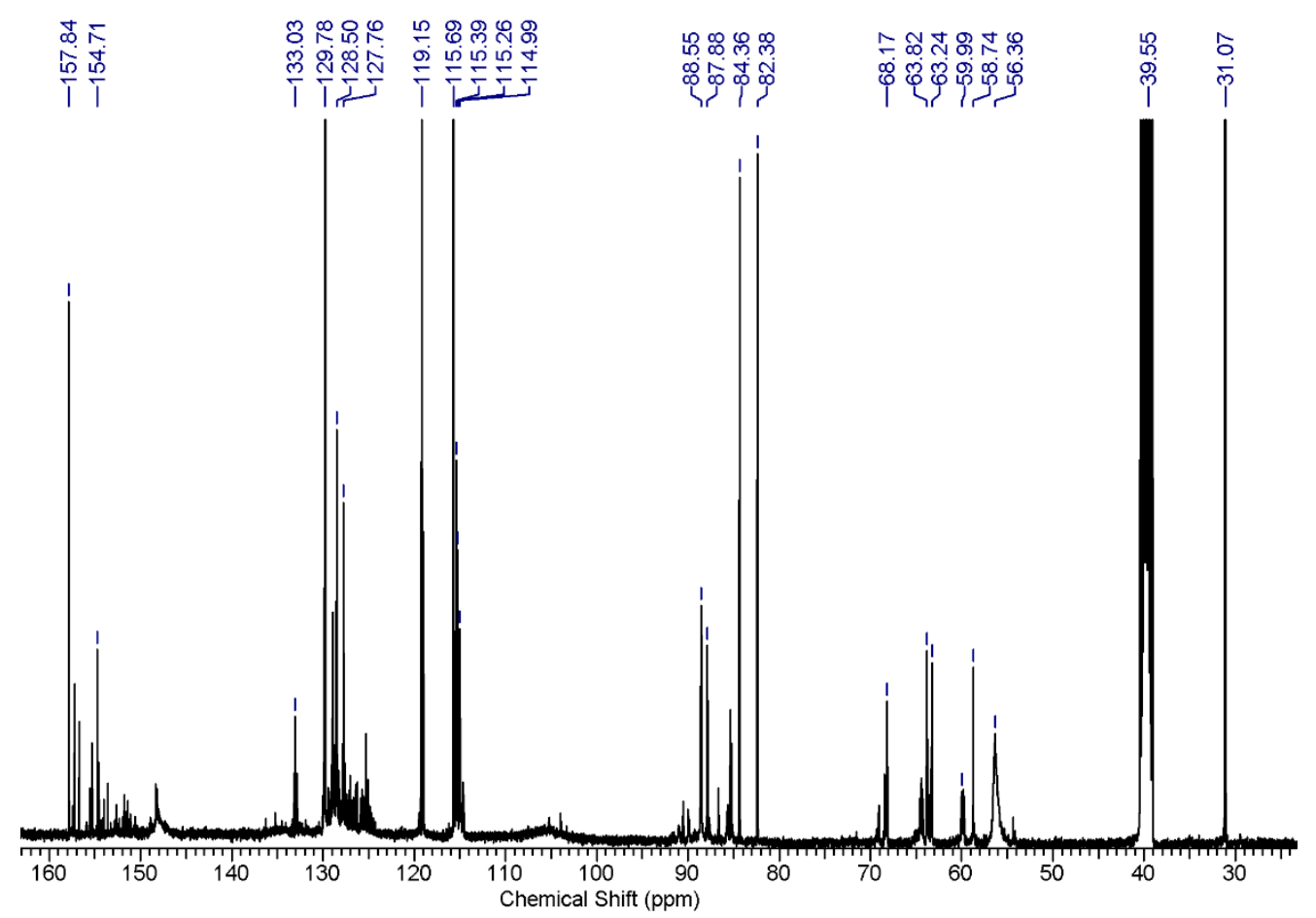

A primeira etapa da síntese da resina lignina-fenol-formaldeído, após a solubilização da lignina kraft em solução de $\mathrm{KOH}(\mathrm{pH}$ 9), é a hidroximetilação (inserção de grupos hidroximetila). Como a lignina de maneira geral possui a posição para (em relação à hidroxila do anel aromático) ocupada por cadeia alifática, a hidroximetilação ocorre principalmente na posição orto (RAMIRES, 2010). No entanto, esta resina também possui grupo fenólicos em sua estrutura e este possui as posições orto e para disponíveis para hidroximetilação e ligação com a lignina, devido à deslocalização de elétrons no anel aromático (Figura 4).

De acordo com Yang et al. (2015), o pico em aproximadamente 35 ppm está associado às pontes orto-para metilênica, indicando que a posição para do anel aromático do fenol foi mais reativa para hidroximetilação e posterior condensação com lignina hidroximetilada. O pico em 82,3 ppm pode estar relacionado à presença de formaldeído residual (RAMIRES, 2010), o qual não teria sido eliminado durante a rotaevaporação da resina por estar aprisionado no meio viscoso. Se presente na resina, o formaldeído é posteriormente incorporado no termorrígido fenólico que se forma durante a moldagem. 
Tabela 27 - Picos presentes no espectro de $\mathrm{RMN}-{ }^{13} \mathrm{C}$ da RLKFF.

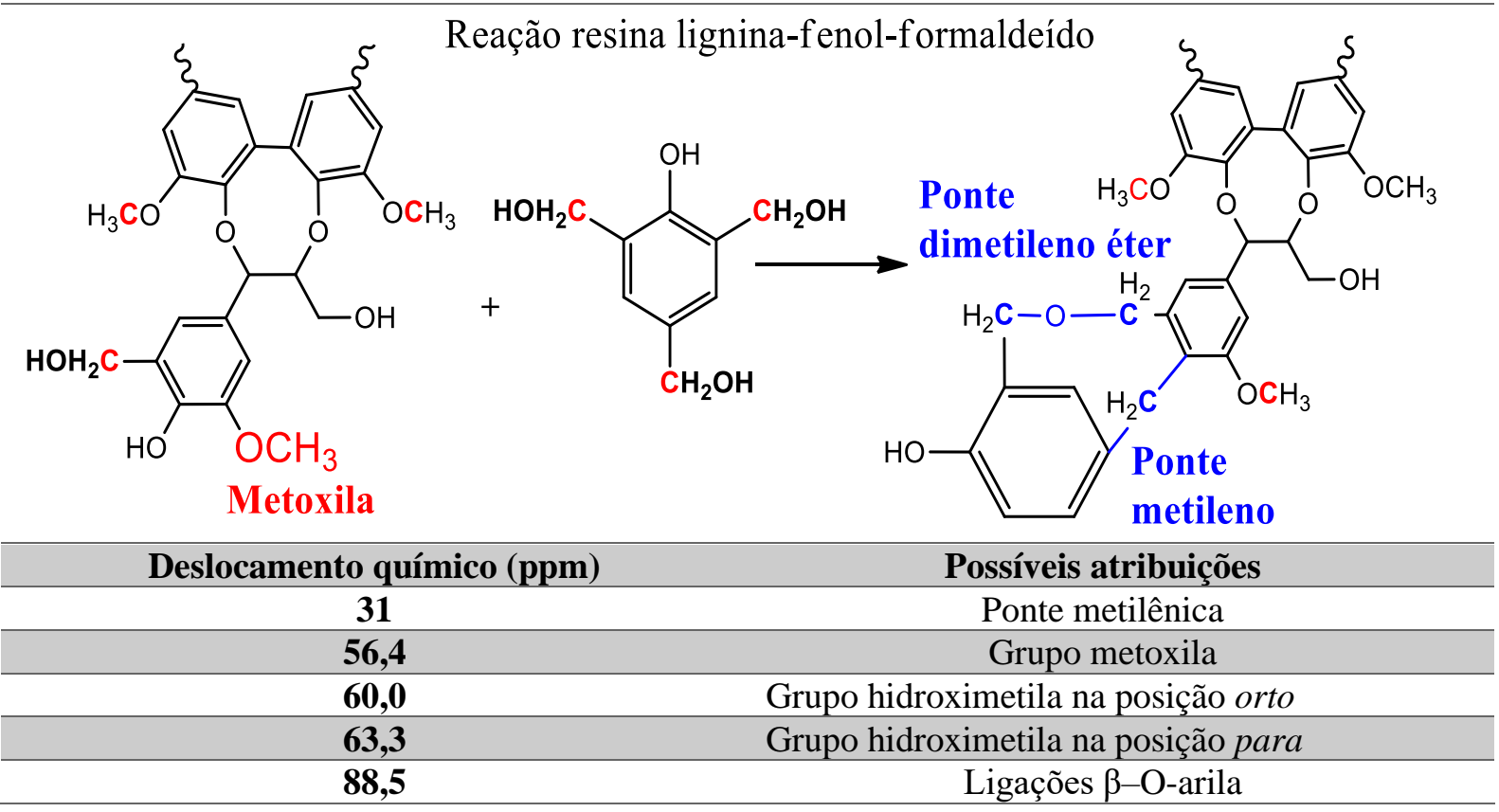

Em 88,5 ppm observou-se sinais de carbono $\beta$ presentes nas unidades fenilpropanóides da lignina. Os sinais observados entre 152 e 157 ppm podem estar associados à carbono de anel aromático ligado à hidroxila fenólica (YANG et al., 2015). Devido a lignina kraft utilizada no presente estudo possuir apenas a estrutura guaiacila com sítio reacional disponível para hidroximetilação, a formação das pontes metilênicas entre as posições orto da lignina e para do fenol podem ter sido mais favoráveis.

\subsubsection{Análise termogravimétrica da Lignina kraft e resina RLKFF}

A Figura 70 apresenta as curvas termogravimétricas e as respectivas curvas derivadas da lignina kraft purificada e da resina RLKFF. A lignina kraft purificada inicialmente sofreu uma perda de massa de aproximadamente 5\% referente à perda de umidade residual, e apresentou $\mathrm{T}_{\text {onset }} \mathrm{em}$ aproximadamente $315^{\circ} \mathrm{C}$.

O segundo evento observado na curva dTG em aproximadamente $375^{\circ} \mathrm{C}\left(\mathrm{T}_{\mathrm{dMÁx}}\right)$, Figura 70- $\mathbf{a}$, pode ser associado ao rompimento de ligações $\beta$ - $\beta$ e C-C entre as unidades monoméricas da lignina (BREBU; VASILE, 2010). Autores como Abdelaziz e Hulteberg (2017) e Domingues-Robles et al. (2017) reportaram picos de $\mathrm{T}_{\mathrm{dMÁx}}$ de aproximadamente $328{ }^{\circ} \mathrm{C}$ para ligninas kraft de palha de trigo e lignoboost. No entanto, mesmo sendo obtidas pelo mesmo tipo de processo, as condições e a biomassa, a partir da qual a lignina foi obtida, interferem diretamente na sua estrutura e na estabilidade térmica. Em $580{ }^{\circ} \mathrm{C}$ notou-se um terceiro evento na curva dTG da lignina Kraft (pico de baixa intensidade), Figura 70- a, que está relacionado 
à decomposição de anéis aromáticos (TEJADO et al., 2007; ALRIOLS et al. 2009; METHACANON et al., 2010).

Figura 70 - Curvas TG e dTG (primeira derivada) da lignina kraft (a) e da resina RLKFF (b) em atmosfera de $\mathrm{N}_{2}$ a $50 \mathrm{~mL} \mathrm{~min}^{-1}$ e taxa de aquecimento de $10{ }^{\circ} \mathrm{C} \mathrm{min}^{-1}$.

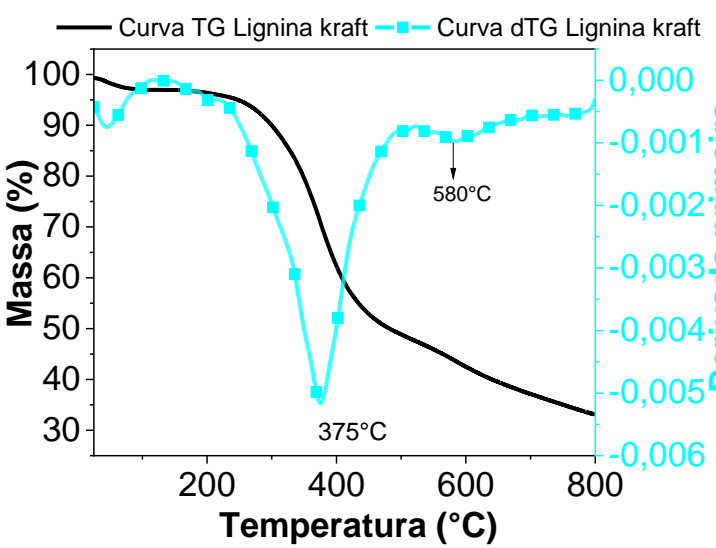

(a)

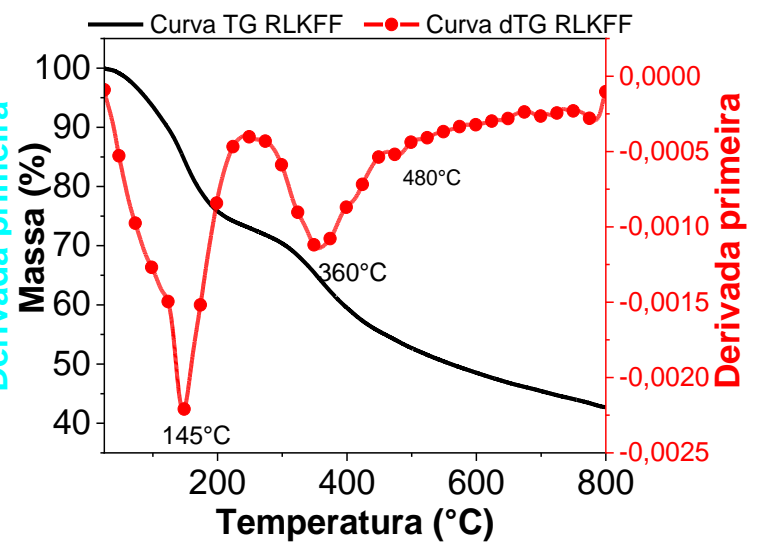

(b)

Com relação às curvas termogravimétricas da resina RLKFF, Figura 70-b, o pico intenso em aproximadamente $145{ }^{\circ} \mathrm{C}$ ( $\left.\mathrm{T}_{\mathrm{dMÁx}}\right)$ pode ser atribuído às etapas de condensação do prépolímero ao ser submetido à aquecimento durante a varredura e que foram acompanhadas por liberação de água (DE OLIVEIRA, 2010). Em aproximadamente $360{ }^{\circ} \mathrm{C}\left(\mathrm{T}_{\mathrm{dMÁx}}\right)$ observou-se um segundo evento na curva dTG da resina RLKFF, Figura 70-b, que pode estar relacionado à quebra de pontes metileno formadas durante a polimerização da resina, decomposição de anéis aromáticos do fenol e da lignina hidroximetilada, (KHAN; ASRAF, 2007; LEE; CHANG; TSENG, 2012), e em temperaturas superiores a $400{ }^{\circ} \mathrm{C}$ (terceiro evento) (Figura 70- b) ocorre o início da decomposição de anéis aromáticos.

O teor de massa residual observado após a decomposição térmica até $800{ }^{\circ} \mathrm{C}$ da lignina kraft purificada e da resina RLKFF, 33 e 43\%, respectivamente, podem ser associadas à formação de estruturas aromáticas condensadas (TEJADO et al., 2007).

\subsubsection{Análise termogravimétrica}

A Figura 71 apresenta as curvas termogravimétricas e as respectivas curvas derivadas do termorrígido TRLKFF e dos compósitos de matriz TRLKFF reforçados com MFS, MFR e híbrido MFS/FMD moída. A Figura 71 mostra que as amostras apresentaram uma perda de massa 
de $10-15 \%$ referente à perda de umidade. O termorrígido TRLKFF apresentou uma $\mathrm{T}_{\text {onset }}$ de $270{ }^{\circ} \mathrm{C}$. O compósito $\mathrm{C}_{\mathrm{RLKFF}} 19 \% \mathrm{MFR}$ apresentou uma $\mathrm{T}_{\text {onset }}$ de aproximadamente $270{ }^{\circ} \mathrm{C}$.

Figura 71 - Curvas TG e dTG (primeira derivada) do termorrígido TRLKFF (a), compósito $\mathrm{C}_{\mathrm{RLKF}} 19 \% \mathrm{MFR}$ (b) e compósito híbrido $\mathrm{C}_{\mathrm{RLKFF}} \mathrm{MFS} 9 \% \mathrm{FMD}_{\text {mó́da }}$ (c) em atmosfera de $\mathrm{N}_{2}$ a $50 \mathrm{~mL}$ $\min ^{-1}$ e uma taxa de aquecimento de $10{ }^{\circ} \mathrm{C} \mathrm{min}^{-1}$.

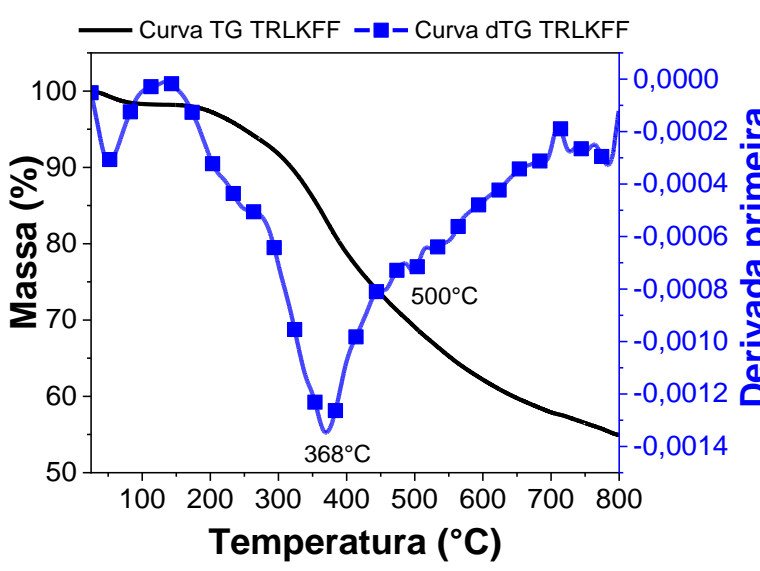

(a)

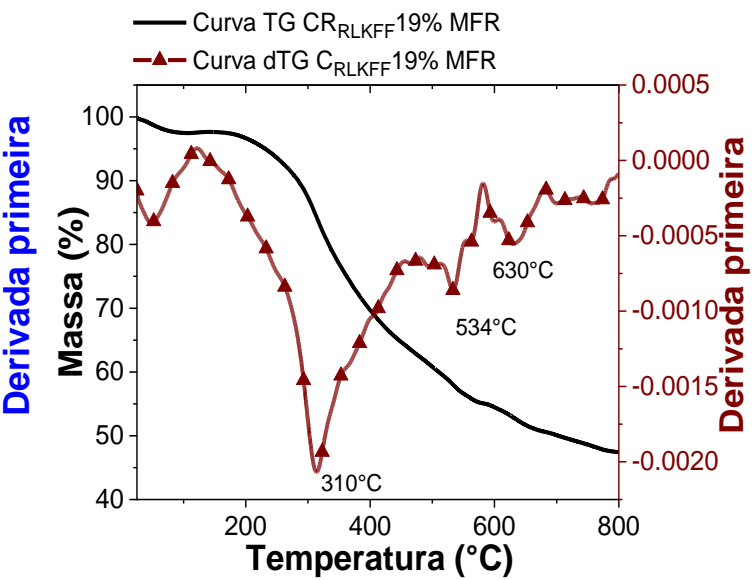

(b)

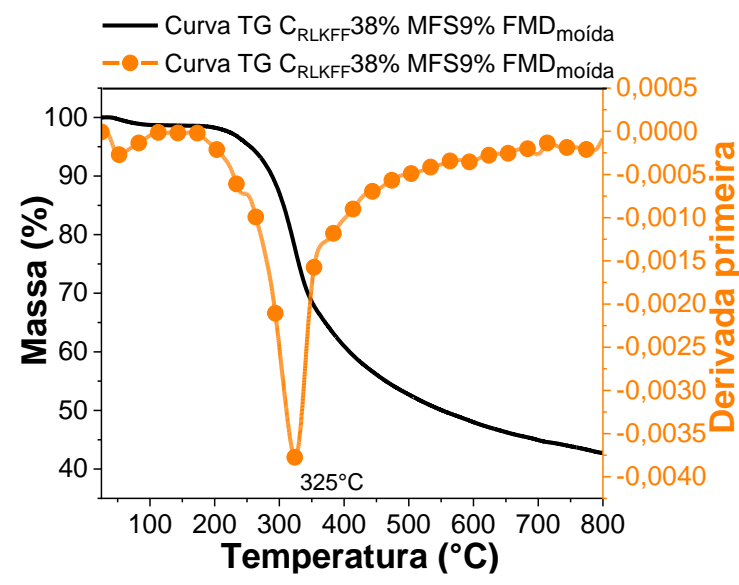

(c)

O segundo evento térmico observado na curva dTG do TRLKFF (Figura 71- a) apresentou uma $\mathrm{T}_{\mathrm{dMÁx}}$ de $368^{\circ} \mathrm{C}$, aproximadamente. Este pico possivelmente está associado ao rompimento de ligações $\beta-\beta$ e $\mathrm{C}-\mathrm{C}$ entre as unidades monoméricas da lignina presentes na resina (BREBU; VASILE, 2010). O pico (baixa intensidade) associado ao terceiro evento $\left(\mathrm{T}_{\mathrm{dMÁx}}=500^{\circ} \mathrm{C}\right)$ deste termorrígido é referente à decomposição de anéis aromáticos presentes tanto na lignina como no fenol, reagentes de partida, já que esta matriz é constituída por $70 \%$ de lignina kraft e $30 \%$ de fenol.

Neste caso a matriz termorrígida inicia a degradação antes da fibra $\left(\mathrm{T}_{\text {onset }}\right.$ fibra rayon $=310$ ${ }^{\circ} \mathrm{C}$ ), conforme apresentado na Figura 40 do Capítulo 2. O compósito $\mathrm{C}_{\mathrm{RLKFF}} \mathrm{MFS} 9 \% \mathrm{FMD}_{\text {moída }}$ 
apresentou uma $\mathrm{T}_{\text {onset }}$ de aproximadamente $280^{\circ} \mathrm{C}$, que pode estar relacionado à presença de $\mathrm{FMD}_{\text {moída, }}$ a qual apresentou esta $\mathrm{T}_{\text {onset }}$ quando a análise foi realizada em nitrogênio (dado não mostrado).

Em relação ao segundo evento (pico curva dTG), Figura 71- b e - c, que foi observado em todos os compósitos entre 310 e $325{ }^{\circ} \mathrm{C}$ comparado com o TRLKFF, notou-se que houve um deslocamento desta temperatura e que pode estar relacionado à interação fibra-matriz. Estes picos possivelmente se devem à decomposição de celulose presente nas fibras.

No compósito $\mathrm{C}_{\mathrm{RLKFF}} 19 \% \mathrm{MFR}$ foi possível observar a presença de dois picos na curva dTG com $\mathrm{T}_{\mathrm{dMÁx}}$ de aproximadamente 534 e $630{ }^{\circ} \mathrm{C}$, os quais estão relacionados à decomposição de anéis aromáticos presentes na matriz.

\subsubsection{Resistência ao impacto dos compósitos de matriz RLKFF}

Os valores de resistência ao impacto dos compósitos de matriz RLKFF reforçado com MFR, $\mathrm{C}_{\text {RLKFF }} 19 \%$ MFR, e do compósito híbrido MFS/FMD moída, $\mathrm{C}_{\mathrm{RLKFF}} 38 \%$ MFS9\%FMD moída, estão apresentados na Figura 72.

Figura 72 - Resultados de resistência ao impacto do termorrígido TRLKFF, e dos compósitos $\mathrm{C}_{\mathrm{RLKFF}} 19 \% \mathrm{MFR}$ e $\mathrm{C}_{\mathrm{RLKFF}} 38 \% \mathrm{MFS} 9 \% \mathrm{FMD}_{\text {moída }}$ (a), e comparativo entre os resultados de resistência ao impacto normalizados os compósitos de matriz RLKFF (b).

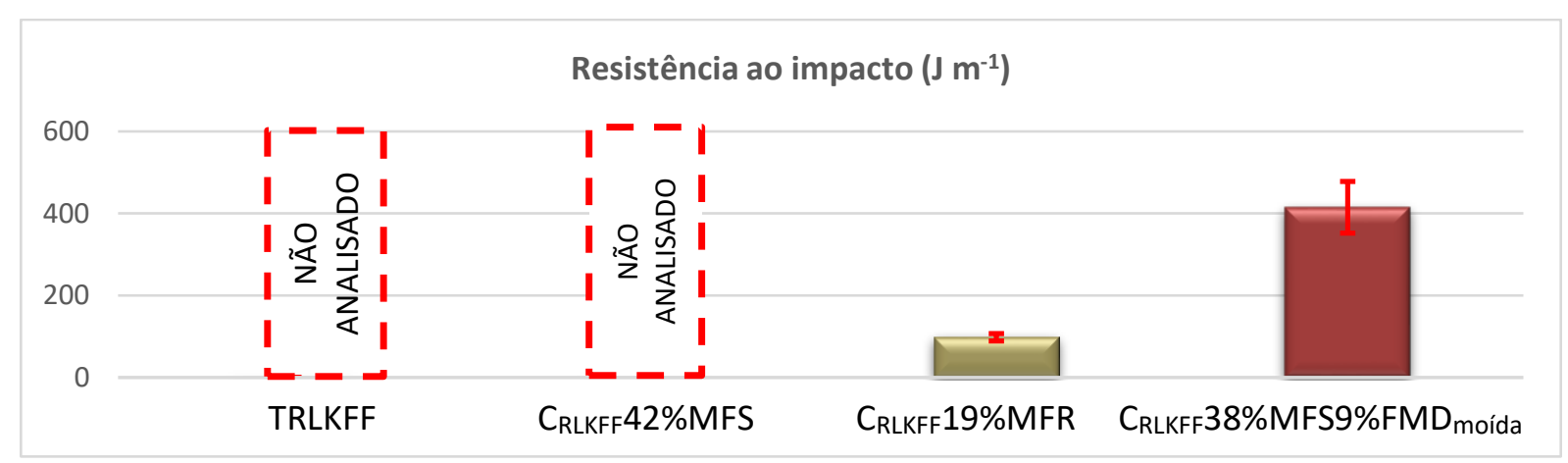

(a) 


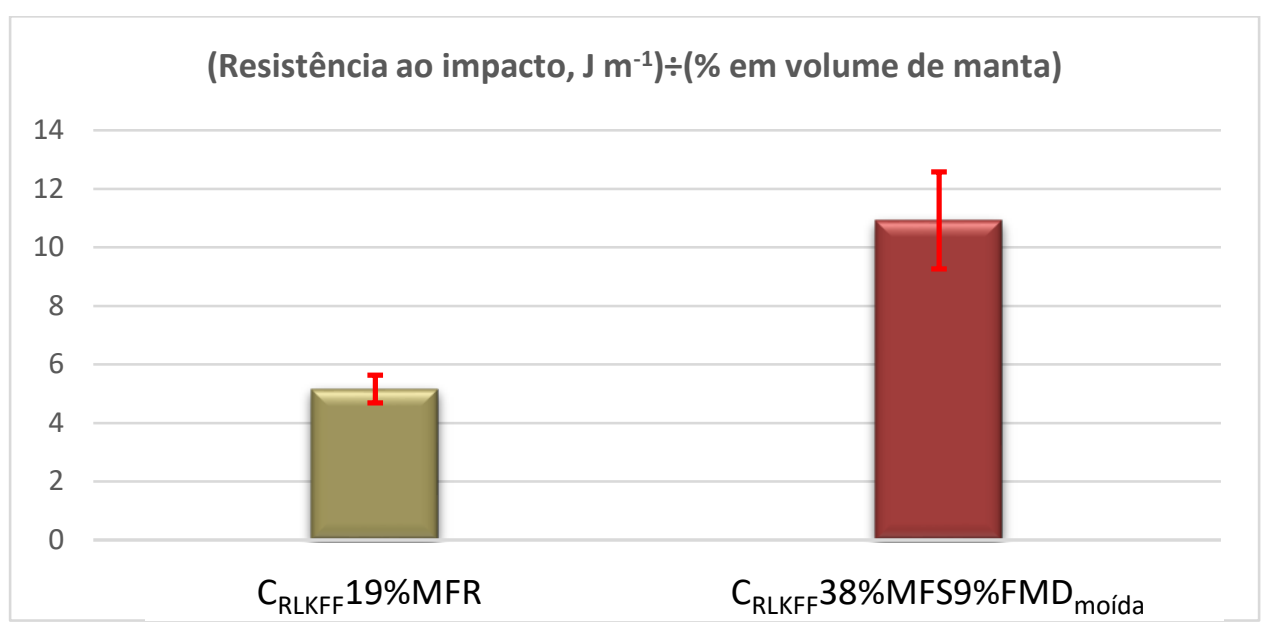

(b)

Vale salientar que no compósito $\mathrm{C}_{\mathrm{RLKFF}} 19 \% \mathrm{MFR}$ contendo manta de rayon, a porcentagem de fibra apresentada no código da amostra se refere à porcentagem em volume e no compósito híbrido a porcentagem de MFS se refere à porcentagem em volume e à de $\mathrm{FMD}_{\text {moída }}$ se refere à porcentagem em massa. O compósito de matriz RLKFF reforçado com MFS também foi preparado no presente estudo, porém devido à fragilidade da matriz se formaram fissuras e trincas nas superfícies do corpo-de-prova durante a obtenção do mesmo, comprometendo a avaliação da propriedade deste material. Por isso, foi avaliado a adição de

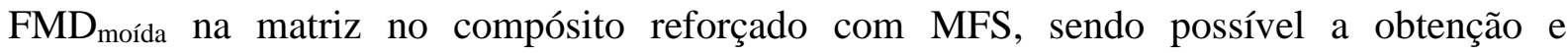
caracterização do compósito híbrido $\mathrm{C}_{\mathrm{RLKFF}} 38 \% \mathrm{MFS} 9 \% \mathrm{FMD}_{\text {moída. }}$

A Figura 72 mostra que houve um aumento considerável nesta propriedade com a inserção de ambos reforços quando comparados ao termorrígido TRLKFF, já que não foi possível a realização deste ensaio para o mesmo devido à fragilidade do material. Comparando os termorrígidos obtidos no presente estudo, o TRFG e TRFF apresentaram característica menos frágeis quando comparado com TRLKFF.

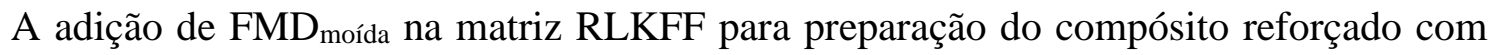
MFS levou à um aumento da resistência do material, pois o compósito contendo a apenas MFS se mostrou frágil na obtenção do corpo de prova, como mencionado. Neste caso a FMD moída atuou como reforço adicional no compósito reforçado com MFS, desempenhando função de portador de carga e estresse, e colaborando com a distribuição do impacto da matriz para as fibras. A mesma tendência foi observada para o compósito híbrido de matriz RFG composto

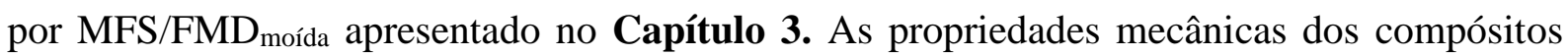
híbridos podem ser melhores ou intermediárias quando comparadas com o mesmo compósito apenas com uma das fibras individual (SAFRI et al., 2018).

Comparando o resultado de resistência ao impacto obtido no compósito $\mathrm{C}_{\mathrm{RLKFF}} 19 \% \mathrm{MFR}$, 
$98 \mathrm{~J} \mathrm{~m}^{-1}$, com os obtidos nos compósitos $\mathrm{C}_{\mathrm{RFF}} 19 \% \mathrm{MFR}, 323 \mathrm{~J} \mathrm{~m}^{-1}$, e $\mathrm{C}_{\mathrm{RFG}} 19 \% \mathrm{MFR}, 455 \mathrm{~J} \mathrm{~m}^{-}$ ${ }^{1}$, observou-se que apesar da matriz RLKFF ser rica em lignina (grupos hidroxilas polares) que poderiam aumentar a interação com os grupos hidroxilas presentes na manta de rayon, a fragilidade da matriz RLKFF, neste caso, pode ter prejudicado a transferência de carga da matriz para as fibras e assim, reduziu a resistência ao impacto do material.

O compósito CRLKFF 19\%MFR apresentou delaminação após o ensaio de impacto Izod, ou seja, o corpo-de-prova se separou na interface em duas lâminas. Mesmo assim, observou uma adesão entre a fibra e a matriz, pois após o ensaio parte da matriz permaneceu aderida na superfície da manta rayon.

\subsubsection{Microscopia eletrônica de varredura}

A Figura 73 apresenta as micrografias obtidas após o ensaio de impacto Izod dos compósitos de matriz RFF reforçados com MFR, $\mathrm{C}_{\mathrm{RLKFF}} 19 \% \mathrm{MFR}$, e híbrido MF/FMD moída, $\mathrm{C}_{\mathrm{RLKFF}} 38 \% \mathrm{MFS}$ \%FMD moída. A análise de MEV de matriz RLKFF foi realizada tanto na superfície de fratura quanto na região da superfície de interface fibra-matriz, como indicado nas micrografias (Figura 73- a e -b), devido a problemas de quebra da matriz durante a preparação dos copos-de-prova para análise. Observou-se que a matriz possui aspecto quebradiço com regiões de propagação de trincas (setas cinzas) em resposta à imposição ao impacto e apresentou grande fragilidade.

Figura 73 - Micrografias das superfícies fraturadas, pós-impacto, dos compósitos reforçados com MFR, $\mathrm{C}_{\text {RLKFF }} 19 \%$ MFR (a) e híbrido MFS/FMD ${ }_{\text {moída }}, \mathrm{C}_{\text {RLKFF }} 38 \%$ MFS9\%FMD moída $(b)$.

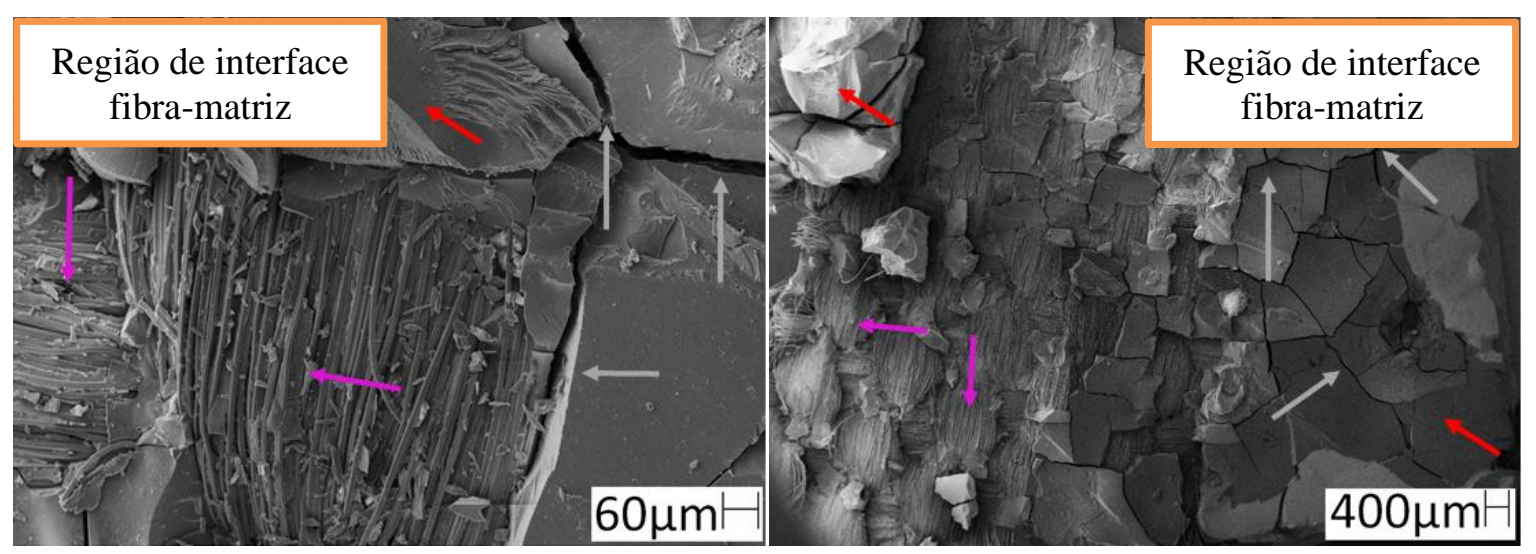

(a) 


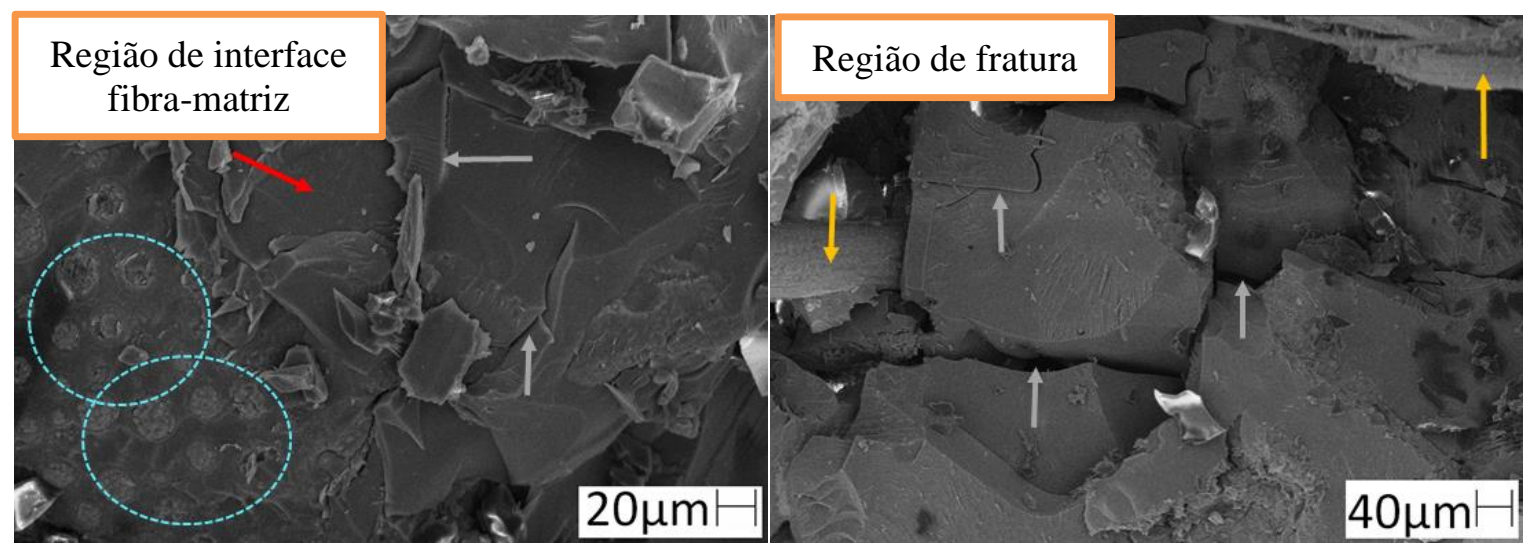

(b)

Devido à fragilidade da matriz RLKFF, a realização da análise de MEV da região de

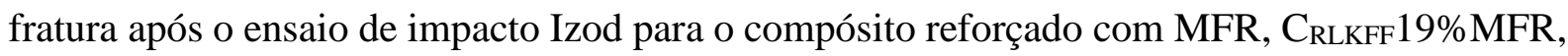
apresentou dificuldade, pois os corpos-de-prova sofreram delaminação e, portanto, a análise foi realizada da superfície da região de adesão manta-matriz em que ocorreu a delaminação. No compósito híbrido, foi possível a realização da análise da região de fratura.

Comparado com as matrizes estudadas nos capítulos anteriores, o termorrígido fenolformaldeído e fenol-glutaraldeído, conforme apresentado nos Capítulos 1 e 3, respectivamente, o TRLKFF apresentou aspecto mais frágil. No compósito $\mathrm{C}_{\text {RLKFF }} 19 \%$ MFR observou-se que houve descolamento da região da matriz entre as mantas que ocasionou na delaminação do compósito. O compósito $\mathrm{C}_{\mathrm{RFG}} 19 \% \mathrm{MFR}$ apresentou a mesma tendência, conforme apresentado no Capítulo 3, enquanto o compósito $\mathrm{C}_{\mathrm{RFF}} 19 \% \mathrm{MFR}$ apresentou ruptura parcial do corpo-deprova, conforme apresentado no Capítulo 2.

A maior fragilidade da matriz RLKFF, além da impossibilidade de analisar sua resistência ao impacto, também foi observada pela superfície do corpo-de-prova do compósito $\mathrm{C}_{\mathrm{RLKFF}} 19 \% \mathrm{MFR}$ após a realização do impacto izod (Figura 73- b). Nesta observou-se a presença de rachaduras em toda a superfície. No entanto, é foi possível observar regiões em a matriz (setas vermelhas) permaneceu aderida à superfície da manta e outras em que houve descolamento e a manta ficou exposta (setas roxas) (Figura 73- a e -b).

Contudo, possivelmente a fragilidade da matriz pode ter dificultado a transferência de carga da matriz para as fibras da manta, composta por feixes de fibras alinhados à $0^{\circ}$ e $90^{\circ}$ (setas roxas) reduzindo a resistência ao impacto do material, conforme observado anteriormente.

Mesmo com a inserção de $\mathrm{FMD}_{\text {moída }}$ na matriz, não possível observar propagação da trinca ao longo do corpo-de-prova e a MFS sofreu ruptura parcial e deformação, permanecendo 
uma ponte de feixe de fibras (fiber bridging). Neste caso, parte da carga aplicada foi transferida à manta que apenas se deformou elasticamente (RAMIRES, 2010; MATTHEWS; RAWLINGS, 1994).

\subsubsection{Resistência à flexão}

Os resultados de flexão e módulo de flexão dos compósitos de matriz RLKFF reforçados

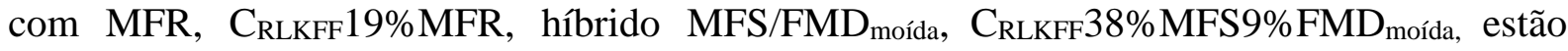
apresentados na Figura 74.

Os resultados de resistência à flexão dos compósitos $\mathrm{C}_{\mathrm{RFF}} 19 \% \mathrm{MFR}, 38,5 \mathrm{MPa}$, e $\mathrm{C}_{\mathrm{RFG}} 19 \% \mathrm{MFR}, 31 \mathrm{MPa}$, obtidos anteriormente em matriz fenol-formaldeído (Capítulo 2) e fenol-glutaraldeído (Capítulo 3), respectivamente, foram superiores ao obtido pelo compósito $\mathrm{C}_{\mathrm{RLKFF}} 19 \% \mathrm{MFR}$. Isto pode tanto estar relacionado com a maior fragilidade da matriz RLKFF comparada às demais quanto menor interface de adesão fibra matriz no compósito $\mathrm{C}_{\text {RLKFF }} 19 \%$ MFR. A mesma tendência foi observada no $\mathrm{C}_{\mathrm{RLKFF}} 38 \% \mathrm{MFS} 9 \% \mathrm{FMD}_{\text {moída }}, 3,22 \pm$ 0,2 MPa comparativamente ao mesmo compósito em matriz RFF, $20 \pm 2 \mathrm{MPa}$. As propriedades da superfície do compósito influenciam significativamente na resistência à flexão do material, devido à predominância de matriz polimérica (DE OLIVEIRA et al., 2017).

Figura 74 - Resultados de resistência à flexão e módulo de flexão normalizados dos compósitos $\mathrm{C}_{\mathrm{RLKFF}} 19 \% \mathrm{MFR}$ e $\mathrm{C}_{\mathrm{RLKFF}} \mathrm{MFS} 9 \%$ FMD moída.

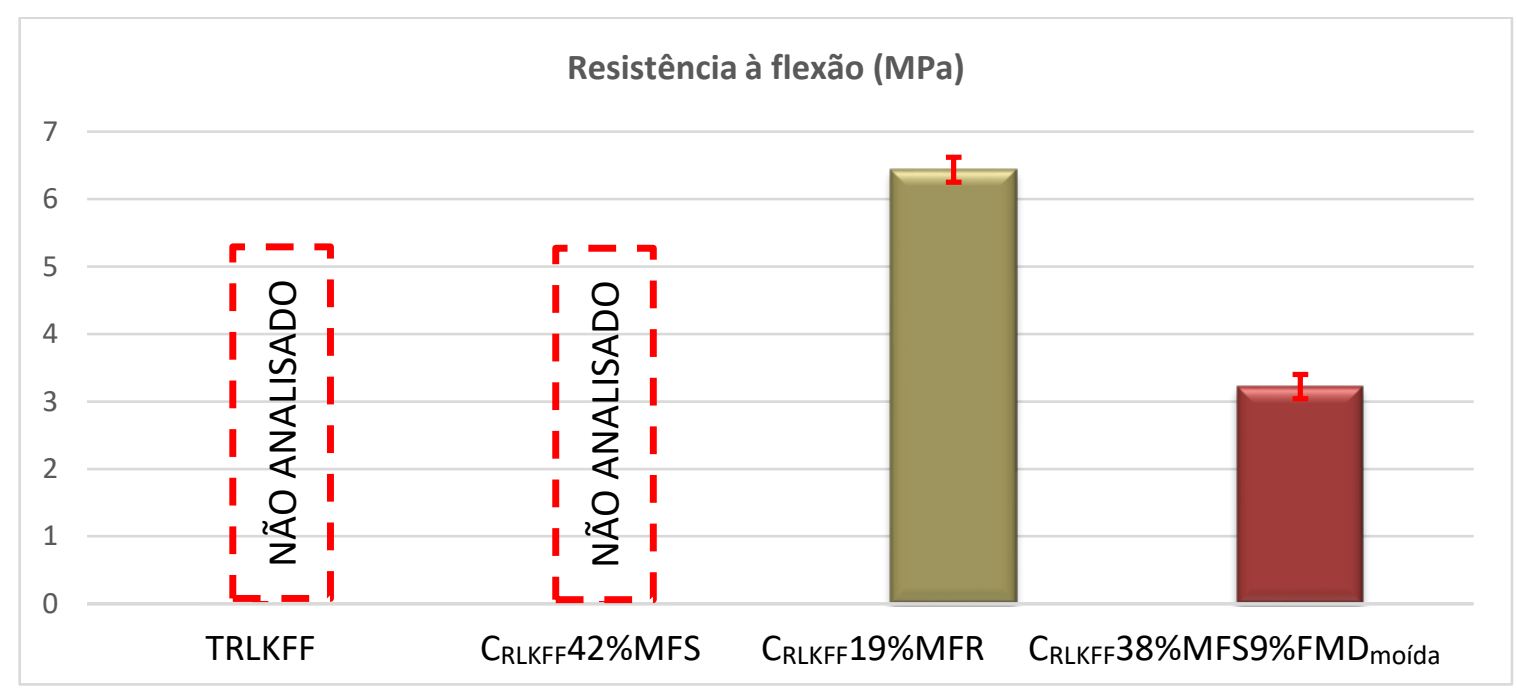

(a) 


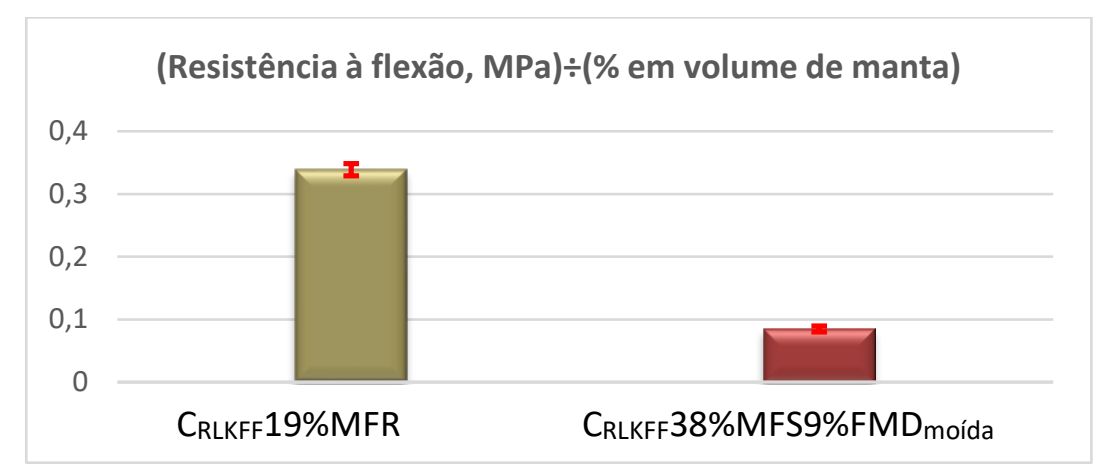

(b)

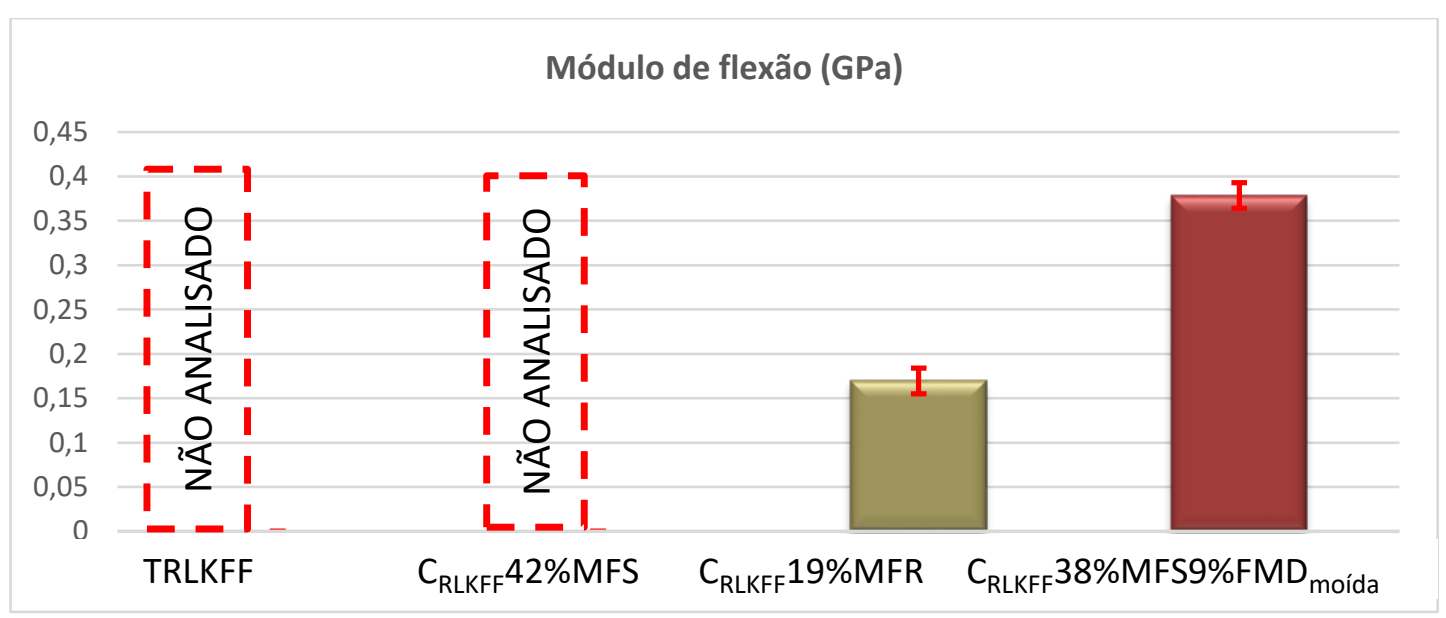

(c)

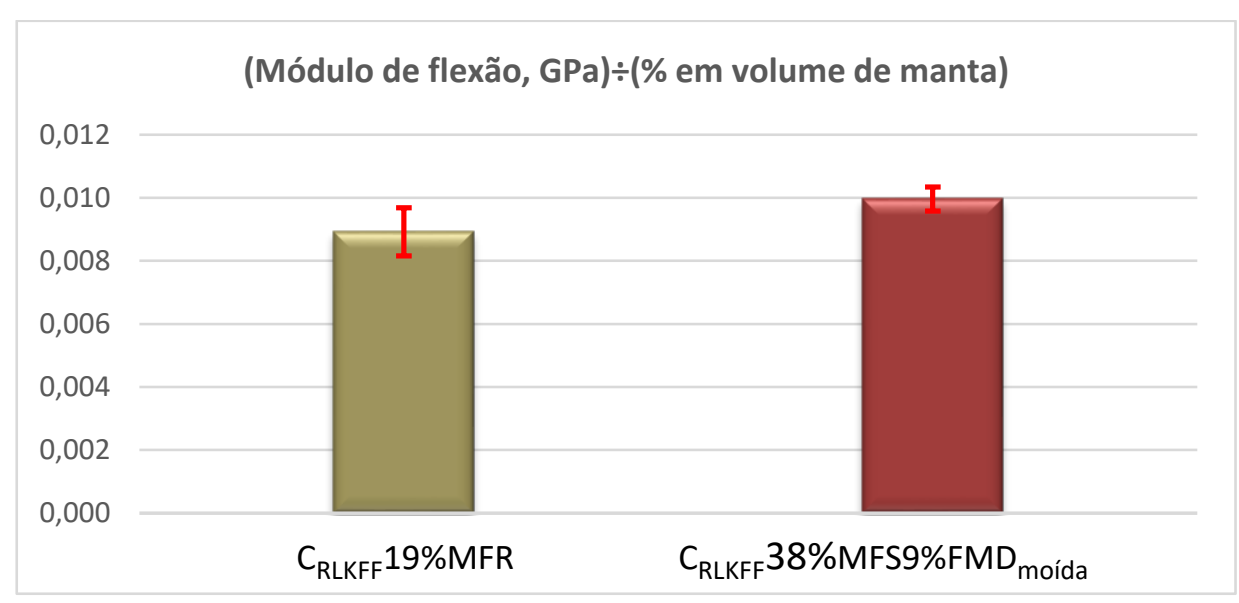

(d)

A Figura 74- b mostra que o $C_{R L K F F} 19 \%$ MFR apresentou maior resistência à flexão normalizado (por \% de unidade de volume de manta) comparativamente ao híbrido

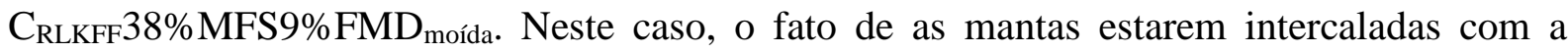
matriz levou a uma melhora na distribuição da tensão no corpo-de-prova, pois neste ensaio as fibras da manta sofrem tanto força de compressão quanto de tração. A mesma tendência foi observada no compósito $\mathrm{C}_{\mathrm{RFG}} 19 \% \mathrm{MFR}$ (obtido em matriz RFG) (Capítulo 3). 


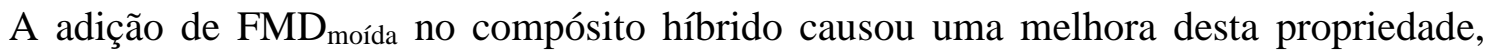
comparativamente ao mesmo compósito somente reforçado com MFS (dado não analisado). No entanto, a adição da mesma pode ter aumentado a quantidade de vazios, que atuaram como propagadores do estresse quando o material foi submetido às forças de compressão e tração, quando comparado ao $\mathrm{C}_{\text {RLKFF }} 19 \%$ MFR (LIU et al. 2006; BLEDZKI et al., 2015; FIORE et al., 2016).

Com relação ao módulo de flexão normalizado (por porcentagem de unidade de volume de manta) (Figura 74- d), o $\mathrm{C}_{\mathrm{RLKFF}} 38 \% \mathrm{MFS} 9 \% \mathrm{FMD}_{\text {moída }}$ apresentou maior módulo comparativamente ao ao $\mathrm{C}_{\mathrm{RLKFF}} 19 \% \mathrm{MFR}$ mesmo com a aproximação dos valores pelos desvios. A inserção de fibra moída na matriz do compósito híbrido levou à um aumento da rigidez do material à pequenas taxas de deformação.

\subsubsection{DMA}

A Figura 75 apresenta as curvas de módulo de armazenamento (E') e $\tan$ delta $(\tan \delta)$ versus temperatura dos compósitos $\mathrm{C}_{\mathrm{RLKFF}} 19 \% \mathrm{MFR}$ e $\mathrm{C}_{\mathrm{RLKFF}} 38 \% \mathrm{MFS} 9 \% \mathrm{FMD}_{\text {moída }}$. Devido à fragilidade da matriz termorrígida lignofenólica, não foi possível a obtenção de corpos-de-prova do termorrígido para realização desta análise.

Figura 75 - Curvas DMA- Módulo de armazenamento (E') e tan $\delta$ versus temperatura (b) dos compósitos matriz RLKFF reforçados com MFR, C $\mathrm{C}_{\mathrm{RLKFF}} 38 \% \mathrm{MFS} 9 \% \mathrm{FMD}_{\text {moída. }}$

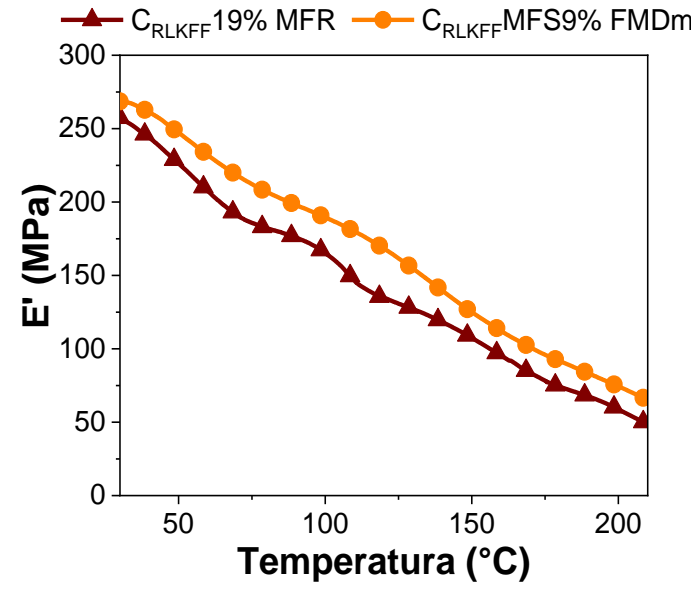

(a)

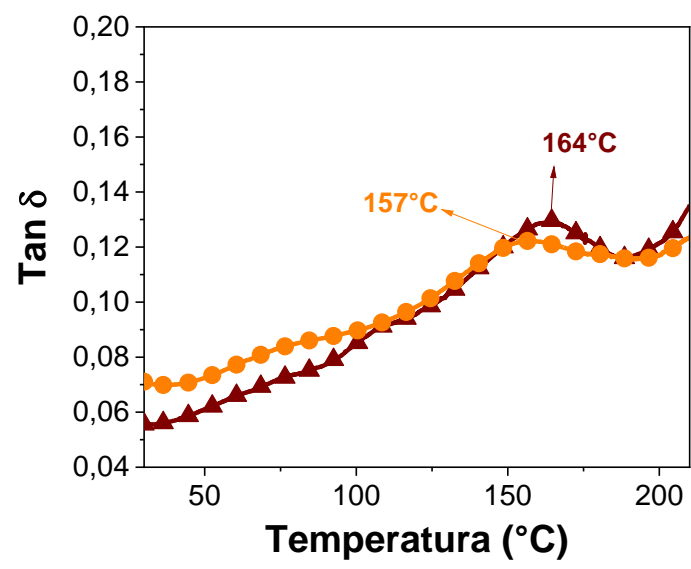

(b)

Apesar do compósito híbrido $\mathrm{C}_{\mathrm{RLKFF}} 38 \% \mathrm{MFS} 9 \% \mathrm{FMD}_{\text {moída }}$ ter apresentado valor de resitência ao impacto muito superior ao $\mathrm{C}_{\mathrm{RLKFF}} 19 \% \mathrm{MFR}$ (Figura 74- a), ambos apresentaram 
valores de E' próximos, sugerindo interação em nível molecular semelhantes reduzindo a mobilidade dos segmentos.

Comparados aos valores de E' obtidos nestes compósitos com os obtidos nos compositos de matriz RFF, a inserção da lignina, uma macromolécula de grande volume, pode ter levado a um menor entrecruzamento, devido ao impedimento estérico da estrutura da mesma, que dificulta a formção das ligações cruzadas entre os segmentos das cadeias (RAMIRES et al., 2010), levando a baixos valores de $\mathrm{E}^{\prime}$.

As curvas Tan $\delta$ versus temperatura (Figura 75- b) mostram que a $\mathrm{T}_{\mathrm{g}}$ foi de $164 \mathrm{e}$ $157{ }^{\circ} \mathrm{C}$, respectivamente, para o $\mathrm{C}_{\mathrm{RLKFF}} 19 \% \mathrm{MFR}$ e $\mathrm{C}_{\mathrm{RLKFF}} 38 \% \mathrm{MFS} 9 \% \mathrm{FMD}_{\text {moída}}$. O aumento desta temperatura está relacionado às interações entre os componentes dos compósitos que reduzem a mobilidade dos segmentos. $\mathrm{O}$ fato de a FMD ser rica em lignina (rica em hidroxilas) e a matriz ser constituída por lignina pode ter aumentado a interação entre ambas através de interações intermoleculares tipo ligação hidrogênio, levando à maior $\mathrm{T}_{\mathrm{g}}$.

Comparando os valores de $\mathrm{T}_{\mathrm{g}}$ dos compósitos obtidos neste capítulo com os compósitos de matriz RFG (Capítulo 3), observou-se que estes foram inferiores aos de matriz RLKFF. Isto pode estar relacionado à estrutura da lignina rica em anéis aromáticos e de elevada complexidade, a qual está presente na matriz polimérica, que restrige a movimentação dos segmentos. Já em comparação com os valores de $\mathrm{T}_{\mathrm{g}}$ dos compósitos de matriz RFF, $\mathrm{C}_{\mathrm{RFF}} 19 \% \mathrm{MFR}$ e $\mathrm{C}_{\mathrm{RFF}} 38 \% \mathrm{MFS} 16 \% \mathrm{FMD}_{\text {moída }}$, os valores de $\mathrm{T}_{\mathrm{g}}$ dos compósitos de matriz RLKFF apresentaram os mesmos valores.

\subsection{Conclusões parcíaís}

A lignina Kraft utilizada no presente estudo apresentou reatividade limitada devido à preponderância de estruturas guaiacila e siringila, sendo possível a obtenção de uma resina com $70 \%$ de lignina em substituição do fenol, resina lignina kraft-fenol-formaldeído.

A inserção de FMD moída na matriz RLKFF foi essencial para a obtenção de compósito híbrido com uma melhor resistência ao impacto, $415 \mathrm{~J} \mathrm{~m}^{-1}$. Possivelmente devido ao menor entrecruzamento ocasionado pela inserção de lignina na resina (como observado pelos baixos valores de E'), a matriz apresentou aspecto extremamente frágil, o que afetou negativamente as propriedades de flexão dos materiais obtidos. 


\section{Conclusões gerais}

A utilização da FMD (sem comprimento definido e distribuídas de maneira aleatória) como reforço em matriz RFF levou à obtenção de compósitos de matriz RFF aquém do esperado, sendo então avaliado o impacto da utilização de mantas vegetais ao invés de FMD sobre as propriedades dos materiais. Foram utilizadas mantas de sisal e rayon como agente de reforço em matriz RFF, RFG e RLKFF na preparação de compósitos. Ainda, visando valorizar o uso da FMD na área de compósitos, utilizou-se esta moída, a fim de avaliar se a mesma atuaria como carga ou reforço adicional.

Dentre os resultados de resistência ao impacto obtidos nos compósitos de matriz RFF reforçados com MFS (42\% em volume) obtidos por dois métodos de impregnação, observouse que a melhora na impregnação influenciou positivamente no aumento da resistência ao impacto do material. A FMD moída atuou de forma eficiente como reforço adicional em todos compósitos híbridos, pois a inserção da mesma levou à uma melhora na resistência ao impacto normalizado comparado aos demais. No entanto, a inserção de $\mathrm{FMD}_{\text {moída }}$ pode ter ocasionado uma maior quantidade de vazios no compósito, pois levou à uma redução no módulo de armazenamento e resistência à flexão, quando comparado ao compósito apenas com MFS em matriz RFF.

A utilização de duas mantas de rayon nas matrizes RFF e RFG, levou à compósitos com maior absorção de energia e, consequentemente, melhor resistência ao impacto. A substituição do formaldeído por glutaraldeído levou à maior adesão fibra/matriz no compósito reforçado com duas MFR. A susbstituição de $70 \%$ do fenol por lignina levou à obtenção de compósitos muito frágeis, sendo de grande importância a inserção da $\mathrm{FMD}_{\text {moída }}$ na matriz para obtenção de melhor resultado de resistência ao impacto no compósito híbrido reforçado com MFS/FMD moída.

Em linhas gerais, pode-se concluir que os objetivos traçados para o presente estudo foram atingidos. Foi possível a obtenção de compósitos utilizando mantas como reforço, tanto de sisal quanto de rayon, em matriz RFF e RFG como boas propriedades mecânicas utilizando pequenas porcentagens em massa de fibras. A orientação dos feixes de fibras das mantas influenciou positivamente na resistência ao impacto do material quando comparado a fibras curtas e aleatoreamente distribuídas na matriz. A utilização da $\mathrm{FMD}_{\text {moída }}$ como reforço adicional em compósitos híbridos reforçados com MFS em matrizes termorrígidas permitiu agregar valor a esta fibra, que é obtida como resíduo, pois foi possível a obtenção de compósitos com boas propriedades mecânicas. Os materiais obtidos no presente estudo podem ser considerados em 
uma ampla gama de aplicações, como isolante elétrico, e aplicações não estruturais em automóveis, aeronaves e na área naval. 


\section{REFER $\hat{E} \mathcal{N C I A S ~ B I B L I O G R A ́ F I C A S ~}$}

ABDELAZIZ, O. Y.; HULTEBERG, C. P. Physicochemical characterisation of technical lignins for their potential valorisation. Waste and Biomass Valorization, Netherlands, v. 8, n. 3, p. 859-869, 2017.

ABDELlAOUI, H.; BENSALAH, H.; ECHAABI, J.; BOUHFID, R.; QAISS, A. Fabrication, characterization and modelling of laminated composites based on woven jute fibres reinforced epoxy resin. Materials and Design, London, v. 68, p. 104-113, 2015.

ABDELWAHAB, N. A.; NASSAR, M. A. Preparation, optimization and characterization of lignin phenol formaldehyde resin as wood adhesive. Pigment \& Resin Technology, Bingley, v. 40, n. 3, p. 169-174, 2011.

ABDUL, P. M.; JAHIM, J. M.; HARUN, S.; MARKOM, M.; LUTPI, N. A.; HASSAN, O.; MOHD NOR, M. T. Effects of changes in chemical and structural characteristic of ammonia fibre expansion (AFEX) pretreated oil palm empty fruit bunch fibre on enzymatic saccharification and fermentability for biohydrogen. Bioresource Technology, Amsterdam, v. 211, p. 200-208, 2016.

ABDULLAH, M. A.; NAZIR, M. S.; RAZA, M. R.; WAHJOEDI, B. A.; YUSSOF, A. W. Autoclave and ultra-sonication treatments of oil palm empty fruit bunch fibers for cellulose extraction and its polypropylene composite properties. Journal of Cleaner Production, Amsterdam, v. 126, p. 686-697. 2016.

ABRAPALMA. Déficit hídrico e impacto na produção de óleo de palma: nota técnica $n^{\circ}$ 001/2016. Belém, 2016. 13 p.

AHMAD, F. B.; ZHANG, Z.; DOHERTY, W. O. S.; O'HARA, I. M. The prospect of microbial oil production and applications from oil palm biomass. Biochemical Engineering Journal, Amsterdam, v. $143,9-23,2019$.

AHUJA, D.; KAUSHIK, A.; SINGH, M. Simultaneous extraction of lignin and cellulose nanofibrils from waste jute bags using one pot pre-treatment. International Journal of Biological Macromolecules, Amsterdam, v. 107, p. 1294-1301, 2018.

ALAAEDDIN, M. H.; SAPUAN, S. M.; ZUHRI, M. Y. M.; ZAINUDIN, E. S.; AL- OQLA, F. M. Physical and mechanical properties of polyvinylidene fluoride - short sugar palm fiber nanocomposites. Journal of Cleaner Production, Amsterdam, v. 235, p. 473-482, 2019

ALEKHINA, M.; ERSHOVA, O.; EBERT, A.; HEIKKINEN, S.; SIXTA, H. Softwood kraft lignin for value-added applications: fractionation and structural characterization. Industrial Crops and Products, Amsterdam, v. 66, p. 220-228, 2015.

ALEMDAR, A.; SAIN, M. Biocomposites from wheat straw nanofibers: morphology, thermal and mechanical properties. Composites Science and Technology, Oxford, v. 68, p.557-565, 2008.

ALEXANDER, L. X-ray diffraction methods in polymer science. New York: Wiley Interscience, 1969. p. 165-172.

AL-OQLA, F. M.; SALIT, M. S. Materials selection for natural fiber composites. Cambridge: Woodhead Publishing, 2017. 286 p. 
AL-OQLA, F. M.; SAPUAN, S. M. Natural fiber reinforced polymer composites in industrial applications: feasibility of date palm fibers for sustainable automotive industry. Journal of Cleaner Production, Amsterdam, v. 66, p. 347-354, 2014.

ALRIOLS, M. G.; TEJADO, A.; BLANCO, M.; MONDRAGON, I.; LABIDI, J. Agricultural palm oil tree residues as raw material for cellulose, lignin and hemicelluloses production by ethylene glycol pulping process. Chemical Engineering Journal, Amsterdam, v. 148, p. 106-114, 2009.

ALSAEED, T.; YOUSIF, B. F.; KU, H. The potential of using date palm fibres as reinforcement for polymeric composites. Materials and Design, Kent, v. 43, p. 177-184, 2013.

AMERICAN SOCIETY FOR TESTING AND MATERIALS INTERNATIONAL. ASTM D256: standard test methods for determining the izod pendulum impact for plastics. Philadelphia, 2001.

AMERICAN SOCIETY FOR TESTING AND MATERIALS INTERNATIONAL. ASTM D790-96: standard test method for flexural properties of unreinforced and reinforced plastics and electrical insulating materials. Philadelphia, 1995.

ASIM, M.; JAWAID, M.; PARIDAH, M. T.; SABA, N.; NASIR, M.; SHAHROZE, R. M. Dynamic and thermo-mechanical properties of hybridized Kenaf/PALF reinforced phenolic composites. Polymer Composites, Hoboken, v. 40, n. 10, p. 3814-3822, 2019.

ATHIJAYAMANI, A.; CHRISPIN, M.; SEKAR, S.; RAMANATHAN, K. Mechanical properties of phenol formaldehyde hybrid composites reinforced with natural cellulose fibers. Bioresources, Raleigh, v. 12, p. 1960-1967, 2017.

AWALLUDIN, M. F., SULAIMAN, O., HASHIM, R., \& NADHARI, W. N. A. W. An overview of the oil palm industry in Malaysia and its waste utilization through thermochemical conversion, specifically via liquefaction. Renewable and Sustainable Energy Reviews, Oxford, v. 50, p. 14691484, 2015.

BALAKRISHNAN, P.; JOHN, M.J.; POTHEN, L.; SREEKALA, M.S.; THOMAS, S. Natural fibre and polymer matrix composites and their applications in aerospace engineering. In: RANA, S.; FANGUEIRO, R. (ed.). Advanced composite materials for aerospace engineering. Cambridge: Woodhead Publishing, 2016. p. 365-383.

BARBOSA, O.; ORTIZ, C.; BERENGUER-MURCIA, A.; TORRES, R.; RODRIGUES, R. C.; FERNANDEZ-LAFUENTE, R. Glutaraldehyde in bio-catalysts design: a useful crosslinker and a versatile tool in enzyme immobilization. RSC Advances, Cambridge, v. 4, n. 4, p. 1583-1600, 2014.

BLEDZKI, A. K.; FRANCISZCZAK, P.; OSMAN, Z.; ELBADAWI, M. Polypropylene biocomposites reinforced with softwood, abaca, jute, and kenaf fibers. Industrial Crops and Products, Amsterdam, v. 70, 91-99, 2015.

BOSSUNIA, I. M. T.; PODDAR, P.; HASAN, M. M.; HOSSAIN, M. T.; GULENOOR, F. $\gamma$-Irradiated jute reinforced polypropylene composites: effect of mercerization and SEM analysis. Journal Material Science Engineering, Watermael-Boitsfort, v. 5, n. 4, p.1-6, 2016.

BOTARO, V. R.; SIQUEIRA, G.; MEGIATTO JUNIOR, J. D.; FROLLINI, E. Sisal fibers treated with $\mathrm{NaOH}$ and benzophenonetetracarboxylic dianhydride (BTDA) as reinforcement of phenolic matrix. Journal of Applied Polymer Science, Hoboken, v. 115, p. 269-276, 2010.

BOY, R. NARAYANAN, G.; KOTEK, R. Formation of cellulose and protein blend biofibers. In: LUCIA, L.; AYOUB, A. (ed.). Polysaccharide-based fibers and composites: chemical and engineering fundamentals and industrial applications. Cham: Springer, 2018. p. 77-117. 
BRACEGIRDLE, W; CLARKE, S.; MCMILLAN, S. Foam composites. WO 2017136878. Concessão: 7 Feb. 2017.

BUNEA, M.; CÎRCIUMARU, A.; BUCIUMEANU, M.; BÎRSAN, I. G.; SILVA, F. S. Low velocity impact response of fabric reinforced hybrid composites with stratified filled epoxy matrix. Composites Science and Technology, Oxford, v. 169, 242-248, 2019.

BUSCHLE-DILLER, G.; ZERONIAN, S.H. Enhancing the reactivity and strength of cotton fibers. Journal Applied Polymer Science, Hoboken, v. 45, p. 967-979, 1992.

BYKOV, I. Characterization of natural and technical lignins using FT-IR spectroscopy. 2008. Master's thesis - Division of Chemical Technology, Department of Chemical Engineering and Geosciences, Lulea University of Technology, Lulea, 2008.

CALABRESE, L.; FIORE, V.; SCALICI, T.; VALENZA, A. Experimental assessment of the improved properties during aging of flax/glass hybrid composite laminates for marine applications. Journal of Applied Polymer Science, Hoboken, v. 136, p. 1-12, 2019.

CALLISTER JUNIOR, W. D. Ciência e engenharia dos materiais: uma introdução. Rio de Janeiro, LTC, 2002.

CARRILlO, F.; COLOM, X.; SUNOL, J. J.; SAURINA, J. Structural FTIR analysis and thermal characterisation of lyocell and viscose-type fibres. European Polymer Journal, Oxford, v. 40, n. 9, 2229-2234, 2004.

CARVAJAL, J. C.; GÓMEZ, Á.; CARDONA, C. A. Comparison of lignin extraction processes: economic and environmental assessment. Bioresource Technology, Amsterdam, v. 214, p. 468-476, 2016.

CASTRO, D. O.; FROLLINI, E., RUVOLO-FILHO, A.; DUFRESNE, A. Cellulose nanocrystal based "Green Polyethylene" and Curau a nanocomposites : effect of vegetable oils as coupling agent and processing technique. Journal of Polymer Science, Hoboken, p. 1010-1019, 2015.

CASTRO, D. O.; RUVOLO-FILHO, A.; FROLLINI, E. Materials prepared from biopolyethylene and curaua fibers: composites from biomass. Polymer Testing, London, v. 31, n. 7, p. 880-888, 2012.

CHABBERT, B.; TERRYN, C.; HERBAUT, M.; VAIDYA, A.; HABRANT, A.; PAËS, G.; DONALDSON, L. Fluorescence techniques can reveal cell wall organization and predict saccharification in pretreated wood biomass. Industrial Crops and Products, Amsterdam, v. 123, p. 84-92, 2018.

CHEE, S. S.; JAWAID, M.; SUlTAN, M. T. H.; AlOTHMAN, O. Y.; ABDUllah, L. C. Thermomechanical and dynamic mechanical properties of bamboo/woven kenaf mat reinforced epoxy hybrid composites. Composites Part B: engineering, Oxford, v. 163, p. 165-174, 2019.

CHENG, D.; GU, J.; XU, B.; LI, Y. Effect of (NH4)2SO4 concentration on the pyrolysis properties of rayon fiber from bamboo. BioResources, Raleigh, v. 10, n. 4, p. 8352-8363, 2015.

CHIENG, B. W.; LEE, S. H.; IBRAHIM, N. A.; THEN, Y. Y.; LOO, Y. Y. Isolation and characterization of cellulose nanocrystals from oil palm mesocarp fiber. Polymers, Basel, v. 9, n. 355, 2017.

CHUNG, H.; KIM, J. Y. Effects of washing parameters on dimensional stability of viscose rayon fabrics. Fibers and Polymers, Dordrecht, v. 17, n. 11, p. 1945-1954, 2016. 
COMNEA-STANCU, I. R.; WIELAND, K.; RAMER, G.; SCHWAIGHOFER, A.; LENDL, B. On the identification of rayon/viscose as a major fraction of microplastics in the marine environment: discrimination between natural and manmade cellulosic fibers using fourier transform infrared spectroscopy. Applied Spectroscopy, Thousand Oaks, v. 71, p. 939-950, 2017.

CONAB. Acompanhamento de safra brasileira: grãos, primeiro levantamento, 2017/2018. Brasília, 2018. Disponível em: agricultura.gov.br/assuntos/camaras-setoriais-tematicas/documentos/camarassetoriais/fibras-naturais/2018/copy_of_19-ro/csfn-20-a-ro-in-sisal.pdf. Acesso em 12 nov. 2019.

CONSTANT, S.; WIENK, H. L. J.; FRISSEN, A. E.; PEINDER, P.; BOELENS, R.; VAN ES, D. S.; BRUIJNINCX, P. C. A. New insights into the structure and composition of technical lignins: a comparative characterisation study. Green Chemistry, Cambridge, v. 18, n. 9, p. 2651-2665, 2016.

CORREIA, S. A.; CRUZ, P. V.; RODRIGUES, T. C.; MONTEIRO, A.; DIAZ, F. R.; MOURA, E. A. Production and characterization of a hybrid composite of polypropylene reinforced with Piassava (Attalea funifera Martius) fiber and light green clay. The Minerals, Metals \& Materials Series, Cham, p. 735-746, 2019.

COSTA, A. G.; PINHEIRO, G. C.; PINHEIRO, F. G. C.; DOS SANTOS, A. B.; SANTAELLA, S. T., LEITÃO, R. C. Pretreatment strategies to improve anaerobic biodegradability and methane production potential of the palm oil mesocarp fibre. Chemical Engineering Journal, Amsterdam, v. 230, p. 158$165,2013$.

COSTA, C. S. M. F.; FONSECA, A. C.; SERRA, A. C.; COELHO, J. F. J. Dynamic mechanical thermal analysis of polymer composites reinforced with natural fibers. Polymer Reviews, New York, v. 56, p. $362-383,2016$.

CREDOU, J.; BERTHELOT, T. Cellulose: from biocompatible to bioactive material. Journal of Materials Chemistry B, Cambridge, v. 2, n. 30, p. 4767-4788, 2014.

CRESPY, D.; BOZONNET, M.; MEIER, M. 100 Years of bakelite, the material of a 1000 Uses. Angewandte Chemie International Edition, Weinheim, v. 47, p. 3322-3328, 2008.

DARROS, A. B. Compósitos de matrizes poliméricas com mantas aleatórias de fibras vegetais de sisal e de coco. 2013. Dissertação (Mestre em Ciências dos Materiais) - Universidade Federal de São Carlos, Sorocaba, 2013.

DA SILVA, C. G. D. Bagaço de cana de açúcar como reforço de matrizes termorrígidas baseadas em macromoléculas de ligninas. 2011. Tese (Doutorado em Físico-Química) - Instituto de Química de São Carlos, Universidade de São Paulo, São Carlos, 2011.

DA SILVA, C. G.; OLIVEIRA, F.; RAMIRES, E. C.; CASTELLAN, A.; FROLLINI, E. Composites from a forest biorefinery by-product and agrofibers: lignosulfonate-phenolic type matrices reinforced with sisal fibers. Tappi Journal, Norcross, v. 11, p. 41-49, 2012.

DA SILVA, C. G.; GRELIER, S.; PICHAVANT, F.; FROLLINI, E.; CASTELLAN, A. Adding value to lignins isolated from sugarcane bagasse and Miscanthus. Industrial Crops and Products, Amsterdam, v. 42, p. 87- 95, 2013.

DA SILVA, C. G.; DE OLIVEIRA, F.; FROLLINI, E. Sugarcane bagasse fibers treated and untreated: performance as reinforcement in phenolic-type matrices based on lignosulfonates. Waste and Biomass Valorization, Dordrecht, p. 1-10, 2018.

DAVIS, A. M.; HANZLY, L. E.; DEBUTTS, B. L.; BARONE, J. R. Characterization of dimensional stability in flax fiber reinforced polypropylene composites. Polymer Composites, Hoboken, v. 40, p.132-140, 2019. 
DE OLIVEIRA, F.; DA SILVA, C. G.; RAMOS, L. A.; FROLLINI, E. Phenolic and lignosulfonatebased matrices reinforced with untreated and lignosulfonate-treated sisal fibers. Industrial Crops and Products, Hoboken, v. 96, p. 30-41, 2017.

DE OLIVEIRA, F.; RAMIRES, E. C.; FROLLINI, E.; BELGACEM, M. N. Lignopolyurethanic materials based on oxypropylated sodium lignosulfonate and castor oil blends. Industrial Crops and Products, Hoboken, v. 72, p. 77-86, 2015.

DERMAN, E.; ABDULLA, R.; MARBAWI, H.; KHALIZAN, M. Oil palm empty fruit bunches as a promising feedstock for bioethanol production in Malaysia. Renewable Energy, New York, v. 129, p. 285-298, 2018.

DESHPANDE, R.; GIUMMARELLA, N.; HENRIKSSON, G.; GERMGÅRD, U.; SUNDVALL, L.; GRUNDBERG, H.; LAWOKO, M. The reactivity of lignin carbohydrate complex (LCC) during manufacture of dissolving sulfite pulp from softwood. Industrial Crops and Products, Amsterdam, v. 115, p. 315-322, 2018.

DOMÍNGUEZ-ROBLES, J.; SÁNCHEZ, R.; ESPINOSA, E.; SAVY, D.; MAZZEI, P.; PICCOLO, A.; RODRÍGUEZ, A. Isolation and characterization of Gramineae and Fabaceae soda lignins. International Journal of Molecular Sciences, Basel, v. 18, n. 2, 2017.

DOS SANTOS, P. S. B.; ERDOCIA, X.; GATTO, D. A.; LABIDI, J. Characterisation of Kraft lignin separated by gradient acid precipitation. Industrial Crops and Products, Amsterdam, v. 55, 149-154.

DOS SANTOS, R. P. O.; CASTRO, D. O., RUVOLO-FILHO, A. C.; FROLLINI, E. Processing and thermal properties of composites based on recycled PET, sisal fibers, and renewable plasticizers. Journal of Applied Polymer Science, New York, v. 131, p. 1-13, 2014.

DUFRESNE, A. Cellulose-based composites and nanocomposites. In: BELGACEM, M. N.; GANDINI, A. (ed.). Monomers, polymers and composites from renewable resources. Amsterdam: Elsevier, 2008. p. 401-418.

DWIATMOKO, A. A., LEE, S., HAM, H. C., CHOI, J. W., SUH, D. J., HA, J. M. Effects of carbohydrates on the hydrodeoxygenation of lignin-derived phenolic compounds. ACS Catalysis, Washington, v. 5, n. 1, p. 433-437, 2014.

EL MANSOURI, N. E.; FARRIOL, X.; SALVADO, J. Structural characterization of technical lignins for the production of adhesives: Application to lignosulfonate, kraft, soda-anthraquinone, organosolv and ethanol process lignins. Industrial Crops and Products, Amsterdam, v. 24, p. 8-16, 2006.

EL MANSOURI, N. Q.; HUANG, F. Characterization of alkaline lignin for use in phenol- formaldehyde and epoxy resin. BioResources, Raleigh, v. 6, p. 2647-2662, 2011.

ENG, C. C.; IBRAHIM, N. A.; ZAINUDDIN, N.; ARIFFIN, H.; ZIN, W.; YUNUS, W. Impact strength and flexural properties enhancement of methacrylate silane treated oil palm mesocarp fiber reinforced biodegradable hybrid composites. Scientific World Journal, v. 2014, article ID 213180, 2014.

ERDOCIA, X.; RUIZ, E.; ROMERO, I.; DIAZ, M. J.; CASTRO, E.; LABIDI, J. Lignin characterization from two different pretreatments in bioethanol production processes from olive tree pruning. Chemical Engineering Transactions, Crows Nest, v. 61, 421-426, 2017.

FARES, M. C., SOUZA, G.; CARVALHO, A. J. F. Thermoformed polypropylene composite reinforced with cotton fabric. Macromolecular Symposia, Weinheim, v. 383, p. 1-6, 2019. 
FARIS, A. H.; RAHIM, A. A.; MOHAMAD IBRAHIM, M. N.; HUSSIN, M. H.; ALKURDI, A. M.; SALEHABADI, A. Investigation of oil palm-based Kraft and auto-catalyzed organosolv lignin susceptibility as a green wood adhesives. International Journal of Adhesion and Adhesives, London, v. 74, p. 115-122, 2017.

FARHAT, W.; VENDITTI, R.; QUICK, A.; TAHA, M.; MIGNARD, N.; BECQUART, F.; AYOUB, A. Hemicellulose extraction and characterization for applications in paper coatings and adhesives. Industrial Crops and Products, Amsterdam, v. 107, p. 370-377, 2017.

FARUK, O.; BLEDZKI, A. K.; FINK, H. P.; SAIN, M. Biocomposites reinforced with natural fibers: 2000-2010. Progress in Polymer Science, London, v. 37, n. 11, p. 1552-1596, 2012.

FATEHI, P.; GAO, W.; SUN, Y.; DASHTBAN, M. Acidification of prehydrolysis liquor and spent liquor of neutral sulfite semichemical pulping process. Bioresource Technology, Amsterdam, v. 218, p. 518-525, 2016.

FENG, A.; WU, G.; PAN, C.; WANG, Y. The behavior of acid treating carbon fiber and the mechanical properties and thermal conductivity of phenolic resin matrix composites. Journal of Nanoscience and Nanotechnology, Valencia, v. 17, p. 3786-3791, 2017.

FENG, S.; YUAN, Z.; LEITCH, M.; XU, C. C. Adhesives formulated from bark bio-crude and phenol formaldehyde resole. Industrial Crops and Products, Amsterdam, v. 76, p. 258-268, 2015.

FERNÁNDEZ-COSTAS, C.; GOUVEIA, S.; SANROMÁN, M. A.; MOLDES, D. Structural characterization of Kraft lignins from different spent cooking liquors by 1D and 2D nuclear magnetic resonance spectroscopy. Biomass and Bioenergy, Amsterdam, v. 63, p. 156-166, 2014.

FERNÁNDEZ-RODRÍGUEZ，J.; ROBLES，E.; GORDOBIL，O.; GONZÁLEZ-ALRIOLS， M.; LABIDI, J. Lignin valorisation from side-streams produced during agriculture waste pulping and TCF bleaching. Chemical Engineering Transactions, Melbourne, v. 52, p. 187-192, 2016.

FERREIRA, S. R.; SILVA, F. D. A.; LIMA, P. R. L.; TOLEDO FILHO, R. D. Effect of fiber treatments on the sisal fiber properties and fiber-matrix bond in cement based systems. Construction and Building Materials, Amsterdam, v. 101, p. 730-740, 2015.

FIDELIS, M. E. A.; PEREIRA, T. V. C.; GOMES, O. D. F. M.; DE ANDRADE SILVA, F.; TOLEDO FILHO, R. D. The effect of fiber morphology on the tensile strength of natural fibers. Journal of Materials Research and Technology, Rio de Janeiro, v. 2, n. 2, p. 149-157, 2013.

FIORE, V.; SCALICI, T.; NICOLETTI, F.; VITALE, G.; PRESTIPINO, M.; VALENZA, A. A new eco-friendly chemical treatment of natural fibres: effect of sodium bicarbonate on properties of sisal fibre and its epoxy composites. Composites Part B: engineering, Oxford, v. 85, p. 150-160, 2016.

FRANCISZCZAK, P.; BLEDZKI, A. K. Tailoring of dual-interface in high tenacity PP composites toughening with positive hybrid effect. Composites Part A: applied science and manufacturing, Oxford, v. 83, p. 185-192, 2016.

FRANCISZCZAK, P.; MERIJS-MERI, R.; KALNIN, K.; BŁEDZKI, A. K.; ZICANS, J. Short-fibre hybrid polypropylene composites reinforced with PET and Rayon fibres - effects of SSP and interphase tailoring. Composites Structure, London, v. 181, p. 121-137, 2017.

FRENCH, A. D. Idealized powder diffraction patterns for cellulose polymorphs. Cellulose, Dordrecht, v. 21, n. 2, p. 885-896, 2014. 
FROLLINI, E.; TRINDADE, W. G.; RAZERA, I. A. T.; CASTELLAN, A.; HOAREAU, W. Phenolic thermoset matrix reinforced with sugar cane bagasse fibers: attempt to develop a neaw fiber surface chemical modification involving formation of quinones followed by reaction with furfuryl alcohol. Macromolecular Materials and Engineering, Weinheim, v. 289, n. 8, p. 728-736, 2004.

FU S.Y.; LAUKE B.; MÄDER E.; HU X.; YUE, C. Y. Fracture resistance of short-glass-fiberreinforced and short-carbon-fiber-reinforced polypropylene under charpy impact load and its dependence on processing. Journal of Materials Processing Technology, Amsterdam, v. 89, n. 90, 1999.

GALKIN, M. V.; SAMEC, J. S. M. Lignin valorization through catalytic lignocellulose fractionation: a fundamental platform for the future biorefinery. ChemSusChem, Weinheim, v. 9, p. 1544-1558, 2016.

GARCÍA, A.; GONZÁLEZ ALRIOLS, M.; SPIGNO, G.; LABIDI, J. Lignin as natural radical scavenger. Effect of the obtaining and purification processes on the antioxidant behaviour of lignin. Biochemical Engineering Journal, Amsterdam, v. 67, p. 173-185, 2012.

GARDZIElla, A.; PILATO, L A.; KNOP, A. Phenolic resins: chemistry, applications, standardization, safety and ecology. Berlin: Springer Science \& Business Media, 2013.

GE, D.; SHI, M.; YAO, Y.; JIANG, S.; HE, D.; HUANG, Z. Preparation and properties of anti-insulation integrated phenolic resin composites. IOP Conference Series: materials science and engineering, Amsterdam, v. 472, article 012047, 2019.

GHORBANI, M.; LIEBNER, F.; VAN HERWIJNEN, H. W.; PFUNGEN, L.; KRAHOFER, M.; BUDJAV, E.; KONNERTH, J. Lignin phenol formaldehyde resoles: the impact of lignin type on adhesive properties. Bioresources, Raleigh, v. 11, n. 3, p. 6727-6741, 2017.

GORDOBIL, O., HERRERA, R., YAHYAOUI, M., İLK, S., KAYA, M.; LABIDI, J. Potential use of kraft and organosolv lignins as a natural additive for healthcare products. RSC Advances, Cambridge, v. 8, n. 43, p. 24525-24533, 2018.

GORDOBIL, O.; MORIANA, R.; ZHANG, L.; LABIDI, J.; SEVASTYANOVA, O. Assesment of technical lignins for uses in biofuels and biomaterials: structure-related properties, proximate analysis and chemical modification. Industrial Crops and Products, Amsterdam, v. 83, p. 155-165, 2016.

GOSSELINK, R. J. A. Lignin as a renewable aromatic resource for the chemical industry. 2011. Doctor's Thesis - University of Wageningen, Wageningen, 2011.

GUNA, V.; ILANGOVAN, M.; HU, C.; VENKATESH, K. Valorization of sugarcane bagasse by developing completely biodegradable composites for industrial applications. Industrial Crops \& Products, Amsterdam, v. 131, p. 25-31, 2019.

HAMDAN, M. H. M.; SIREGAR, J. P.; BACHTIAR, D.; REJAB, M. R. M.; SAMYKANO, M.; AGUNG, E. H.; JAAFAR, J. Effect of alkaline treatment on mechanical properties of woven ramie reinforced thermoset composite. IOP Conference Series: materials science and engineering, Amsterdam, v. 257, n. 1, p. 12044, 2017.

HASSAN, A.; SALEMA, A. A.; ANI, F. N.; BAKAR, A. A. A review on oil palm empty fruit bunch fiber-reinforced polymer composite materials. Polymer Composites, Hoboken, v. 31, n. 12, p. 2079$2101,2010$.

HELANDER, M. The use of membrane filtration to improve the properties of extracted wood components. 2014. Doctoral thesis - KTH Royal Institute of Technology, Stockholm, 2014 
HEMMILÄ, V.; TRISCHLER, J.; SANDBERG, D. Lignin: an adhesive raw material of the future or waste of research energy? In: BRISCHKE, C.; MEYER, L. (ed.). Proceeding of the 9th Meeting of the Northern European Network for Wood Science and Engineering (WSE). Hannover: Leibniz Universität, 2013. p. 98-103.

HERAKOVICH, C. T. Mechanics of composites: a historical review. Mechanics Research Communications, Tarrytown, v. 41, p. 1-20, 2012.

HERMIATI, E.; RISANTO, L.; LUBIS, M. A. R.; LAKSANA, R. P. B.; DEWI, A. R. Chemical characterization of lignin from kraft pulping black liquor of Acacia mangium. AIP Conference Proceedings, Melville, v. 1803, article 020005, 2017. Trabalho apresentado no 2nd International Symposium on Applied Chemistry (ISAC), 2016,Tangerang, Indonesia.

HIRANO, K.; ASAMI, M. Phenolic resins-100 years of progress and their future. Reactive and Functional Polymers, Amsterdam, v. 73, p. 256-269, 2013.

HOAREAU, W. Valorisation de la bagasse de canne a sucre. Chimie, photochimie et al elaboration de panneaux et compositese. 2005. $208 \mathrm{f}$. Tese (Doutorado) - L' Université de la Reunion - Ecole Doctarale Interdisciplinaire, Bordeaux, 2005.

HOAREAU, W.; OLIVEIRA, F.B.; GRELIER, S.; SIEGMUND, B.; FROLLINI, E.; CASTELLAN, A. Fiberboards based on sugarcane bagasse lignin and fibers. Macromolecular Materials and Engineering, Weinheim, v. 291, p. 829-839, 2006.

HOLLADAY, J. E.; WHITE, J. F.; BOZELL, J. J.; JOHNSON, D. Top value-added chemicals from biomass. Richland: Pacific Northwest National Laboratory, 2007. p. 1-87.

HU, J.; ZHANG, Q.; LEE, D. J. Kraft lignin biorefinery: a perspective. Bioresource Technology, Oxford, v. 247, p. 1181-1183, 2018.

HUANG, Z.; GE, H.; YIN, J.; LIU, F. Effects of fiber loading and chemical treatments on properties of sisal fiber-reinforced sheet molding compounds. Journal of Composite Materials, London, v. 51, $\mathrm{n}$. 22, p. 3175-3185, 2017.

HUANG, Z.; GE, H.; ZHAO, Y.; LIU, F.;YIN, J. Reuse FRP waste as filler replacement for sisal fiber reinforced sheet molding compound. Polymer Composites, Hoboken, v. 39, n. 6, p.1896-1904, 2018.

HUSSIN, M. H.; HAN, H.; AZILA, N.; ABD, N.; HASSAN, A.; NASIR, M.; HAAFIZ, M. K. M. Preparation of environmental friendly phenol-formaldehyde wood adhesive modified with kenaf lignin. Journal of Basic and Applied Sciences, Heidelberg, v. 6, p. 409-418, 2017.

IBRAHIM, H.; MEHANNY, S.; DARWISH, L.; FARAG, M. A comparative study on the mechanical and biodegradation characteristics of starch-based composites reinforced with different lignocellulosic fibers. Journal of Polymers and the Environment, New York, v. 26, n. 6, p. 2434-2447, 2018.

ISHAK, M. R.; LEMAN, Z.; SAPUAN, S. M.; RAHMAN, M. Z. A.; ANWAR, U. M. K. Impregnation modification of sugar palm fibres with phenol formaldehyde and unsaturated polyester. Fibers and Polymers, Dordrecht, v. 14, n. 2, p. 250-257, 2013.

ISLAM, F.; ISLAM, M. N.; SHAHIDA, S.; RASHID, H. A.; KARMAKER, N.; KOLY, F. A.; KHAN, R. A. Mechanical and interfacial characterization of jute fabrics reinforced unsaturated polyester resin composites. Nano Hybrids and Composites, Pfaffikon, v. 25, p. 22-31, 2019. 
IZANI, M. A. N.; PARIDAH, M. T., ANWAR, U. M. K., MOHD NOR, M. Y. Effects of fiber treatment on morphology, tensile and thermogravimetric analysis of oil palm empty fruit bunches fibers. Composites Part B: engineering, Oxford, v. 45, n. 1, p. 1251-1257, 2013.

JABBAR, A. Sustainable jute-based composite materials. New York: Springer International Publishing, 2017. (Springer briefs in applied sciences and technology).

JACOB, M., THOMAS, S., VARUGHESE, K. T. Mechanical properties of sisal/oil palm hybrid fiber reinforced natural rubber composites. Composites Science and Technology, Oxford, v. 64, n. 7-8, p. 955-965, 2004.

JAWAID, M.; KHALIL, H. P. S. A.; BAKAR, A. A.; KHANAM, P. N. Chemical resistance, void content and tensile properties of oil palm/jute fibre reinforced polymer hybrid composites. Materials and Design, London, v. 32, n. 2, p. 1014-1019, 2011.

JENKINS, B.M.; BAXTER, L.L.; MILES JR., T.R.; MILES, T.R. Combustion properties of biomass. Fuel Processing Technology, Amsterdam, v. 54, p. 17-46, 1998.

JOSEPH, A.; SREEKALA, M.S.; OOMEN, Z.; KOSHY, P.; THOMAS, S. A. A comparison of the mechanical properties of phenol formaldehyde composites reinforced with banana fibre and glass fibres. Composites Science and Technology, Oxford, v. 62, p. 1857-1868, 2002.

KABIR, G.; DIN, A. M.; HAMEED, B. H. Pyrolysis of oil palm mesocarp fiber and palm frond in a slow-heating fixed-bed reactor: a comparative study. Bioresource Technology, Amsterdam, v. 241, p. 563-572, 2017.

KABIR, G.; DIN, A. M.; HAMEED, B. H. Pyrolysis of oil palm mesocarp fiber catalyzed with steel slag-derived zeolite for bio-oil production. Bioresource Technology, Amsterdam, v. 249, p. 42-48, 2018.

KADLA, J. F.; GILBERT, R. D. Cellulose structure: a review. Cellulose Chemistry and Technology, Bucharest, v. 34, n. 3-4, p. 197-216, 2000.

KALAIVANI, R.; EWE, L. I.; YAP, B. K.; TALIK, N. A.; IBRAHIM, Z. The effects of density on microstructure and acoustic properties of opt natural fibers. Journal of Fundamental and Applied Sciences, El Oued, v. 10, p. 434-445, 2018.

KALAM, A.; SAHARI, B. B.; KHALID, Y. A.; WONG, S. V. Fatigue behaviour of oil palm fruit bunch fibre/epoxy and carbon fibre/epoxy composites. Composite Structures, London, v. 71, n. 1, p. 34-44, 2005.

KHALID, I.; SULAIMAN, O.; HASHIM, R.; RAZAK, W.; JUMHURI, N.; RASAT, M. S. M. Evaluation on layering effects and adhesive rates of laminated compressed composite panels made from oil palm (Elaeis guineensis) fronds. Materials and Design, London, v. 68, p. 24-28, 2015.

KHAN, M. A.; ASHRAF, S. M. Studies on thermal characterization of lignin. Journal of Thermal Analysis and Calorimetry, Budapest, v. 89, n. 3, p. 993-1000, 2007.

KASCHUK, J. J.; LACERDA, T. M.; COMA, V.; FROLLINI, E. Enzymatic hydrolysis of mercerized and unmercerized sisal pulp. Cellulose, Dordrecht, v. 24, n, 6, p. 2437-2453, 2017.

KAW, A. K. Mechanics of composite materials. Boca Raton, CRC Press, 2006. 
KIM, J.; SHAM, M. Impact and delamination failure of woven-fabric composites. Composites Science and Technology, Oxford, v. 60, p. 745-761, 2000.

KIM, S. J.; UM, B. H. Delignification from Geodae-Uksae1 using soda-pulping followed by evaluation on recycling of liquid-liquid extraction solvent. Biomass and Bioenergy, Oxford, v. 109, p. 23-30, 2018.

KIM, S.; OH, S.; LEE, J.; ROH, H.; PARK, J. Changes of lignin molecular structures in a modification of kraft lignin using acid catalyst. Materials, Basel, v. 9, p. 1-15, 2016.

KIM, Y.-M.; PARK, S.; KANG, B. S.; JAE, J.; RHEE, G. H.; JUNG, S.-C.; PARK, Y.-K. Suppressed char agglomeration by rotary kiln reactor with alumina ball during the pyrolysis of Kraft lignin. Journal of Industrial and Engineering Chemistry, Washington, v. 66, p. 72-77, 2018.

KNOP, A.; PILATO, L. A. Phenolic resins chemistry, applications and performance. Berlin: Springer-Verlag, 1985.

KRINGSTAD, K. P; MÖRCK, R. 13 C-NMR Spectra of Kraft Lignins. Holzforschung, Berlin, v. 37, n. 5, p. 237-244, 1983.

KRISHNAIAH, P.; RATNAM, C. T.; MANICKAM, S. Enhancements in crystallinity, thermal stability, tensile modulus and strength of sisal fibres and their PP composites induced by the synergistic effects of alkali and high intensity ultrasound (HIU) treatments. Ultrasonics Sonochemistry, Amsterdam, v. 34, p. 729-742, 2017.

KROON-BATENBURG, L. M. J.; KROON, J. The crystal and molecular structures of cellulose I and II. Glycoconjugate Journal, New York, v. 14, n. 5, p. 677-690, 1997.

KUMAR, R.; KUMAR, K.; BHOWMIK, S. Mechanical characterization and quantification of tensile, fracture and viscoelastic characteristics of wood filler reinforced epoxy composite. Wood Science and Technology, Heidelberg, v. 52, n. 3, p. 677-699, 2018.

LAURICHESSE, S.; AVEROUS, L. Chemical modification of lignins: towards biobased polymers. Progress in Polymer Science, London, v. 39, p. 1266-1290, 2014.

LEE, W.; CHANG, K.; TSENG, I. Properties of phenol-formaldehyde resins prepared from phenolliquefied lignin. Journal of Applied Polymer Science, Hoboken, v. 124, p. 4782-4788, 2012.

LI, B.; WANG, Y.; MAHMOOD, N.; YUAN, Z.; SCHMIDT, J.; XU, C. Preparation of bio-based phenol formaldehyde foams using depolymerized hydrolysis lignin. Industrial Crops and Products, Amsterdam, v. 97,p. 409-416, 2017.

LI, R.; CHANG, C.; ZHOU, J.; ZHANG, L.; GU, W.; LI, C.; LIU, S.; KUGA, S. Primarily industrialized trial of novel fibers spun from cellulose dope in $\mathrm{NaOH} /$ urea aqueous solution. Industrial \& Engineering Chemistry Research, Washington, v. 49, n. 22, p. 11380-11384, 2010.

LIITIÄ, T. M.; MAUNU, S. L.; HORTLING, B.; TOIKKA, M.; KILPELÄINEN, I. Analysis of technical lignins by two- and three-dimensional NMR spectroscopy. Journal of Agricultural and Food Chemistry, Washington, v. 51, p. 2136-2143, 2003.

LIU, L. ZHANG, B.; WANG, D.; WU, Z. Effects of cure cycles on void content and mechanical properties of composite laminates. Composite Structures, London, v. 73, n. 3, p. 303-309, 2006. 
LOHRE, C.; KLEINERT, M.; BARTH, T. Organosolv extraction of softwood combined with lignin-toliquid-solvolysis as a semi-continuous percolation reactor. Biomass and Bioenergy, Oxford, v. 99, 147$155,2017$.

LORA, J. H.; GLASSER, W. G. Recent industrial applications of lignin: a sustainable alternative to nonrenewable materials. Journal of Polymers and the Environment, New York, v. 10, n. 1-2, p. 39, 2002.

LUZ, F. S.; PACIORNIK, S.; MONTEIRO, S. N.; SILVA, L. C.; TOMMASINI, V. I. O. J. Porosity Assessment for Different Diameters of Coir Lignocellulosic Fibers. The Minerals, Metals \& Materials Society, Cham, v. 69, n. 10, p. 2045-2051, 2017.

LUZ, F. S. D.; MONTEIRO, S. N.; TOMMASINI, F. J. Evaluation of dynamic mechanical properties of PALF and coir fiber reinforcing epoxy composites. Materials Research, São Carlos, v. 21, 2018.

MABROUK, A.; ERDOCIA, X.; ALRIOLS, M. G.; LABIDI, J. Techno-economic evaluation for feasibility of lignin valorisation process for the production of bio-based chemicals. Chemical Engineering Transactions, Milan, v. 61, p. 427-432, 2017.

MAHMUD, N. A. N.; BAHARUDDIN, A. S.; BAHRIN, E. K.; SULAIMAN, A.; NAIM, M. N.; ZAKARIA, R.; HASSAN, M. A.; NISHIDA, H.; SHIRAI, Y. Enzymatic saccharification of oil palm mesocarp fiber (OPMF) treated with superheated steam. BioResources, Raleigh, v. 8, n. 1, p. 1320 1331, 2013.

MALUTAN, T.; NICU, R.; POPA, V. I. Contribution to the study of hidroxymethylation reaction of alkali lignin. Bioresources, Raleigh, v. 3, p. 13-20, 2008.

MANIMARAN, P.; SENTHAMARAIKANNAN, P.; SANJAY, M. R.; MARICHELVAM, M. K.; JAWAID, M. Study on characterization of Furcraea foetida new natural fiber as composite reinforcement for lightweight applications. Carbohydrate Polymers, Oxford, v. 181, p. 650-658, 2018.

MANNA, S.; SAHA, P.; CHOWDHURY, S.;THOMAS, S. Alkali treatment to improve physical, mechanical and chemical properties of lignocellulosic natural fibers for use in various applications. Lignocellulosic Production and Industrial Applications, p. 47-63, 2017.

MATTHEWS, F. L.; RAWLINGS, R. D. Composite materials: engineering and science. New York: CRC Press, 1994. p. 3-12.

MAYA, M.G.; SONEY, C. G.; THOMASUKUTTY, J.; SREEKALA, M.S.; SABU, T. Mechanical properties of short sisal fibre reinforced phenol formaldehyde eco-friendly composites. Polymers from Renewable Resources, Thousand Oaks, v. 8, n. 1, p. 27-42, 2017.

MCKENDRY, P. Energy production from biomass (part 1): overview of biomass. Bioresource Technology, Amsterdam, v. 83, p. 37-46, 2002.

MEGIATTO JUNIOR, J. D. Fibras de sisal: estudo de propriedades e modificações químicas visando aplicação em compósitos de matriz fenólica. 2006. 267 f. Tese (Doutorado em Físico-Química) Instituto de Química de São Carlos, Universidade de São Paulo, São Carlos, 2006.

MEGIATTO JUNIOR, J. D.; SILVA, CRISTINA, G.; RAMIRES, E C ; FROLLINI, E. Thermoset matrix reinforced with sisal fiber: effect of the cure cycle on the properties of the biobased composite. Polymer Testing, London, v. 28, p. 793-800, 2009. 
METHACANON, P.; WEERAWATSOPHON, U.; THAINTHONGDEE, M.; LEKPITTAYA, P. Optimum conditions for selective separation of Kraft Lignin. KasetsartJournal (Natural Science), Bangkok, v. 44, p. 680-690, 2010.

MIFUKA, H.; HIRANO, T.; ISO, K. Resol phenolic resin for friction material, method for producing the same, adhesive for friction material, and wet friction plate. U.S. 10259902. Depósito: 16 abr. 2019.

MORIANA, R.; VILAPLANA, F.; KARLSSON, S.; RIBES, A. Correlation of chemical, structural and thermal properties of natural fibers for their sustainable exploitation. Carbohydrate Polymers, Oxford, v. 112, p. 422-431, 2014.

MUSSATTO, S. I.; DRAGONE, G. M. Biomass pretreatment, biorefineries, and potential products for a bioeconomy development. In: MUSSATTO, S. I. Biomass fractionation technologies for a lignocellulosic feedstock based biorefinery. Amsterdam: Elsevier, 2016. p. 1-22.

NASCIMENTO, D. C. O.; FERREIRA, A. S.; MONTEIRO, S. N.; AQUINO, R. C. M. P.; KESTUR, S. G. Studies on the characterization of piassava fibers and their epoxy composites. Composites Part A: applied science and manufacturing, Oxford, v. 43, n. 3, p. 353-362, 2012.

NASCIMENTO, D. M.; ALMEIDA, J. S.; DIAS, A. F.; FIGUEIRÊDO, M. C. B.; MORAIS, J. P. S.; FEITOSA, J. P.; ROSA, M. D. F. A novel green approach for the preparation of cellulose nanowhiskers from white coir. Carbohydrate Polymers, Oxford, v. 110, p. 456-463, 2014.

NAVEEN, J.; JAWAID, M.; AMUTHAKKANNAN, P.; CHANDRASEKAR, M. Mechanical and physical properties of sisal and hybrid sisal fiber-reinforced polymer composites. In: JAWAID, M.; THARIQ, M.; SABA, N. Mechanical and physical testing of biocomposites, fibre-reinforced composites and hybrid composites. Duxford: Elsevier, 2019. p. 427-440.

NELSON, M. L.; O'CONNOR, R. T. Relation of certain infrared bands to cellulose crystallinity and crystal lattice type. Part II. A new infrared ratio for estimation of crystallinity in celluloses I and II. Journal of Applied Polymer Science, Hoboken, v. 8.3, p. 1325-1341, 1964.

NOGUEIRA, I. M.; AVELINO, F.; DE OLIVEIRA, D. R.; SOUZA, N. F.; ROSA, M. F.; MAZZETTO, S. E.; LOMONACO, D. Organic solvent fractionation of acetosolv palm oil lignin: the role of its structure on the antioxidant activity. International Journal of Biological Macromolecules, Amsterdam, v. 122, p. 1163-1172, 2019.

NORDIN, N. I. A. A.; ARIFFIN, H.; ANDOU, Y.; HASSAN, M. A.; SHIRAI, Y.; YUNUS, W. M. Z. W.; KARUPPUCHAMY, S.; IBRAHIM, N A. Modification of oil palm mesocarp fiber characteristics using superheated - steam treatment. Molecules, Basel, v. 18, n. 8, p. 9132-9146, 2013.

NORDIN, N. I. A. A.; ARIFFIN, H.; HASSAN, M. A.; SHIRAI, Y.; ANDO, Y.; IBRAHIM, N. A.. YUNUS, W. M. Z. W. Superheated steam treatment of oil palm mesocarp fiber improved the properties of fiber-polypropylene biocomposite. BioResources, Raleigh, v. 12, p. 68-81, 2017.

OKAHISA, Y.; FURUKAWA, Y.; ISHIMOTO, K.; NARITA, C.; INTHARAPICHAI, K.; OHARA, $\mathrm{H}$. Comparison of cellulose nanofiber properties produced from different parts of the oil palm tree. Carbohydrate Polymers, Oxford, v. 198, p. 313-319, 2018.

ORUE, A.; JAUREGI, A.; PEÑA-RODRIGUEZ, C.; LABIDI, J.; ECEIZA, A.; ARBELAIZ, A. The effect of surface modifications on sisal fiber properties and sisal/poly (lactic acid) interface adhesion. Composites Part B: engineering, Oxford, v. 73, p. 132-138, 2015. 
ORUE, A.; JAUREGI, A.; UNSUAIN, U.; LABIDI, J.; ECEIZA, A.; ARBELAIZ, A. The effect of alkaline and silane treatments on mechanical properties and breakage of sisal fibers and poly (lactic acid)/sisal fiber composites. Composites Part A: applied science and manufacturing, Oxford, v. 84, p 186- 195, 2016.

PAIVA, J. M. F.; FROLLINI, E. Sugarcane bagasse reinforced phenolic and lignophenolic composites. Journal of Applied Polymer Science, Hoboken, v. 83, n. 4, p. 880-888, 2001.

PAIVA, J. M. F., FROLLINI, E. Unmodified and modified surface sisal fibers as reinforcement of phenolic and lignophenolic matrices composites: thermal analyses of fibers and composites. Macromolecular Materials and Engineering, Weinheim, v. 291, p. 405 - 417, 2006.

PALAMAE, S.; DECHATIWONGSE, P.; CHOORIT, W.; CHISTI, Y.; PRASERTSAN, P. Cellulose and hemicellulose recovery from oil palm empty fruit bunch (EFB) fibers and production of sugars from the fibers. Carbohydrate Polymers, Oxford, v. 155, p. 491-497, 2017.

PALUVAI, N. R.; MOHANTY, S.; NAYAK, S. K. Studies on thermal degradation and flameretardant behavior of the sisal fiber reinforced unsaturated polyester toughened epoxy nanocomposites. Journal of Applied Polymer Science, Hoboken, v. 132, n. 24, 2015.

PANDEY, K. K. A study of chemical structure of soft and hardwood and wood polymers by FTIR spectroscopy. Journal of Applied Polymer Science, Hoboken, v. 71, n. 12, p. 1969-1975, 1999.

PASCAULT, J. P.; SAUTEREAU, H.; VERDU, J.; WILLIAMS, R. J. Thermosetting polymers. Boca Raton, CRC Press, 2002. (Plastics Engineering Handbook, 64).

PEREIRA, A. C.; MONTEIRO, S. N.; DE ASSIS, F. S.; MARGEM, F. M.; DA LUZ, F. S.; BRAGA, F. O. Charpy impact tenacity of epoxy matrix composites reinforced with aligned jute fibers. Journal of Materials Research and Technology, Rio de Janeiro, v. 6, p. 312-316, 2017.

PHITSUWAN, P.; PERMSRIBURASUK, C.; BARAMEE, S.; TEERAVIVATTANAKIT, T.; RATANAKHANOKCHAI, K. Structural analysis of alkaline pretreated rice straw for ethanol production. International Journal of Polymer Science, London, v. 2017, article ID 4876969, 2017.

PILATO, L. Phenolic resins: a century of progress. New York: Springer, 2010.

PILÓ-VELOSO, D.; NASCIMENTO, E. A.; MORAIS, S. A. L. Isolamento e análise estrutural de ligninas. Química Nova, São Paulo, v. 16, p. 435-448, 1993.

PINHEIRO, F. G. C., SOARES, A. K. L., SANTAELlA, S. T., SILVA, L. M. A. E., CANUTO, K. M., CÁCERES, C. A., LEITÃO, R. C. Optimization of the acetosolv extraction of lignin from sugarcane bagasse for phenolic resin production. Industrial Crops and Products, Amsterdam, v. 96, p. 80-90, 2017

PODSCHUN, J.; STÜCKER, A.; BUCHHOLZ, R. I.; HEITMANN, M.; SCHREIBER, A.; SAAKE, B.; LEHNEN, R. Phenolated lignins as reactive precursors in wood veneer and particleboard adhesion. Industrial and Engineering Chemistry Research, Washington, v. 55, p. 5231-5237, 2016.

POLJANŠEK, I.; KRAJNC, M. Characterization of phenol-formaldehyde prepolymer resins by in line FT-IR spectroscopy. Acta Chimica Slovenica, Ljubljana, v. 52, n. 3, p. 238-244, 2005.

PRASHANTH, K. P.; HANUMANTHARAJU, H. G.; LOKESH, G. N. Synthesis and characterization study of chitosan based natural fiber: biodegradable polymer composite. AIP Conference Proceedings, Melville, v. 2057, article: UNSP 020022, 2019. 
PRASOB, P.A.; SASIKUMAR, M. Viscoelastic and mechanical behaviour of reduced graphene oxide and zirconium dioxide filled jute/epoxy composites at different temperature conditions. Materials Today Communications, Oxford, v. 19, p. 252-261, 2019.

RAHMAN, M. M.; KHAN, M. A. Surface treatment of coir (Cocos nucifera) fibers and its influence on the fibers' physico-mechanical properties. Composites Science and Technology, Oxford, v. 67, n. 1112, p. 2369-2376, 2007.

RAJESH, M.; PITCHAIMANI, J. Mechanical properties of natural fiber braided yarn woven composite: comparison with conventional yarn woven composite. Journal of Bionic Engineering, Beijing, v. 14, n. 1, p.141-150, 2017.

RAMIRES, E. C. Biocompósitos a partir de matrizes poliméricas baseadas em lignina, tanino e glioxal reforçadas com fibras naturais. 2010. Tese (Doutorado em Físico-Química) - Instituto de Química de São Carlos, Universidade de São Paulo, São Carlos, 2010.

RAMIRES, E. C.; DE OLIVEIRA, F.; FROLLINI, E. Composites based on renewable materials: polyurethane-type matrices from forest byproduct/vegetable oil and reinforced with lignocellulosic fibers. Journal of Applied Polymer Science, Hoboken, v. 129, p. 2224-2233, 2013.

RAMIRES, E. C.; FROLLINI, E. Tannin phenolic resins: synthesis, characterization, and application as matrix in biobased composites reinforced with sisal fibers. Composites Part B: engineering, Oxford, v. 43, p. 2851-2860, 2012.

RAMIRES, E. C.; MEGIATTO JUNIOR, J. D.; GARDRAT, C.; CASTELLAN, A.; FROLLINI, E. Valorization of an industrial organosolv-sugarcane bagasse lignin: characterization and use as a matrix in biobased composites reinforced with sisal fibers. Biotechnology and Bioengineering, Hoboken, v. 107, 612-621, 2010.

RAMLEE, N. A.; JAWAID, M.; ZAINUDIN, E. S.; YAMANI, S. A. K. Tensile, physical and morphological properties of oil palm empty fruit bunch/sugarcane bagasse fibre reinforced phenolic hybrid composites. Journal of Materials Research and Technology, Rio de Janeiro, v. 8, p. 3466-3474, 2019.

RANA, S. S.; GUPTA, M. K.; SRIVASTAVA, R. K. Effect of variation in frequencies on dynamic mechanical properties of short sisal fibre reinforced epoxy composite. Materials Today: proceedings, Amsterdam, v. 4, n. 2, p. 3387-3396, 2017.

RAO, K. M. M.; RAO, K. M. Extraction and tensile properties of natural fibers: vakka, date and bamboo. Composite Structures, London, v. 77, n. 3, p. 288-295, 2007.

RASHID, B.; LEMAN, Z.; JAWAID, M.; GHAZALI, M. J.; ISHAK, M. R. Physicochemical and thermal properties of lignocellulosic fiber from sugar palm fibers: effect of treatment. Cellulose, Dordrecht, v. 23, p. 2905-2916, 2016.

RAZERA, I. A. T. Fibras lignocelulósicas como agente de reforço de compósitos de matriz fenólica e lignofenólica. 2006. 168f. Tese (Doutorado em Físico-Química) - Instituto de Química de São Carlos, Universidade de São Paulo, São Carlos, 2006.

RAZERA, I. A. T.; FROLLINI, E. Composites based on jute fibers and phenolic matrices: properties of fibers and composites. Journal of Applied Polymer Science, Hoboken, v. 91, n.2, p. 1077-1085, 2004.

RAZERA, I. A. T.; SILVA, C. G.; ALMEIDA, E. V. R.; FROLLINI, E. Treatments of jute fibers aiming at improvement of fiber-phenolic matrix adhesion. Polímeros, São Carlos, v. 24, p. 417-421, 2014. 
RENNER, K.; MÓCZÓ, J.; PUKÁNSZKY, B. Deformation and failure of PP composites reinforced with lignocellulosic fibers: effect of inherent strength of the particles. Composites Science and Technology, Oxford, v. 69, n. 10, 1653-1659, 2009.

RICCIARDI, M. R.; PAPA, I.; LOPRESTO, V.; LANGELLA, A.; ANTONUCCI, V. (2019). Effect of hybridization on the impact properties of flax/basalt epoxy composites: influence of the stacking sequence. Composite Structures, London, v. 214, p. 476-485, 2019.

ROJO, E.; ALONSO, M. V.; OLIET, M.; SAZ-OROZCO, B.; RODRIGUEZ, F. Effect of fiber loading on the properties of treated cellulose fiber-reinforced phenolic composites. Composites Part B: engineering, Oxford, v. 68, p. 185-192, 2015.

SAARI N. F. N.; SAMSUDIN, D.; WAHAB, N. M. A.; MAJID, N. A.; DAIK, R.; ISHAK, M. Preparation and characterization of lignin from Malaysian Coconut Coir Husk $(\mathrm{CCH})$ as a potential precursor in phenol-formaldehyde ( phenolic ) resins for the plastics industry. Advanced Materials Research, Pfaffikon, v. 1133, p. 583-587, 2016.

SABA, N.; JAWAID, M.; ALOTHMAN, O. Y.; PARIDAH, M. T. A review on dynamic mechanical properties of natural fibre reinforced polymer composites. Construction \& Building Materials, Amsterdam, v.106, p. 149-159, 2016.

SABA, N.; SAFWAN, A.; SANYANG, M. L.; MOHAMMAD, F.; PERVAIZ, M.; JAWAID, M.; SAIN, M. Thermal and dynamic mechanical properties of cellulose nanofibers reinforced epoxy composites. International Journal of Biological Macromolecules, Amsterdam, v. 102, p. 822-828, 2017.

SAFRI, S. N. A.; SULTAN, M. T. H.; JAWAID, M.; JAYAKRISHNA, K. Impact behaviour of hybrid composites for structural applications: a review. Composites Part B: engineering, Oxford, v. 133, p. $112-121,2018$.

SAHA, P.; CHOWDHURY, S.; ROY, D.; ADHIKARI, B.; KIM, J. K.;THOMAS, S. A brief review on the chemical modifications of lignocellulosic fibers for durable engineering composites. Polymer Bulletin, Hoboken, v. 73, p. 587-620, 2016.

SAHU, P.; GUPTA, M. K. Mechanical, thermal and morphological properties of sisal fibres. IOP Conference Series: materials science and engineering, Bristol, v. 455, n. 1, p. 12014, 2018.

SARASINI, F.; TIRILLÒ, J.; D’ALTILIA, S.; VALENTE, T.; SANTULLI, C.; TOUCHARD, F.; CHOCINSKI-ARNAULT, L.; MELLIER, D.; LAMPINI, L., GAUDENZI, P. Damage tolerance of carbon/flax hybrid composites subjected to low velocity impact. Composites Part B: engineering, Oxford, v. 91, p. 144-153, 2016.

SATHISHKUMAR, T. P.; NAVEEN, J.; NAVANEETHAKRISHNAN, P.; SATHEESHKUMAR, S.; RAJINI, N. Characterization of sisal/cotton fiber woven mat reinforced polymer hybrid composites. Journal of Industrial Textiles, London, v. 47, n. 4, p. 429-452, 2017.

SAUNDERS, K. J. Organic polymer chemistry: an introduction to the organic chemistry of adhesives, fibres, paints, plastics and rubbers. New York, Springer Science \& Business Media, 1998.

SAVAGE, L.; EVANS, K. The importance of the mesostructure in toughening cellulosic short fiber composites. Composites Science and Technology, Oxford, v. 93, p. 97-105, 2014.

SEMAN, S. A. H.; AHMAD, R.; AKIL, H. Meso-scale modelling and failure analysis of kenaf fiber reinforced composites under high strain rate compression loading. Composites Part B: engineering, Oxford, v. 163, p. 403-412, 2019. 
SENA NETO, A. R.; ARAUJO, M. A. M.; BARBOZA, R. M. P.; FONSECA, A. S.; TONOLI, G. H. D.; SOUZA, F. V. D.; MATTOSO, L. H. C.; MARCONCINI, J. M. Comparative study of 12 pineapple leaf fiber varieties for use as mechanical reinforcement in polymer composites. Industrial Crops and Products, Amsterdam, v. 64, p. 68-78, 2015.

SENA NETO, A. R.; ARAUJO, M. A. M.; SOUZA, F. V. D.; MATTOSO, L. H. C.; MARCONCINI, J. M. Characterization and comparative evaluation of thermal, structural, chemical, mechanical and morphological properties of six pineapple leaf fiber varieties for use in composites. Industrial Crops and Products, Amsterdam, v. 43, p. 529-537, 2013.

SENTHAMARAIKANNAN, P.; KATHIRESAN, M. Characterization of raw and alkali treated new natural cellulosic fiber from Coccinia grandis L. Carbohydrate Polymers, Oxford, v. 186, p. 332-343, 2018.

SEPE, R.; BOLLINO, F.; BOCCARUSSO, L.; CAPUTO, F. Influence of chemical treatments on mechanical properties of hemp fiber reinforced composites. Composites Part B: engineering, Oxford, v.133, p. 210-217, 2018.

SERGI, C.; TIRILlÒ, J.; SEGHINI, M. C.; SARASINI, F.; FIORE, V.; SCALICI, T. Durability of basalt/hemp hybrid thermoplastic composites. Polymers, San Jose, v. 11, n. 4, p. 603, 2019.

SHAHZAD, A. Mechanical properties of lignocellulosic fiber composites. In: JAWAID, M.; TAHIR, P.; SABA, N. (ed.). Lignocellulosic fibre and biomass-based composite materials: processing, properties and applications. Duxford: Elsevier, 2017. p. 193-223

SHAMSUDDIN, S. R.; LEE, K. Y.; BISMARCK, A. Ductile unidirectional continuous rayon fiberreinforced hierarchical composites. Composites Part A: applied science and manufacturing, Oxford, v. 90, p. 633-641, 2016.

SHINOJ, S.; VISVANATHAN, R.; PANIGRAHI, S.; KOCHUBABU, M. Oil palm fiber (OPF) and its composites: a review. Industrial Crops \& Products, Amsterdam, v. 33, n. 1, p. 7-22, 2011.

SILVERSTEIN, R. M.; BASSLER, G. C.; MORRIL, T. C. Indentificação espectrométrica de compostos orgânicos. Rio de Janeiro: Guanabara Koogan, 1994. p. 93-152.

SIMÃO, J. A.; MARCONCINI, J. M.; CAPPARELLI MATTOSO, L. H.; SANADI, A. R. Effect of SEBS-MA and MAPP as coupling agent on the thermal and mechanical properties in highly filled composites of oil palm fiber/PP. Composite Interfaces, Oxfordshire, v. 26, n. 8, 699-709, 2019.

SINHA, E.; ROUT, S. K. Influence of fibre-surface treatment on structural, thermal and mechanical properties of jute fibre and its composite. Bulletin of Materials Science, Karnataka, v. 32, n. 1, p. 6576, 2009.

SISALL. All about sisal fiber. O sisal. Riachão do Jacuípe, 2017. Disponível em: http://www.sisall.com.br/o-sisal/. Acesso em: 05 set. 2017.

SOUZA, N. F.; PINHEIRO, J. A.; SANTA BRÍGIDA, A. I.; MORAIS, J. P. S.; DE FREITAS ROSA, M. Fibrous residues of palm oil as a source of green chemical building blocks. Industrial Crops and Products, Amsterdam, v. 94, 480-489, 2016.

SREEKALA, M.; KUMARAN, M.; JOSEPH, S.; JACOB, M. Oil palm fiber reinforced phenol formaldehyde composites: influence of fiber surface modifications on mechanical properties. Applied Composite Materials, Dordrecht, v. 7, n. 5-6, p. 295-329, 2000. 
SRINIVAS, K.; LAKSHUMU NAIDU, A.; RAJU BAHUBALENDRUNI, M. V. A. A review on chemical and mechanical properties of natural fiber reinforced polymer composites. International Journal of Performability Engineering, Rajasthan, v. 13, p. 189-200, 2017.

STÜCKER, A.; SCHÜTT, F.; SAAKE, B.; LEHNEN, R. Lignins from enzymatic hydrolysis and alkaline extraction of steam refined poplar wood: utilization in lignin-phenol-formaldehyde resins. Industrial Crops \& Products, Amsterdam, v. 85, p. 300-308, 2016.

SUBIYANTO, B.; RASYID, E.; GOPAR, M.; FIRMANTI, A. Veneer and thin plywood overlaid for quality improvement of particleboard made of palm oil empty fruit bunches (EFB). Jurnal Ilmu dan Teknologi Kayu Tropis, Bogor, v.6, p. 17-20, 2018.

SUN, S.; SUN, S.; CAO, X.; SUN, R. The role of pretreatment in improving the enzymatic hydrolysis of lignocellulosic materials. Bioresource Technology, Amsterdam, v. 199, p. 49-58, 2016.

SURESH, A. G.; THIRUCHITRAMBALAM, M.; SHANMUGAM, D. Effect of layering pattern on thermal and mechanical properties of lyocell/rayon fabric reinforced textile composites. Journal of Reinforced Plastics and Composites, London, v. 35, n. 12, p. 957-973, 2016.

TANG, QIHENG; LU, FANG; GUO, WENJING. Effects of bamboo fiber length and loading on mechanical, thermal and pulverization properties of phenolic foam composites. Journal of Bioresources and Bioproducts, Amsterdam, v. 4, n. 1, p. 51-59, 2019.

TAPPI. T 204 cm-97: solvent extractives of wood and pulp. Peachtree Corners, 1997. 4 p.

TAPPI. T 412 om-93: ash in wood, pulp, paper and paperboard: combustion at $900^{\circ} \mathrm{C}$. Peachtree Corners, $1993.4 \mathrm{p}$.

TAPPI. T 211 om-02: ash in wood, pulp, paper and paperboard: combustion at $525^{\circ} \mathrm{C}$. Peachtree Corners, 2002a. 5 p.

TAPPI. T 222 om-02: acid-insoluble lignin in wood and pulp. Peachtree Corners, 2002 b. 5 p.

TAPPI. T 203 cm-99: alpha-, beta- and gamma-cellulose in pulp. Peachtree Corners, 2009. 7 p.

TEIXEIRA, R. S.; SANTOS, S. F.; CHRISTOFORO, A. L.; PAYÁ, J.; JR, H. S.; LAHR, F. A. R. Impact of content and length of curauá fibers on mechanical behavior of extruded cementitious composites : analysis of variance. Cement and Concrete Composites, Oxford, v. 102 p. 134-144, 2019.

TEJADO, A.; PEÑA, C.; LABIDI, J.; ECHEVERRIA, J. M.; MONDRAGON, I. Physico-chemical characterization of lignins from different sources for use in phenol- formaldehyde resin synthesis. BioResource Technology, Amsterdam, v. 98, p. 1655- 1663, 2007.

TENG, Y.; YU, G.; FU, Y.; YIN, C. The preparation and study of regenerated cellulose fibers by cellulose carbamate pathway. International Journal of Biological Macromolecules, Amsterdam, v. 107, p. 383-392, 2018.

THAKUR, V. K.; SINGHA, A. S. (ed.). Surface modification of biopolymers. Hoboken: John Wiley, 2015.

THEN, Y. Y.; IBRAHIM, N. A.; ZAINUDDIN, N.; ARIFFIN, H.; YUNUS, M. Z. W. Oil palm mesocarp fiber as new lignocellulosic material for fabrication of polymer / fiber. International Journal of Polymer Science, London, v. 2013, article ID 797452, 2013.

THEN, Y. Y.; IBRAHIM, N. A.; ZAINUDDIN, N.; ARIFFIN, H.; CHIENG, B. W.; YUNUS, M. Z. W. 
Surface modifications of oil palm mesocarp fiber by superheated steam, alkali, and superheated steamalkali for biocomposite applications. BioResources, Raleigh, v. 9, n. 4, p. 7467-7483, 2014.

THEN, Y. Y.; IBRAHIM, N. A.; ZAINUDDIN, N.; ARIFFIN, H.; CHIENG, B. W.; YUNUS, W. M. Z. W. Influence of fiber content on properties of oil palm mesocarp fiber/poly (butylene succinate) biocomposites. BioResources, Raleigh, v. 10, n. 2, p. 2949-2968, 2015.

TIAN, M.; QU, L.; ZHANG, X.; ZHANG, K.; ZHU, S.; GUO, X.; HAN, G.; TAN, X.; SUN, Y. Enhanced mechanical and thermal properties of regenerated cellulose/graphene composite fibers. Carbohydrate polymers, Oxford, v. 111, p. 456-462, 2014.

TITA, S. P. D. S.; MEDEIROS, R.; TARPANI, J. R.; FROLLINI, E.; TITA, V. Chemical modification of sugarcane bagasse and sisal fibers using hydroxymethylated lignin: influence on impact strength and water absorption of phenolic composites. Journal of Composite Materials, London, v. 52, n. 20, p. 2743-2753, 2018.

TRACHE, D.; DONNOT, A.; KHIMECHE, K.; BENELMIR, R.; BROSSE, N. Physico-chemical properties and thermal stability of microcrystalline cellulose isolated from Alfa fibres. Carbohydrate Polymers, Oxford, v. 104, p. 223-230, 2014.

TRINDADE, W. G.; HOAREAU, W.; MEGIATTO JUNIOR, J. D.; RAZERA, I. A. T.; CASTELLAN, A.; FROLLINI, E. Thermoset phenolic matrices reinforced with unmodified and surface grafted furfuryl alcohol sugarcane bagasse and curaua fibers: properties of fibers and composites. Biomacromolecules, Washington, v. 6, p. 2485-2496, 2005.

TRINDADE, W. G.; PAIVA, J. M. F.; LEÃO, A. L.; FROLLINI, E. Ionized air treated curaua fibers as reinforcement for phenolic matrices. Macromolecular Materials and Engineering, Weinheim, v. 293, p. 521- 528, 2008.

UMAR, M. S.; URMEE, T.; JENNINGS, P. A policy framework and industry roadmap model for sustainable oil palm biomass electricity generation in Malaysia. Renewable Energy, New York, v.128, p. 275-284, 2018.

VALENTE, M.; SARASINI, F.; MARRA, F.; TIRILLÒ, J.; PULCI, G. Hybrid recycled glass fiber/wood flour thermoplastic composites: manufacturing and mechanical characterization. Composites Part A: applied science and manufacturing, Oxford, v. 42, p. 649-657, 2011.

VIEIRA, J. D. S.; LOPES, F. P.; DE MORAES, Y. M.; MONTEIRO, S. N.; MARGEM, F. M.; MARGEM, J. I.; SOUZA, D. Comparative mechanical analysis of epoxy composite reinforced with malva/jute hybrid fabric by izod and charpy impact test. In: CHARACTERIZATION of materials, metals, and materials 2018. Cham: Springer, 2018. p. 177-183. (The Minerals, Metals \& Materials Series).

VIVEK, S.; KANTHAVEL, K. Effect of bagasse ash filled epoxy composites reinforced with hybrid plant fibres for mechanical and thermal properties. Composites Part B: engineering, Oxford, v. 160, p. 170-176, 2019.

WALLMO, H., LINDHOLM, K., CHRISTIANSEN, G., KARLSSON, H., LITTORIN, A. The nextgeneration lignoboost-tailor-made lignin production for different lignin bioproduct markets. Journal of Science \& Technology for Forest Products and Processes, Brossard, v. 7, n. 2, p. 6-10, 2018.

WANG, H.; LI, D.; YANO, H.; ABE, K. Preparation of tough cellulose II nanofibers with high thermal stability from wood. Cellulose, Dordrecht, v. 21, n. 3, p. 1505-1515, 2014. 
WANG, M.; LEITCH, M.; XU, C. Synthesis of phenol-formaldehyde resol resins using organosolv pine lignins. European Polymer Journal, New York, v. 45, p. 3380-3388, 2009.

WERSTLER, D. D. Quantitative 13C N.M.R. characterization of aqueous formaldehyde resins: 1. Phenol-formaldehyde resins. Polymer, London, v. 27, n. 5, p. 750-756, 1985.

WU, Q.; QIANG, T. C.; ZENG, G.; ZHANG, H.; HUANG, Y.; WANG, Y. Sustainable and renewable energy from biomass wastes in palm oil industry: a case study in Malaysia. International Journal of Hydrogen Energy, London, v. 42, p. 23871-23877, 2017 b.

WU, Z.; XI, X.; LEI, H.; DU, G. Soy-based adhesive cross-linked by phenol-formaldehydeglutaraldehyde. Polymers, Dordrecht, v. 9, p. 169, 2017 a.

XU, Y.; YIN, X.; LIN, T.; DUAN, C.; YANG, B. Silica retention by the addition of sodium metaaluminate during the impregnation stage of bamboo kraft pulping. Journal of Wood Chemistry and Technology, New York, v. 38, n. 1, p. 35-43, 2018.

YAN, L.; HAO, M.; YIOU, S.; QIAN, L.; ZHUOYUAN, Z. Effects of resin inside fiber lumen on the mechanical properties of sisal fiber reinforced composites. Composites Science and Technology, Oxford, v. 108, p. 32-40, 2015.

YANG, H.; YAN, R.; CHEN, H.; LEE, D. H.; ZHENG, C. Characteristics of hemicellulose, cellulose and lignin pyrolysis. Fuel, v. 86, n. 12-13, p. 1781-1788, 2007.

YANG, M., WANG, F., ZHOU, S., LU, Z., RAN, S.; LI, L.; SHAO, J. Thermal and mechanical performance of unidirectional composites from bamboo fibers with varying volume fractions. Polymer Composites, Bethel, p. 3929-3937, 2019.

YANG, S.; ZHANG, Y.; YUAN, T. Q.; SUN, R. C. Lignin-phenol-formaldehyde resin adhesives prepared with biorefinery technical lignins. Journal of Applied Polymer Science, Hoboken, v. 132, n. 36, p. 1-8, 2015.

YANG, Y. P.; ZHANG, Y.; LANG, Y. X.; YU, M. H. Structural ATR-IR analysis of cellulose fibers prepared from a $\mathrm{NaOH}$ complex aqueous solution. IOP Conference Series: materials science and engineering, Bristol, v. 213, n. 1, p. 012039, 2017.

YE, C. Spectroscopic imaging ellipsometry: real-time measurement of single, intact wood pulp fibers. Applied Optics, Washington, v. 45, n. 36, p. 9092-9104, 2006.

YI, T.; ZHAO, S.; GAO, W.; GUO, C.; YANG, L.; DU, G. The similar in-situ polymerization of nano cupric oxide preparation and phenol formaldehyde resin synthesis: the process and mechanism. International Journal of Adhesion and Adhesives, London, p. 109-118, 2018.

YU, Y.; XU, P.; CHEN, C.; CHANG, J.; LI, L. Formaldehyde emission behavior of plywood with phenol-formaldehyde resin modi fi ed by bio-oil under radiant $\mathrm{fl}$ oor heating condition. Building and Environment, Amsterdam, v. 144, p. 565-572, 2018.

YUAN, Z.; KAPU, N. S.; BEATSON, R.; CHANG, X. F.; MARTINEZ, D. M. Effect of alkaline preextraction of hemicelluloses and silica on kraft pulping of bamboo (Neosinocalamus affinis Keng). Industrial Crops and Products, Amsterdam, v. 91, p. 66-75, 2016.

YUNOS, N. S. H. M.; BAHARUDDIN, A. S.; YUNOS, K. F.; NAIM, M. N.; NISHIDA, H. Physicochemical property changes of oil palm mesocarp fibers treated with high-pressure steam. BioResources, Raleigh, v. 7, n. 4, p. 5983-5994, 2012. 
YUSOFF, M. Z. M; SALIT, M. S.; ISMAIL, N.; WIRAWAN, R. Mechanical properties of short random oil palm fibre reinforced epoxy composites. Sains Malaysiana, Selangor, v. 39, n. 1, p. 87-92, 2010.

YUSUP, E. M.; MAHZAN, S.; KAMARUDDIN, M. A. H. Natural Fiber Reinforced Polymer for the Application of Sports Equipment using Mold Casting Method. IOP Conference Series: materials science and engineering, Amsterdam, v. 494, p. 12040, 2019.

ZHANG, S.; HE, Y.; YIN, Y.; JIANG, G. Fabrication of innovative thermoplastic starch bio-elastomer to achieve high toughness poly (butylene succinate) composites. Carbohydrate Polymers, Oxford, v. 206, p. 827-836, 2019.

ZHANG, Y.; YU, G.; LI, B.; MU, X.; PENG, H.; WANG, H. Hemicellulose isolation, characterization, and the production of xylo-oligosaccharides from the wastewater of a viscose fiber mill. Carbohydrate Polymers, Oxford, v.141, p. 238-243, 2018.

ZHAO, M.; JING, J.; ZHU, Y. YANG, X.; WANG, X.; WANG, Z. Preparation and performance of lignin-phenol-formaldehyde adhesives. International Journal of Adhesion and Adhesives, London, v. 64, p. 163-167, 2016.

ZHUANG, X.; WANG, W.; YU, Q.; QI, W.; WANG, Q.; TAN, X.; ZHOU, G; YUAN, Z. Liquid hot water pretreatment of lignocellulosic biomass for bioethanol production accompanying with high valuable products. Bioresource Technology, Amsterdam, v. 199, p.68-75, 2016.

ZUKOWSKI, B.; ANDRADE SILVA, F. A.; TOLEDO FILHO, R. D. Design of strain hardening cement-based composites with alkali fi ber treated natural curaua. Cement and Concrete Composites, Oxford, v. 89, p. 150-159, 2018. 